PEDRO HENRIQUE FERREIRA PINTO

DESENVOLVIMENTO DE ROTAS PARA COMINUIÇÃO DE ITABIRITOS COMPACTOS DO QUADRILÁTERO FERRÍFERO

SÃO PAULO

2016 
PEDRO HENRIQUE FERREIRA PINTO

\section{DESENVOLVIMENTO DE ROTAS PARA COMINUIÇÃO DE ITABIRITOS COMPACTOS DO QUADRILÁTERO FERRÍFERO}

Dissertação apresentada à Escola Politécnica da Universidade de São Paulo para obtenção do título de Mestre em Engenharia

SÃO PAULO

2016 
PEDRO HENRIQUE FERREIRA PINTO

\section{DESENVOLVIMENTO DE ROTAS PARA COMINUIÇÃO DE ITABIRITOS COMPACTOS DO QUADRILÁTERO FERRÍFERO}

Dissertação apresentada à Escola Politécnica da Universidade de São Paulo para obtenção do título de Mestre em Engenharia

Área de Concentração: Engenharia Mineral

Orientador: Prof. Dr. Homero Delboni Junior

SÃO PAULO

2016 
Este exemplar foi revisado e corrigido em relação à versão original, sob responsabilidade única do autor e com a anuência de seu orientador.

São Paulo, de de

Assinatura do autor:

Assinatura do orientador:

Catalogação-na-publicação

Pinto, Pedro

DESENVOLVIMENTO DE ROTAS PARA COMINUIÇÃO DE ITABIRITOS COMPACTOS DO QUADRILÁTERO FERRÍFERO / P. Pinto -- versão corr. -São Paulo, 2016.

$185 \mathrm{p}$.

Dissertação (Mestrado) - Escola Politécnica da Universidade de São Paulo. Departamento de Engenharia de Minas e Petróleo.

1.COMINUIÇÃO 2.DESENVOLVIMENTO DE ROTAS PARA COMINUIÇÃO DE ITABIRITOS COMPACTOS DO QUADRILÁTERO FERRÍFERO

I.Universidade de São Paulo. Escola Politécnica. Departamento de Engenharia de Minas e Petróleo II.t. 


\section{AGRADECIMENTOS}

$\mathrm{O}$ autor agradece a todos que direta ou indiretamente participaram e colaboraram para a realização desse trabalho e, em particular:

À Universidade de São Paulo, pela oportunidade de fazer o curso de Mestrado em Engenharia Mineral.

Ao Professor Homero Delboni Junior, pela orientação, suas recomendações e críticas, que além de contribuir para este trabalho, foram de grande valia para a minha formação como profissional de Beneficiamento de Minérios.

Aos funcionários do Departamento de Engenharia de Minas e de Petróleo e do Laboratório de Simulação e Controle de Processos Minerais pelo apoio e boa vontade, fundamentais para que a distância não fosse um impeditivo para a realização do trabalho.

À Vale, pelo fornecimento de todo apoio e recursos necessários para a realização deste trabalho.

Aos colegas de trabalho, em especial a equipe da GADMF, pelas enriquecedoras discussões técnicas sobre beneficiamento de minérios e oportunidade de troca de conhecimentos.

Ao Centro de Pesquisas Tecnológicas, pelo excelente trabalho realizado, quanto à execução dos ensaios piloto e preparação de amostras.

A toda a minha família, em especial aos meus pais, pelo incentivo e confiança.

À Bárbara, pelo apoio, carinho, companheirismo e correções ortográficas. 


\section{RESUMO}

Este trabalho consistiu no desenvolvimento e análise comparativa de rotas de cominuição para Itabiritos Compactos do Quadrilátero Ferrífero a partir de uma amostra de grande volume. As rotas desenvolvidas foram: Rota Convencional, composta por quatro estágios de britagem até a malha de $12 \mathrm{~mm}$, seguido por moagem em moinho de bolas. Rota $S A B$, composta por uma etapa de britagem até a malha de $200 \mathrm{~mm}$, seguida por moagem SAG e moagem em moinho de bolas. Para esta rota foi estudada a inclusão de uma segunda etapa de britagem, antes da alimentação do moinho SAG, e de uma britagem de pebbles, para a carga circulante do moinho SAG. Rota SSSAG, composta por uma etapa de britagem seguida por moagem SAG. Assim como para a rota $S A B$, foi avaliada para esta última rota a inclusão de uma segunda etapa de britagem, antes da alimentação do moinho SAG. Em todas as rotas, o produto da moagem foi fixado em $10 \%$ retido em $0,15 \mathrm{~mm}$ Os circuitos de moagem, SAG e de moinho de bolas foram desenvolvidos a partir de resultados de ensaios em escala piloto, ajustados via simulador JKSimMet. O consumo de energia e o dimensionamento dos equipamentos obtidos a partir dos ensaios piloto foram comparados aos resultados obtidos pelos métodos Bond e de Donda. O circuito de britagem foi dimensionado a partir de um ensaio industrial, que determinou a eficiência de britagem em função da abertura na posição fechada do britador. As rotas desenvolvidas foram comparadas quanto ao consumo específico de energia $(\mathrm{kWh} / \mathrm{t})$, dimensionamento dos equipamentos e geração de material menor que $0,010 \mathrm{~mm}$ (lamas) no produto da moagem. A rota SSSAG apresentou o menor consumo de energia e também o menor quantitativo de equipamentos. Quanto à geração de lama no produto da moagem, foram obtidos valores semelhantes nos ensaios piloto das três rotas estudadas.

Palavras-chave: Moagem. Moagem SAG. Itabiritos Compactos 


\begin{abstract}
This work consists in the development and comparative analysis of comminution routes to Compact Itabirites from Quadrilátero Ferrífero, based on a large volume sample. The developed routes were: Conventional Route, comprising four crushing stages, down to $12 \mathrm{~mm}$, followed by ball milling. SAB Route comprising one crushing step, down to $200 \mathrm{~mm}$, followed by SAG milling and ball milling. Secondary crushing and pebble crushing were also included as variations of SAB route. Route SSSAG, comprising one crushing step, down to $200 \mathrm{~mm}$, followed by SAG milling. Secondary crushing was also included as a variation of SSSAG route. In all cases grinding product was set to $10 \%$ retained at 0,15 mm. All grinding models were fitted at JKSimMet simulator on the basis of pilot plant data. Energy consumption and equipment design were compared with Bond and Donda method results. Crushing circuit design was based on industrial tests carried out for determining efficiency as a function of closed side setting (CSS). The routes were compared in term of energy consumption $(\mathrm{kWh} / \mathrm{t})$, comminution equipment numbers and the amount passing at 0,010 $\mathrm{mm}$ (slimes) in the grinding circuit product. The SSSAG route indicated the lowest energy consumption, together less pieces of equipment. Similar slime values were obtained for all three routes in pilot testing.

Keywords: Grinding, SAG Mill, Compact Itabirites
\end{abstract}




\section{Lista de Figuras}

Figura 1- Evolução do Tratamento de Minério de Ferro no Brasil .......................... 12

Figura 2- Fluxograma do Projeto Conceição Itabiritos .......................................... 13

Figura 3- Influência do percentual passante em $0,010 \mathrm{~mm}$ na qualidade do concentrado de flotação de itabiritos compactos............................................ 14

Figura 4- Fluxograma esquemático da rota convencional de cominuição ............... 15

Figura 5- Fluxograma esquemático das rotas SAB e SABC ............................... 17

Figura 6- Fluxograma esquemático das rotas SSSAG e SSSAGC ...................... 18

Figura 7- Fluxograma do circuito de britagem da usina de Brucutu - Vale ............. 25

Figura 8- Desenho esquemático dos dois tipos principais de britador de mandíbulas 26

Figura 9- Fotografia de uma grelha e um britador de mandíbula em operação ....... 27

Figura 10- Desenho esquemático do britador giratório ........................................ 28

Figura 11- Vista superior do britador giratório..................................................... 29

Figura 12- Desenho esquemático do britador cônico ........................................... 30

Figura 13- Desenho de um moinho tubular ......................................................... 32

Figura 14- Desenho esquemático das formas de cominuição do minério ................ 33

Figura 15- Fluxograma esquemático de moagem de bolas em $0,15 \mathrm{~mm}$................ 35

Figura 16-Seções de um moinho SAG ....................................................... 37

Figura 17- Influência do slurry pool na operação da moagem SAG ........................ 38

Figura 18- Imagens do crivo do moinho SAG antes e após operação...................... 39

Figura 19- Desenho esquemático da ocorrência de flowback ............................... 40

Figura 20- Desenho esquemático do pulp lifter de câmara dupla, TCPL................. 40

Figura 21- Circuito de moagem da usina do Sossego, Vale................................. 42

Figura 22- Circuito de moagem da usina de Granny Smith 43

Figura 23- Distribuição Granulométrica dos Produtos dos Britadores da Série CS . 46

Figura 24- Distribuição Granulométrica dos Produtos dos Britadores da Série CH. 46

Figura 25- Modelo esquemático de operação de britadores................................... 47

Figura 26-Modelo de curva de eficiência de britagem ........................................ 49

Figura 27- Figura Esquemática de Peneiramento ……….................................... 51

Figura 28- Curva de Partição Ideal .............................................................. 54

Figura 29- Parâmetros da Curva de Partição Real e Corrigida ............................. 56 
Figura 30- Desenho Esquemático do Balanço Granulométrico do Moinho 64

Figura 31-Curva r/d* da Moagem Semi Autógena de Yanacocha 66

Figura 32- Curva r/d* da Moagem de Bolas de Carajás 66

Figura 33- Amostra de Itabirito Compacto 68

Figura 34- Fluxograma da Usina de Córrego do Feijão ........................................ 75

Figura 35- Verificação da Abertura do Britador................................................. 76

Figura 36- Britador terciário e silo de alimentação............................................. 77

Figura 37- Pilha de Alimentação da Britagem Terciária....................................... 78

Figura 38- Granulometria de Alimentação do Circuito de Britagem Terciária 78

Figura 39- Amostragem do Transportador de Correia no Ensaio Industrial de Britagem . 79

Figura 40- Moinho para os Ensaios Piloto de Moagem 80

Figura 41- Fluxograma de Preparação da Amostra para os Ensaios Piloto de Moagem. 81

Figura 42- Granulometria da Alimentação do Ensaio Piloto de Moagem de Bolas.. 82 Figura 43- Fluxograma Ensaio Piloto de Moagem de Bolas 83

Figura 44- Granulometria da Alimentação do Ensaio Piloto de Moagem SAG. 88

Figura 45- Fluxograma Integrado dos Ensaios Piloto de Moagem SAG e e Moagem em Moinho de Bolas. 90

Figura 46- Fluxograma dos Ensaios Piloto de Moagem SAG em Circuito Fechado 90 Figura 47- Equipamentos da Planta Piloto do CIMM 90

Figura 48- Representação da relação energia/fragmentação obtida a partir de ensaios DWT 96

Figura 49- Exemplo de Aplicação do Ensaio de Moabilidade de Donda 100

Figura 50- Resultados dos ensaios de DWT 105

Figura 51- Resultados dos ensaios de moabilidade de Donda 107

Figura 52- Curva de Eficiência de Britagem 108

Figura 53- Granulometria - Ensaio Piloto Moagem de Bolas 111

Figura 54- Granulometria - Ensaio Piloto de Moagem SAG 1 113

Figura 55- Granulometria - Ensaio Piloto de Moagem SAG 2. 114

Figura 56- Granulometria - Ensaio Piloto de Moagem SAG 3. 114

Figura 57- Granulometria - Ensaio Piloto de Moagem SAG 4. 115

Figura 58- Granulometria - Ensaio Piloto de Moagem SAG 5 115 
Figura 59- Carga Interna dos Ensaios de Moagem SAG................................. 118

Figura 60- Granulometria - Ensaio Piloto MB1 .............................................. 120

Figura 61- Granulometria - Ensaio Piloto MB2 …….................................... 120

Figura 62- Eficiência de Britagem - Teste Industrial, Calibração e Simulação...... 124

Figura 63 - Rota Convencional - Fluxograma de Processo da Britagem ............... 125

Figura 64 - Ensaio Piloto de Moagem de Bolas - Calibração do Ciclone ............. 128

Figura 65 - Ensaio Piloto de Moagem de Bolas - Calibração do Moinho .............. 129

Figura 66 - Ensaio Piloto de Moagem de Bolas - Parâmetro $\mathrm{r} / \mathrm{d}^{*}$......................... 129

Figura 67 - Ensaio Piloto de Moagem de Bolas - Granulometria Simulação 1...... 130

Figura 68 - Ensaio Piloto de Moagem de Bolas - Granulometria Simulação 2..... 131

Figura 69 - Rota Convencional - Fluxograma de Processo da Moagem ............. 134

Figura 70 - Ensaio SAG 1 e SAG 2 - Granulometria do Undersize do Tromell ..... 139

Figura 71 - Rota SAB/C - Fluxograma de Processo da Moagem ........................ 142

Figura 72 - Ensaio Piloto SAG 4 - Calibração do Classificador Espiral................. 147

Figura 73 - Ensaio Piloto SAG 4 - Calibração do Moinho ................................... 147

Figura 74 - Ensaio Piloto SAG 4 - Parâmetro $r / d^{*}$........................................... 148

Figura 75 - Ensaio Piloto SAG 4 - Taxa de Descarga do Moinho ........................ 148

Figura 76 - Ensaio Piloto SAG 4 - Granulometria Simulação............................... 149

Figura 77 - Rota SSSAG - Fluxograma de Processo da Moagem........................ 152

Figura 78 - Granulometria - Alimentação do Moinho de Bolas e do Moinho SAG 158 


\section{Lista de Tabelas}

Tabela 1 - Moinhos SAG em operação no Brasil............................................... 19

Tabela 2 - Desempenho de Britadores Terciários - Vale ....................................... 50

Tabela 3 - Desempenho de Britadores Quaternários - Vale ................................... 50

Tabela 4 - Premissas de Balanço de Massas..................................................... 70

Tabela 5 - Capacidade do Britador em Função da Abertura na Posição Fechada .. 71

Tabela 6 - Capacidade de Peneiramento para Minério de Ferro ........................... 71

Tabela 7 - Parâmetros Operacionais do Ciclone do Ensaio Piloto de Moagem de

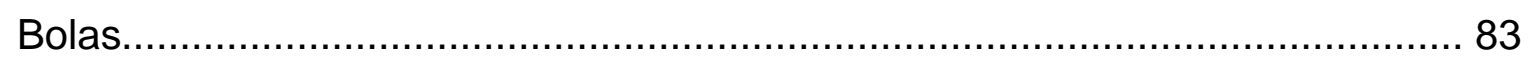

Tabela 8 - Parâmetros Operacionais do Moinho do Ensaio Piloto de Moagem de

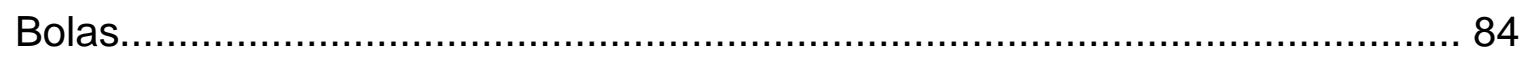

Tabela 9 - Colar de Bolas para Start Up do Moinho ............................................ 84

Tabela 10 - Colar de Bolas de Equilíbrio do Moinho............................................ 85

Tabela 11 - Média entre Carga de Start Up e Colar de Equilíbrio............................ 85

Tabela 12 - Tamanho Máximo de Bolas ............................................................. 86

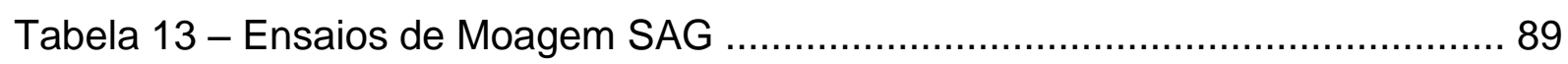

Tabela 14 - Parâmetros de Operação do Moinho SAG ........................................ 91

Tabela 15 - Parâmetros de Operação do Moinho de Bolas com Produto da Moagem

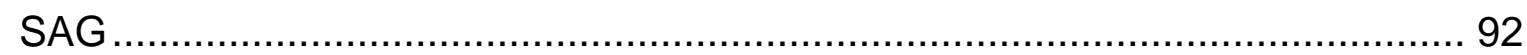

Tabela 16 - Colar de Bolas dos Ensaios Piloto de Moagem SAG ......................... 92

Tabela 17 - Condições experimentais utilizadas nos ensaios DWT ........................ 95

Tabela 18 - Classificação de resistência ao impacto de amostras conforme IQ...... 96

Tabela 19 - Classificação de resistência à abrasão de amostras conforme ta ........ 97

Tabela 20 - Distribuição da carga de bolas do ensaio de Bond.............................. 98

Tabela 21 - Classificação da abrasividade dos minérios ..................................... 99

Tabela 22 - Parâmetros para Realização do Ensaio de Moabilidade de Donda para a

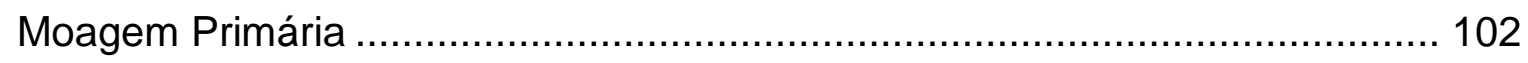

Tabela 23 - Resultados de resistência à abrasão _................................... 105

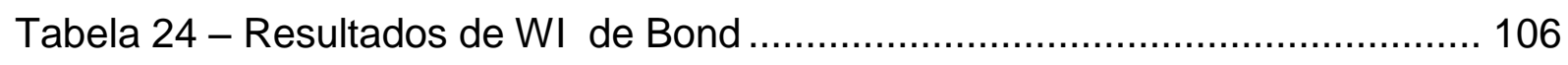

Tabela 25 - Resultado do ensaio de abrasividade ............................................... 106

Tabela 26 - Resultados do ensaio de moabilidade de Donda.............................. 107

Tabela 27 - Resultados de Vazão Mássica do Ensaio Industrial de Britagem ....... 109 
Tabela 28 - Capacidade de Catálogo do Britador do Ensaio Industrial de Britagem 109

Tabela 29 - Balanço de Massa do Ensaio Piloto de Moagem de Bolas ................ 110

Tabela 30 - Consumo de Energia do Ensaio Piloto de Moagem de Bolas ........... 111

Tabela 31 - Balanço de Massas do Ensaio Piloto de Moagem SAG 1 ................. 112

Tabela 32 - Balanço de Massas do Ensaio Piloto de Moagem SAG 2 ….............. 112

Tabela 33 - Balanço de Massas do Ensaio Piloto de Moagem SAG 3 ................ 112

Tabela 34 - Balanço de Massas do Ensaio Piloto de Moagem SAG 4 ................ 112

Tabela 35 - Balanço de Massas do Ensaio Piloto de Moagem SAG 5 ................. 113

Tabela 36 - Consumo de Energia dos Ensaios Piloto de Moagem SAG ............. 116

Tabela 37 - Análise da Carga Interna dos Testes de Moagem SAG …............... 117

Tabela 38 - Resultados do Ensaio Piloto de Moagem de Bolas para a Rota SAG

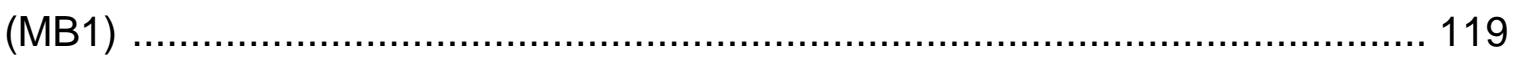

Tabela 39 - Resultados do Ensaio Piloto de Moagem de Bolas para a Rota SAG

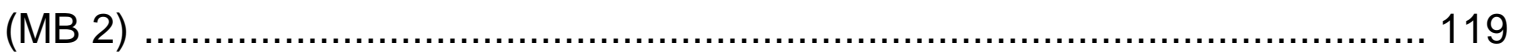

Tabela 40 - Consumo de Energia dos Ensaios Piloto MB1 e MB2 ....................... 121

Tabela 41 - Rota Convencional - Balanço de Massa da Britagem ...................... 126

Tabela 42 - Rota Convencional - Dimensionamento de Peneiras ....................... 126

Tabela 43 - Rota Convencional - Dimensionamento de Britadores ..................... 127

Tabela 44 - Ensaio Piloto de Moagem de Bolas - Resultados da Simulação ...... 132

Tabela 45 - Rota Convencional - Dimensionamento do Moinho de Bolas ........... 133

Tabela 46 - Rota Convencional - Balanço de Massas da Moagem ..................... 134

Tabela 47 - Rota Convencional - Dimensionamento dos Ciclones ..................... 135

Tabela 48 - Rota Convencional - Lista de Equipamentos ……….................... 135

Tabela 49 - Comparativo dos Ensaios Piloto para as Rotas SABC e SAB .......... 138

Tabela 50 - Rota SAB/C - Dimensionamento do Moinho SAG ........................... 140

Tabela 51 - Rota SAB/C - Dimensionamento do Moinho de Bolas ...................... 141

Tabela 52 - Rota SAB - Balanço de Massa da Moagem .................................... 143

Tabela 53 - Rota SABC - Balanço de Massa da Moagem ................................. 143

Tabela 54 - Rota SAB/C - Dimensionamento dos Ciclones ................................. 144

Tabela 55 - Rota SAB - Dimensionamento dos Equipamentos............................ 144

Tabela 56 - Rota SABC - Dimensionamento dos Equipamentos ......................... 145

Tabela 57 - Ensaio Piloto SAG 4 - Resultados da Simulação ............................. 150 
Tabela 58 - Rota SSSAG - Dimensionamento do Moinho SAG

Tabela 59 - Rota SSSAG - Balanço de Massa da Moagem

Tabela 60 - Rota SSSAG - Dimensionamento dos Ciclones 153

Tabela 61 - Rota SSSAG - Lista de Equipamentos 153

Tabela 62 - Rota SSSAG - Balanço de Massa da Simulação Moinho 6' X 6' 154

Tabela 63 - Comparação do Percentual de Lamas no Produto da Moagem 156

Tabela 64 - Comparação do Consumo de Energia para as Rotas de Cominuição 157 Tabela 65 - Comparação do Quantitativo de Equipamentos para as Rotas de Cominuição 158 


\section{SUMÁRIO}

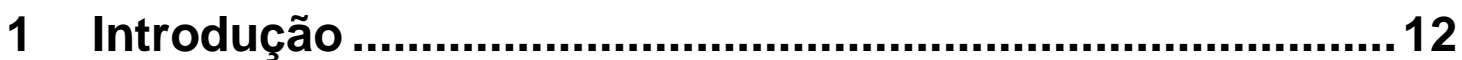

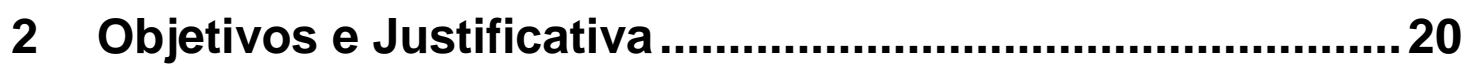

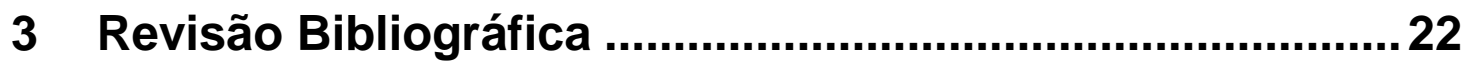

3.1 Operações de Cominuição ………………................................. 23

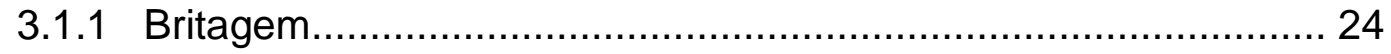

3.1.2 Moagem ......................................................................... 31

3.2 Modelagem e Simulação ................................................................... 44

3.2.1 Modelagem da Britagem ............................................................ 44

3.2.2 Modelagem de Peneiramento ……………........................... 50

3.2.3 Modelagem da Classificação ................................................... 53

3.2.4 Modelagem da Moagem .................................................... 58

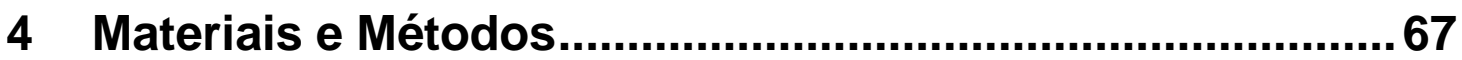

4.1 Premissas para Balanço de Massa e Dimensionamento de Equipamentos de Processo ................................................................. 70

4.2 Ensaio Industrial de Britagem ................................................ 74

4.3 Ensaio Piloto de Moagem de Bolas ......................................... 80

4.4 Ensaio Piloto de Moagem Semi-Autógena .................................. 88

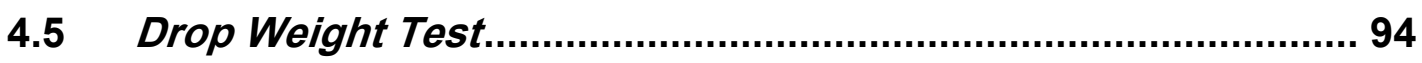

4.6 Ensaio de Resistência à Abrasão .............................................. 97

4.7 Ensaios de WI e Abrasividade de Bond..................................... 98

4.8 Ensaio de Moabilidade de Donda........................................... 100

5 Resultados .................................................................. 104

5.1 Resultados dos Ensaios de Caracterização de Bancada......... 105

5.2 Resultados do Ensaio Industrial de Britagem ......................... 108

5.3 Resultados dos Ensaios Piloto de Moagem de Bolas e SAG .. 110

6 DISCUSSÃO DOS RESULTADOS ...................................122

6.1 Rota Convencional .................................................................. 123

6.1.1 Circuito de Britagem ............................................................ 123

6.1.2 Circuito de Moagem .......................................................... 127 
6.2 Rota SAB/C ..................................................................... 137

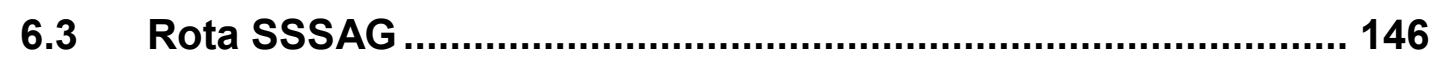

6.4 Comparação das Rotas de Cominuição ................................. 156

6.4.1 Geração de Lamas .................................................... 156

6.4.2 Consumo de Energia ................................................ 157

6.4.3 Quantitativo de Equipamentos ..................................... 158

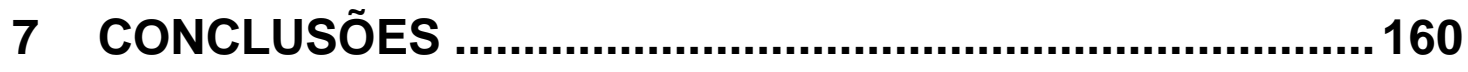

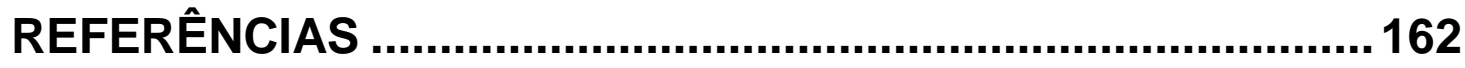

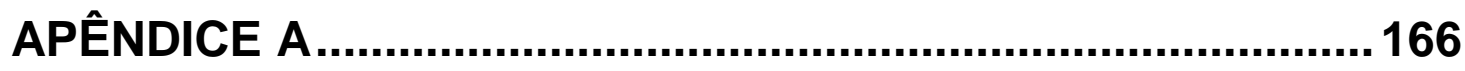

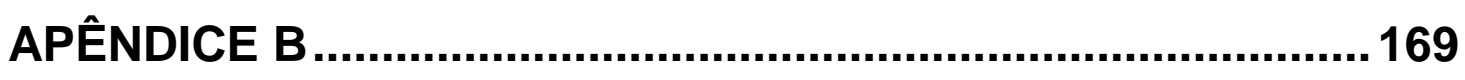

APÊNDICE C................................................................... 173 


\section{INTRODUÇÃO}

A redução de teor de ferro dos minérios brasileiros, em especial os lavrados no Quadrilátero Ferrífero, resulta na necessidade crescente de concentração, de forma a atender as especificações da indústria siderúrgica. A figura 1 mostra a evolução do tratamento de minério de ferro no Brasil.

Figura 1- Evolução do Tratamento de Minério de Ferro no Brasil

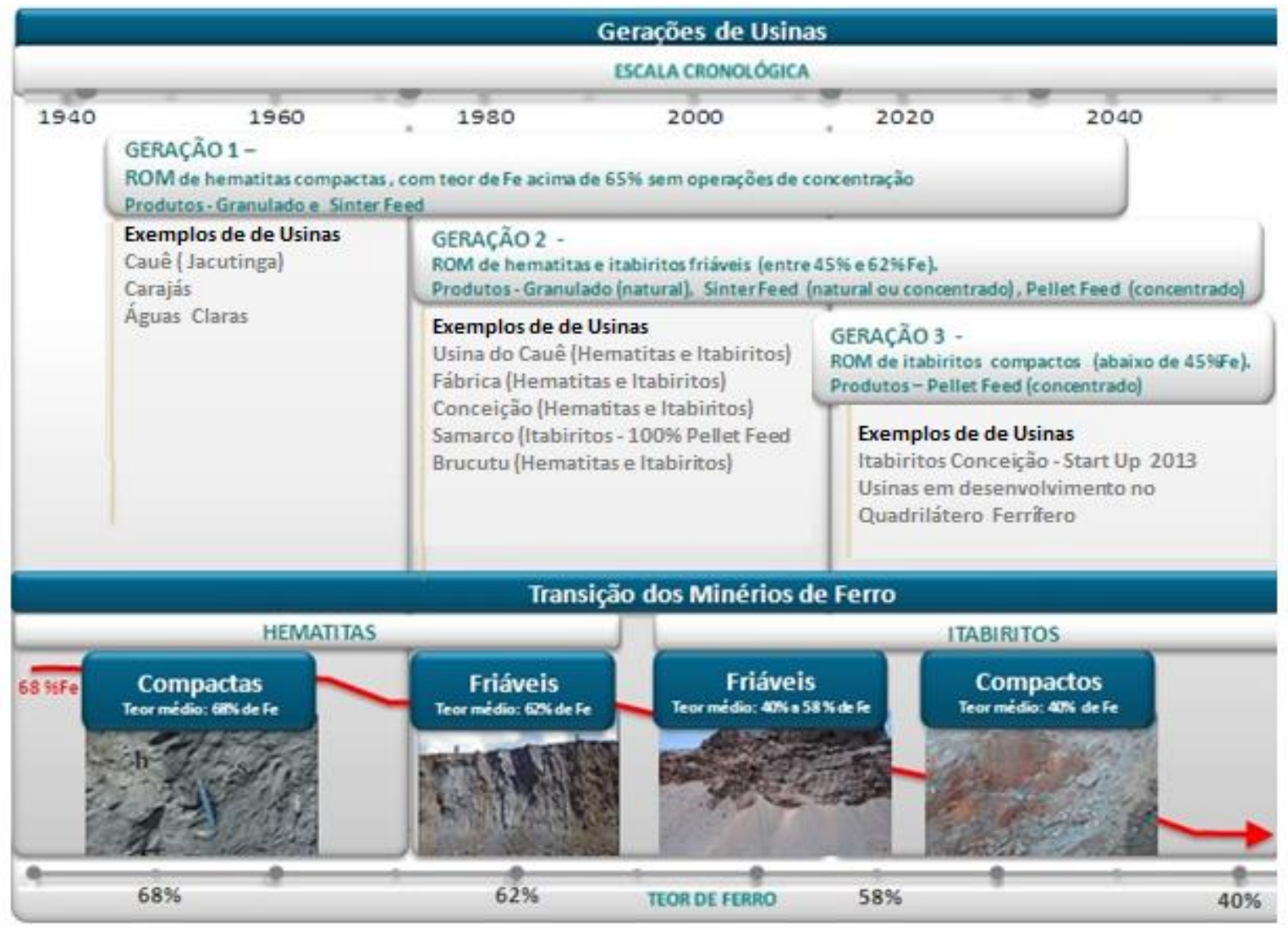

Fonte: Pinto (2015)

Esse contexto se aplica a várias minas do Quadrilátero Ferrífero, em Minas Gerais, que atualmente operam com processamento de hematitas ou itabiritos friáveis e precisam, no médio prazo, desenvolver rotas para beneficiamento dos itabiritos compactos, que atualmente não são aproveitados. Dessa forma, o desenvolvimento de rotas técnica e economicamente viáveis para concentração dos itabiritos compactos, com geração de produtos dentro das especificações do 
mercado, é fundamental para garantir a sustentabilidade das operações de minério de ferro na região do Quadrilátero Ferrífero.

A rota para beneficiamento dos itabiritos compactos compreende, basicamente, cominuição de toda a alimentação da usina, seguida pelas etapas de deslamagem e flotação, com a produção somente de Pellet Feed. Muitas vezes, em função do requerimento energético e da malha de liberação do minério, são aplicadas até três etapas de moagem combinadas com até duas etapas de flotação. Um exemplo de beneficiamento de itabiritos compactos é o projeto Itabiritos Conceição, localizado em Itabira, MG, de propriedade da Vale, que iniciou suas operações em 2013. A figura 2 mostra o fluxograma de processo do projeto Itabiritos Conceição.

Figura 2- Fluxograma do Projeto Conceição Itabiritos

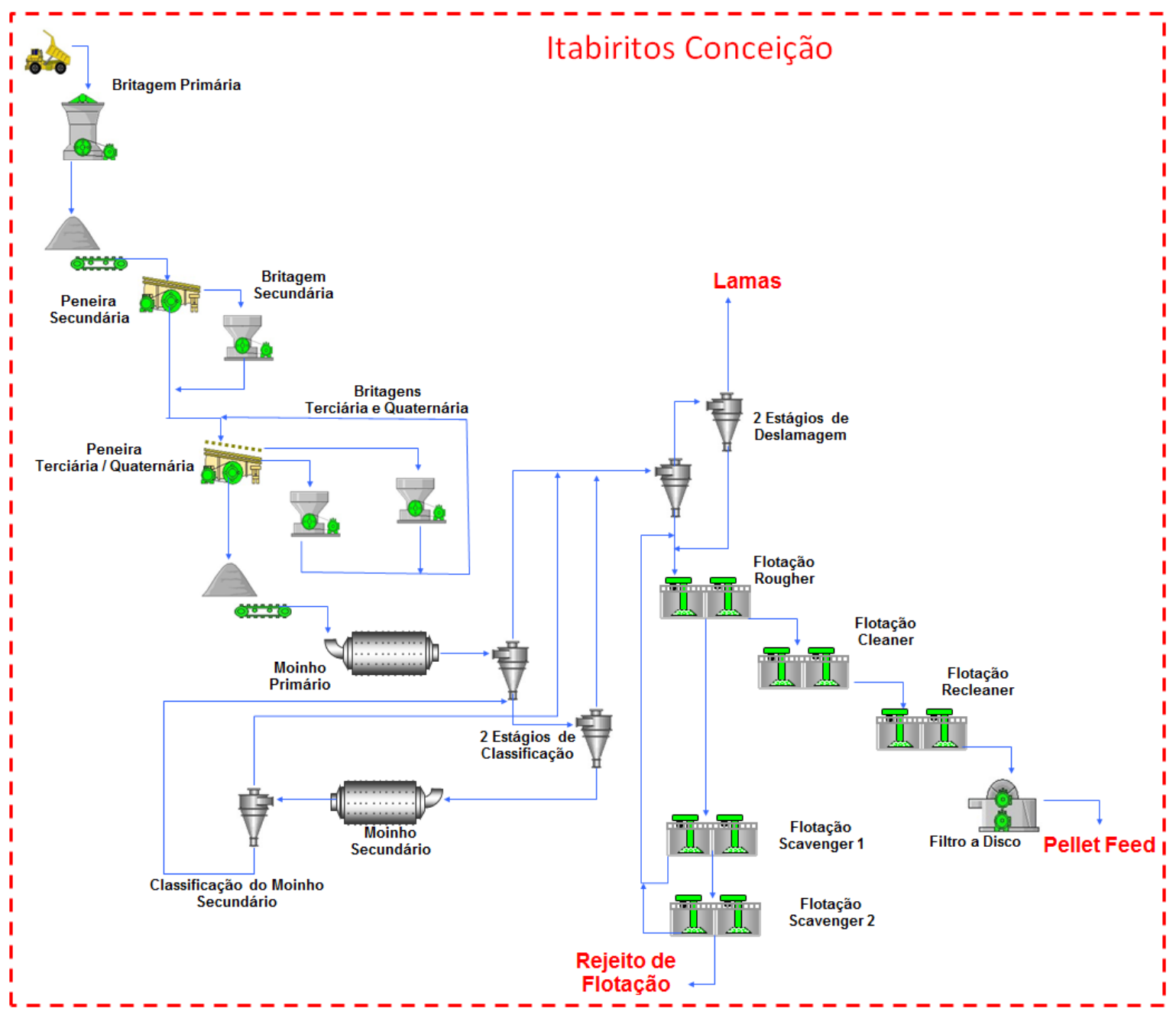

Fonte: Pinto (2015) 
Apesar de conterem baixos índices de contaminantes e de minerais hidratados, a presença de lamas (material menor que 0,010 $\mathrm{mm}$ ), mesmo em baixas percentagens, afeta negativamente os resultados da concentração por flotação dos itabiritos compactos. Marques (2013) estudou o comportamento de minérios de ferro na concentração por flotação na presença de lamas e demonstrou que, mesmo em baixos percentuais, as lamas afetam negativamente a qualidade do concentrado de flotação, em especial para os itabiritos compactos. A figura 3 (MARQUES 2013) mostra o teor de $\mathrm{SiO}_{2}$ do concentrado de flotação de itabiritos compactos de Conceição, em função do percentual de material menor que 0,010 mm na alimentação da flotação, para diferentes dosagens de amina e na presença de dispersante.

Figura 3- Influência do percentual passante em 0,010 mm na qualidade do concentrado de flotação de itabiritos compactos

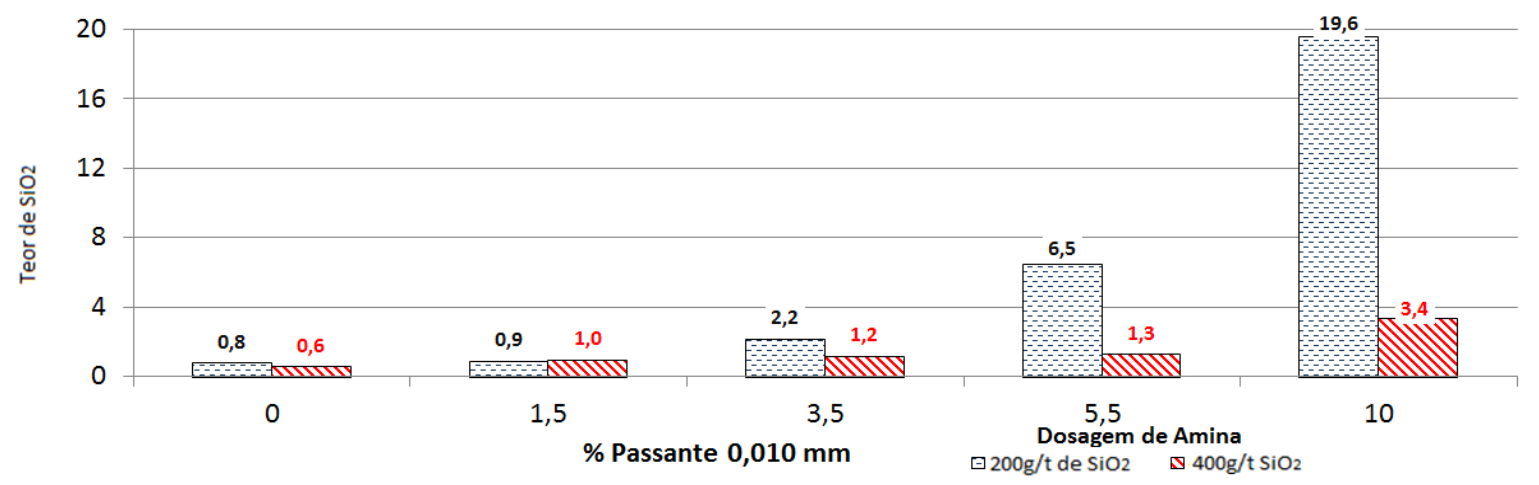

Fonte: Marques (2013) Adaptado pelo autor

Dessa forma, é fundamental que as etapas de cominuição produzam o menor percentual possível de partículas menores que $0,010 \mathrm{~mm}$, pois estas terão de ser removidas do circuito, prejudicando, assim, a recuperação em massa da usina.

As etapas de cominuição têm alto consumo de energia: 4\% do consumo mundial de energia elétrica, segundo o site Energy Efficiency Exchange (2013), e por esta razão, representam a principal fonte de custos operacionais em uma usina de beneficiamento de minério, além de serem responsáveis também por um percentual expressivo do custo de capital do projeto devido ao grande porte dos equipamentos utilizados. O consumo energético e o custo de capital das etapas de cominuição se tornam mais significativos na medida em que o minério se torna mais 
tenaz, com um maior consumo específico de energia, e com teores de ferro mais baixos, necessitando assim de maior capacidade de processamento da usina para uma mesma produção do mineral útil.

Dessa forma, o estudo e desenvolvimento de rotas de cominuição para os itabiritos compactos, com baixo teor de ferro, são de fundamental importância para viabilização e otimização dos projetos de beneficiamento desses minérios.

Para a moagem de minério de ferro, o circuito convencional de cominuição consiste na britagem, em três ou quatros estágios até a malha de $12 \mathrm{~mm}$, seguida por uma moagem em moinho de bolas em circuito fechado. O circuito é mostrado de forma esquemática na figura 4.

Figura 4- Fluxograma esquemático da rota convencional de cominuição

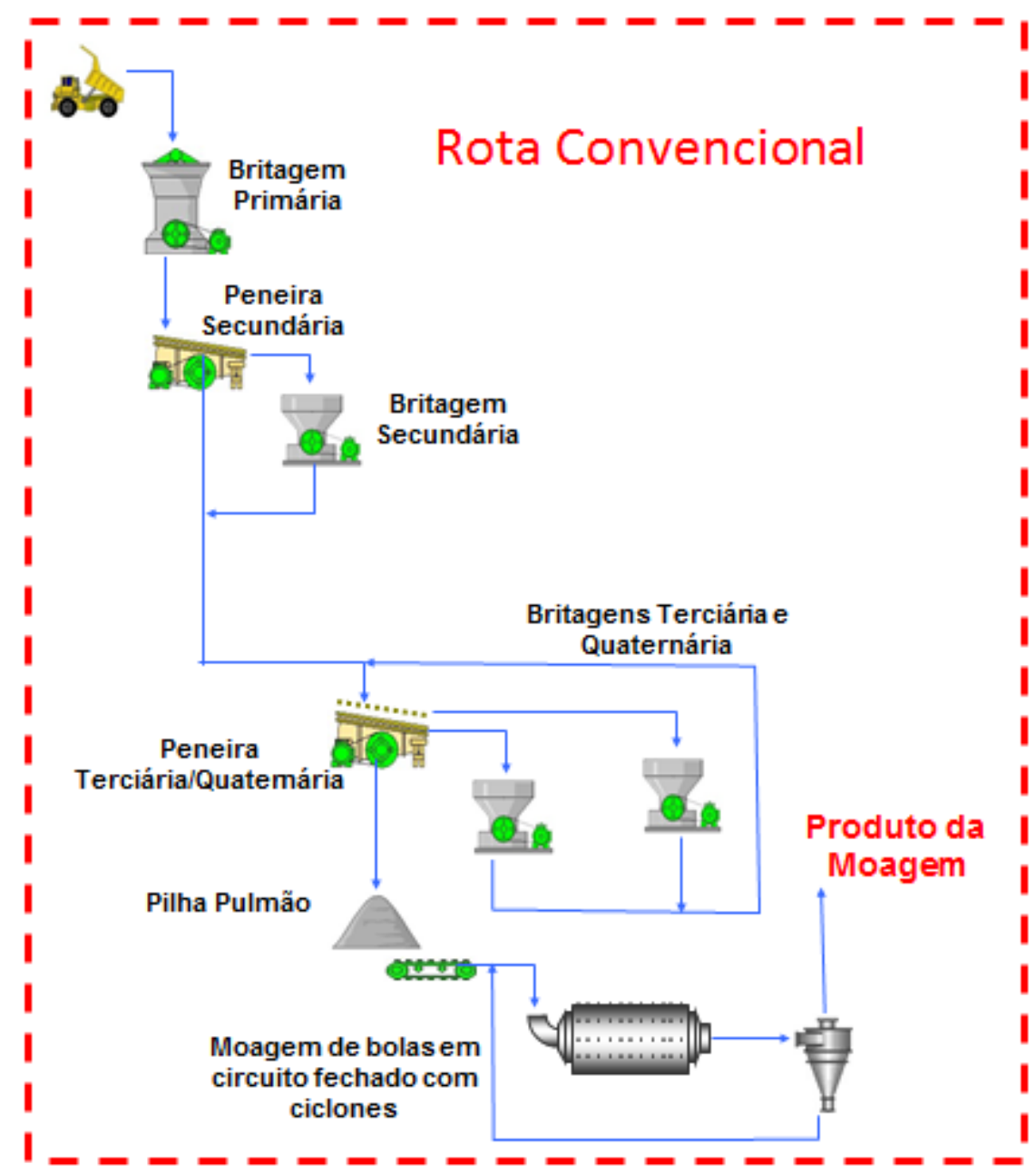

Fonte: Pinto (2015)

Essa configuração de circuito apresenta como vantagens a alimentação do moinho com uma granulometria relativamente mais fina, a possibilidade de 
homogeneização da alimentação e também a possibilidade de divisão do circuito em várias linhas, o que aumenta a confiabilidade do sistema. Todavia, com a necessidade de processamento de minérios com teores mais baixos e compactos, é necessário utilizar um número elevado de britadores e peneiras que demandam a construção de instalações de grande porte, o que onera significativamente o custo de capital, CAPEX, do projeto.

Neste contexto, a moagem semi-autógena (SAG) surge como oportunidade de simplificação da rota de processo, mediante a redução do número de operações unitárias e do porte das instalações das usinas de beneficiamento.

De forma geral, o circuito de moagem SAG consiste na alimentação deste moinho com produto da britagem primária (menor que $200 \mathrm{~mm}$ ) ou, alternativamente com produto de britagem secundária, e operação em circuito fechado com peneira dotada de tela com abertura de $12 \mathrm{~mm}$. O oversize da peneira (pebbles) retorna para a alimentação do moinho SAG, fechando, portanto esta etapa do circuito. O produto do SAG (undersize da peneira) alimenta um moinho de bolas que opera em circuito fechado, de forma a garantir a granulometria para etapa seguinte de concentração. Esta rota é geralmente denominada como SAB, sigla para SAG and $\mathrm{Bal}$ Mill. Dependendo da aplicação, ajustam-se as aberturas da grelha do moinho SAG para se obter uma descarga mais grosseira (pebbles), de forma a que a fração retida na peneira seja encaminhada à uma rebritagem. Neste caso a configuração é denominada $S A B C$, onde a letra $C$ é a sigla para Crushing. A rota SABC está mostrada na figura 5 . 
Figura 5- Fluxograma esquemático das rotas SAB e SABC

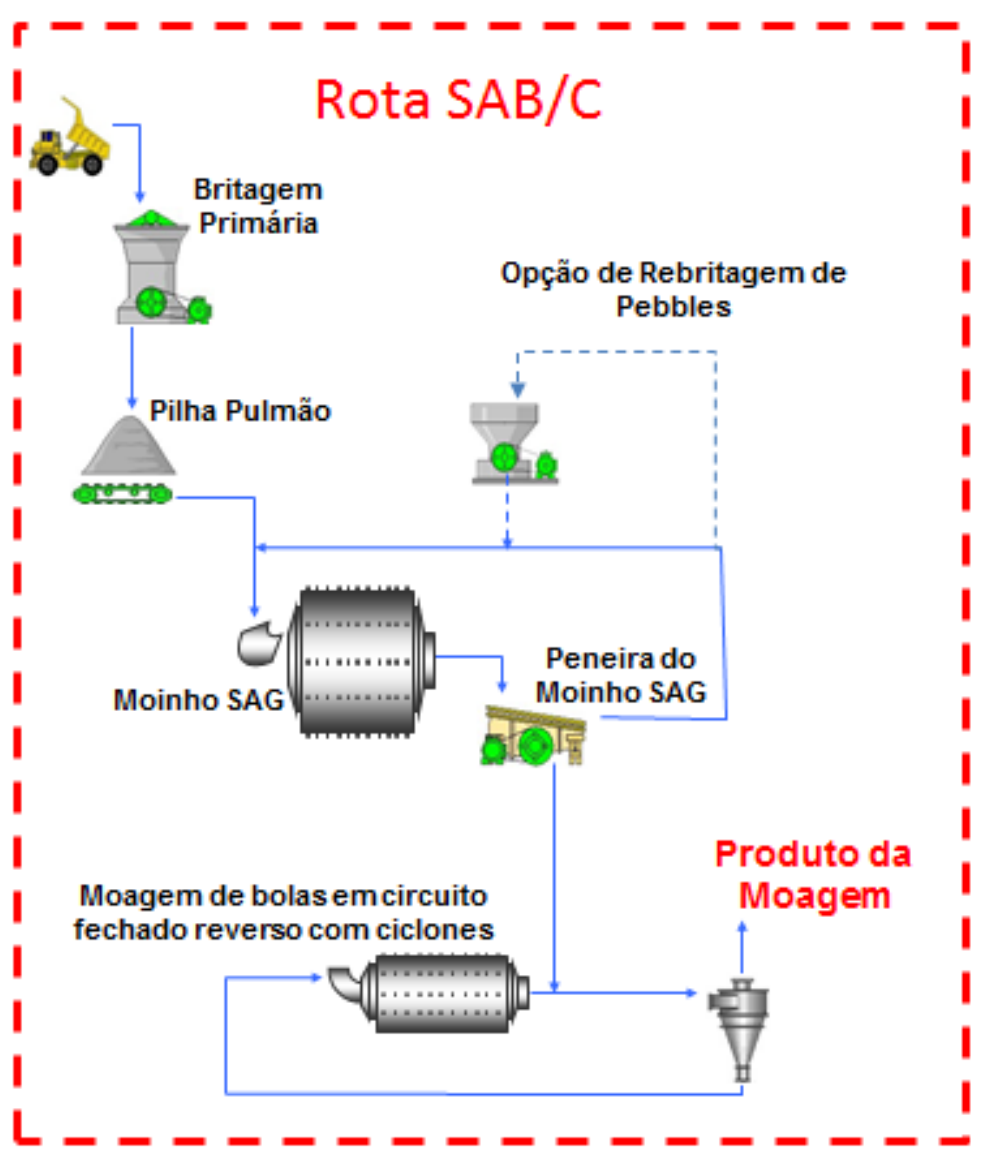

Fonte: Pinto (2015)

Em razão do porte dos moinhos SAG, rotas SAB ou SABC são geralmente compostas de um moinho SAG seguido de dois ou mais moinhos de bolas. Com o desenvolvimento de moinhos SAG com diâmetros acima de 38', as instalações com a rota acima chegam a processar mais de 5.000 t/h em um único moinho SAG.

Rotas de cominuição de moagem SAG seguida de moagem de bolas apresentam vantagem competitiva para itabiritos com valores de WI operacional superiores a $7,8 \mathrm{kWh} / \mathrm{t}$, com redução de aproximadamente $15 \%$ do CAPEX e 7\% do OPEX. (LIMA et al., 2013)

Uma simplificação adicional das rotas SAB e SABC é a utilização do moinho SAG em estágio único, com recirculação de pebbles e circuito fechado com ciclones no próprio moinho SAG. Esta rota, denominada SSSAG, sigla para Single Stage SAG Mill, permite a utilização de apenas uma etapa de cominuição dentro da usina, com uma relação de redução elevada. 
Para a moagem em estágio único, em geral, não é utilizada a rebritagem dos pebbles, pois como o moinho SAG trabalha com um percentual de enchimento elevado e a energia disponível por tonelada alimentada é maior, a geração de pebbles é inferior à rota SAB. Todavia se for necessária a rebritagem de pebbles a rota é denominada SSSAGC

A figura 6 mostra as rotas SSSAG e SSSAGC.

Figura 6- Fluxograma esquemático das rotas SSSAG e SSSAGC

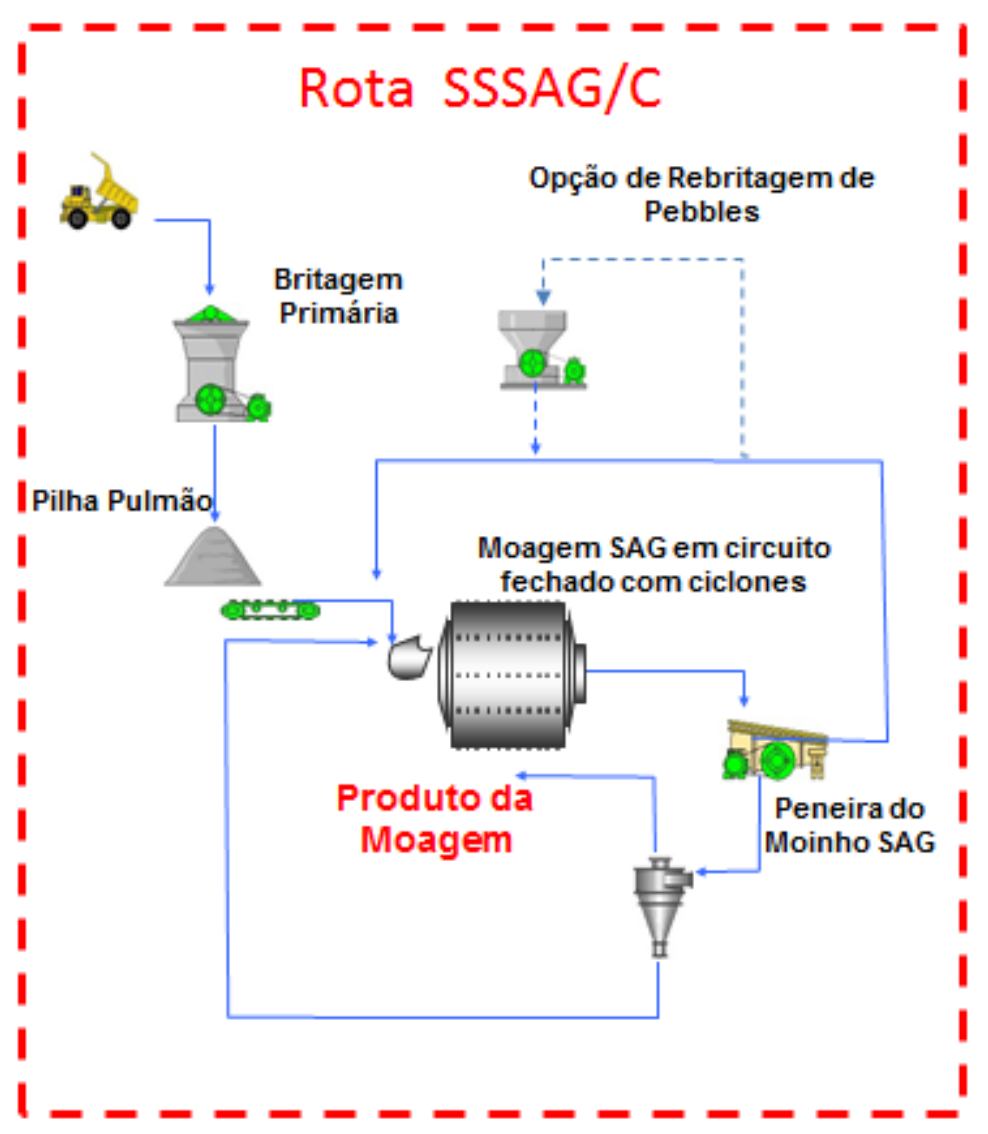

Fonte: Pinto (2015)

Segundo Delboni (2014)1 "Existem, atualmente, quatorze moinhos SAG em operação no Brasil, sendo todos instalados nos últimos 18 anos". Atualmente, em função das condições de mercado, alguns destes moinhos não estão em operação. 
A tabela 1 (DELBONI 2014) mostra os moinhos SAG instalados e em operação no Brasil. $^{1}$

Tabela 1 - Moinhos SAG em operação no Brasil

\begin{tabular}{|c|c|c|c|c|c|c|c|}
\hline Operação & Empresa & Minério & $\begin{array}{c}\begin{array}{c}\text { Dimensões } \\
\text { (pés) }\end{array} \\
\end{array}$ & $\begin{array}{c}\text { Potência } \\
\text { (kW) }\end{array}$ & Circuito & $\begin{array}{c}\text { Capacidade } \\
\text { (Mtpa) }\end{array}$ & Condição \\
\hline $\begin{array}{l}\text { Serra da } \\
\text { Fortaleza }\end{array}$ & Votoramtim & $\mathrm{Ni}$ & $16 \times 6,3$ & 0,65 & SABC & 0,6 & Paralisado \\
\hline Sossego & Vale & $\mathrm{Cu} / \mathrm{Au}$ & $38 \times 23$ & 20 & SABC & 15,0 & Em Operação \\
\hline Paragominas & Hydro & Bauxita & $26 \times 16(2 x)$ & 5 & SABC & $2 \times 6,0$ & Em Operação \\
\hline Paracatu & Kinross & $\mathrm{Au}$ & $38 \times 25$ & 20 & SAB & 41,0 & Em Operação \\
\hline Chapada & Yamana & $\mathrm{Cu} / \mathrm{Au}$ & $34 \times 19,5$ & 12,5 & SABC & 16,0 & Em Operação \\
\hline Mirabela & Mirabela & $\mathrm{Ni}(\mathrm{Co}, \mathrm{Cu}, \mathrm{MGP})$ & $30 \times 16,5$ & 8 & SABC & 6,4 & Paralisado \\
\hline Aurizona & Luana Gold & $\mathrm{Au}$ & $17 \times 15$ & 0,82 & $S A B$ & 2,0 & Em Operação \\
\hline $\begin{array}{l}\text { Corrego do } \\
\text { sítio }\end{array}$ & $\begin{array}{l}\text { Anglo Gold } \\
\text { Ashanti }\end{array}$ & $\mathrm{Au}$ & $12 \times 12$ & 0,37 & $\mathrm{SAB}$ & 0,6 & Em Operação \\
\hline Tucano & Beadell & $\mathrm{Au}$ & $24 \times 26$ & 7 & SSSAG & 3,5 & Em Operação \\
\hline Itafós & Mbac & Fosfato & $16,5 \times 30$ & 4 & SSSAG & 3,2 & Em Operação \\
\hline Pilar & Yamana & $\mathrm{Au}$ & $19 \times 19$ & 3 & SSSAG & 1,3 & Em Operação \\
\hline C1 - Santa Luz & Yamana & $\mathrm{Au}$ & $19 \times 36$ & 6,2 & SSSAG & 2,4 & Em Operação \\
\hline $\begin{array}{c}\text { Ernesto Pau a } \\
\text { Pique }\end{array}$ & Yamana & $\mathrm{Au}$ & $19 \times 19$ & 3 & SSSAG & 1,0 & Em Operação \\
\hline
\end{tabular}

Fonte: Delboni (2014) Adaptado pelo autor

Conforme mostrado na tabela 1, a aplicação de moinhos SAG para o minério de ferro ainda é inédita no Brasil, porém estes moinhos são utilizados para processamento de minério de ferro nos Estados Unidos e na Suécia desde meados do século XX.

1 Apresentação realizada no $1^{\circ}$ Seminário Vale de Moagem Semi Autógena. A tabela 1 também foi apresentada neste seminário 


\section{OBJETIVOS E JUSTIFICATIVA}

O objetivo deste trabalho é desenvolver e analisar, comparativamente, alternativas de cominuição para itabiritos compactos do Quadrilátero Ferrífero.

Para tanto, foram desenvolvidas três rotas de cominuição, circuito convencional, circuito SAB/C e circuito SSSAG para processamento de itabiritos compactos. O método empregado foi a modelagem matemática de equipamentos, através de modelos fenomenológicos, visando a simulação dos processos integrados, conforme cada configuração de circuito selecionada. As calibrações dos modelos foram baseadas em ensaios padronizados de caracterização e campanhas piloto de cominuição.

Para cada rota desenvolvida, foi elaborado o respectivo balanço de massa para um circuito com capacidade de alimentação de $25 \mathrm{Mt}$ por ano. E, a partir desse balanço de massa, foram dimensionados os equipamentos de processo. Para as rotas desenvolvidas, foram comparados o dimensionamento dos equipamentos, o consumo energético e a geração de lamas (percentual de material menor que $0,010 \mathrm{~mm}$ ) no produto da moagem. O dimensionamento dos moinhos e o consumo energético obtidos pelos modelos fenomenológicos foram comparados aos obtidos pelos métodos empíricos de Donda e Bond.

As rotas foram desenvolvidas a partir de uma amostra de itabirito compacto da mina da Jangada, de propriedade da Vale, localizada no município de Sarzedo, MG. É importante ressaltar que essa amostra não teve o objetivo de representar a reserva de itabiritos da mina da Jangada, mas, sim, de representar um itabirito compacto e assim servir de base para a realização de estudos de cominuição que possam servir de referências para o aproveitamento futuro de jazidas com grande participação deste litotipo.

Para os itabiritos compactos, o circuito de britagem na rota tradicional de cominuição demanda um número elevado de peneiras e britadores, bem como equipamentos de manuseio como silos, alimentadores, transportadores de correia, chutes, pilha intermediária, empilhadeira, retomadoras etc. Todos estes equipamentos aumentam o tamanho das instalações e a área impactada do projeto, além de onerarem, significativamente, o custo operacional. 
Neste contexto, se torna oportuno o desenvolvimento de rotas alternativas de cominuição, com a redução do número de operações unitárias e de equipamentos de processo, o que, além de reduzir o tamanho dos prédios e desonerar o custo de implantação do projeto, simplifica a operação e manutenção da usina e reduz o número de pessoas expostas ao risco.

Além do dimensionamento dos equipamentos e do consumo energético, a geração de lamas é um aspecto muito importante para avaliação no desenvolvimento de rotas de cominuição. A maior quantidade de lamas no produto da moagem impacta, diretamente, na recuperação em massa da usina, pois estas são descartadas antes da etapa de concentração. 


\section{REVISÃO BIBLIOGRÁFICA}

De forma a melhor situar o estudo de caso abordado neste trabalho e embasar as discussões e resultados apresentados, foi realizada uma revisão da literatura com a seguinte estrutura:

1- Operações de cominuição: Discussão dos conceitos fundamentais das etapas de britagem e moagem, bem como a apresentação dos principais equipamentos utilizados na indústria mineral para essas operações, e 2- Modelagem e simulação: Apresentação dos conceitos de modelagem matemática das operações de britagem, peneiramento, classificação e moagem, assim como a descrição das equações utilizadas para simulação dos circuitos de beneficiamento. 


\subsection{Operações de Cominuição}

As operações de cominuição podem ser definidas como o conjunto de técnicas que têm por finalidade reduzir, de forma controlada, o tamanho de um material, através da aplicação de forças mecânicas internas ou externas.

Cominuição é o conjunto de operações de redução de tamanho de partículas minerais, executado de maneira controlada de modo a cumprir um objetivo pré-determinado. Isto inclui as exigências de controlar o tamanho máximo dos produtos e de evitar a geração excessiva de finos. (CHAVES; PERES, 2003)

No beneficiamento de minérios, os principais objetivos da cominuição são:

1- Liberação do mineral de interesse para posterior etapa de concentração;

2- Adequação granulométrica para processo industrial posterior, como metalurgia extrativa, $\mathrm{e}$

3- Manuseio e transporte do minério.

Segundo Almeida; Figueira e Luz (2004) "a operação de cominuição compreende diversos estágios que se aplicam ao minério, desde a mina até sua adequação ao processo industrial subsequente". As três principais etapas de cominuição do minério são:

1- Desmonte mecânico ou detonação do maciço rochoso, cujo objetivo é produzir blocos de minério com tamanho adequado para manuseio, transporte e alimentação da britagem;

2- Britagem, utilizada tanto para permitir o manuseio do material através de transportadores de correia e máquinas de pátio, quanto para adequar a granulometria do minério para a etapa de moagem. Para minérios que não necessitam de concentração (e.g. minério de ferro de origem hematítica), a etapa de britagem é utilizada para se obter o tamanho adequado ao processo de metalurgia extrativa. O peneiramento é o processo utilizado para separação por tamanho, e

3- Moagem, é a ultima etapa de cominuição cujo objetivo é, geralmente, liberar o mineral de interesse para a etapa de concentração. Todavia, também pode ser utilizada para adequar o minério a um processo que exija uma granulometria fina (e.g. pelotização e lixiviação). De forma geral, são 
utilizados equipamentos de classificação hidráulica (e.g. ciclone e classificador espiral) para garantir a granulometria do produto.

Como o objetivo deste trabalho é analisar comparativamente rotas com as operações de britagem e moagem para a cominuição de itabiritos compactos, a revisão bibliográfica foi focada nestas duas operações unitárias.

\subsubsection{Britagem}

A etapa de britagem recebe o run of mine e reduz o minério a granulometrias compatíveis com as etapas posteriores de transporte, processamento ou utilização direta. Segundo Almeida; Figueira e Luz (2004) "A britagem é aplicada para fragmentos de distintos tamanhos, desde rochas de $1 \mathrm{~m}$ até cerca de $10 \mathrm{~mm}$ ".

A fratura (na etapa de britagem) se desenvolve segundo as tensões principais de cisalhamento, de inclinação constante em relação à direção das tensões de compressão. Em consequência, as partículas tendem a apresentar certa cubicidade e faces relativamente planas. (CHAVES; PERES, 2003)

A fragmentação do minério nas etapas de britagem utiliza, principalmente, as forças de compressão e impacto para granulometrias mais grosseiras (acima de 30 $\mathrm{mm}$ ), e abrasão para granulometrias mais finas. Segundo Chaves e Peres (2003) "A britagem tem, necessariamente, uma relação de redução pequena: as forças aplicadas são elevadas e a geometria do equipamento tem importância fundamental".

Em função da baixa relação de redução e da necessidade de se adequar a geometria do britador ao top size da alimentação, geralmente são utilizados até quatro estágios de britagem nas instalações de beneficiamento de minério. Cada um desses estágios pode operar em circuito aberto ou fechado. Este último, com peneiramento a seco ou a úmido. A figura 7 mostra o fluxograma do circuito de britagem da usina de beneficiamento de minério de ferro de Brucutu, de propriedade da Vale, no município de São Gonçalo do Rio Abaixo, MG. 
Figura 7- Fluxograma do circuito de britagem da usina de Brucutu - Vale

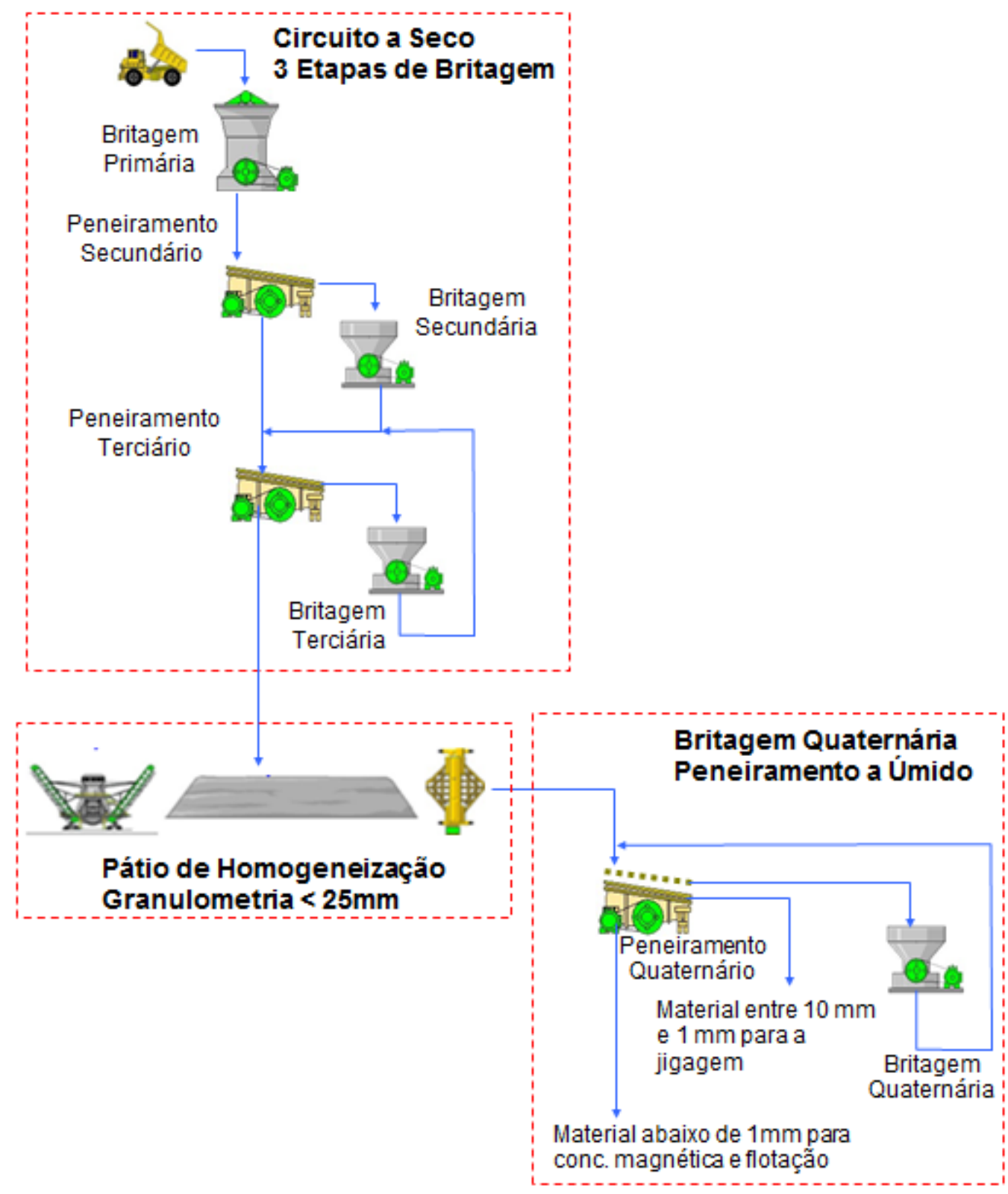

Fonte: Pinto (2015)

Em razão de serem utilizados em praticamente todas as usinas de beneficiamento de minério, foram desenvolvidos os mais variados tipos de britadores, que se diferem tanto pela forma de alimentação e escoamento do material dentro da câmara de britagem, quanto pelo tipo de esforço mecânico aplicado para quebra do minério. No beneficiamento de minério de ferro, os britadores mais utilizados são os britadores de mandíbulas, giratórios e cônicos. 
Os britadores de mandíbulas são geralmente utilizados na primeira etapa de britagem e são capazes de receber blocos de até $1 \mathrm{~m}$. A câmara de britagem consiste em duas mandíbulas, sendo uma móvel e a outra fixa. A mandíbula móvel pode ter um eixo, nos chamados britadores tipo Dodge, ou dois eixos, nos britadores tipo Blake. A figura 8 (CHAVES; PERES, 2003) mostra de forma esquemática os dois tipos de britadores de mandíbulas.

Figura 8- Desenho esquemático dos dois tipos principais de britador de mandíbulas
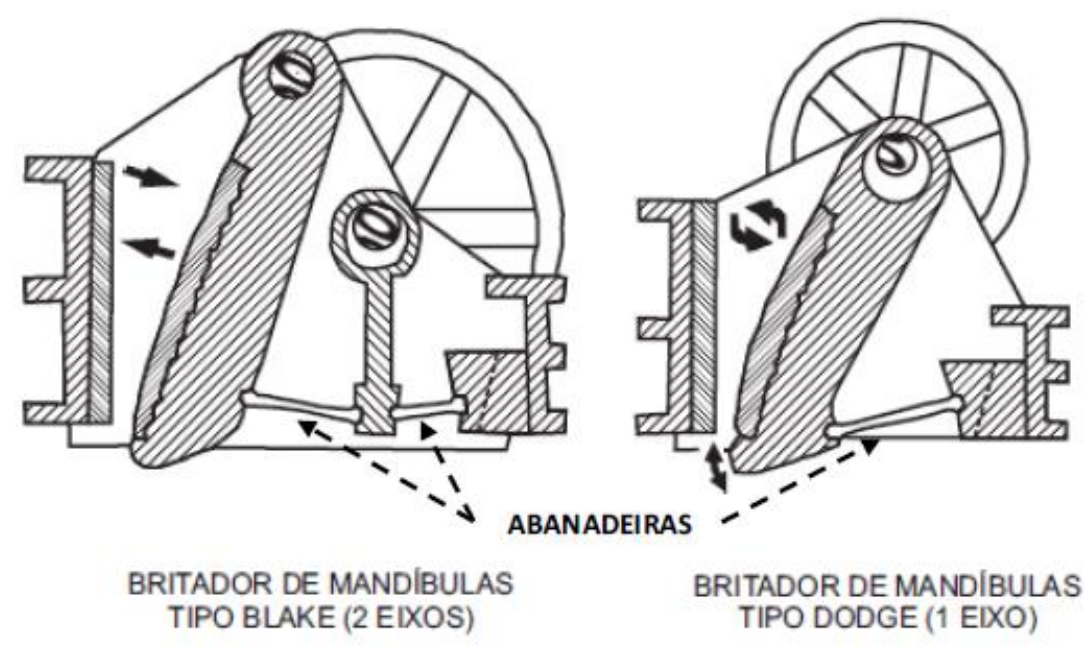

Fonte: Chaves e Peres (2003) Adaptado pelo autor.

O fragmento de rocha ou minério a ser britado é introduzido no espaço entre as duas mandíbulas, e, durante o movimento de aproximação, é esmagado. Os fragmentos resultantes escoam para baixo durante o movimento de afastamento, cada qual se deslocando até uma posição em que fique contido pelas mandíbulas e seja novamente esmagado. (CHAVES; PERES, 2003)

Para minério de ferro, a utilização de britadores de mandíbulas é recomendada para minérios de baixa e média tenacidade. Geralmente é empregada uma grelha de escalpe antes do britador, de forma a reduzir o desgaste por abrasão das mandíbulas, bem como aumentar a capacidade da instalação em função da redução do volume de material que passa pelo britador. A figura 9 mostra a visão superior da operação de um britador de mandíbulas em conjunto com uma grelha de escalpe. 
Figura 9- Fotografia de uma grelha e um britador de mandíbula em operação

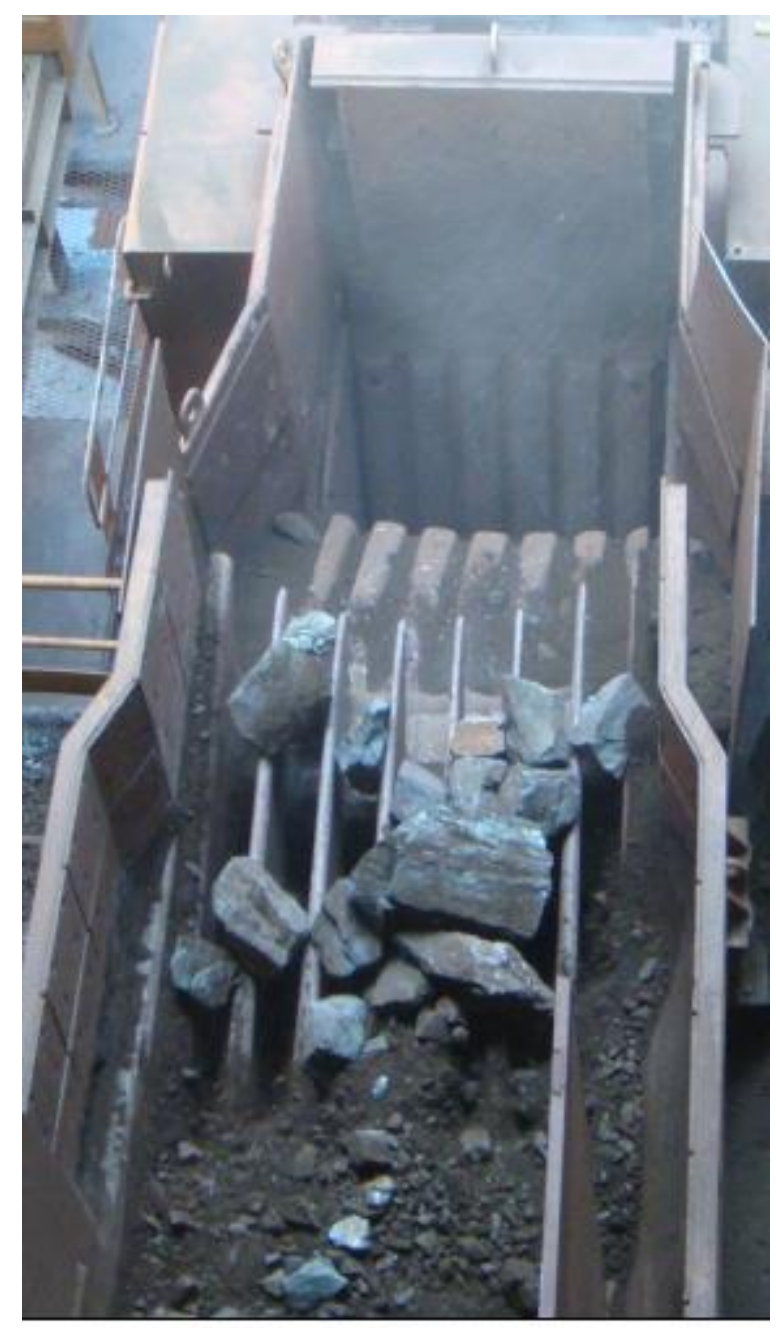

Fonte: Pinto (2015)

Britadores giratórios, assim como os britadores de mandíbulas, são geralmente utilizados na primeira etapa de britagem com capacidade de receber blocos de até $1 \mathrm{~m}$. A câmara de britagem é constituída por um longo e pesado eixo vertical, ao qual está acoplado um cone de aço revestido, denominado manto. $\mathrm{O}$ sistema eixo/manto é suportado por um cilindro hidráulico, que serve para regular a abertura e aliviar a pressão de trabalho em caso de passagem de material não britável.

O princípio de funcionamento do britador giratório consta do movimento de aproximação e distanciamento do cone central em relação à carcaça invertida. Este movimento circular (85 a $150 \mathrm{rpm}$ ) faz com que toda a área da carcaça seja utilizada na britagem, o que fornece ao britador uma grande capacidade de operação. (ALMEIDA; FIGUEIRA; LUZ, 2004) 
A figura 10 (ALMEIDA; FIGUEIRA; LUZ, 2004) mostra, de forma esquemática, um britador giratório.

Figura 10- Desenho esquemático do britador giratório

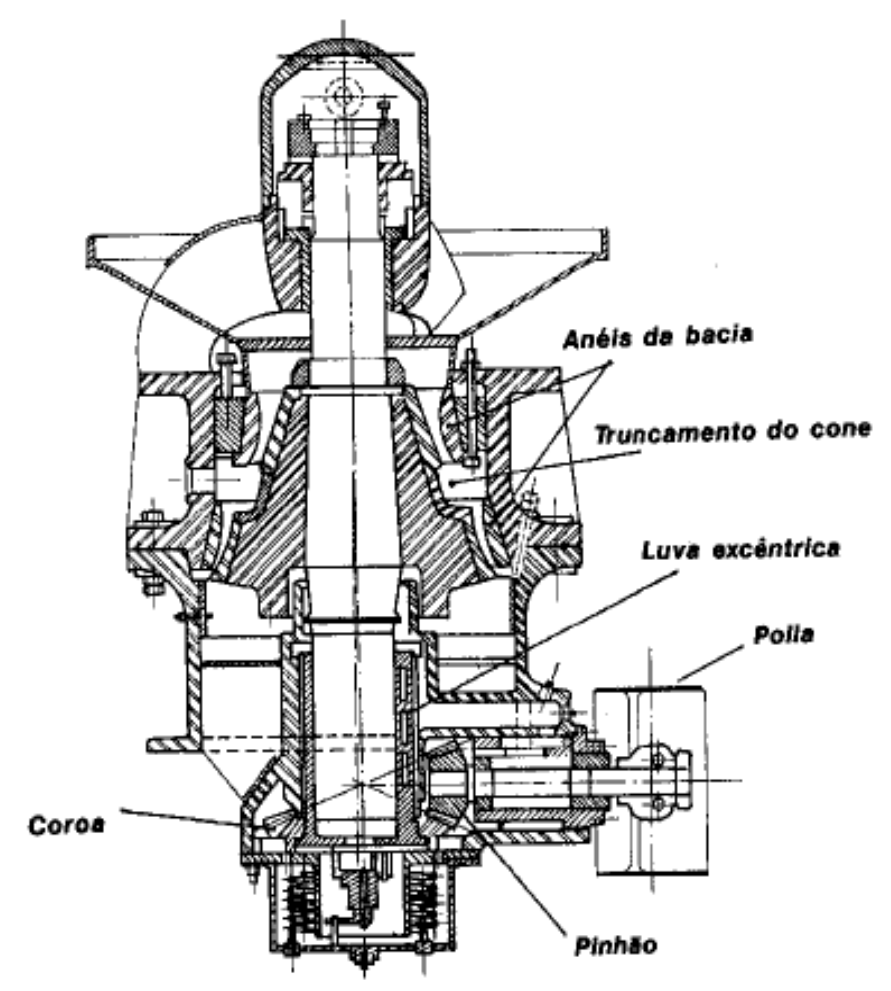

Fonte: Almeida; Figueira e Luz (2004) Adaptado pelo autor

Os britadores giratórios são equipamentos robustos, com grande capacidade de alimentação e que podem ser utilizados para minérios tenazes. Em função do porte do equipamento, são necessários prédios e estruturas robustas, o que, além de onerar o CAPEX do projeto, dificulta significativamente a relocação da instalação de britagem primária. A figura 11 mostra a visão superior de um britador giratório. 
Figura 11- Vista superior do britador giratório

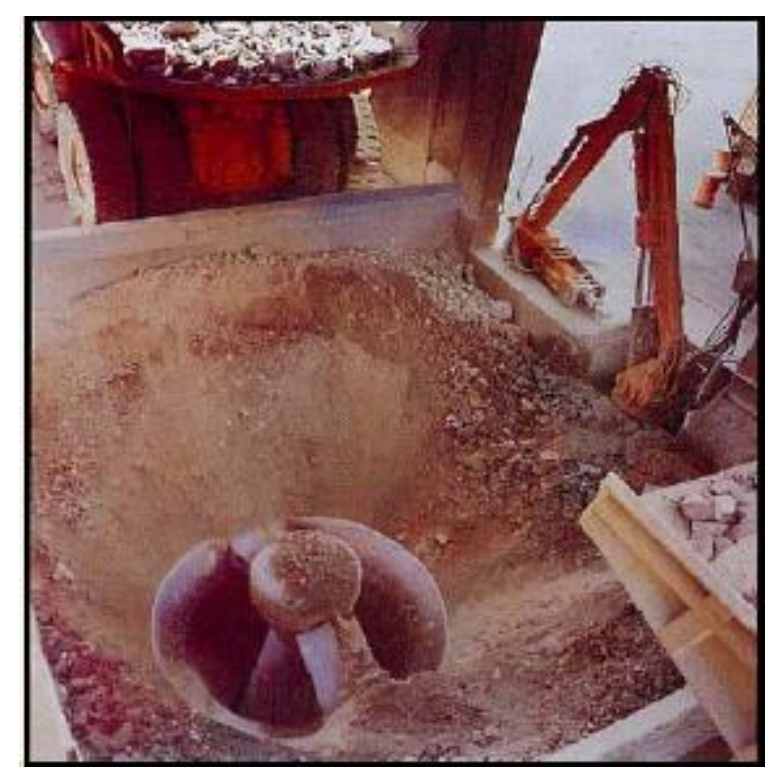

Fonte: Pinto (2015)

Britadores cônicos têm o mesmo princípio de funcionamento dos britadores giratórios, porém, além de terem menor porte, o eixo possui movimento excêntrico, o que faz com que a abertura de saída tenha tamanho variável. Segundo Asbjörnsson; Húlten e Evertsson (2012) "A rotação do eixo com movimento excêntrico na câmara de britagem faz com que o minério seja britado várias vezes, entre o cone e a superfície côncava, enquanto passa pelo britador".

Os britadores cônicos são aplicados a partir da britagem secundária até a britagem quaternária, com variações na abertura de saída, no tipo de revestimento utilizado e na geometria da câmara de britagem. A relação geométrica entre a altura do cone e o diâmetro da base define o ângulo do cone. Os equipamentos com maior ângulo de cone são denominados standard, e, com menor ângulo, de cone short head.

De um modo geral, britadores standard são utilizados para a britagem mais grosseira (acima de $25 \mathrm{~mm}$ ), pois permitem uma maior área para compressão das partículas. Já britadores short head são utilizados para uma britagem mais fina (até $10 \mathrm{~mm}$ ), pois promovem maior abrasão entre as partículas dentro da câmara de britagem. A figura 12 (CHAVES; PERES, 2003) mostra, de forma esquemática, os dois tipos de britadores cônicos. 
Figura 12- Desenho esquemático do britador cônico

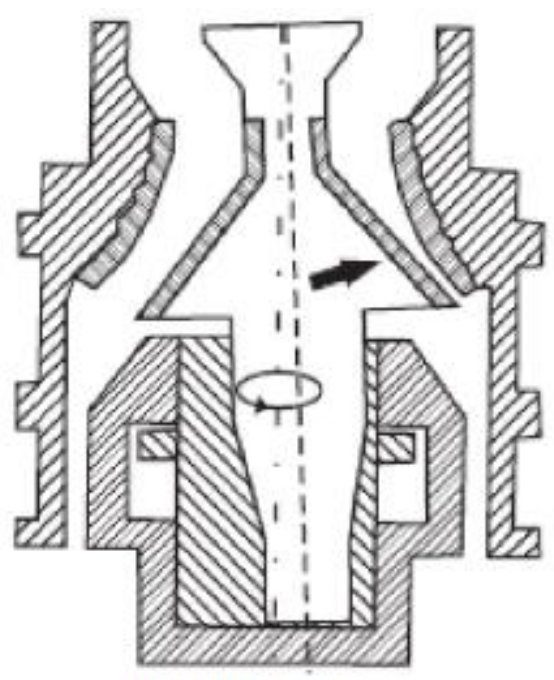

BRITADOR STANDARD

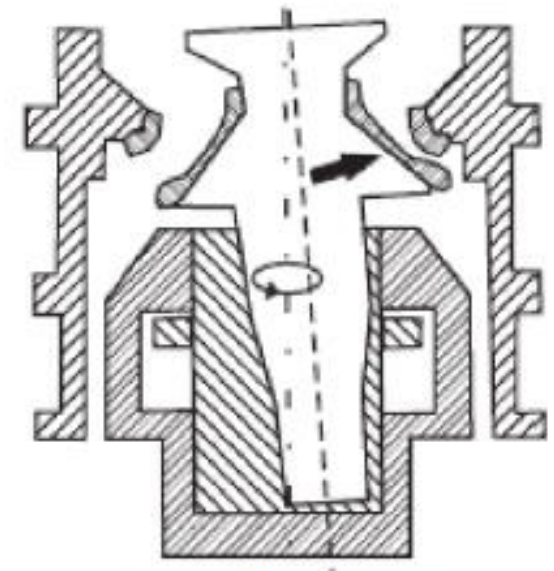

BRITADOR SHORT HEAD

Fonte: Chaves e Peres (2003) Adaptado pelo autor

Britadores cônicos podem trabalhar em circuito aberto, com escalpe dos finos, ou fechado, com peneiramento a seco ou a úmido. Em geral, a britagem secundária opera em circuito aberto e as britagens terciárias e quaternárias, em circuito fechado.

Assim como nos britadores de mandíbulas, é importante a retirada dos finos da alimentação do britador, de forma a se reduzir o desgaste dos revestimentos e aumentar a capacidade da instalação de britagem. Outro ponto importante na operação do equipamento é instalar um silo de alimentação antes do britador, de forma que se possa manter a câmara de britagem cheia (afogada), aumentando assim, consideravelmente, a eficiência da operação.

O design e o posicionamento dos silos e alimentadores são importantes para assegurar a produtividade e a confiabilidade do circuito de britagem. $O$ fluxo de material nos silos, com múltiplas entradas e saídas, pode ocasionar problemas no processo posterior em função da segregação dentro do silo.

(HULTÉN; ABJORNSSON; EVERTSSON, 2012)

Os dois principais parâmetros de operação de um britador cônico são a abertura na posição fechada (APF) e a velocidade de rotação do eixo. Essas variáveis afetam tanto a capacidade de alimentação do britador quanto a curva granulométrica da descarga do britador. Segundo Asbjörnsson; Hultén e Evertsson (2012) "Enquanto a alteração na APF move a curva granulométrica do produto 
horizontalmente, a alteração na velocidade de rotação tende a rotacionar a curva granulométrica do produto".

\subsubsection{Moagem}

A moagem é a última etapa do processo cominuição, e pode ser utilizada tanto para a liberação do mineral de interesse, quanto para adequação granulométrica para etapa posterior, ou ainda para geração de produtos finais do processo.

A moagem é a área da fragmentação que requer maiores investimentos, maior gasto de energia e é considerada uma operação importante para o bom desempenho de uma instalação de tratamento. A submoagem do minério resulta num produto grosso com liberação parcial do mineral útil, inviabilizando o processo de concentração. Neste caso, a recuperação parcial do mineral útil e a baixa razão de enriquecimento respondem pela inviabilidade do processo. A sobremoagem também não é desejada, pois ela reduz o tamanho das partículas, desnecessariamente, o que acarretará maior consumo de energia e perdas no processo de concentração. (ALMEIDA; FIGUEIRA; LUZ, 2004)

No beneficiamento de minério de ferro, a moagem é normalmente feita a úmido, em moinhos tubulares, e tem como função a liberação dos minerais para a etapa de concentração magnética ou flotação, e a geração de área específica para o processo de pelotização. Com a redução de teor dos minérios e a sua consequente necessidade de beneficiamento, a moagem passa a ser cada vez mais utilizada nas novas usinas de beneficiamento.

Nos moinhos tubulares, a carcaça do moinho é rotacionada, e o movimento é transferido para a carga através da estrutura do moinho. São utilizados como corpos moedores: barras, bolas ou o próprio minério. Moinhos tubulares são normalmente utilizados para moagem grosseira com um tamanho de alimentação entre $5 \mathrm{~mm}$ e $250 \mathrm{~mm}$ e geração de produto entre $0,04 \mathrm{~mm}$ e 0,30 mm. (WILLS; NAPIER-MUNN, 2006)

A figura 13 (CHAVES; PERES, 2003) mostra um moinho tubular. 
Figura 13- Desenho de um moinho tubular

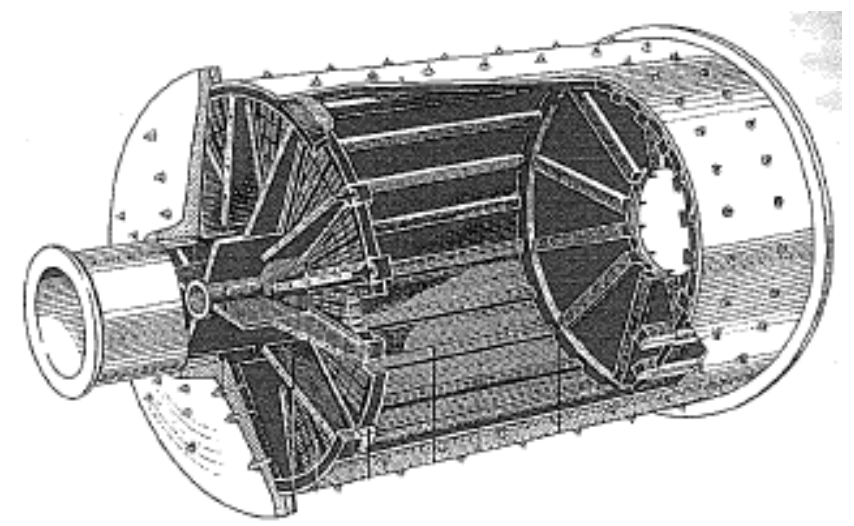

Fonte: Chaves e Peres (2003)

A moagem do minério nos moinhos tubulares ocorre tanto por impacto, com a queda dos corpos moedores sobre o minério, quanto por abrasão e atrito devido à movimentação dos corpos moedores sobre as partículas de minério. A figura 14 (NAPIER-MUNN et al., 1999) mostra, de forma esquemática, os mecanismos principais de cominuição, bem como a dinâmica da carga em moinhos tubulares. 
Figura 14- Desenho esquemático das formas de cominuição do minério

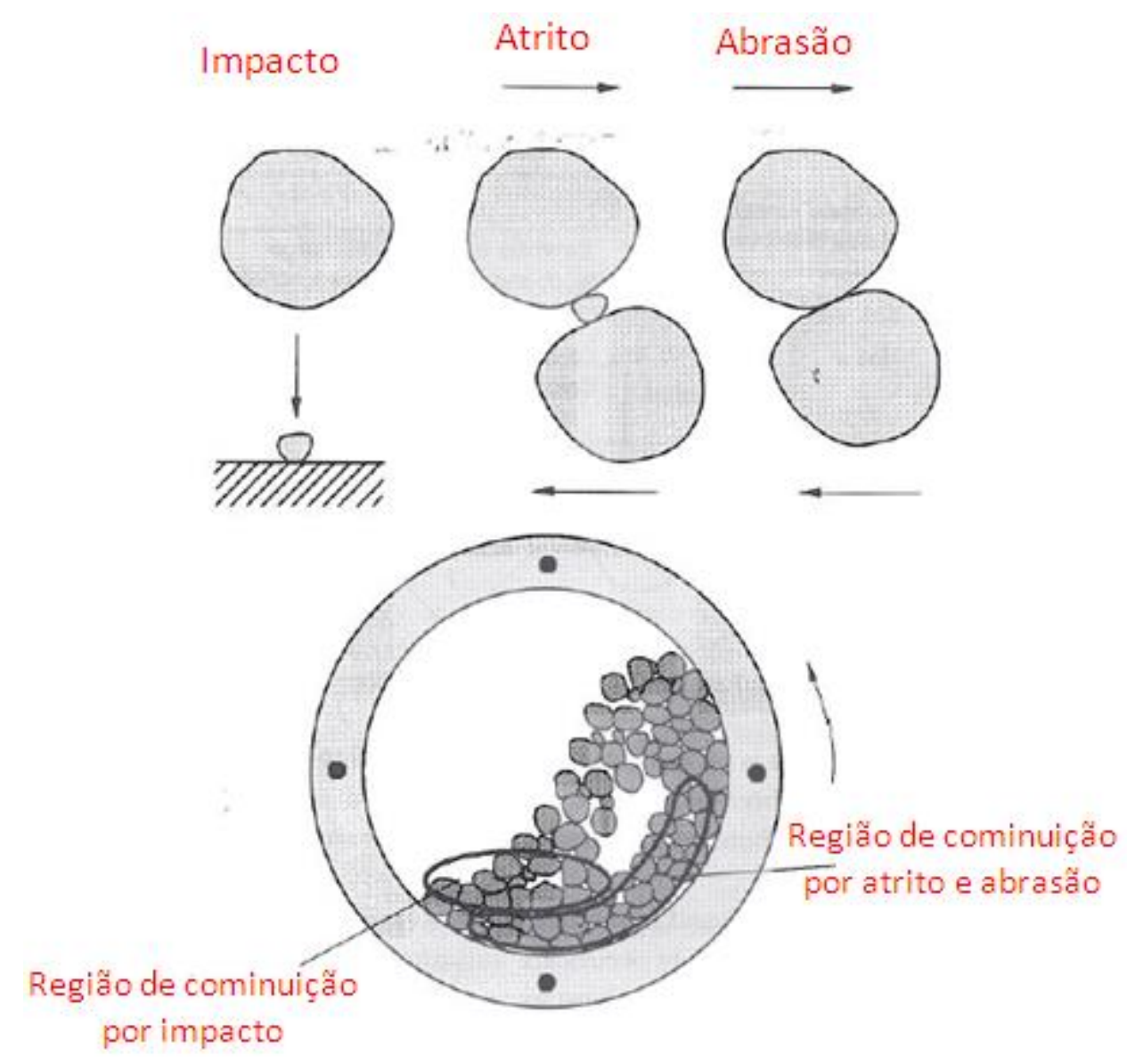

Fonte: Napier-Munn et al. (1999) Adaptado pelo autor

A fragmentação por impacto é adequada para uma moagem com alimentação mais grosseira, onde é necessário quebrar partículas maiores de minério sem a geração excessiva de finos. Este tipo de fragmentação é favorecido quando se tem menor volume de corpos moedores dentro do moinho e maior velocidade de operação. A fragmentação por abrasão e atrito é adequada para moagens finas, onde o objetivo é obter uma maior área específica. Para se favorecer este tipo de fragmentação, deve se utilizar corpos moedores relativamente menores, com alto percentual de enchimento e baixa velocidade de operação.

Apesar do desenvolvimento constante dos moinhos e da alta eficiência dos dispositivos de transmissão e acionamento, grande parte da energia fornecida a um moinho tubular não é utilizada de forma eficiente em moagem.

Os moinhos tubulares são extremamente ineficientes na utilização da energia fornecida, pois, a quebra do minério é resultado de impactos 
repetitivos e aleatórios, que quebram tanto as partículas liberadas quanto as não liberadas. Até o presente momento, não existe forma alguma prática de direcionar esses impactos para as interfaces dos grãos dos minérios, de forma a se otimizar a liberação. (WILLS; NAPIER-MUNN, 2006)

Moinhos tubulares são classificados conforme o corpo moedor utilizado. Os tipos mais comuns são os moinhos de bola, moinhos de barra, moinhos autógenos (AG), estes últimos são os que utilizam blocos do próprio minério como corpo moedor, e moinhos semi-autógenos (SAG) que utilizam bolas em conjunto com os blocos do minério como corpos moedores.

Os moinhos de bolas são o tipo mais comum de moinho tubular, provavelmente porque eles operam com eficiência tanto em escala de laboratório, com poucos watts de potência, quanto em escala industrial, onde atingem potência de 10-12 MW. (NAPIER-MUNN et al, 1999)

De forma geral, moinhos de bolas apresentam uma relação de comprimento versus diâmetro entre 2 e 1 e são utilizados nas últimas etapas de cominuição, com uma malha mais fina de moagem.

As bolas de moinho são feitas, geralmente, de aço alto carbono ou ferro fundido, sendo, eventualmente, utilizados elementos ligantes, como o cromo, para aumento da resistência mecânica e à corrosão. O diâmetro das bolas está relacionado com a malha de moagem e com o top size de alimentação.

O consumo de corpo moedor varia de $0,1 \mathrm{~kg} / \mathrm{t}$ até $1,0 \mathrm{~kg} / \mathrm{t}$ de minério e depende da dureza e abrasividade do minério, da granulometria de moagem e da qualidade do corpo moedor (tipo de aço utilizado). O consumo de corpo moedor pode ter um valor considerável e, em alguns casos, atingir até $40 \%$ do custo total de moagem. (WILLS; NAPIER-MUNN, 2006)

Como exemplo da utilização de moinhos de bolas no beneficiamento de minério de ferro, podem ser citadas as usinas de Germano, localizadas em Mariana, MG de propriedade da Samarco, e os novos circuitos em implantação de beneficiamento de itabiritos de Cauê e Conceição, localizados em Itabira, MG de propriedade da Vale. A figura 15 mostra a rota convencional de moagem em 0,15 mm para minério de ferro em circuito fechado com duplo estágio de classificação. 
Figura 15- Fluxograma esquemático de moagem de bolas em $0,15 \mathrm{~mm}$

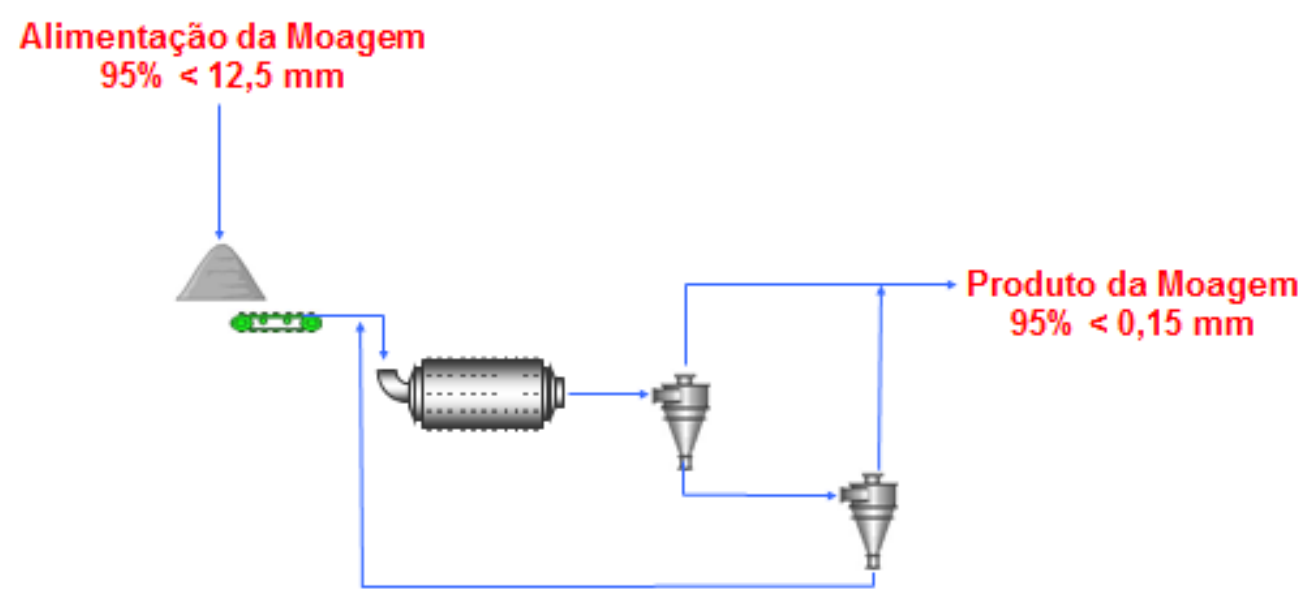

Fonte: Pinto (2015)

Para cálculo da potência dos moinhos de bola, foi desenvolvida em 1986 por Rowland, (ROWLAND 1986) a seguinte equação, para moinhos com diâmetros acima de 2,44 metros que fornece a potência do moinho por tonelada de bolas na carga de moagem:

$$
k W b=4.879 D^{0.3}(3.2-3 V p) C s\left(1-\frac{0.1}{2^{9-10 C s}}\right)+S s
$$

Onde:

$\mathrm{kWb}=$ Potência no eixo pinhão por tonelada de bola $(\mathrm{kW} / \mathrm{t})$

$\mathrm{D}=$ Diâmetro interno ao revestimento do moinho $(\mathrm{m})$

$\mathrm{Vp}=$ Enchimento de bolas no moinho (\%)

$\mathrm{Cs}=$ Fração da velocidade crítica do moinho (\%)

Ss $=$ Termo relativo ao diâmetro máximo de bolas.

Para bolas de aço (densidade de $7,8 \mathrm{t} / \mathrm{m}^{3}$ ), a massa de corpos moedores, em toneladas $(\mathrm{Mb})$, dentro do moinho, é determinada pela seguinte equação:

$$
M b=3,652 D^{2} L^{*} V p
$$

Onde: $\mathrm{L}=$ Comprimento do moinho interno ao revestimento $(\mathrm{m})$ 
Moinhos autógenos (AG) e semi-autógenos (SAG) utilizam os blocos do próprio minério como corpos moedores, e, por este motivo, o minério deve conter uma quantidade suficiente de blocos competentes para que seja aplicado este método de moagem. Em geral, como a densidade dos blocos de minério é menor que a densidade das bolas de aço, são necessários grandes blocos de minério em conjunto com moinhos de grande diâmetro para que se consiga obter potências elevadas, e, consequentemente, a energia proporcionada às partículas resulte em fragmentação das mesmas.

O moinho SAG é um moinho autógeno que utiliza bolas de aço em conjunto com corpos moedores do próprio minério. Conforme prática industrial, para uma moagem mais eficiente, a carga de bolas deve ser de 4 a $15 \%$ do volume do moinho. (WILLS; NAPIER-MUNN, 2006)

Enquanto os moinhos de bolas são alimentados com uma granulometria mais fina, geralmente abaixo de $20 \mathrm{~mm}$, os moinhos $A G$ e SAG são alimentados com material mais grosseiro, com um top size de até $200 \mathrm{~mm}$.

Segundo Delboni (1999) apud Bergerman (2009):

A partir de 1950, este revolucionário equipamento foi introduzido com sucesso nas instalações de processamento mineral. Apesar de, inicialmente confinado às minas de ouro, a utilização de moinhos autógenos aumentou na indústria de processamento mineral, principalmente nas duas últimas décadas. Esta opção se mostrou tão viável, que hoje não é incomum observar, em usinas com altas capacidades, a substituição dos tradicionais circuitos com britagem, moagem de barras e bolas, por circuitos de moagem autógena com um único estágio. (DELBONI, 1999 apud BERGERMAN, 2009)

Quanto à estrutura e forma de operação, moinhos AG/SAG apresentam diferenças significativas em relação aos moinhos de bolas, como relação comprimento versus diâmetro menor ou igual a um, revestimento interno com estruturas que maximizam o levantamento da carga, dispositivos para o transporte de polpa (pulp lifters), potência instalada que pode atingir valores acima de $20 \mathrm{MW}$ com acionamento por sistema gearless, e presença de crivos para retenção do material grosseiro.

A figura 16 (WILLS; NAPIER-MUNN, 2006) mostra as principais partes que constituem um moinho SAG. 


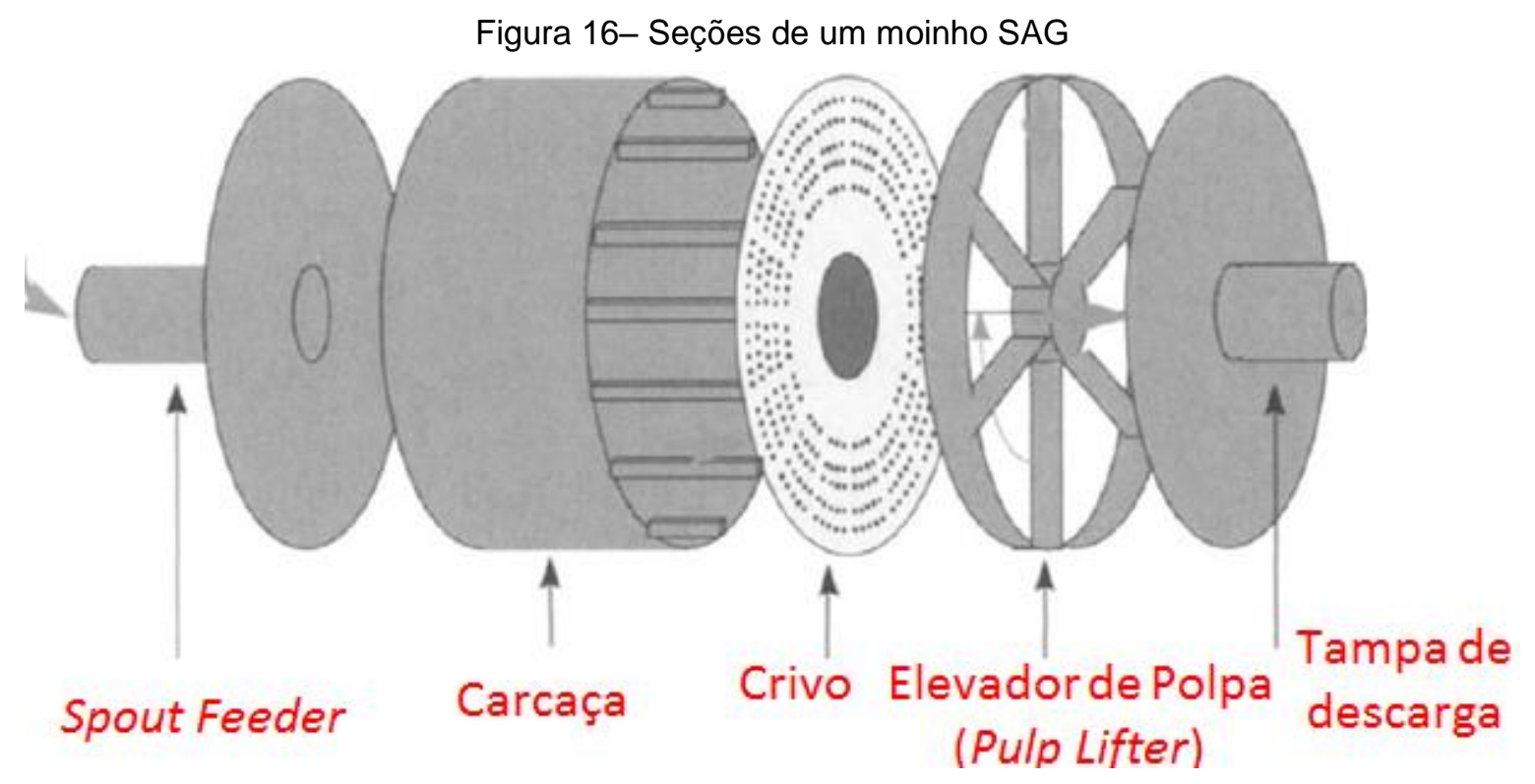

Fonte: Wills e Napier-Munn (2006) Adaptado pelo autor

O crivo do moinho SAG tem papel fundamental na operação do equipamento, pois deve reter os corpos moedores e permitir a passagem do fluxo de polpa de forma eficiente. Segundo Napier-Munn et al. (1999) "todos os moinhos AG e SAG utilizam um crivo de aço ou borracha para manter os corpos moedores, enquanto permite a passagem da polpa". Após passar pelo crivo, a polpa deve ser removida do moinho pelo sistema de pulp lifter. Caso a polpa não seja removida de forma eficiente, haverá o acúmulo de polpa no pé da carga do moinho, um fenômeno conhecido como slurry pool. O slurry pool reduz a eficiência de moagem, em função do amortecimento do impacto dos corpos moedores e diminuição da potência do moinho devido ao deslocamento do centro de massa. A figura 17 (LATCHIREDDI, 2002) mostra de forma esquemática a operação do moinho SAG com e sem a ocorrência do slurry pool. 
Figura 17- Influência do slurry pool na operação da moagem SAG

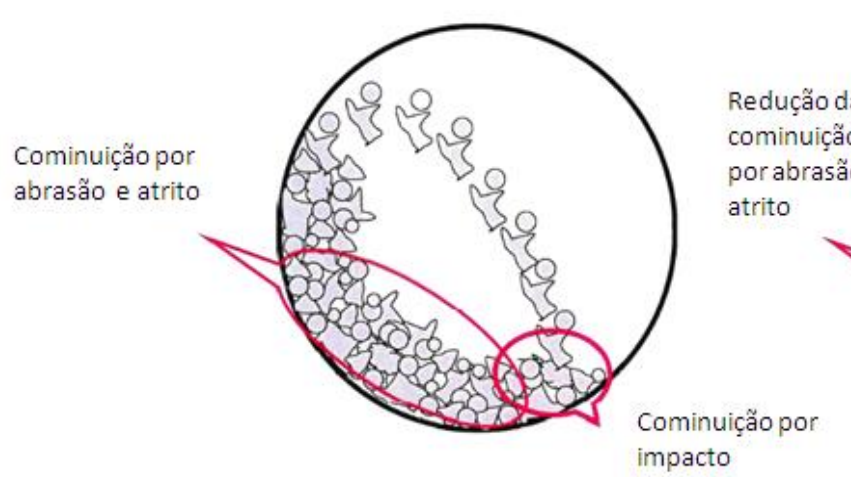

impacto

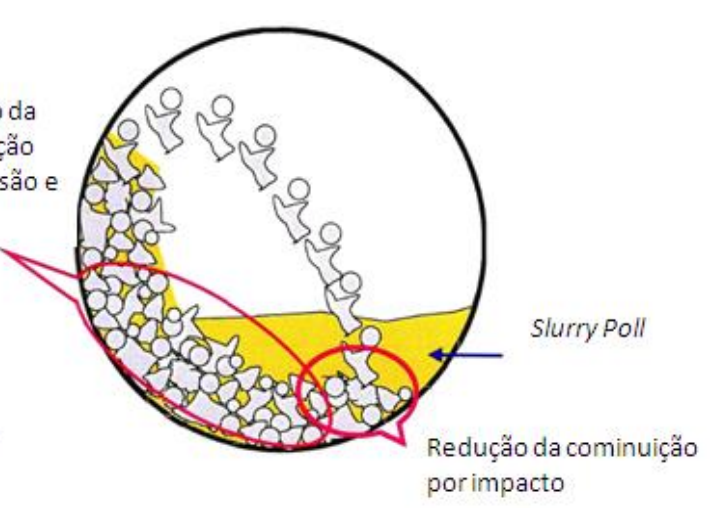

Fonte: Latchireddi (2002) Adaptado pelo autor

Assim, para a maximização do fluxo de polpa no moinho SAG, deve ser buscada a maior área aberta no crivo, sem prejuízo de sua vida útil e da retenção dos corpos moedores, bem como de um projeto do pulp lifter que permita uma remoção eficiente de polpa do moinho. São mostrados a seguir dois estudos (BURGER et al., 2011 e DELBONI et al., 2006) sobre a otimização industrial da operação de crivos e um estudo (LATCHIREDDI, 2002) sobre o desenvolvimento de pulp lifter para maximização da remoção de polpa no moinho.

Em uma avaliação do start up da usina de beneficiamento de minério de ouro de Yanacocha no Peru, Burger et al. 2011 afirma que:

Logo após o start up da planta, uma série de problemas operacionais apareceu, entre os quais se destaca um forte entupimento (pegging) do crivo, o que resultou em forte queda na vazão de alimentação da usina e no aumento da carga interna do moinho. No curto prazo, foram estabelecidas intervenções manuais de corte das bolas que entupiam o crivo a cada 10 ou 20 dias, enquanto eram desenvolvidos novos tipos de crivo. (BURGER et al., 2011)

O moinho de Yanacocha opera em circuito fechado, rota SSSAG, e por esta razão o fluxo de polpa no moinho SAG é um item crítico de operação, e os crivos não podem restringir a passagem do fluxo de polpa pelo moinho, sob forte risco de ocorrência de slurry pool.

A figura 18 mostra a condição dos crivos do moinho SAG de Yanacocha antes e após a operação. Conforme mostrado na mesma figura 18, somente o crivo de borracha não entupiu após a operação. 
Figura 18- Imagens do crivo do moinho SAG antes e após operação

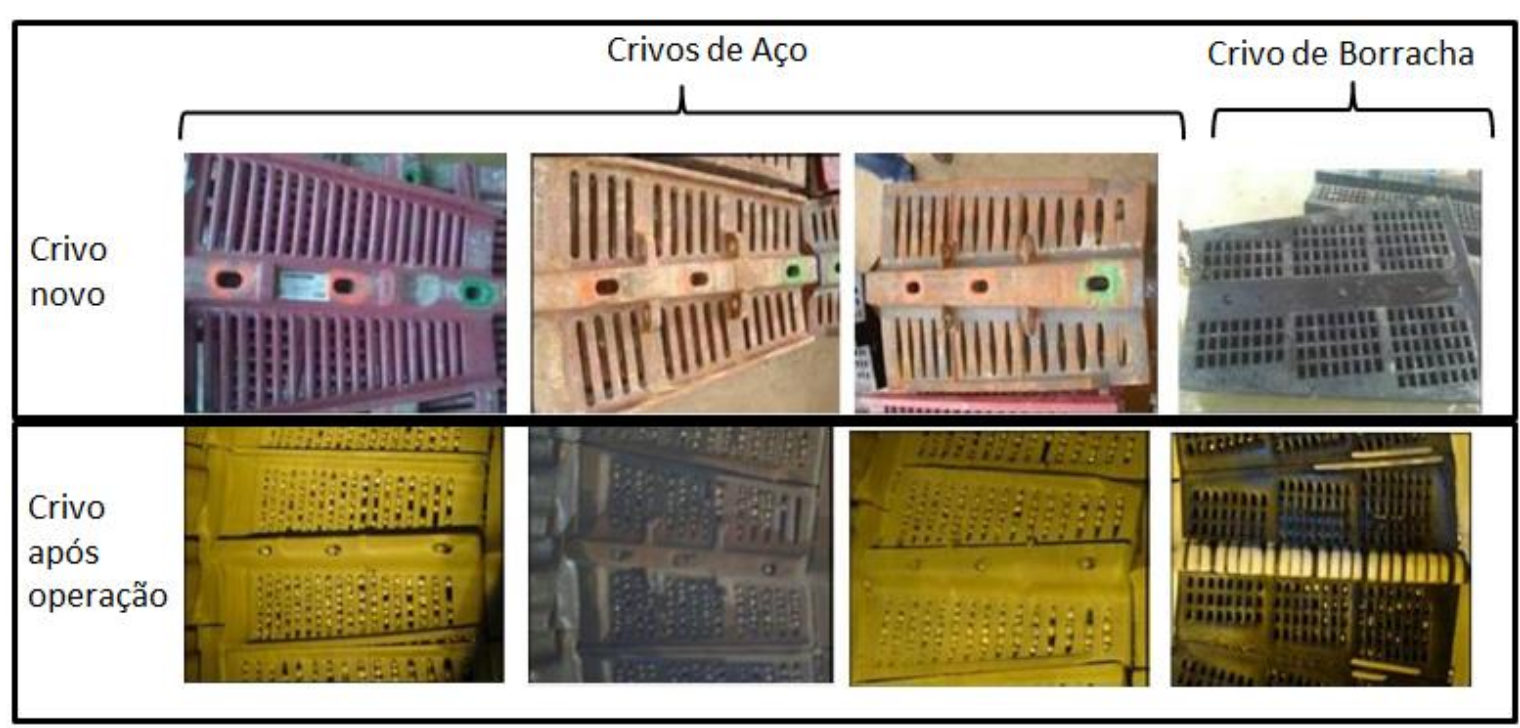

Fonte: Burger et al. (2011) Adaptado pelo autor

Na usina de beneficiamento de cobre do Sossego, localizada em Canaã dos Carajás, PA, de propriedade da Vale, Delboni et al. 2006, mostraram a necessidade de desenvolvimento de sete gerações de crivos para a descarga do SAG, até a obtenção do ponto ótimo entre área aberta, tamanho de abertura e vida útil da grelha.

Para maximização da remoção de polpa no moinho SAG, foi desenvolvido em 2002, por Latchireddi, um sistema de pulp lifter com câmara dupla (TCPL). O principio de funcionamento deste pulp lifter é impedir, através da presença de câmara dupla, o flowback, que é o retorno da polpa para dentro do moinho após a passagem pelo crivo. As figuras 19 e 20 (LATCHIREDDI 2002) mostram, de forma esquemática, o fenômeno do flowback e o desenho do TCPL. 
Figura 19- Desenho esquemático da ocorrência de flowback

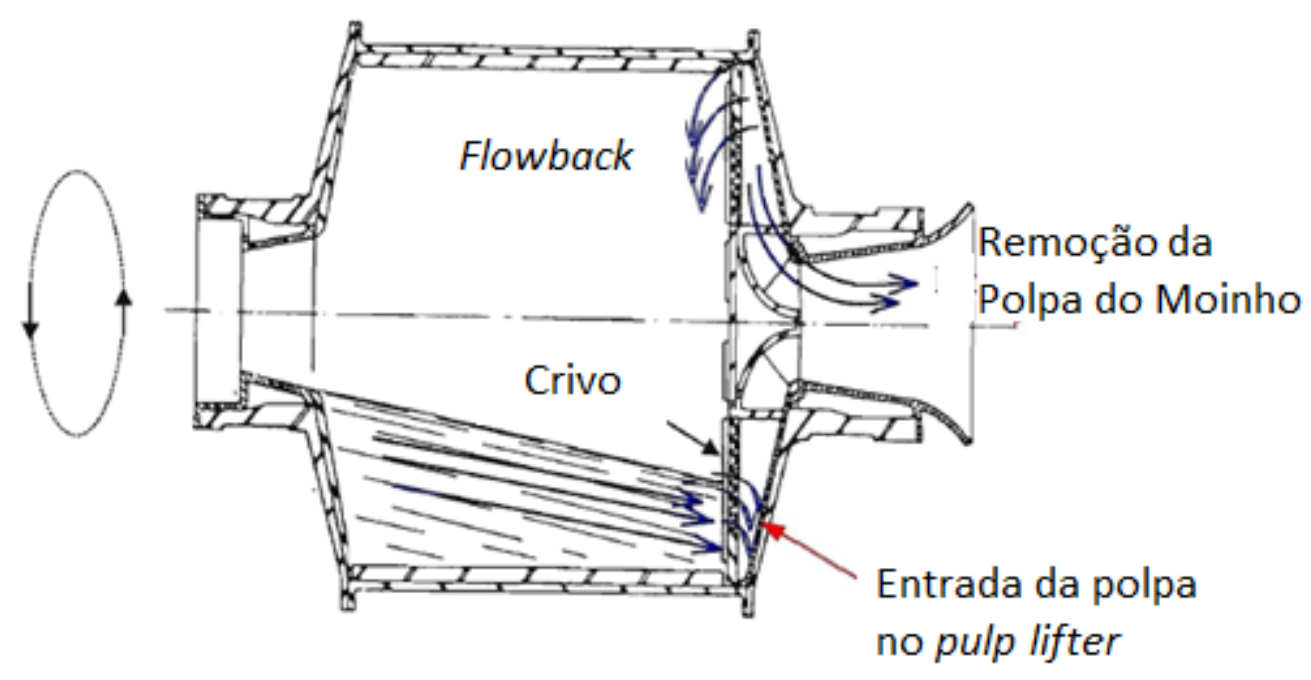

Fonte: Latchireddi (2002) Adaptado pelo autor

Figura 20- Desenho esquemático do pulp lifter de câmara dupla, TCPL.

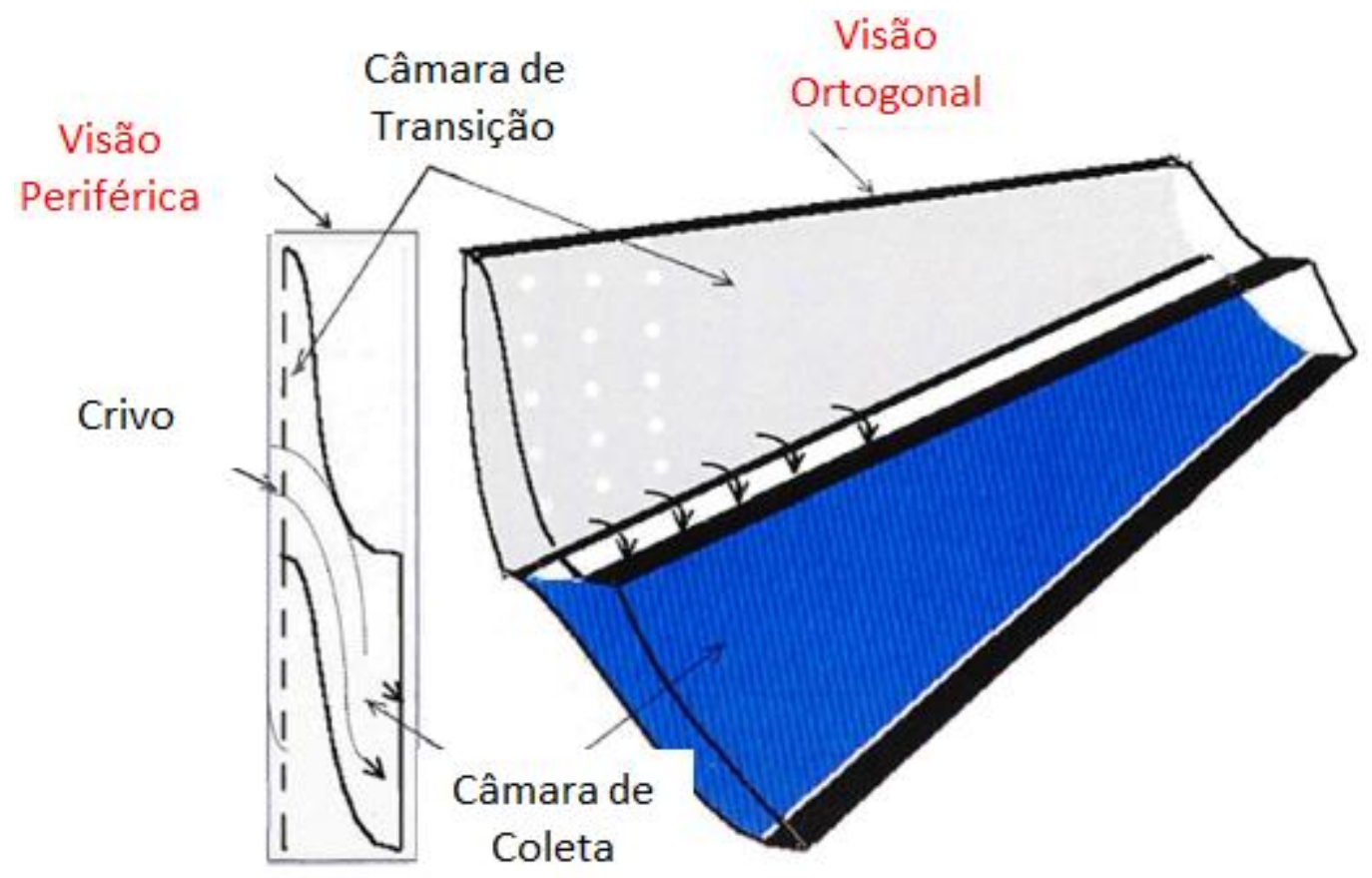

Fonte: Latchireddi (2002) Adaptado pelo autor

Outro aspecto importante na operação de moinhos SAG é a geração de fragmentos de tamanho crítico, que são muito pequenos para atuarem como corpos moedores e muito grandes para serem moídos dentro do moinho. Segundo Wills e Napier-Munn (2006) "Na operação da moagem AG e SAG os fragmentos entre 25 mm e $50 \mathrm{~mm}$ (pebbles) são críticos, pois são muito pequenos para atuar como corpo 
moedor, porém são muito grandes para serem quebrados". Quando é gerado um volume considerável de pebbles, é necessário que este material seja retirado do moinho, geralmente por uma saída com maior abertura disposta na grelha, denominada pebble port, e seja rebritado antes de voltar para o moinho. Devido à dificuldade de se prever a geração de pebbles em circuitos AG/SAG, é comum que seja previsto, no projeto da instalação, um espaço para a rebritagem de pebbles. Porém, os equipamentos só são instalados após a operação do circuito e a confirmação da necessidade da rebritagem.

Para minérios com presença de material magnético, como o minério de ferro e alguns minérios de cobre, a rebritagem de pebbles se torna um item crítico para as moagens SAG devido à dificuldade de separação do expurgo de bolas dos pebbles.

Para cálculo da potência dos moinhos SAG, foi desenvolvida em 1990 por Austin (AUSTIN 1990) a seguinte equação:

$$
k W=10.6 D^{2.5} L(1-1.03 T l)\left((1-e) \frac{p s}{c s} T l+0.6 T b\left(p b-\frac{p s}{c s}\right)\right) \operatorname{Vr}\left(1-\frac{0.1}{2^{9-10 V r}}\right)
$$

Onde:

$$
\begin{aligned}
& \text { kW }=\text { Potência no eixo pinhão }(\mathrm{kW}) \\
& \mathrm{D}=\text { Diâmetro interno do moinho }(\mathrm{m}) \\
& \mathrm{L}=\text { Comprimento do moinho }(\mathrm{m}) \\
& \mathrm{TI}=\text { Volume de carga }(\%) \\
& \mathrm{e}=\text { Porosidade da carga }(\%) \\
& \mathrm{ps}=\text { Densidade do Sólidos }\left(\mathrm{t} / \mathrm{m}^{3}\right) \\
& \mathrm{CS}=\text { Concentração de Sólidos na Polpa }(\%) \\
& \mathrm{Tb}=\text { Volume de Bolas }(\%) \\
& \mathrm{pb}=\text { Densidade da Bola }\left(\mathrm{t} / \mathrm{m}^{3}\right) \\
& \mathrm{Vr}=\text { Velocidade Crítica }(\%)
\end{aligned}
$$

Em geral, o moinho SAG, opera em circuito aberto, ou fechado com uma peneira de corte acima de 6,3 $\mathrm{mm}$. Desta forma o undersize da peneira alimenta uma moagem de bolas em circuito fechado reverso. Esta rota é denominada pela literatura como SAB. 
Outra configuração de operação do moinho SAG é em circuito fechado com ciclones e geração de produto final em uma única etapa de moagem. Esta rota é denominada pela literatura como SSSAG.

É prática comum a operação de moinhos de bola em circuito fechado, com classificador de corte fino como um ciclone. O mesmo não se pode dizer dos moinhos AG/SAG, com exceção das operações da África do Sul. Na maioria dos países, a operação em circuito aberto (ou circuito fechado com uma peneira de corte grosseiro) é a norma. Porém, cada vez mais operadores e projetistas estão reconhecendo $o$ valor de se trabalhar em circuito fechado, e, na Austrália, a prática vem ganhando popularidade. Todavia, sérias dificuldades vêm sendo encontradas em algumas plantas, 0 que leva a questionamentos sobre a aplicabilidade deste tipo de circuito. (NAPIER-MUNN et al., 1999)

Para a ilustração das opções de circuito de moagem SAG, as figuras 21 e 22 mostram dois exemplos para minerais não ferrosos. A primeira figura (BERGERMAN 2009) mostra o fluxograma de moagem da usina de beneficiamento de minério de cobre do Sossego. Nesta usina, o moinho SAG opera em conjunto com dois moinhos de bolas. A segunda figura (DANCE et al., 2011) mostra o fluxograma de moagem da usina de beneficiamento de ouro de Granny Smith, localizada na Austrália, de propriedade da Barrick Gold Corporation. Nesta instalação, o SAG opera em estágio único, em circuito fechado com ciclones.

Figura 21- Circuito de moagem da usina do Sossego, Vale.

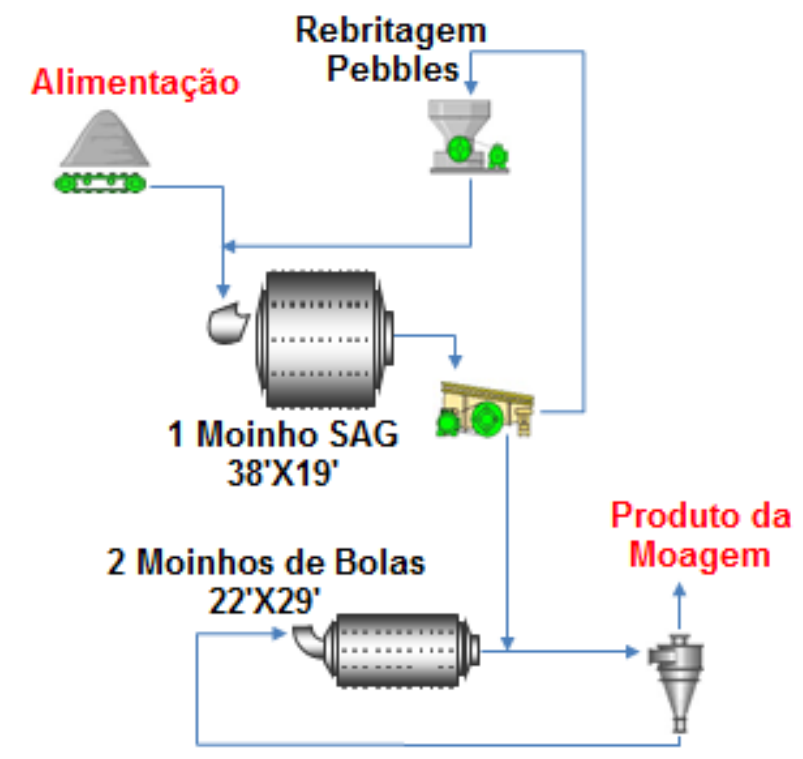


Fonte: Bergerman (2009) Adaptado pelo autor

Figura 22- Circuito de moagem da usina de Granny Smith

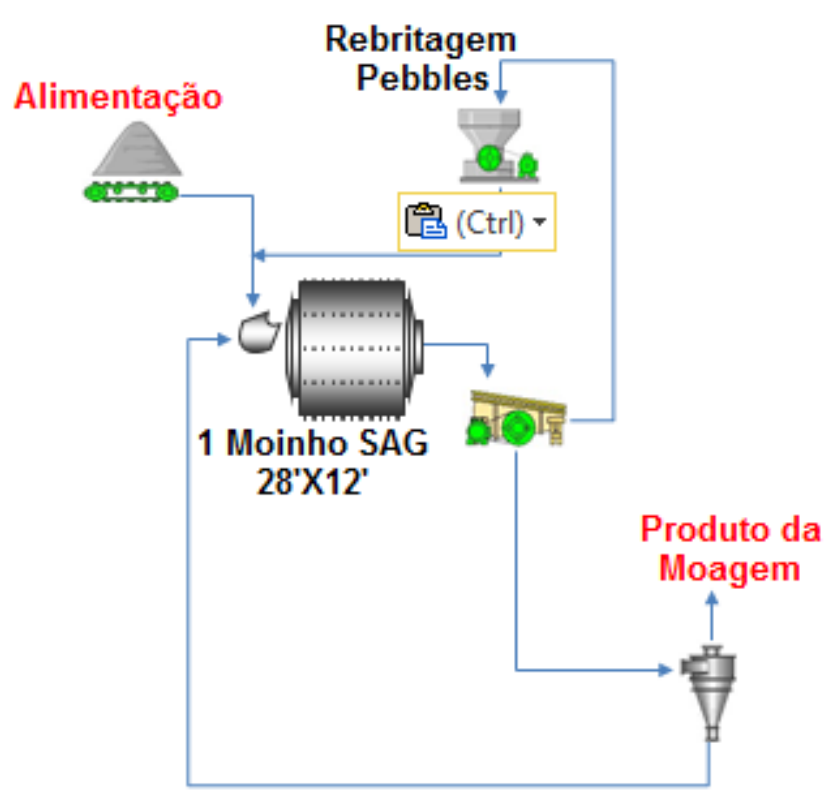

Fonte: Dance et al. (2011) Adaptado pelo autor 


\subsection{Modelagem e Simulação}

A simulação de rotas de beneficiamento mineral é uma ferramenta essencial, tanto para a operação e otimização de usinas existentes, quanto para o projeto e dimensionamento de novas plantas de beneficiamento.

As simulações correspondem a previsão do desempenho da operação de um equipamento ou circuito em operação contínua (simulação dinâmica) ou em regime estacionário (steady state). Em geral, para o desenvolvimento de projetos e dimensionamento de novas plantas de beneficiamento é utilizada a simulação em regime estacionário.

Nos circuitos de cominuição, o desempenho se traduz nas propriedades dos
fluxos - como vazão de sólidos, porcentagem de sólidos e distribuição
granulométrica - em função das propriedades do minério, das
características dos equipamentos e das condições operacionais.
(FOGGIATO, 2009)

Para a simulação das operações de beneficiamento de minério, são utilizados modelos que, com variados graus de fidelidade, representam, matematicamente, os resultados obtidos por essas operações. Para a construção e desenvolvimento dos modelos, são utilizados dados obtidos em ensaios e operações industriais, em conjunto com a descrição dos fenômenos físicos e físico-químicos relacionados à operação de beneficiamento de minérios.

Dessa forma, os modelos permitem prever, dentro de uma determinada condição operacional e para um determinado tipo de minério, qual será o desempenho das operações de beneficiamento de minério.

Nesta revisão bibliográfica, são discutidos os conceitos básicos da modelagem das etapas de britagem, peneiramento, classificação e moagem, com discussão das principais equações utilizadas para o balanço de massas e dimensionamentos de equipamentos utilizados neste trabalho.

\subsubsection{Modelagem da Britagem}


A modelagem da etapa de britagem consiste em prever o comportamento do material enquanto este passa pela câmara de britagem.

No caso de britadores, o processo de cominuição é composto, de maneira simplificada, como uma sucessão de eventos de classificação, e, de quebra, à medida que o material caminha no sentido da descarga do equipamento. Essa observação é válida para britadores de mandíbula, giratórios, cônicos e de rolos, nos quais, independente do tipo de equipamento, existe um estreitamento contínuo da câmara de britagem. (DELBONI, 2003)

A geometria interna da câmara de britagem tem importância fundamental na modelagem da etapa de britagem, posto que influencie tanto a classificação das partículas que serão quebradas, quanto o tipo de quebra (compressão ou abrasão) ao qual as partículas serão submetidas.

As distribuições granulométricas fornecidas pelos equipamentos de britagem tendem a serem sempre as mesmas, independentes do material que está sendo britado, dependendo apenas da geometria da câmara de britagem, (ou seja, para um determinado tamanho de britador, da abertura de descarga). Isto é verdade, tanto que os fornecedores de equipamentos publicam as curvas de distribuição granulométricas de seus produtos. (CHAVES; PERES, 2003)

As figuras 23 e 24 mostram, a seguir, as curvas granulométricas do produto do britador em função da abertura da câmara na posição fechada em milímetros (CSS) para os equipamentos das séries CS e $\mathrm{CH}$ fabricados pela empresa Sandvik. 
Figura 23- Distribuição Granulométrica dos Produtos dos Britadores da Série CS

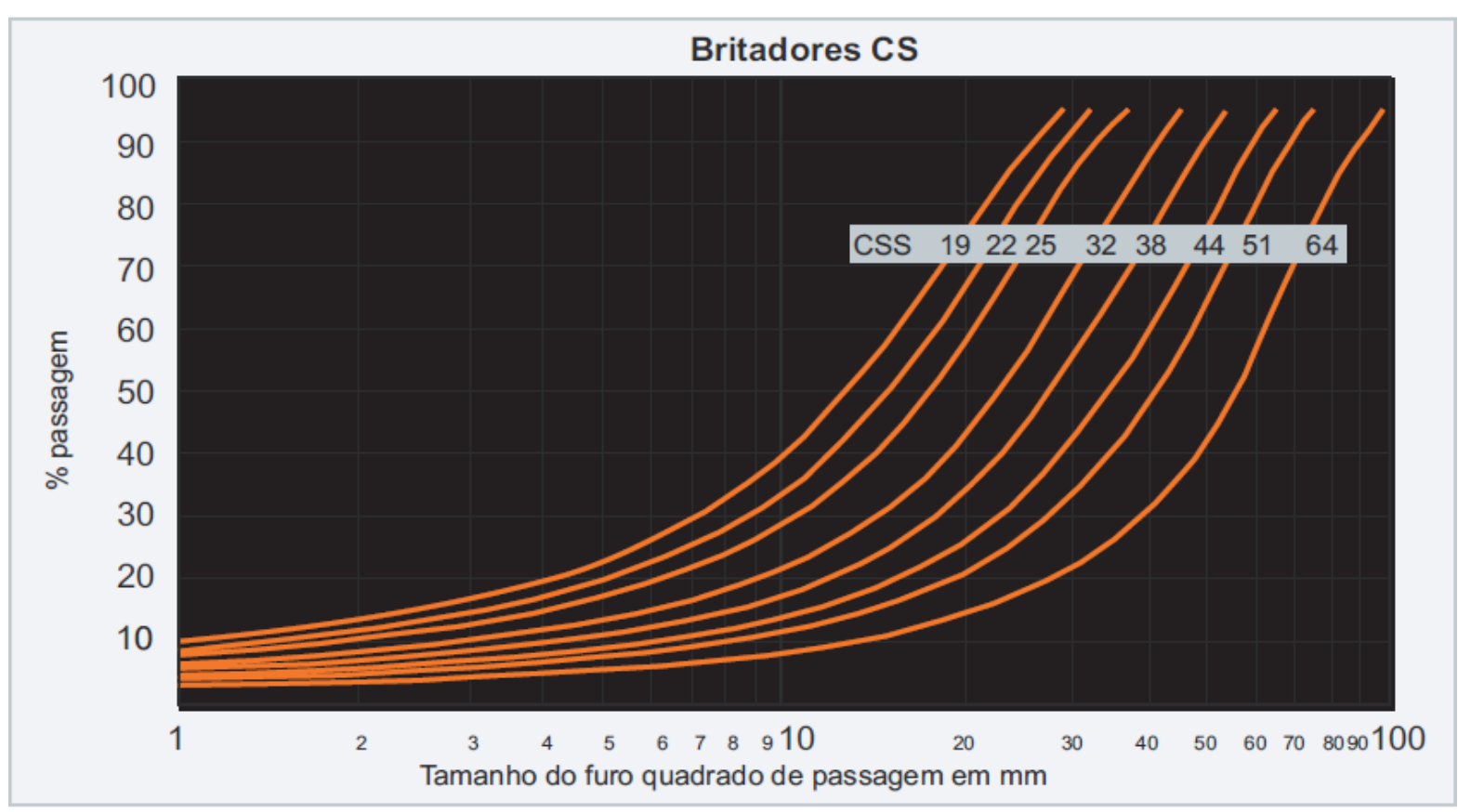

Fonte: Sandvik (2011)

Figura 24- Distribuição Granulométrica dos Produtos dos Britadores da Série $\mathrm{CH}$

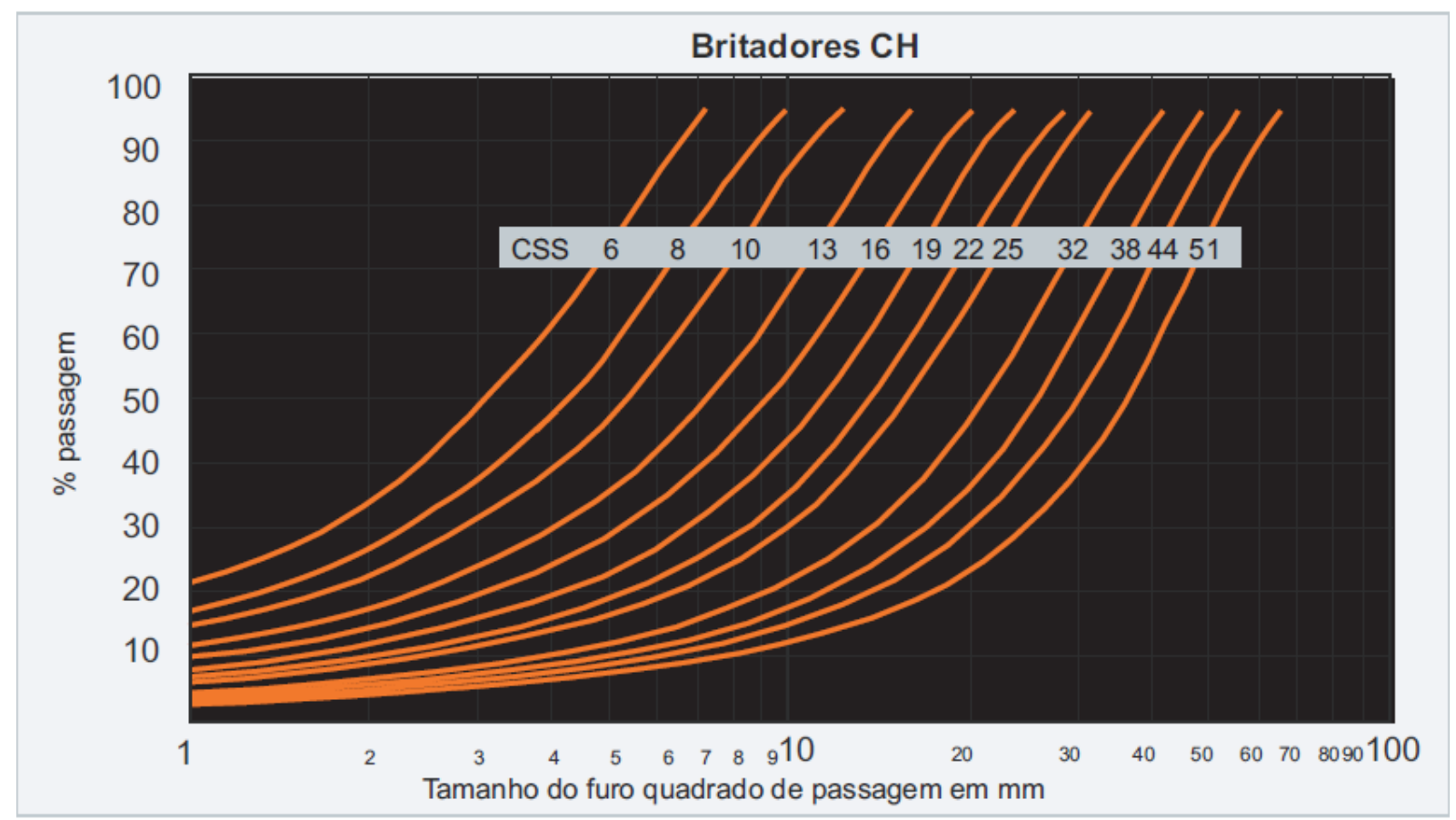

Fonte: Sandvik (2011)

De toda forma, as características do minério também influenciam na distribuição granulométrica do produto do britador.

A distribuição granulométrica do produto de um evento de cominuição depende, diretamente, do fragmento inicial e das características físicas do 
material. Para fins de modelagem, a função quebra representa a distribuição granulométrica do produto da cominuição. (BERGERMAN, 2009)

O processo de britagem pode ser descrito como uma sequência de fenômenos de classificação e eventos de cominuição. Inicialmente, todo fragmento é classificado (selecionado) dentro da câmara interna de um britador. As frações muito finas serão descarregadas diretamente, não sofrendo cominuição alguma. Fragmentos maiores serão quebrados e o produto será classificado, tornando a ser quebrados, de modo contínuo, até que sejam descarregados pela abertura inferior do equipamento. (DELBONI, 2007)

De acordo com a definição acima, o processo de britagem pode ser descrito de acordo com o fluxograma da figura 25 (DELBONI 2007).

Figura 25- Modelo esquemático de operação de britadores

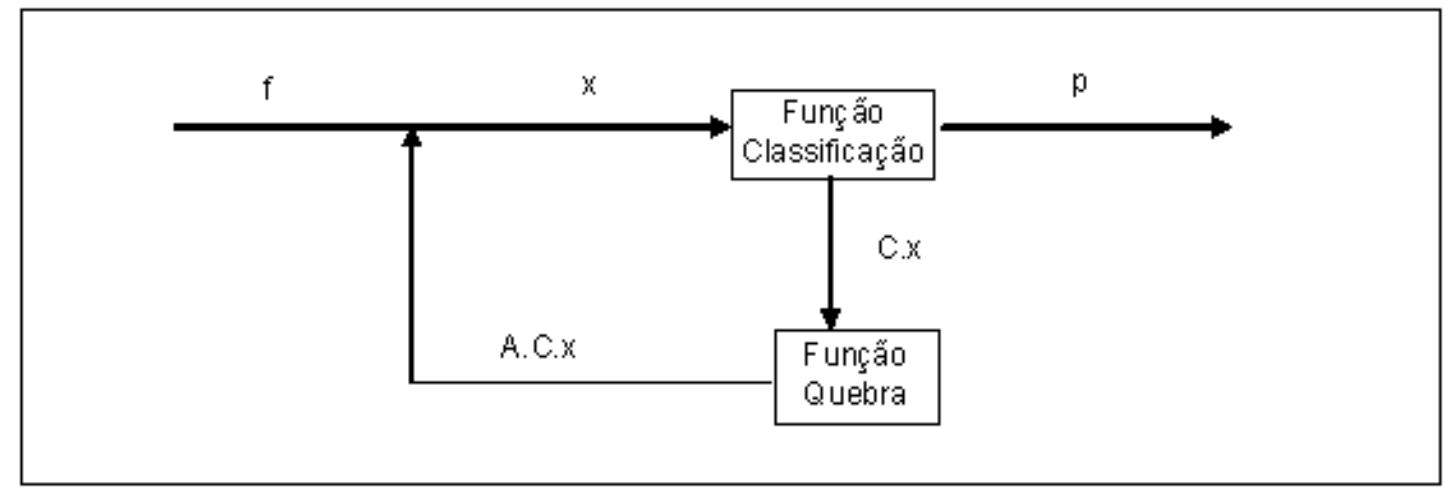

Fonte: Delboni (2007)

O balanço de massa do fluxo acima é determinado pelas seguintes equações:

$$
\begin{aligned}
& x=f+A \cdot C x \\
& x=p+C x
\end{aligned}
$$

Onde:

$\mathrm{X}=$ Vetor que representa a massa de cada fração granulométrica no interior da câmara do britador.

$f=$ Vetor que representa a distribuição granulométrica da alimentação do britador.

$p=$ Vetor que representa a distribuição granulométrica do produto do britador . 
C = Função classificação ou seleção, matriz diagonal que contém a proporção de cada fração granulométrica que será submetida à cominuição.

$A=$ Função appearance, matriz triangular contendo a distribuição granulométrica de cada fração granulométrica, após um evento de cominuição.

Com a combinação das equações 3.4 e 3.5, e considerando como I a matriz identidade, chega-se a equação 3.6, que é o modelo proposto por Whiten (WHITEN, 1974) para modelagem da britagem.

$$
p=\left(\frac{I-C}{I-A C}\right) \times f
$$

De acordo com a equação acima, o produto da britagem (p), depende da geometria interna da câmara de britagem (função seleção, matriz $C$ ) e da forma como o material se quebra dentro do britador (função appearance, matriz A)

Um parâmetro muito utilizado para avaliação da britagem é a eficiência de britagem em função da granulometria, que é definido conforme a equação 3.7 .

$$
E(m)=\left(1-\frac{R_{A}(m)}{R_{p}(m)}\right) \times 100
$$

Onde:

$\mathrm{E}=$ Eficiência de britagem na malha $\mathrm{m}$

$\mathrm{R}_{\mathrm{a}}=$ Retido acumulado na alimentação do britador na malha $\mathrm{m}(\%)$

$\mathrm{R}_{\mathrm{p}}=$ Retido acumulado no produto do britador na malha $\mathrm{m}(\%)$.

A eficiência de britagem mostra a probabilidade de quebra de uma partícula em função do seu tamanho. Quanto maior o tamanho da partícula, maior será a probabilidade de quebra desta partícula dentro do britador, pois ela tenderá a ficar retida na câmara de britagem. Para partículas finas, a probabilidade de quebra será menor, pois estas partículas têm maior chance de passar pela câmara de britagem sem sofrer cominuição. A eficiência de britagem é afetada pelas condições operacionais do britador, dentre as quais podem ser destacadas a abertura e a geometria interna da câmara de britagem, o modo de operação da câmara de britagem (vazia ou afogada) e a velocidade de rotação do eixo do britador.

A figura 26 mostra um exemplo de curva de eficiência de britagem em função da granulometria. 
Figura 26-Modelo de curva de eficiência de britagem

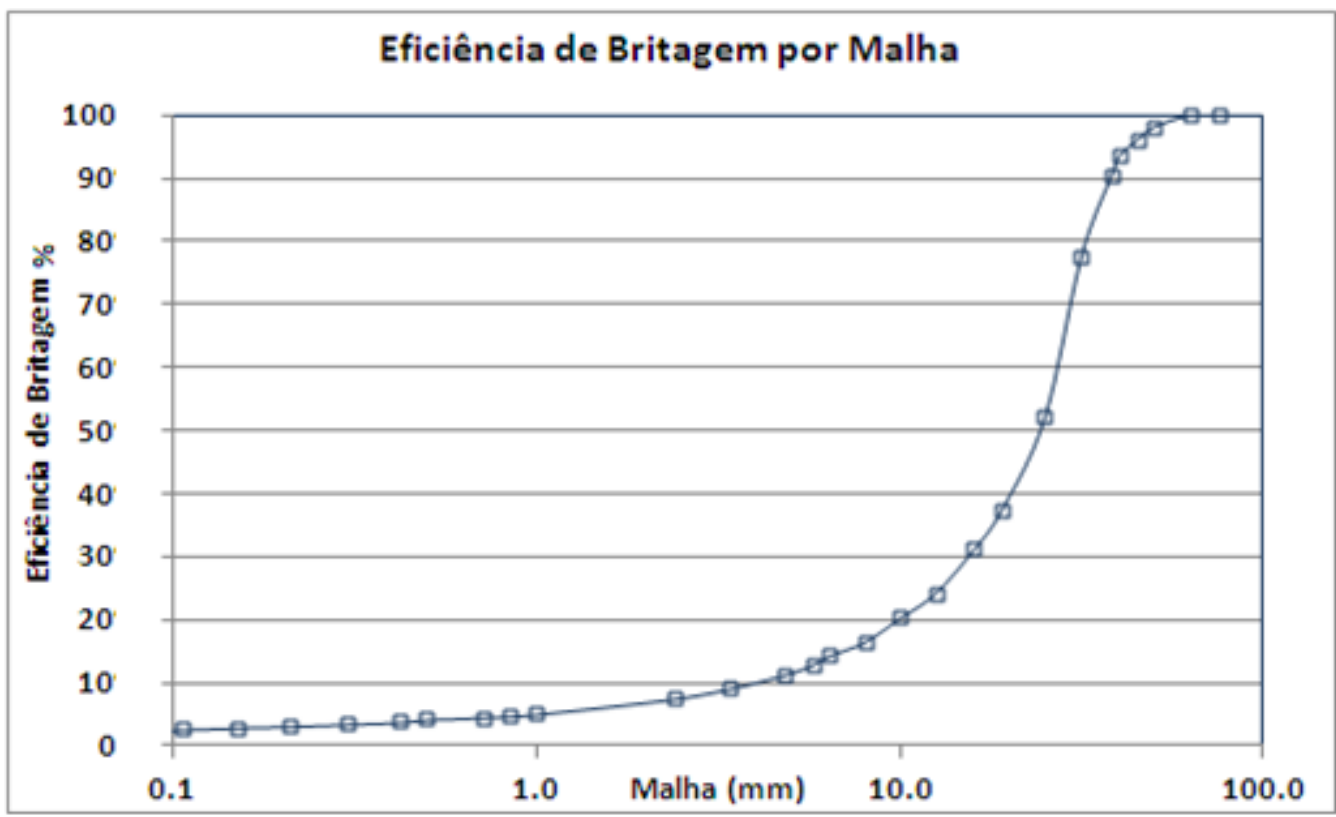

Fonte: Pinto (2015)

Lima; Silva; Pena (2009) demonstraram, com uma série de ensaios industriais para minérios de ferro do quadrilátero ferrífero, que a eficiência de britagem é função não apenas das condições do britador, mas também de características do minério, como granulometria e mineralogia. Os mesmos autores mostraram também que estas últimas características afetam também a capacidade, em toneladas, por hora do britador. Dessa forma, a realização de ensaios industriais é uma ferramenta fundamental para o correto dimensionamento das etapas de britagem para minério de ferro.

As tabelas 2 e 3 comparam desempenhos dos britadores terciários e quaternários, em diferentes operações de cominuição de minério de ferro da Vale, em função da vazão de alimentação e da eficiência de britagem na malha de corte (tamanho no qual se deseja obter um máximo de 5\% retido no produto do circuito de britagem, undersize do peneiramento). 
Tabela 2 - Desempenho de Britadores Terciários - Vale

\begin{tabular}{lccc}
\hline Usina & Brucutu & Carajás & Cauê \\
\hline Modelo & H-6.800 & HP-5 & HP-500 \\
Fabricante & Sandvik & Metso & Metso \\
APF do britador (mm) & 28 & 25 & 40 \\
Potência (hp) & 400 & 600 & 500 \\
Vazão de Alimentação (t/h) & 200 & 794 & 1643 \\
Malha de corte (mm) & 31,5 & 16 & 31,5 \\
\%< Malha de corte na alimentação & 53 & 18 & 36 \\
Eficiência na Malha de corte $(\%)$ & 74 & 48 & 84 \\
\hline
\end{tabular}

Tabela 3 - Desempenho de Britadores Quaternários - Vale

\begin{tabular}{lccccc}
\hline Usina & \multicolumn{2}{c}{ Brucutu } & \multicolumn{2}{c}{ Pico } & \multicolumn{2}{c}{ Timbopeba } \\
\hline Modelo & HP-400 & CH-660 & HP-400 & HP-400 & 52 SBS \\
Fabricante & Metso & Sandvik & Metso & Metso & TelSmith \\
APF do britador (mm) & 23 & 18 & 21 & 18 & 18 \\
Potência (hp) & 400 & 400 & 400 & 400 & 400 \\
Vazão de Alimentação (t/h) & 273 & 358 & 418 & 336 & 254 \\
Malha de corte (mm) & 8 & 8 & 6,3 & 6,3 & 6,3 \\
\%< Malha de corte na alimentação & 33 & 33 & 8 & 10 & 9 \\
Eficiência na Malha de corte (\%) & 52 & 34 & 56 & 51 & 52 \\
\hline
\end{tabular}

\subsubsection{Modelagem de Peneiramento}

Para a modelagem matemática, a etapa de peneiramento pode ser definida como uma série de tentativas de as partículas passarem por uma tela de determinada abertura. Assim, os modelos de simulação devem prever a probabilidade de partículas de uma determinada faixa granulométrica passarem pela tela da peneira. Essa probabilidade deve ser função tanto de parâmetros operacionais, como frequência e amplitude da vibração da peneira, tipo de tela utilizada e vazão de alimentação unitária da peneira, quanto de características do material a ser peneirado, como agregação, distribuição granulométrica e condição de peneiramento (peneiramento a seco, a umidade natural ou a úmido).

Considerando um peneiramento conforme a figura 27 , onde $A, U$ e $O$ são as vazões de sólidos na alimentação, undersize e oversize, e $a$, $u$ e $o$ são as frações 
retidas acumuladas na malha de peneiramento para esses três fluxos, os seguintes balanços de consistência são válidos para oversize e undersize, respectivamente:

$$
\begin{gathered}
A a=O o+U u \\
A(1-a)=O(1-o)+U(1-u)
\end{gathered}
$$

Figura 27- Figura Esquemática de Peneiramento

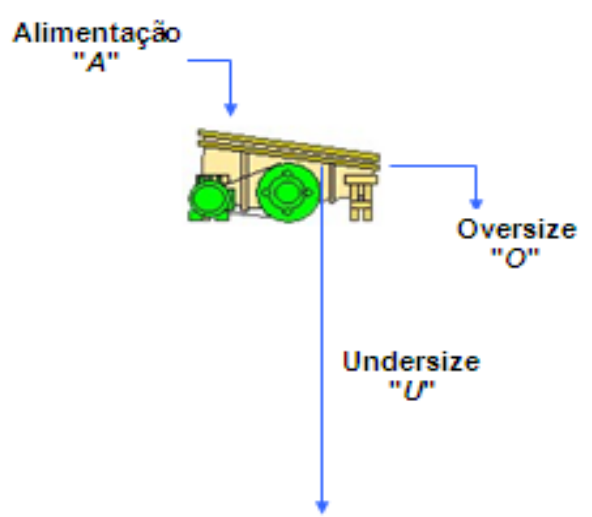

Fonte: Pinto (2015)

A partir das equações 3.8 e 3.9 são obtidas as partições em massa para oversize $(O / A)$ e undersize $(U / A)$ em função da granulometria dos fluxos.

$$
\begin{gathered}
O / A=\frac{(a-u)}{(o-u)} \\
U / A=\frac{(a-o)}{(u-o)}
\end{gathered}
$$

A eficiência de peneiramento avalia o desempenho da operação em relação à separação granulométrica ideal estipulada. Assim, a eficiência de peneiramento para oversize é a relação entre a quantidade de partículas, mais grosseiras que a abertura da tela de peneiramento, que ficam efetivamente retidas na peneira, e a quantidade total de partículas mais grosseiras presente na alimentação. Da mesma forma, a eficiência de peneiramento para undersize é a relação entre a quantidade de partículas, mais finas que a abertura da tela de peneiramento, e que passam por ela e a quantidade delas presente na alimentação. As eficiências de peneiramento 
para oversize e undersize são mostradas, respectivamente, nas equações 3.12 e 3.13 .

$$
\begin{gathered}
\frac{O o}{A a}=\frac{(a-u) \times o}{(o-u) \times a} \\
\frac{U \times(1-u)}{A \times(1-a)}=\frac{(a-o)}{(u-o)} \times \frac{(1-u)}{(1-a)}
\end{gathered}
$$

Multiplicando as eficiências para oversize e undersize, listadas nas equações 3.12 e 3.13, é possível obter a eficiência global de peneiramento $E$, dada pela equação 3.14 .

$$
E=\frac{o(a-u) \times(1-u) \times(o-a)}{a \times(o-u)^{2} \times(1-a)}
$$

Segundo Wills e Napier-Munn (2006) "Para peneiramentos onde a malha de corte está próxima à tela de peneiramento e cuja tela não esteja rasgada ou deformada, a quantidade de material grosseiro no undersize é muito baixa". Assim, se considerarmos que não há presença de material grosseiro no undersize, (u igual à zero) a equação 3.14 pode ser simplificada, conforme equação 3.15.

$$
E=\frac{(o-a)}{o(1-a)}
$$

Industrialmente, a eficiência de peneiramento situa-se entre 80 e 90\%, atingindo, em alguns casos, 95\%. As partículas com diâmetros superiores a uma vez e meia a abertura da tela não influenciam no resultado do peneiramento, bem como àquelas inferiores à metade da abertura da tela. As partículas compreendidas entre esta faixa é que constituem a classe crítica de peneiramento e influem fortemente na eficiência e na capacidade das peneiras. (CARRISO; CORREIA, 2014)

Para o peneiramento realizado a úmido (material empolpado), é possível a obtenção de eficiência elevada de peneiramento, acima de 95\%, mesmo para granulometrias mais finas (abaixo de $8 \mathrm{~mm}$ ). Para tanto, é necessário uma distribuição uniforme do material da alimentação por toda peneira, assim como a utilização de sprays de lavagem para desagregarem o material. 
Para o peneiramento realizado à umidade natural (material não empolpado), a umidade de alimentação, o grau de hidratação das partículas e a presença de materiais ultrafinos afetam diretamente a eficiência de peneiramento que pode chegar a valores inferiores a $80 \%$.

O efeito da umidade é especialmente sensível quando há grande quantidade de partículas finas. Como a área específica dessas partículas é muito grande, a umidade de superfície é relativamente maior que a das demais. Nessas circunstâncias, o peneiramento a úmido torna-se imperativo. (CHAVES; PERES, 2003)

\subsubsection{Modelagem da Classificação}

A classificação consiste na separação de partículas de diferentes tamanhos quando imersas em um meio fluido. Dessa forma, enquanto o peneiramento considera, para efeito de separação, a segunda maior dimensão da partícula, a classificação considera o diâmetro hidráulico como propriedade diferenciadora (o diâmetro hidráulico equivale ao diâmetro da esfera que tem a mesma velocidade de sedimentação da partícula em um fluido). Outra diferença é que, no peneiramento, a fração fina (undersize) tem limitação superior de tamanho, enquanto, na classificação, podem estar presentes partículas de todas as classes de tamanhos, tanto na fração fina (underflow) quanto na fração grossa (overflow).

Segundo Delboni (2003) "Modelos matemáticos da operação de equipamentos de classificação são baseados em dois componentes. O primeiro é o modelo da curva de partição do sistema minério/equipamento, e o segundo, o modelo de operação do equipamento que fornece, principalmente, valores de capacidade".

A curva de partição representa o percentual em massa de cada granulometria que se dirige para a fração grosseira, underflow. Matematicamente, pode ser representada pela equação 3.16 .

$$
Y_{i}=\frac{W_{u}}{W_{a}}
$$

Onde i corresponde às classes de granulometria e $W_{u}$ e $W_{a}$, a vazão de cada fração granulométrica no underflow e na alimentação, respectivamente. 
Em uma classificação perfeita, 100\% da massa de partículas mais grosseiras do que um determinado tamanho, conhecida como granulometria de corte, se dirigem para o underflow, e todas as partículas menores que esse mesmo tamanho se dirigem para o overflow. A figura 28 mostra um exemplo teórico de uma curva de partição de um classificador ideal.

Figura 28- Curva de Partição Ideal

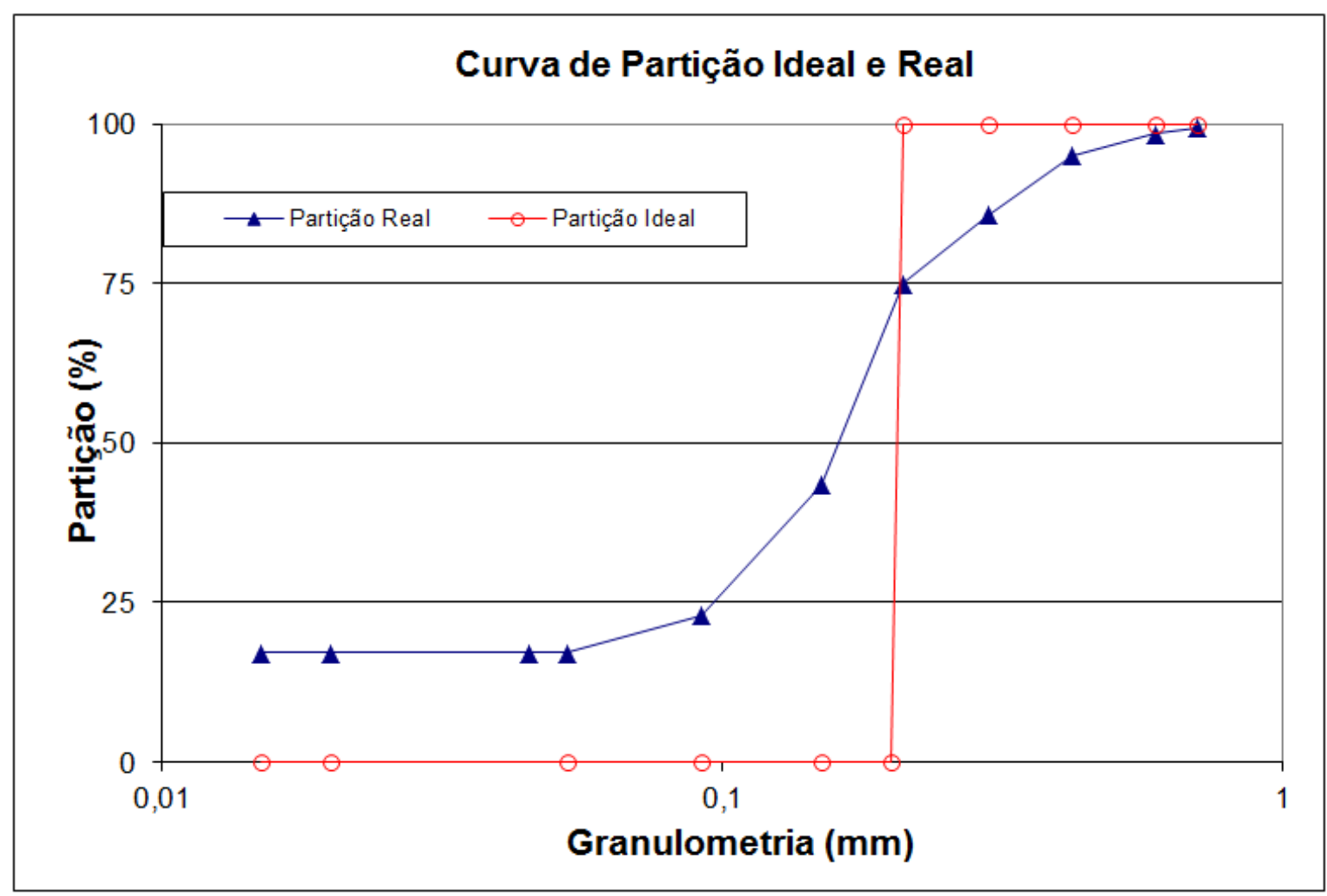

Fonte: Pinto (2015)

Em escala industrial, nenhum equipamento de classificação realiza uma classificação perfeita, assim, partículas finas que deveriam se dirigir ao overflow vão para o underflow, e algumas partículas grosseiras, eventualmente, se dirigem para 0 overflow.

A partir da curva de partição, é possível obter vários parâmetros que caracterizam a classificação. $O$ mais utilizado é o $D_{50}$, que corresponde à classe de granulometria, na qual $50 \%$ das partículas vão para o underflow. 
$\mathrm{Na}$ curva de partição, além do $\mathrm{D}_{50}$, podem ser obtidos a nitidez de classificação e o by pass do classificador. A nitidez de classificação (I) corresponde à inclinação da curva de partição. Uma das definições de nitidez de classificação é definida pela equação 3.17 .

$$
I=\frac{D_{75}-D_{25}}{2 \times D_{50}}
$$

Onde $D_{75}$ e $D_{25}$ correspondem às faixas granulométricas cujos $75 \%$ e $25 \%$ da massa, respectivamente, se dirigem para o underflow.

O by pass corresponde às partículas finas que são arrastadas pela água para o underflow sem sofrer classificação. $\mathrm{Na}$ curva de partição, corresponde à extrapolação do percentual de partículas de diâmetro próximo a zero que se dirigem para o underflow. Segundo Kelsall (1953) apud Delboni (2003) "Uma forma de correção do by pass na curva partição é considerar que o mesmo percentual de água que se dirige ao underflow (Rf) é o percentual de partículas que foram arrastadas para o underflow sem serem classificadas". Assim, a curva de partição corrigida será dada por:

$$
Y_{(i) c}=\frac{Y_{i}-R_{f}}{100-R_{f}} \times 100
$$

Os parâmetros de corte e de nitidez podem ser recalculados para a curva de partição corrigida, e passam a ser denominados como $D_{50 c}$ e $I_{c}$

A figura 29 ilustra de forma esquemática a curva de partição real e a curva de partição corrigida com a indicação dos parâmetros listados acima. 
Figura 29- Parâmetros da Curva de Partição Real e Corrigida

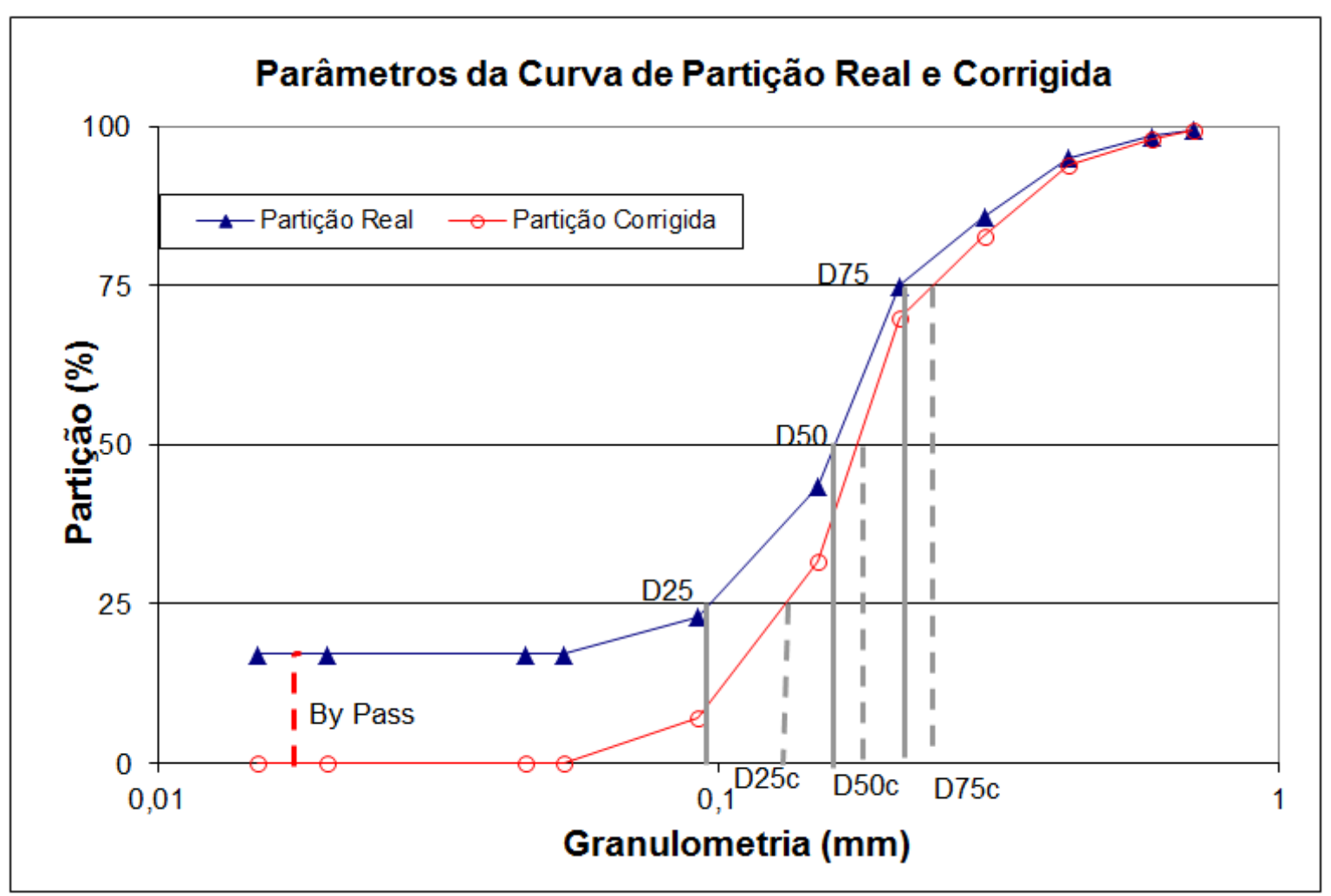

Fonte: Pinto (2015)

Outra forma de apresentação da curva de partição para o ciclone foi proposta por Lynch (LYNCH 1977) e é conhecida como curva padrão de partição. A equação 3.19 mostra a curva padrão de partição

$$
Y_{i}=\frac{\exp \left(\alpha X_{i}\right)-1}{\exp \left(\alpha X_{i}\right)-\exp (\alpha)-2}
$$

Onde:

$i=d_{i} / d_{50 c}$

$\alpha=$ parâmetro característico do material que define a inclinação da curva de partição corrigida

Lynch (LYNCH 1977) demonstrou que o parâmetro $\alpha$ é uma característica do material e independe das condições de operação do ciclone. Assim, é possível a partir de um ensaio em escala de laboratório, determinar o valor de $\alpha$ e prever resultados em escala industrial. 
Os modelos de operação de ciclones têm como objetivo obter parâmetros de partição e capacidade volumétrica dos ciclones, a partir da geometria do equipamento e de parâmetros operacionais.

Um dos modelos mais utilizados é o modelo de Nageswararao, que foi obtido diretamente da curva padrão de partição der Lynch. Esse modelo é constituído por quatro equações para cálculo, respectivamente do $D_{50 c}$, da partição de água e polpa para underflow e da vazão volumétrica de alimentação do ciclone.

O modelo de Nageswararao tem por premissa fundamental a curva padrão de partição independer das condições de operação do ciclone, além de ser válida para equipamentos que guardem aproximadamente as mesmas relações geométricas entre seus elementos. Dessa forma, é necessária a realização de pelo menos um ensaio (amostragem) com o minério para se obter a curva padrão de partição do sistema. Tal curva servirá para simulações posteriores. (DELBONI, 2003)

As equações do modelo de Nageswararao, ajustadas para o sistema métrico internacional, estão listadas abaixo (DELBONI 2003)

$$
\begin{aligned}
& D_{50 c}=K_{D}\left(\frac{D i}{D c}\right)^{-0,50}(\theta)^{0,15}\left(\frac{L c}{D c}\right)^{0,20} D c^{0,35}\left(\frac{D o}{D c}\right)^{0,52}\left(\frac{D u}{D c}\right)^{-0,47}\left(\frac{10^{1,82 c v}}{8,05(1-C v)^{2}}\right)^{0,93}\left(\frac{P}{d p \times g \times D c}\right)^{-0,22} \\
& R f=K_{w}\left(\frac{D i}{D c}\right)^{-0,50}(\theta)^{-0,24}\left(\frac{L c}{D c}\right)^{0,22}\left(\frac{D o}{D c}\right)^{-1,19}\left(\frac{D u}{D c}\right)^{2,40}\left(\frac{10^{1,82 C v}}{8,05\left(1-C v^{2}\right)}\right)^{0,27}\left(\frac{P}{d p \times g \times D c}\right)^{-0,53} \\
& R v=K_{v}\left(\frac{D i}{D c}\right)^{-0,25}(\theta)^{-0,24}\left(\frac{L c}{D c}\right)^{0,22}\left(\frac{D o}{D c}\right)^{-0,94}\left(\frac{D u}{D c}\right)^{1,83}\left(\frac{P}{d p \times g \times D c}\right)^{-0,31} \\
& Q=K_{q}\left(\frac{D i}{D c}\right)^{0,45}(\theta)^{-0,1}\left(\frac{L c}{D c}\right)^{0,20}(D c)^{2}\left(\frac{D o}{D c}\right)^{0,68}\left(\frac{P}{d p}\right)^{0,50}
\end{aligned}
$$

Onde:

$\mathrm{C}_{\mathrm{v}}=$ Concentração de sólidos em volume (decimal)

$d_{p}=$ Densidade da polpa $\left(t / m^{3}\right)$ 
$\theta=$ Ângulo da seção cônica do ciclone (ํ)

$\mathrm{D}_{50 c}=$ Diâmetro mediano da curva de partição corrigida $(\mathrm{mm})$

$\mathrm{R}_{\mathrm{f}}=$ Partição de água para underflow $(\%)$

$\mathrm{R}_{\mathrm{v}}=$ Partição de polpa para underflow $(\%)$

$Q=$ Vazão volumétrica de polpa na alimentação do ciclone $\left(\mathrm{m}^{3} / \mathrm{h}\right)$

$\mathrm{P}=$ Pressão na alimentação do ciclone $(\mathrm{kPa})$

$\mathrm{L}_{\mathrm{c}}=$ Comprimento da seção cilíndrica do ciclone $(\mathrm{m})$

$\mathrm{K}_{\mathrm{w}}=$ Constante relativa a recuperação de água

$\mathrm{K}_{\mathrm{v}}=$ Constante relativa a recuperação de polpa

$\mathrm{K}_{\mathrm{d}}=$ Constante relativa ao D50c

$\mathrm{K}_{\mathrm{q}}=$ Constante relativa a vazão de polpa

$\mathrm{g}=$ Aceleração gravitacional $\left(\mathrm{m} / \mathrm{s}^{2}\right)$

$\mathrm{D}_{\mathrm{u}}=$ Diâmetro do apex do ciclone $(\mathrm{m})$

$\mathrm{D}_{0}=$ Diâmetro do vortex do ciclone $(\mathrm{m})$

$D_{i}=$ Diâmetro equivalente do orifício de entrada do ciclone $(m)$

$\mathrm{D}_{\mathrm{c}}=$ Diâmetro do ciclone $(\mathrm{m})$

\subsubsection{Modelagem da Moagem}

Os simuladores de moagem têm, por objetivo básico, prever a distribuição granulométrica da descarga do moinho em função da energia consumida no processo. Como se trata de uma operação fundamental no beneficiamento de minérios, e que concentra grande parte dos custos de uma usina, os modelos de moagem surgiram ainda no século XIX.

Os primeiros modelos de moagem tiveram por objetivo principal descrever os mecanismos de fratura das partículas, e obtiveram como resultado relações entre 0 consumo de energia e o tamanho das partículas da alimentação e do produto.

A primeira equação foi desenvolvida em 1867 por von Rittinger (VON RITTINGER, 1867 apud WILLS; NAPIER-MUNN, 2006), é conhecida como primeira lei da cominuição. Essa lei, representada pela equação 3.23 , determina que a energia consumida na quebra de uma partícula é diretamente proporcional à nova superfície gerada. Como a área específica é inversamente proporcional ao diâmetro 
da partícula, a energia específica é inversamente proporcional ao diâmetro das partículas após a fragmentação.

$$
E=K\left(\frac{1}{D_{i}}-\frac{1}{D_{f}}\right)
$$

Onde:

$\mathrm{E}=$ Energia específica $(\mathrm{kWh} / \mathrm{t})$;

$\mathrm{K}=$ Constante de proporcionalidade;

$D_{i}=$ Diâmetro inicial da partícula;

$D_{f}=$ Diâmetro final da partícula.

Uma segunda equação, conhecida como segunda lei da cominuição, foi proposta em 1885 por Kick (KICK 1885 apud WILLS; NAPIER-MUNN, 2006). Tal equação considera que a energia requerida é proporcional à redução de volume das partículas, o que significa que iguais quantidades de energia produzirão iguais mudanças geométricas no tamanho de um sólido. Essa teoria considera que a energia necessária para fraturar um sólido ideal (homogêneo, isotrópico e sem falhas) é equivalente à energia gasta para deformar esse sólido até seu limite de ruptura, desprendendo a energia adicional para produzir a ruptura do mesmo. A equação matemática que expressa a segunda lei da cominuição é dada por:

$$
E=C \times \log \left(\frac{D i}{D_{f}}\right)
$$

Onde:

$\mathrm{E}=$ Energia específica $(\mathrm{kWh} / \mathrm{t})$;

$\mathrm{C}=$ Constante de proporcionalidade;

$D_{i}=$ Diâmetro inicial da partícula;

$D_{f}=$ Diâmetro final da partícula;

Rabelo ett all (2007) mostraram que o consumo de energia para geração de superfície especifica na remoagem de minério de ferro pode ser descrito pela lei de Kick, a partir de uma série de amostragens realizadas no circuito de remoagem de concentrado de minério de ferro da usina de Germano, de propriedade da Samarco, localizada em Mariana, MG. 
As leis de von Rittinger e de Kick são baseadas em ensaios de laboratório, e consideram a moagem como um processo de quebra de uma única partícula de um tamanho específico, e não como processo contínuo, onde partículas de diferentes tamanhos são submetidas a diferentes tipos de esforços e são fragmentadas de forma diferente. Essas leis de moagem não apresentam ensaios padronizados para definição das constantes.

Em 1952, após uma série de ensaios em escala de laboratório, e ensaios piloto, bem como uma extensa base de dados industriais, Bond postulou a terceira lei da cominuição, onde a energia de moagem é proporcional ao comprimento das fissuras iniciais que se desenvolvem no processo de fratura. A lei de Bond é descrita matematicamente pela equação 3.25 :

$$
W=10 W i \times\left(\frac{1}{\sqrt{P_{80}}}-\frac{1}{\sqrt{F_{80}}}\right)
$$

Onde:

$\mathrm{W}=$ Energia consumida em $\mathrm{kWh} / \mathrm{st}$;

$\mathrm{P}_{80}=$ Tamanho no qual passa $80 \%$ do produto do moinho em $\mu \mathrm{m}$;

$\mathrm{F}_{80}=$ Tamanho no qual passa $80 \%$ da alimentação do moinho em $\mu \mathrm{m}$;

$\mathrm{Wi}=$ Work inde $\mathrm{x}$ do material;

O conceito de Wi foi proposto também por Bond, e é definido como a energia necessária para reduzir uma tonelada curta do mineral considerado, desde um tamanho inicialmente infinito, até uma granulometria $80 \%$ passante em $100 \mu \mathrm{m}$. A equação 3.26 ilustra a definição de Wi, onde $E_{o}$ é uma constante específica de cada mineral. $\mathrm{O}$ ensaio para determinação do Wi de Bond será descrito posteriormente neste trabalho.

$$
W i=E_{0} \times\left(\frac{1}{\sqrt{100}}-\frac{1}{\sqrt{\infty}}\right)
$$

A lei de Bond tem sido extensivamente aplicada para o dimensionamento e otimização dos processos de moagem nas últimas décadas, mesmo que com restrições, dentre as quais podem ser destacadas: 
- Não consideração de parâmetros operacionais, como ineficiência de classificação, grau de enchimento do moinho, distribuição da carga de bolas, tempo de residência da polpa no moinho e reologia da polpa;

- Utilização do $D_{80}$ como característica de toda a distribuição granulométrica. Dessa forma não é possível prever, no modelo de Bond, a influência do top size da alimentação e nem do tamanho médio das partículas no consumo energético da moagem;

- Diferença de resultados quando aplicado fora das condições de operação na qual foi desenvolvido, quais sejam, WI maior que $10 \mathrm{kWh} / \mathrm{st}$ e relação de redução maior que 6 .

Rowland (1983) apud Donda (2003) comparou os valores de Wi determinados em laboratório e o Wi operacional (Wio). O Wio é o valor do Wi calculado a partir dos valores de $F_{80}$ e $P_{80}$ obtidos industrialmente, bem como da energia específica consumida pelo moinho. Os limites obtidos para a relação Wio/Wi situam-se entre 0,89 e 1,16 para moinhos de bolas operando em estágio único.

Em função das características específicas dos itabiritos do Quadrilátero Ferrífero, tais como, Wi menor que $6 \mathrm{kWh} / \mathrm{st}$, curva de distribuição granulométrica bimodal e baixa relação de redução na etapa de moagem, foi desenvolvida por Donda (2003) uma equação específica para o consumo energético dos itabiritos do quadrilátero ferrífero. Esse modelo foi comprovado, industrialmente, conforme ilustrado por Donda e Rosa (2014), com base em resultados das usinas de Germano, de propriedade da Samarco.

A equação de Donda e Rosa (3.27) considera a moagem como um fenômeno de remanescência e tem o mesmo formato da lei de Kick, considerando, porém, o percentual retido acumulado ao invés do diâmetro da partícula.

$$
E=1 / k \times \ln \left(\frac{R f}{R p}\right)
$$

Onde:

$E$ = Energia específica em $\mathrm{kWh} / \mathrm{t}$ no eixo pinhão do moinho;

$k$ = Parâmetro característico do minério para a malha de interesse, naquela condição de moagem;

$R_{f}=$ Percentagem retida acumulada na alimentação do moinho; 
$\mathrm{R}_{\mathrm{p}}=$ Percentagem retida acumulada no produto do moinho;

$\mathrm{O}$ coeficiente $\mathrm{k}$ é determinado a partir de um ensaio em escala de bancada, que será descrito posteriormente neste trabalho.

Os modelos empíricos de cominuição descritos acima permitem prever, com boa precisão, o consumo energético em função da malha de moagem, porém, é difícil prever, a partir desses modelos, a influência de parâmetros, como o percentual de sólidos do moinho, a carga de bolas utilizadas, a eficiência de classificação e outros.

Para responder a essas questões, foram desenvolvidos os chamados modelos fenomenológicos da cominuição.

Os modelos fenomenológicos, conhecidos como Black Box Models (BBM), ajudam a prever a distribuição granulométrica do produto, a partir da distribuição granulométrica da alimentação, da caracterização da fragmentação e de experiências anteriores com equipamentos similares. Esses modelos buscam representar o fenômeno de quebra por meio de variáveis artificiais, e não dos princípios físicos envolvidos. A notação vetorial é utilizada para representar as vazões de entrada e saída de cada fração de tamanho presente no fluxo. (FOGGIATO, 2009)

Segundo Alves (2006) "Estes modelos têm sido largamente estudados nos últimos anos, e, com isso, tem se alcançado níveis de precisão e detalhe satisfatórios para aplicações práticas".

Um dos modelos fenomenológicos de cominuição é o modelo do balanço populacional.

O modelo do balanço populacional é também conhecido como "modelo de taxa de primeira ordem", porque nele assume-se que a produção de material moído no interior do moinho, por intervalo de tempo, depende unicamente da massa da fração granulométrica considerada que estiver presente na carga do moinho. Assim, existe uma constante para cada fração granulométrica, que caracteriza a taxa de desaparecimento. (DELBONI, 2003)

Dentre os modelos de moagem existentes, o modelo do balanço populacional de partículas, inicialmente proposto por Epstein, se baseia no reconhecimento de que eventos sucessivos de quebra acontecem dentro do moinho. (MONTENEGRO, 1997)

As principais premissas do modelo do balanço populacional são: 
- Velocidade Específica de Quebra ou Função Seleção - é a velocidade com que as partículas de determinado tamanho são fragmentadas;

- Função Distribuição ou Função Quebra - é a estequiometria da fragmentação, ou seja, como se dá a distribuição do material proveniente de um dado intervalo de tamanho quando este se quebra;

- Função Classificação ou Coeficiente de Difusão - representa o movimento das partículas em um sistema contínuo de moagem, sendo dependente do tamanho das partículas.

- Tempo de Residência ou Tempo de Permanência - representa o tempo de residência das partículas dentro do moinho, sendo dependente da vazão de alimentação do moinho e do tamanho das partículas.

Uma simplificação do modelo do balanço populacional, utilizado para representar a moagem em moinhos tubulares, é o Modelo Misturador Perfeito (PMM), desenvolvido por Whiten (WHITEN, 1974). Esse modelo considera que a polpa está perfeitamente homogeneizada dentro do moinho (um misturador perfeito), e assim, elimina a necessidade de estabelecer um tempo de residência e um tipo de movimento específico para cada faixa granulométrica dentro do moinho.

Segundo Delboni (2003):

O modelo de Whiten, chamado de Perfect Mixing Model - PMM, ou Modelo Misturador Perfeito, empregado para modelagem de qualquer equipamento de fragmentação, apresenta as mesmas vantagens e limitações das simplificações introduzidas inerentes ao modelo do balanço populacional. Entretanto, em ambientes industriais, esse modelo é largamente aplicado, desde que as mudanças nas condições operacionais estejam contidas em faixas relativamente estreitas. (DELBONI 2003)

De acordo com o modelo de misturador perfeito, a massa de determinada granulometria na carga do moinho $\left(\mathrm{s}_{\mathrm{i}}\right)$ está relacionada com o produto do moinho $\left(\mathrm{p}_{\mathrm{i}}\right)$, através de uma relação de descarga $\left(\mathrm{d}_{\mathrm{i}}\right)$, conforme mostra a equação 28.

$$
p_{i}=d_{i} s_{i}
$$

O balanço de massas para cada faixa granulométrica dentro do moinho pode ser representado pela equação vetorial abaixo.

$$
f_{i}+\sum_{j=1}^{i} r_{j} s_{j} a_{i j}=p_{i}+r_{i} s_{i}
$$


Onde:

$\mathrm{f}_{\mathrm{i}}=$ Vazão de alimentação da fração granulométrica i no moinho

$r_{j}=$ Frequência de quebra da fração granulométrica j (fração acima da malha i)

$\mathrm{S}_{\mathrm{j}}=$ Massa da fração granulométrica dentro do moinho

$\mathrm{p}_{\mathrm{i}}=$ Vazão de descarga da fração i no moinho

$a_{i j}=$ Fração retida na malha i proveniente de eventos de quebra na malha $j$.

A figura 30 (DELBONI 2003) mostra, de forma esquemática, o evento representado pela equação 3.29 .

Figura 30- Desenho Esquemático do Balanço Granulométrico do Moinho

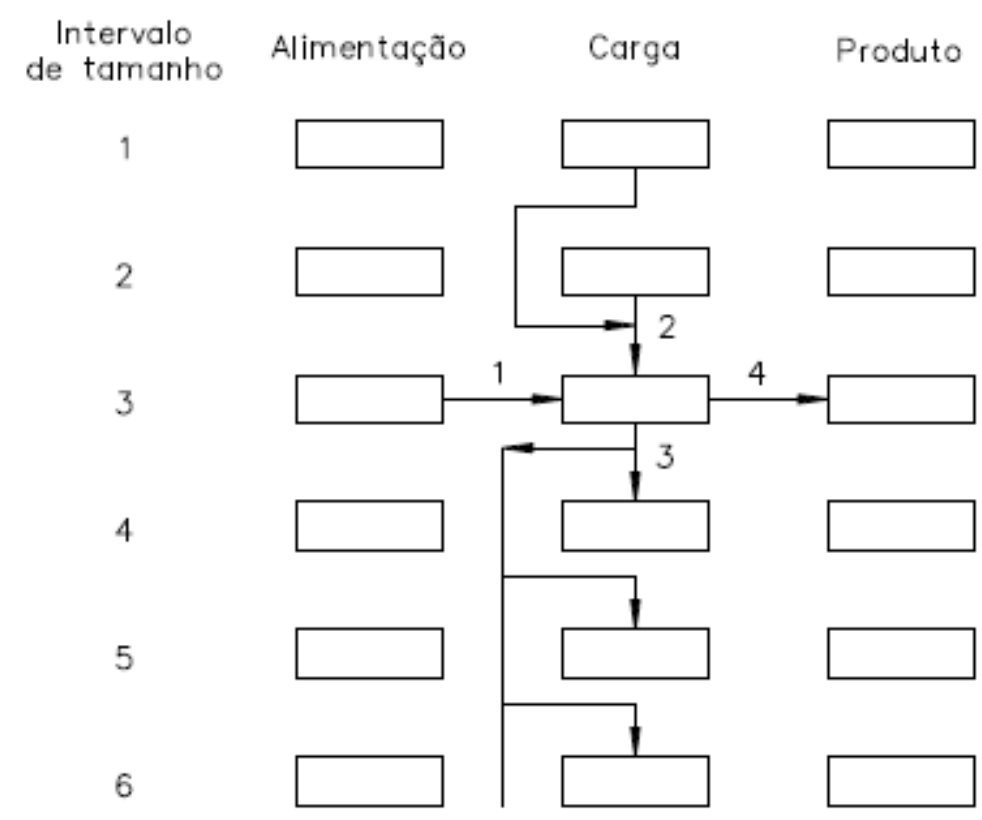

Fonte: Delboni (2003)

A combinação das equações 3.28 e 3.29 leva à equação fundamental do modelo do misturador perfeito, mostrada na equação 3.30 .

$$
f_{i}+\sum_{j=1}^{i} \frac{r_{j} p_{j} a_{i j}}{d_{j}}=p_{i}+\frac{r_{i} p_{i}}{d_{i}}
$$

De acordo com a equação 3.30, fica definido o principal parâmetro do modelo do misturador perfeito, $r / d$, que representa um quociente entre a frequência de quebra e a frequência de descarga para cada faixa granulométrica. Ou seja, quanto maior esse parâmetro, mais eficiente é o moinho para cominuição dessa granulometria.

O parâmetro r/d pode ser retrocalculado, diretamente, por meio de amostragens e estimativas das distribuições granulométricas da 
alimentação e do produto do moinho, bem como de uma função quebra que represente, com fidelidade, as características do minério processado. (FOGGIATO, 2009)

Segundo Delboni (2003) "A divisão desse parâmetro ( $r / d)$ pelo tempo de residência médio das partículas no interior do moinho leva à normalização do mesmo, qual seja, independe das dimensões, ou mesmo condições operacionais do moinho estudado". A equação abaixo mostra o parâmetro $r / d$ normalizado $\left(r / d^{*}\right)$.

$$
\frac{r}{d^{*}}=\frac{r_{i}}{d_{i}} \times\left(\frac{4 Q}{D^{2} L}\right)
$$

Dessa forma, o parâmetro $\mathrm{r} / \mathrm{d}^{*}$, que representa as características do equipamento e da interação entre este o minério, é representado por uma curva quadrática definida por 3, ou, no máximo, 4 pontos. Para cobrir toda a faixa granulométrica estudada, utiliza-se o método spline function. (FOGGIATO, 2009)

As figuras 31 e 32 mostram dois exemplos de curvas do parâmetro $r / d^{*}$. A figura 31 (BURGER et al. 2011) mostra a curva $\mathrm{r} / \mathrm{d}^{*}$ obtida para o moinho SAG, em operação em circuito fechado, SSSAG, da usina de beneficiamento de ouro de Yanacocha, localizada no Peru. A figura 32 (FOGGIATO 2009) mostra a curva r/d* obtida para a moagem de bolas da usina de beneficiamento de minério de ferro de Carajás, localizada em Parauapebas, PA, de propriedade da Vale. 
Figura 31- Curva r/d da Moagem Semi Autógena de Yanacocha

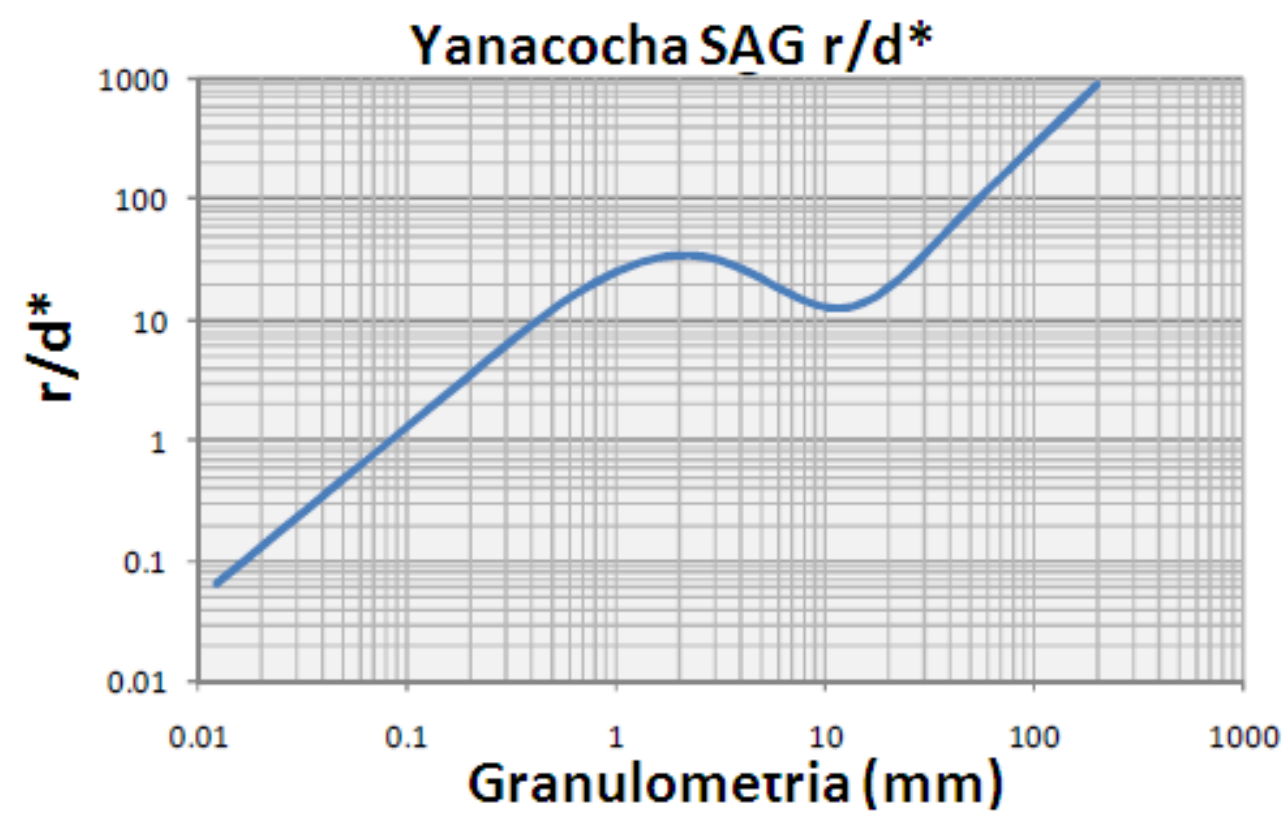

Fonte: Burger et al. (2011) Adaptado pelo autor

Figura 32- Curva r $/ \mathrm{d}^{*}$ da Moagem de Bolas de Carajás
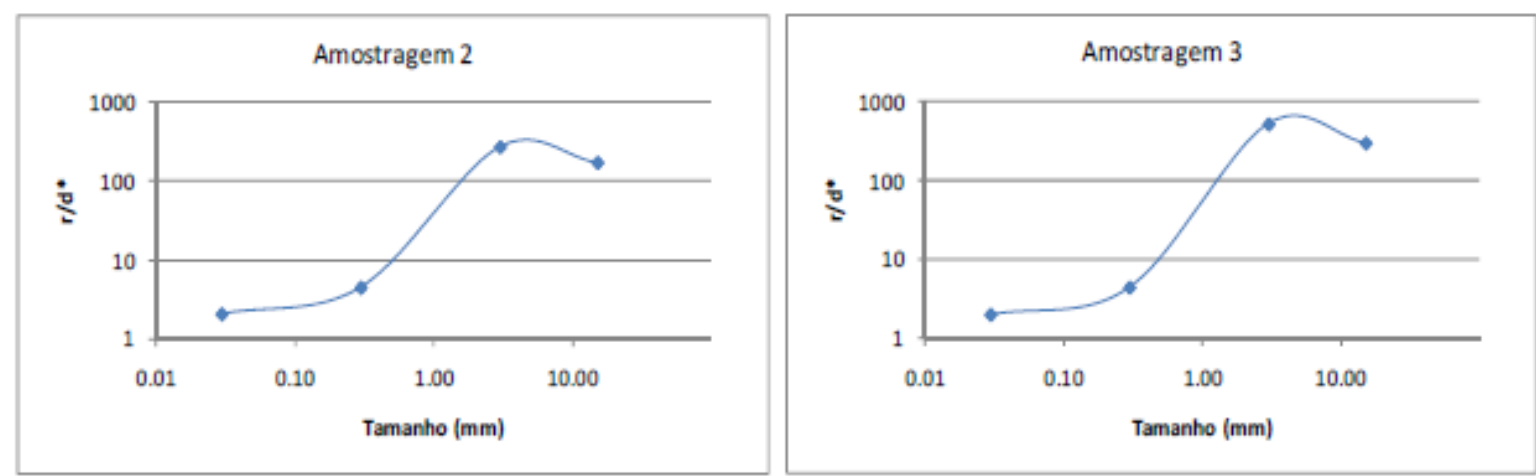

Fonte: Foggiato (2009) 


\section{MATERIAIS E MÉTODOS}

Conforme descrito anteriormente, o objetivo deste trabalho é desenvolver e analisar, comparativamente, rotas para cominuição de Itabiritos Compactos.

O método adotado consistiu em dimensionar equipamentos de processo para circuitos industriais de cominuição, visando produto com $10 \%$ retido em $0,15 \mathrm{~mm}$. As rotas estudadas estão descritas a seguir:

Rota Convencional: Composta por quatro estágios de britagem e peneiramento à seco, com geração de produto mais fino que $12 \mathrm{~mm}$ para alimentação da moagem de bolas, este último em circuito fechado com estágio único de classificação em ciclones.

Rota SAB/C: Composta por um estágio de britagem com geração de produto mais fino que $200 \mathrm{~mm}$ para a alimentação da moagem SAG com recirculação de pebbles. Durante o desenvolvimento dos ensaios, foi avaliada a rebritagem dos pebbles e a redução do top size de alimentação do moinho SAG com utilização de britagem secundária. $O$ undersize da peneira do moinho SAG alimenta a moagem de bolas, este último, em circuito fechado reverso com estágio único de classificação em ciclones.

Rota SSSAG: Composta por um estágio de britagem com geração de produto mais fino que $200 \mathrm{~mm}$ para a alimentação da moagem SAG em circuito fechado com estágio único de classificação em ciclones e recirculação de pebbles. Durante o desenvolvimento dos ensaios, foi avaliada a redução do top size de alimentação do moinho SAG com utilização de britagem secundária. A rebritagem de pebbles não foi testada para essa rota devido ao baixo percentual de oversize do trommel em relação à alimentação total do moinho.

Para o desenvolvimento das rotas listadas acima, foi tomada uma amostra de grande volume, $2000 \mathrm{t}$, de itabiritos compactos da mina de Jangada, de propriedade da Vale, localizada na região do Quadrilátero Ferrífero, no munícipio de Sarzedo, MG. É importante ressaltar que essa amostra não teve como objetivo representar a reserva de itabiritos da mina de Jangada, mas sim de representar um itabirito compacto, com granulometria grosseira (acima de $80 \%$ retido em $1 \mathrm{~mm}$ ) e WI de Bond acima de $10 \mathrm{kWh} / \mathrm{t}$. Dessa forma, os estudos e análises realizadas poderão ser 
utilizados como referências para aproveitamento futuro de jazidas com grande participação deste litotipo. A figura 33 mostra as frentes de lavra amostradas e a amostra utilizada.

Figura 33- Amostra de Itabirito Compacto

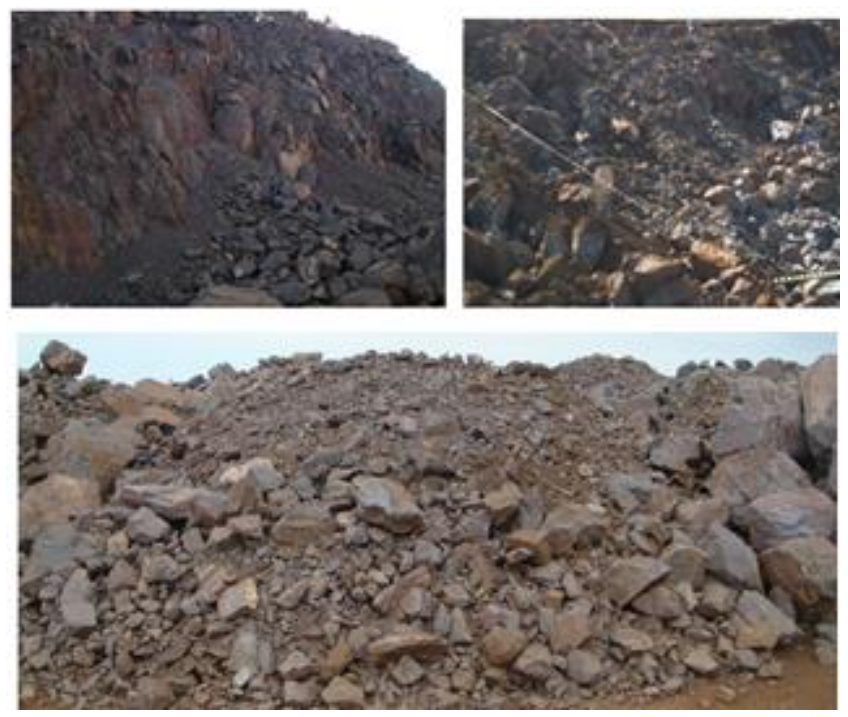

Fonte: Pinto (2015)

Segue abaixo uma breve descrição dos ensaios realizados com a amostra de grande volume;

1- Ensaio industrial de britagem: Avaliação do desempenho da amostra em um circuito industrial de britagem convencional de minério de ferro com britadores cônicos. Foi obtida a curva de eficiência de britagem em função da abertura na posição fechada (APF) do britador, e comparada à vazão mássica obtida industrialmente com os valores de catálogo do fornecedor.

2- Ensaio piloto de moagem de bolas: Avaliação do comportamento da amostra em um circuito fechado de moagem de bolas, com a determinação do consumo específico de energia ( $\mathrm{kWh} / \mathrm{t})$, obtenção de dados para calibração do simulador de moagem e determinação do percentual de lamas, neste caso, material mais fino que $0,010 \mathrm{~mm}$.

3- Ensaio piloto de moagem SAG: Avaliação do desempenho da amostra em diferentes configurações de circuitos de moagem SAG (SAB, SABC e SSSAG), com determinação do consumo específico de energia (kWh/t), 
obtenção de dados para calibração do simulador de moagem e determinação do percentual de lamas, neste caso, material mais fino que $0,010 \mathrm{~mm}$.

4- Drop Weight Test (DWT): Ensaio em escala de bancada para avaliação da resistência do minério à fragmentação por impacto. Os resultados deste ensaio foram utilizados como parâmetros de calibração do simulador de moagem.

5- Ensaio de resistência à abrasão: Ensaio em escala de bancada para avaliação da resistência do minério à fragmentação por abrasão. Os resultados deste ensaio foram utilizados como parâmetros de calibração do simulador de moagem.

6- Ensaio de WI e abrasividade de Bond: Ensaio em escala de bancada para determinação do WI de bolas e abrasividade (Ai) do minério. Os valores obtidos foram utilizados tanto para a determinação do consumo energético, conforme o método de Bond (BOND 1985), quanto para calibração do simulador de moagem.

7- Ensaio de moabilidade de Donda: Ensaio em escala de bancada para determinação do consumo específico de energia $(\mathrm{kWh} / \mathrm{t})$, conforme o método de Donda (DONDA e ROSA 2014), e comparação com os valores obtidos nos ensaios piloto de moagem.

A partir dos resultados dos ensaios acima, bem como calibração dos respectivos modelos matemáticos e intergração conforme o respectivo circuito, foi feita a simulação de um circuito industrial para cada rota estudada, incluindo 0 dimensionamento dos equipamentos de cominuição e classificação. Como o objetivo do trabalho é o desenvolvimento de rotas de processo, os resultados dos ensaios piloto são apresentados já reconciliados, conforme relatórios técnicos dos laboratórios responsáveis pela sua execução.

Os ensaios realizados e as premissas utilizadas para o balanço de massa e dimensionamento dos equipamentos estão detalhados nos itens que se seguem. 


\subsection{Premissas para Balanço de Massa e Dimensionamento de Equipamentos de Processo}

Para cada rota estudada, foi elaborada uma simulação para processamento de 25 Mta de minério base seca. A partir dos rendimentos operacionais estipulados, foram consideradas 6000 horas de operação efetiva para as etapas de britagem e 7800 horas para a moagem. Não foi considerada pilha pulmão entre as operações de britagem, de forma que todas as opções estudadas tivessem somente uma pilha pulmão antes da alimentação da moagem. As premissas das simulações estão listadas na tabela 4.

Tabela 4 - Premissas de Balanço de Massas

\begin{tabular}{lc}
\hline Alimentação Nova (Mta) & 25 \\
Rend. Operacional das Britagens (h/ano) & 6000 \\
Vazão de Alimentação das Britagens (t/h) & 4167 \\
Rend. Operacional da Moagem (h/ano) & 7800 \\
Vazão de Alimentação da Moagem (t/h) & 3205 \\
\hline
\end{tabular}

Como o circuito de britagem primária foi o mesmo para as três rotas estudadas, não foi realizado o dimensionamento deste britador, pois este não influencia na análise comparativa entre as rotas. Para dimensionamento dos demais britadores (britagem secundária, terciária, quaternária e rebritagem dos pebbles), foi considerada a utilização de equipamentos com $600 \mathrm{~kW}$ de potência. A capacidade de catálogo do britador em função da abertura na posição fechada (APF) está mostrada na tabela 5 (Sandivik, 2011). 
Tabela 5 - Capacidade do Britador em Função da Abertura na Posição Fechada

\begin{tabular}{|c|c|c|c|c|c|c|c|}
\hline \multirow{3}{*}{ Equipamento } & \multirow{3}{*}{$\begin{array}{c}\text { Abertura na Posição } \\
\text { Fechada (mm) }\end{array}$} & \multicolumn{3}{|c|}{ Capacidade (t/h) } & \multicolumn{3}{|c|}{ Capacidade (t/h) } \\
\hline & & \multicolumn{3}{|c|}{ Cálcario Densidade $1,6 \mathrm{t} / \mathrm{m}^{3}$} & \multicolumn{3}{|c|}{ Minério de Ferro Densidade $2,2 \mathrm{t} / \mathrm{m}^{3}$} \\
\hline & & Mínimo & Médio & Máximo & Mínimo & Médio & Máximo \\
\hline \multirow{6}{*}{$\begin{array}{c}\text { CH } 880 \\
\text { Potência } \\
600 k W\end{array}$} & 19 & 465 & 572 & 678 & 639 & 786 & 932 \\
\hline & 22 & 496 & 610 & 724 & 682 & 839 & 996 \\
\hline & 25 & 587 & 815 & 1043 & 807 & 1121 & 1434 \\
\hline & 38 & 739 & 1027 & 1314 & 1016 & 1411 & 1807 \\
\hline & 44 & 810 & 1125 & 1440 & 1114 & 1547 & 1980 \\
\hline & 51 & 892 & 1239 & 1586 & 1227 & 1704 & 2181 \\
\hline
\end{tabular}

Fonte: Sandvik (2011) Adaptado pelo autor

Os valores de capacidade de catálogo dos britadores foram validados para itabiritos compactos a partir dos resultados do ensaio industrial de britagem.

Para dimensionamento das peneiras do circuito de britagem, foram utilizados os valores de capacidade unitária de peneiramento $\left(\mathrm{t} / \mathrm{h} / \mathrm{m}^{2}\right)$, obtidos por Lima; Silva; Pena (LIMA; SILVA; PENA 2009) para o peneiramento de minério de ferro em umidade natural. Estes valores consideram uma eficiência de peneiramento de $90 \%$ e até $15 \%$ de partículas contidas na alimentação com diâmetro entre 0,5 vezes e 1,5 vezes da abertura da tela. Os valores estão apresentados na tabela 6.

Tabela 6 - Capacidade de Peneiramento para Minério de Ferro

\begin{tabular}{cc}
\hline $\begin{array}{c}\text { Etapa de } \\
\text { Peneiramento }\end{array}$ & $\begin{array}{c}\text { Capacidade Específica } \\
\text { da Peneira }\left(\mathrm{t} / \mathbf{h} / \mathbf{m}^{2}\right)\end{array}$ \\
\hline Secundário & 85 \\
Terciário & 45 \\
Quaternário & 35 \\
\hline
\end{tabular}

Fonte: Lima; Silva e Pena (2009)

Para o peneiramento secundário, foi considerada a utilização de peneira convencional, com movimento linear de 12 pés de largura por 24 pés de comprimento (12' x 24'), e para o peneiramento terciário e quaternário, foi considerada uma única peneira, de movimento circular, com duplo deck de 12 pés de largura por 24 pés de comprimento (12' x 24'). Dessa forma, o dimensionamento das peneiras foi feito para o deck inferior, peneiramento quaternário, e foi considerada uma área efetiva de peneiramento de $80 \%$ nesse deck. 
O balanço de massas do circuito de britagem foi obtido mediante simulação, tendo por premissas eficiência de peneiramento de $90 \%$ e eficiência de britagem obtidas através de simulações no software JKSimMet, conforme aberturas na posição fechada do britador. Os modelos dos equipamentos foram calibrados a partir dos resultados de amostragens realizadas no ensaio industrial de britagem.

As dimensões dos moinhos foram determinadas a partir da potência requerida, esta última estimada em função do consumo específico de energia, multiplicado pela vazão de alimentação nova, além da aplicação da equação de Rowland (3.1) para os moinhos de bolas. Para dimensionamento dos moinhos SAG, foi utilizada a equação de Austin (3.4). Para peneiramento de pebbles foi considerada a utilização de uma peneira $12^{\prime}$ x $24^{\prime}$.

O consumo específico de energia da moagem foi obtido a partir das simulações dos circuitos via simulador JKSimMet, com a utilização dos seguintes modelos: Perfect Mixing Ball Mill para o moinho de bolas, Variables Rates SAG/Ag Mill para o moinho SAG, e Single Component Efficiency Curve para os equipamentos de classificação.

Os circuitos foram calibrados a partir dos resultados dos testes em escala piloto. Para a rota $\mathrm{SAB} / \mathrm{C}$, o critério foi empregar diretamente o consumo de energia obtido nos ensaios piloto.

Para dimensionamento da classificação dos circuitos industriais de moagem, foi considerada a utilização de ciclone de 26 polegadas de diâmetro. Para a determinação do número de ciclones, foi considerada uma vazão unitária de 450 $\mathrm{m} 3 / \mathrm{h}$, e um fator de projeto de 1,2 para garantia operacional do circuito. A vazão unitária adotada é típica da operação de um ciclone com tal diâmetro, dotado de vortex com diâmetro de 12" e pressão de operação de $100 \mathrm{kPa}$. Os ciclones não foram dimensionados a partir dos resultados do ensaio piloto de moagem de bolas, devido à grande diferença entre o diâmetro do ciclone do ensaio, 4 polegadas, e 0 ciclone previsto para o circuito industrial. A carga circulante e os percentuais de sólido na alimentação dos moinhos e dos ciclones foram adotados conforme os resultados do ensaio piloto. Para os circuitos de moagem SAG, em cujas plantas piloto foram utilizados classificadores espiral para fechamento do circuito, foi 
considerado para o circuito industrial o mesmo percentual de sólidos na alimentação do ciclone do ensaio piloto de moagem de bolas.

Os dimensionamentos dos moinhos obtidos pelos testes piloto e simulações foram comparados com os resultados obtidos através do dimensionamento de moinhos pelos métodos de Bond e de Donda. 


\subsection{Ensaio Industrial de Britagem}

O objetivo do ensaio industrial de britagem foi avaliar o desempenho de britadores cônicos na cominuição de itabiritos compactos, com a determinação da curva de eficiência de britagem. Neste caso, também foi avaliada a aplicabilidade dos dados de catálogo de fornecedores para determinação da capacidade de alimentação dos britadores.

O ensaio industrial de britagem foi realizado na etapa terciária de britagem da usina industrial de Córrego de Feijão, de propriedade da Vale, localizada no munícipio de Brumadinho, MG. A britagem terciária de Córrego do Feijão possui duas peneiras de 8' de largura por 20' de comprimento, dotadas de tela de aço de 40 $\mathrm{mm}$ de abertura. Estas peneiras operam em circuito fechado, com dois britadores cônicos modelo HP 300, cada um com potência instalada de $300 \mathrm{cv}$, fabricados pela Metso. A figura 34 mostra o fluxograma das instalações de beneficiamento de minério de ferro de Córrego de Feijão, com destaque para a britagem terciária. 
Figura 34- Fluxograma da Usina de Córrego do Feijão

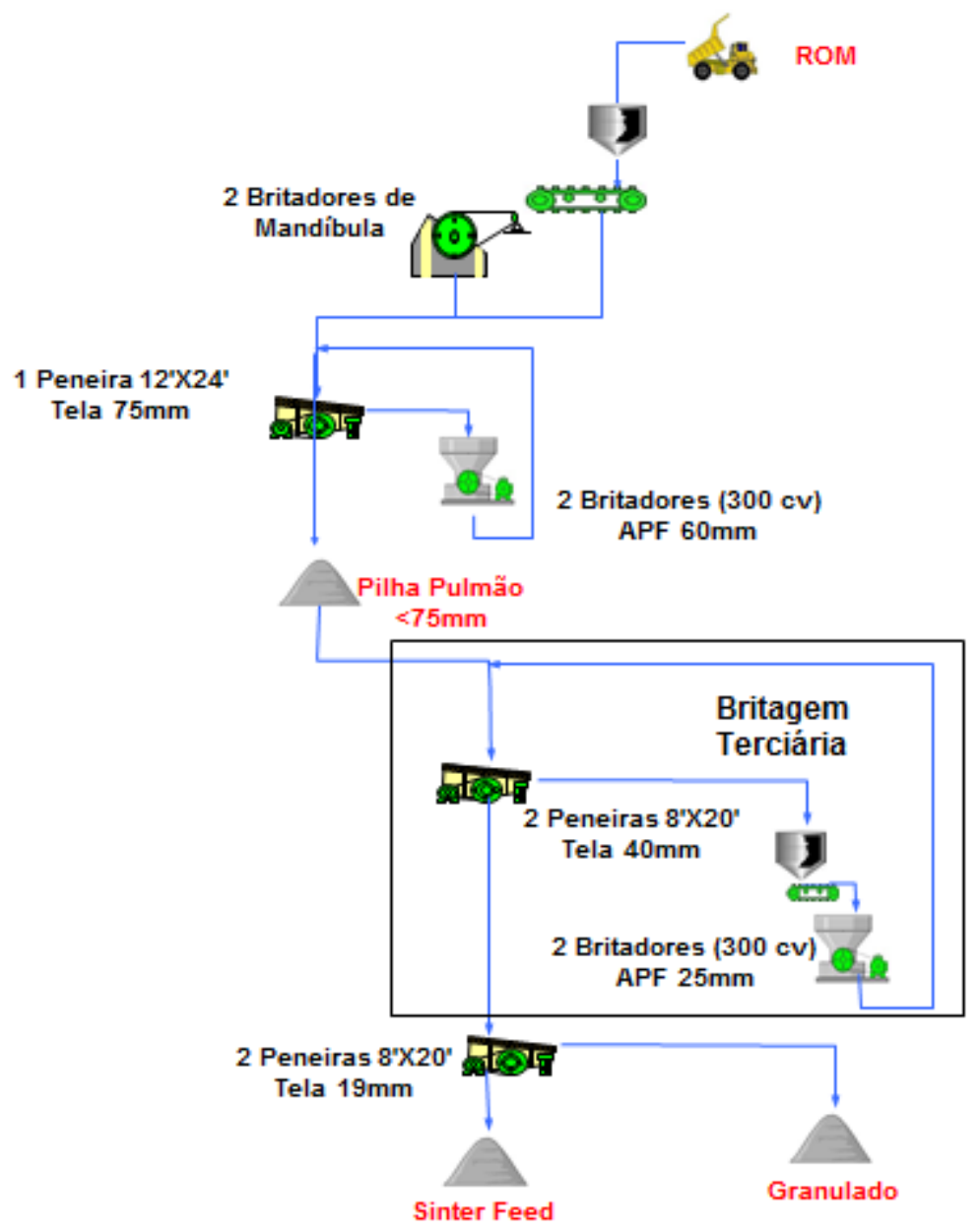

Fonte: Pinto (2015)

Os britadores terciários operam com abertura na posição fechada (APF) em 25 $\mathrm{mm}$, medida esta verificada através de gabarito de chumbo no dia do ensaio. $\mathrm{A}$ figura 35 mostra a verificação da APF do britador no dia do ensaio industrial. 
Figura 35- Verificação da Abertura do Britador

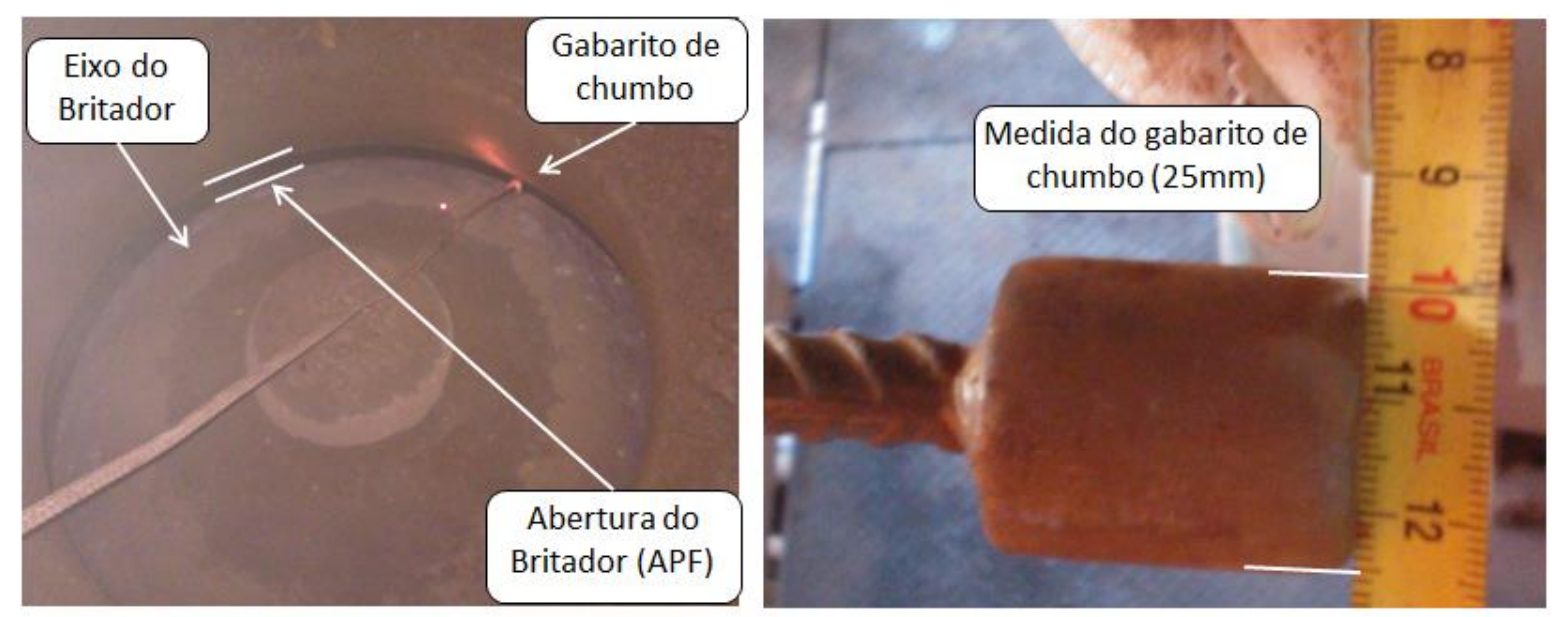

Fonte: Pinto (2015)

Cada um dos britadores terciários possui um silo com capacidade aproximada 50 toneladas, de forma a permitir a operação em modo afogado dos britadores. A figura 36 mostra os silos para alimentação dos britadores terciários da usina de Córrego do Feijão. 
Figura 36- Britador terciário e silo de alimentação

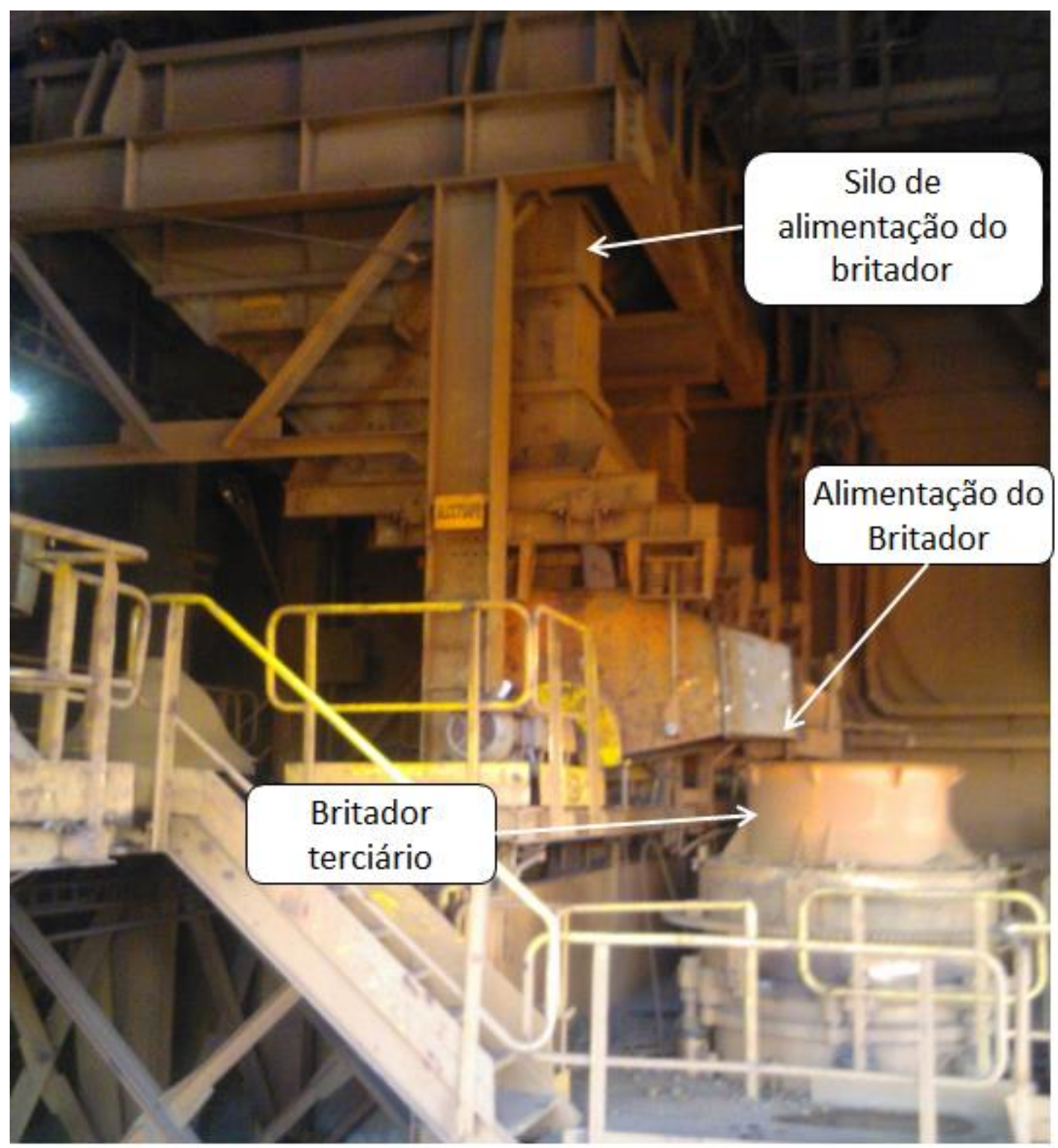

Fonte: Pinto (2015)

A amostra foi, inicialmente, processada nas instalações de britagem primária e secundária de Córrego do Feijão, com a geração de um produto com um $D_{95}$ em $76 \mathrm{~mm}$ para a alimentação da britagem terciária. Após o processamento do material, foi feita uma amostragem manual, na pilha de produto britado, de forma a se conhecer a granulometria de alimentação do circuito de britagem terciária. A figura 37 mostra a pilha de alimentação da britagem terciária, e a figura 38, a curva granulométrica da amostra coletada nesta pilha. 
Figura 37- Pilha de Alimentação da Britagem Terciária

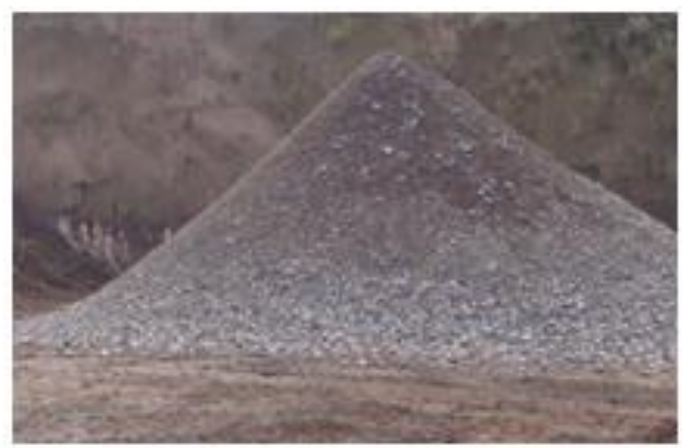

Fonte: Pinto (2014)

Figura 38- Granulometria de Alimentação do Circuito de Britagem Terciária

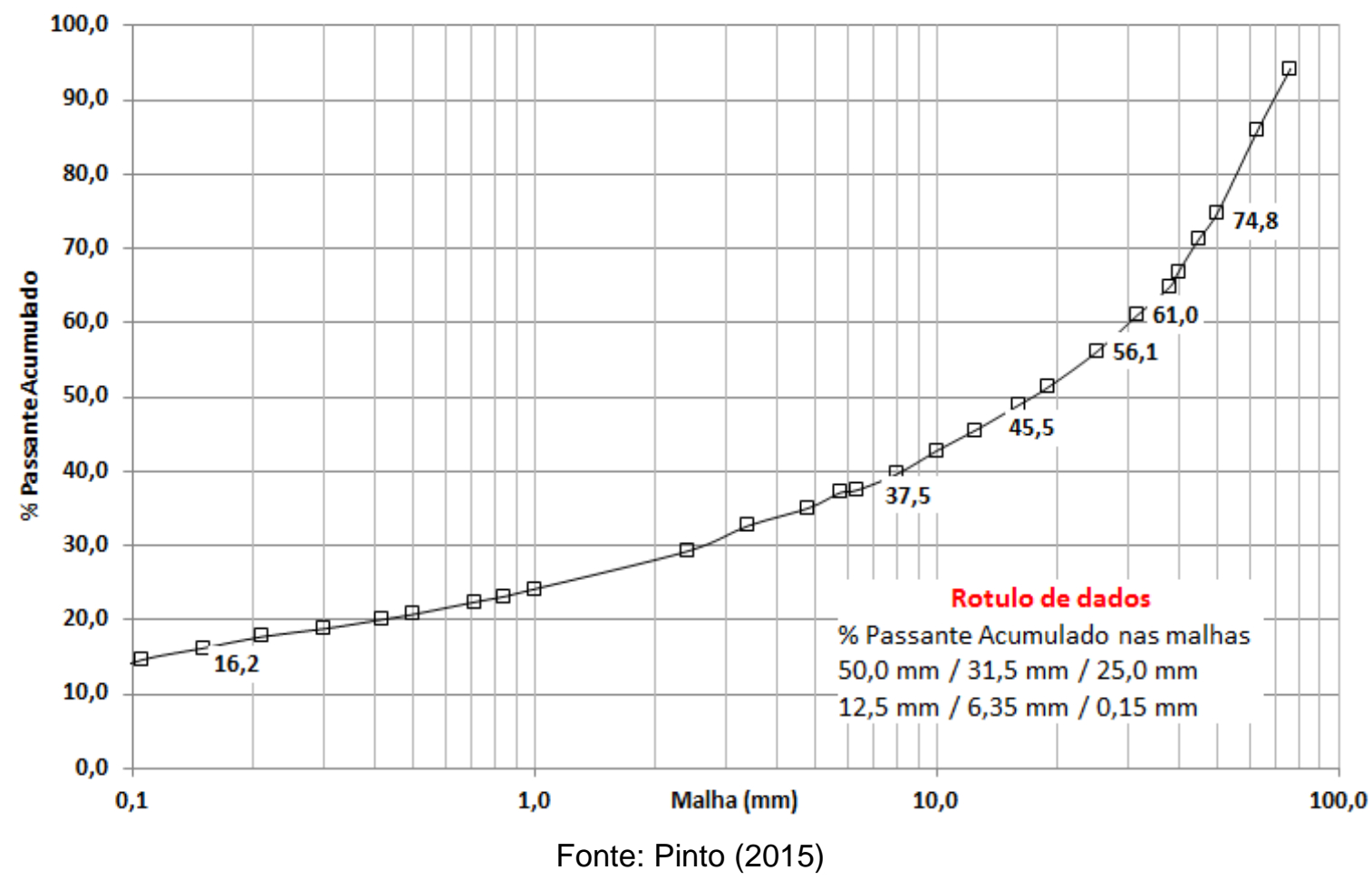

O ensaio consistiu na alimentação da britagem terciária, com o material mostrado acima, estabilização da vazão de alimentação da usina, e posterior amostragem simultânea da alimentação e descarga do britador. O procedimento de amostragem consistiu na parada instantânea do circuito (crash stop), com a retirada de todo o material presente em um metro dos transportadores de correia da alimentação e a descarga do britador. A tomada da amostra foi realizada de forma manual, com auxílio de pá e pincel para retirada dos finos. A figura 39 mostra o transportador de correia de descarga do britador após a tomada da amostra. 
Figura 39- Amostragem do Transportador de Correia no Ensaio Industrial de Britagem

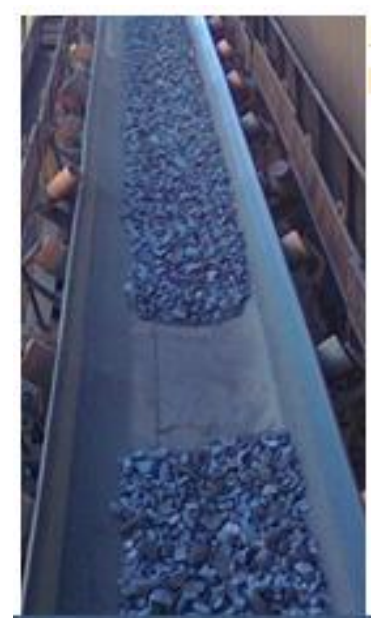

Fonte: Pinto (2015)

As amostragens foram repetidas três vezes, e a granulometria de cada amostra foi analisada individualmente, de forma a se obter a respectiva curva de eficiência de britagem para cada amostragem. A análise granulométrica foi realizada com peneiramento, a úmido, até a malha de 0,045 mm. Cada uma das frações foi seca em estufa a $105^{\circ} \mathrm{C}$ de temperatura, para posterior pesagem.

A vazão mássica processada pelo britador foi determinada através de medição da velocidade do transportador de correia da descarga do equipamento, durante a realização do ensaio, e posterior pesagem das amostras. 


\subsection{Ensaio Piloto de Moagem de Bolas}

O ensaio piloto de moagem em moinho de bolas foi realizado no Centro de Pesquisas Tecnológicas (CPT) da Vale, na planta piloto localizada na mina de Alegria, em Mariana, MG. Conforme descrito anteriormente, o ensaio piloto de moagem foi realizado com a amostra de grande volume de itabiritos compactos da Mina de Jangada. A figura 40 mostra o moinho de bolas Nordberg, modelo AM 435, utilizado para os ensaios em escala piloto de moagem de bolas.

Figura 40- Moinho para os Ensaios Piloto de Moagem
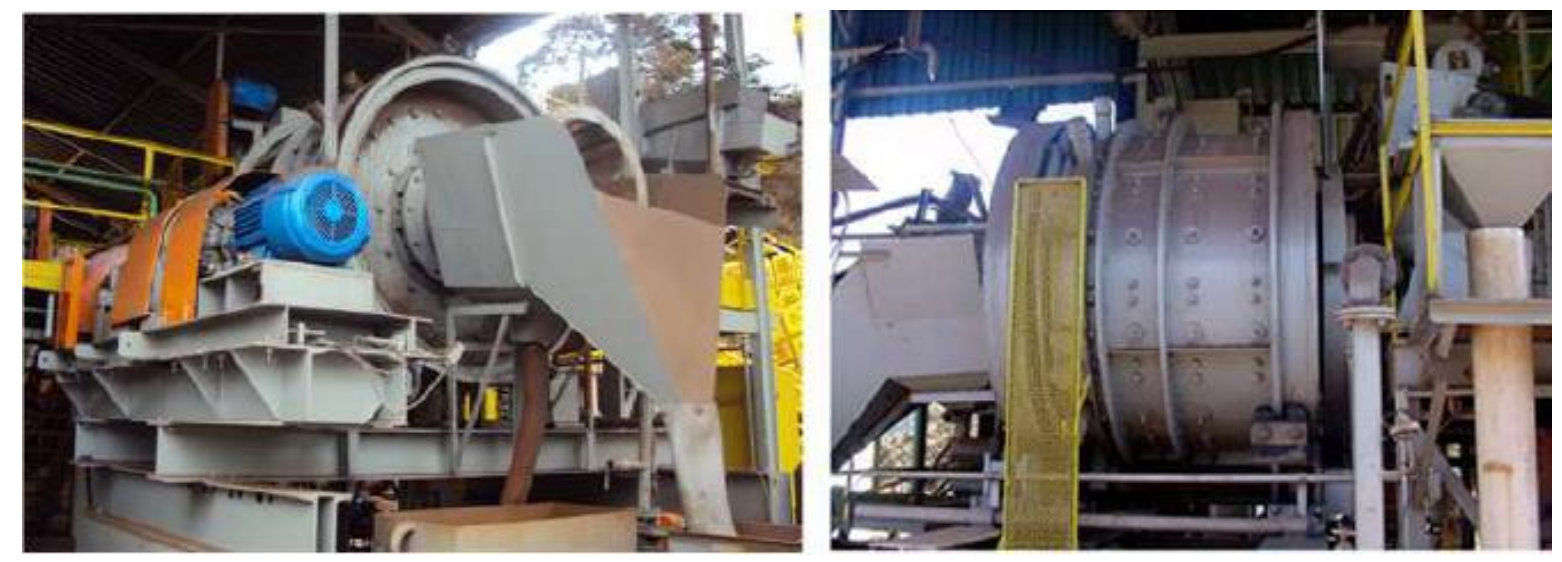

Fonte: Pinto (2015)

A preparação para o ensaio piloto de moagem de bolas consistiu na britagem da amostra em circuito industrial semi-móvel até a malha de $25,0 \mathrm{~mm}$, seguido de britagem, em circuito piloto, até a malha de $12 \mathrm{~mm}$. A figura 41 mostra o fluxograma de preparação da amostra para o ensaio piloto de moagem em moinho de bolas, enquanto a figura 42 mostra a granulometria de alimentação do ensaio piloto de moagem em moinho de bolas. 
Figura 41- Fluxograma de Preparação da Amostra para os Ensaios Piloto de Moagem

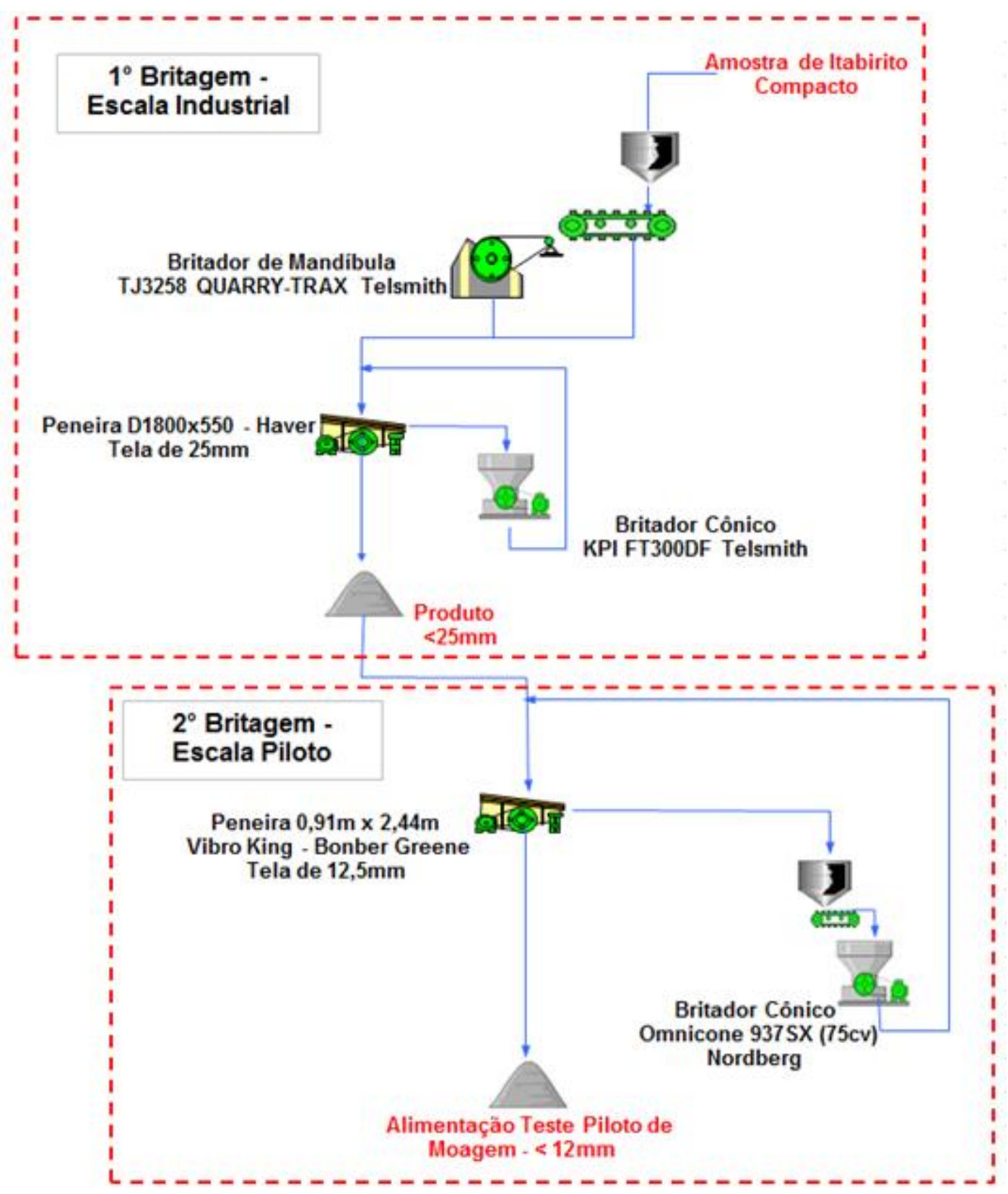

Fonte: Pinto (2015) 
Figura 42- Granulometria da Alimentação do Ensaio Piloto de Moagem de Bolas

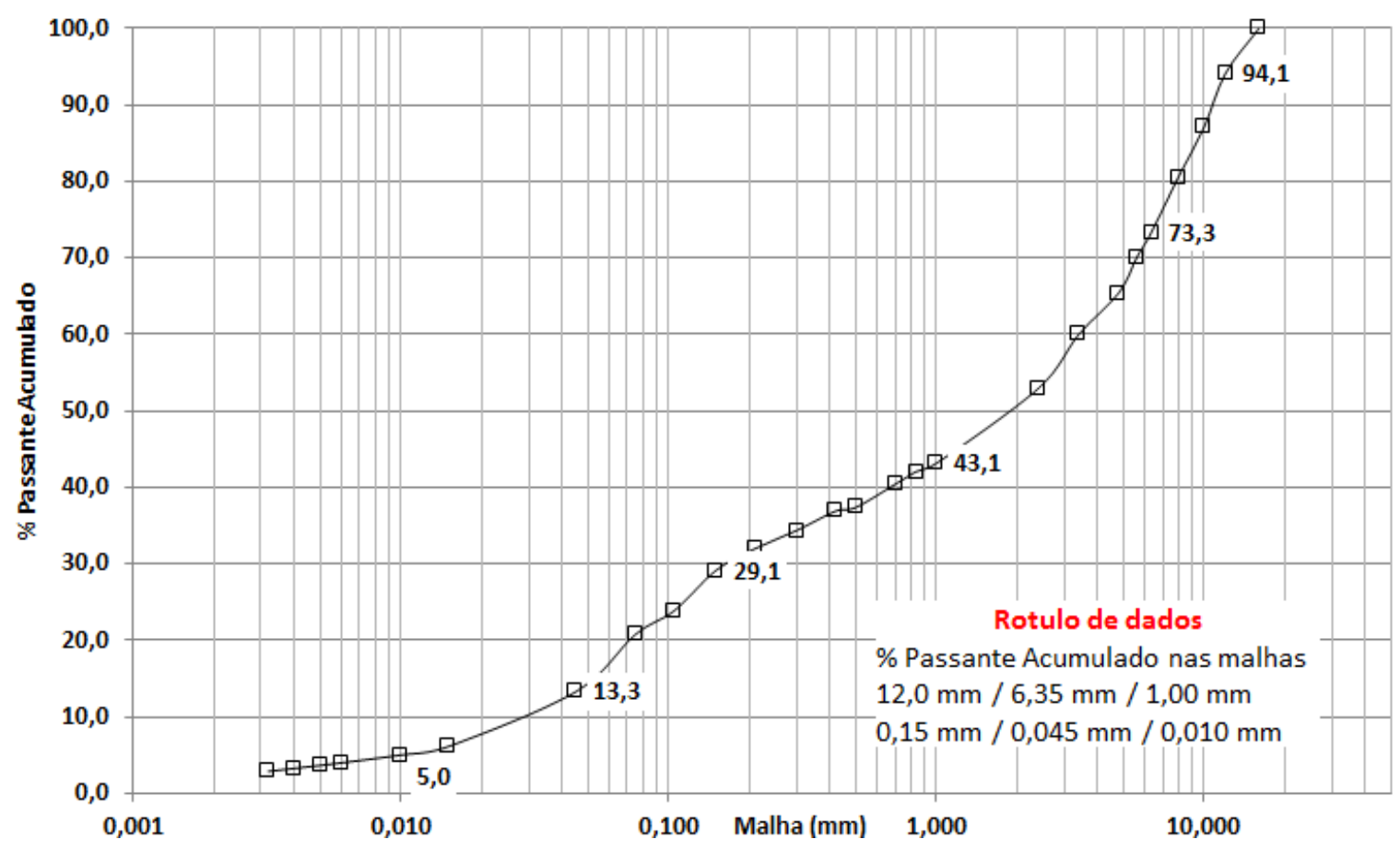

Fonte: Pinto (2015)

O ensaio piloto de moagem em moinho de bolas foi realizado em estágio único, alimentação direta no moinho, e classificação em hidrociclone de fundo plano de 4 polegadas de diâmetro. Foi utilizado um trommel com tela de $6,35 \mathrm{~mm}$ de abertura para retirada de expurgo do moinho, bem como para evitar entupimentos do sistema de bombeamento. A figura 43 e as tabelas 7 e 8 mostram o fluxograma do ensaio piloto de moagem de bolas e as dimensões do moinho e ciclone utilizados. 
Figura 43- Fluxograma Ensaio Piloto de Moagem de Bolas

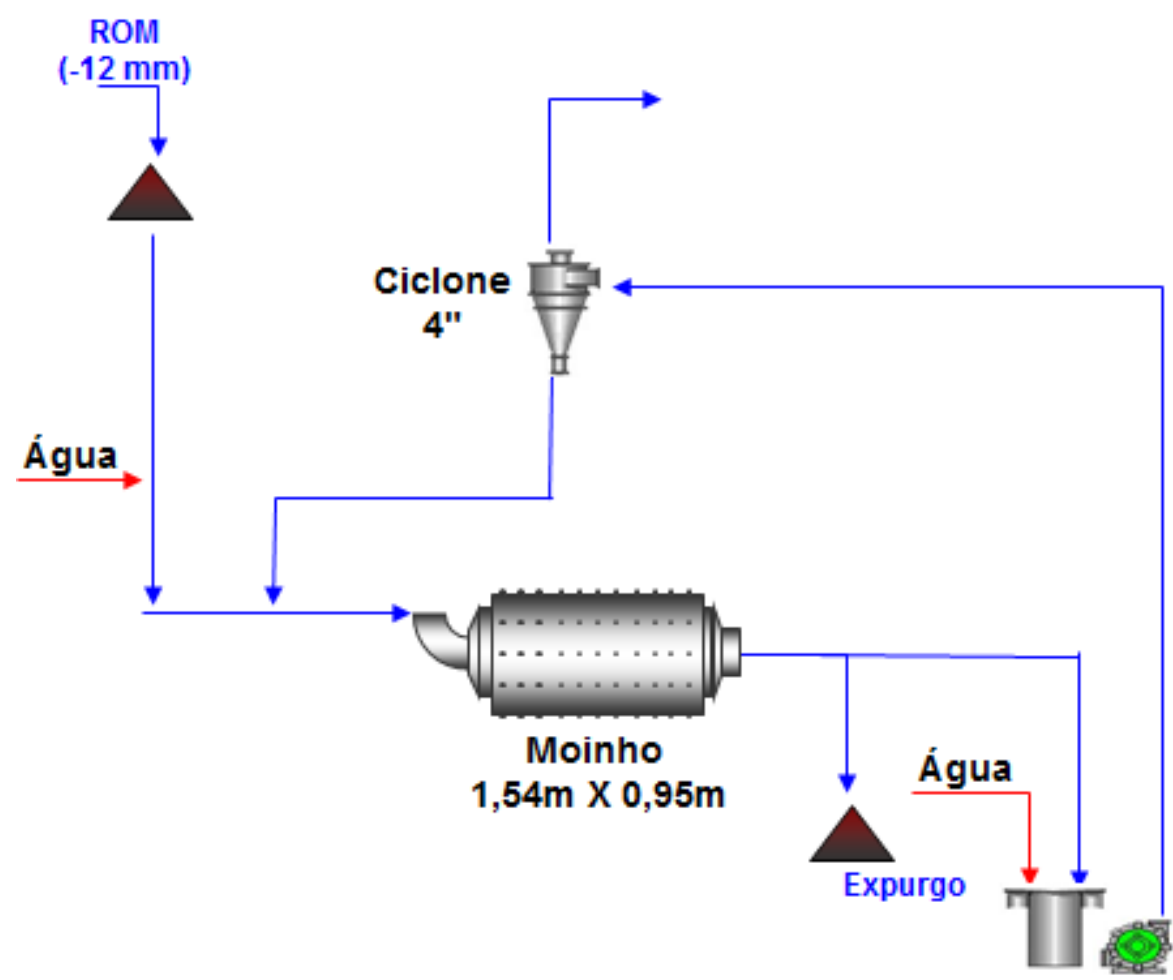

Fonte: Pinto (2015)

Tabela 7 - Parâmetros Operacionais do Ciclone do Ensaio Piloto de Moagem de Bolas

\begin{tabular}{cc}
\hline \multicolumn{2}{c}{ Parâmetros de Operação do Ciclone - } \\
Teste Piloto de Moagem de Bolas \\
\hline Diâmetro (") & 4 \\
Ápex $(\mathrm{mm})$ & 25 \\
Vortex $(\mathrm{mm})$ & 36 \\
Dimensões do bocal de entrada $(\mathrm{mm})$ & $18 \times 48$ \\
Seção Cônica $(\mathrm{mm})$ & - \\
Seção Cilíndirca $(\mathrm{mm})$ & 598 \\
Pressão de Operação $\left(\mathrm{kgf} / \mathrm{cm}^{2}\right)$ & 1,0 \\
\hline
\end{tabular}


Tabela 8 - Parâmetros Operacionais do Moinho do Ensaio Piloto de Moagem de Bolas

\begin{tabular}{cc}
\hline \multicolumn{3}{c}{ Parâmetros de Operação do Moinho - } \\
Teste Piloto de Moagem de Bolas \\
\hline Comprimento livre da câmara (mm) & 950 \\
Diâmetro medido entre vales (mm) & 1570 \\
Diâmetro medido entre cristas (mm) & 1510 \\
Diâmetro interno do moinho (mm) & 1540 \\
Velocidade de rotação (rpm) & 22 \\
Velocidade crítica (rpm) & 34 \\
\% Velocidade crítica & 64,5 \\
Abertura da tela do trommel (mm) & 6,3 \\
Grau de enchimento (\%) & 33 \\
\hline
\end{tabular}

Para a determinação da carga de bolas do ensaio piloto, foi considerado um valor médio entre a carga de start up e a carga de equilíbrio de um moinho industrial, conforme proposto por Bond (BOND, 1964). As tabelas 9, 10 e 11 apresentam tais distribuições para top size de bolas entre $101,6 \mathrm{~mm}$ e $38,1 \mathrm{~mm}$.

Tabela 9 - Colar de Bolas para Start Up do Moinho

\begin{tabular}{|c|c|c|c|c|c|c|c|}
\hline \multicolumn{2}{|c|}{ Diâmetro de Bolas } & \multicolumn{6}{|c|}{ Diâmetro Máximo de Bola - \% Massa } \\
\hline $\mathrm{mm}$ & Polegadas & $101.6 \mathrm{~mm}$ & $88.9 \mathrm{~mm}$ & $76,2 \mathrm{~mm}$ & $63,5 \mathrm{~mm}$ & $50,8 \mathrm{~mm}$ & $38,1 \mathrm{~mm}$ \\
\hline 101,6 & 4 & 23 & & & & & \\
\hline 88,9 & $31 / 2$ & 34 & 24 & & & & \\
\hline 76,2 & 3 & 21 & 38 & 31 & & & \\
\hline 63,5 & $21 / 2$ & 12 & 21 & 39 & 34 & & \\
\hline 50,8 & 2 & 7 & 12 & 19 & 43 & 40 & \\
\hline 38,1 & $11 / 2$ & 3 & 5 & 8 & 17 & 45 & 51 \\
\hline 25,4 & 1 & 1 & 2 & 3 & 6 & 15 & 49 \\
\hline
\end{tabular}

Fonte: Bond (1964) Adaptado pelo autor 
Tabela 10 - Colar de Bolas de Equilíbrio do Moinho

\begin{tabular}{|c|c|c|c|c|c|c|c|}
\hline \multicolumn{2}{|c|}{ Diâmetro de Bolas } & \multicolumn{6}{|c|}{ Diâmetro Máximo de Bola - \% Massa } \\
\hline $\mathrm{mm}$ & Polegadas & $101.6 \mathrm{~mm}$ & $88.9 \mathrm{~mm}$ & $76,2 \mathrm{~mm}$ & $63,5 \mathrm{~mm}$ & $50,8 \mathrm{~mm}$ & $38,1 \mathrm{~mm}$ \\
\hline 101,6 & 4 & & & & & & \\
\hline 88,9 & $31 / 2$ & 42 & & & & & \\
\hline 76,2 & 3 & 40 & 45 & & & & \\
\hline 63,5 & $21 / 2$ & 18 & 38 & & & & \\
\hline 50,8 & 2 & 8 & 17 & 56 & 32 & & \\
\hline 38,1 & $11 / 2$ & 4 & 8 & 24 & 38 & 49 & \\
\hline 25,4 & 1 & 2 & 4 & 11 & 17 & 29 & 55 \\
\hline 19,1 & $3 / 4$ & 1 & 2 & 5 & 8 & 13 & 27 \\
\hline 12,7 & $1 / 2$ & 0 & 1 & 2 & 4 & 6 & 12 \\
\hline 9,5 & $3 / 8$ & 0 & 0 & 1 & 2 & 3 & 6 \\
\hline
\end{tabular}

Fonte: Bond (1964) Adaptado pelo autor

Tabela 11 - Média entre Carga de Start Up e Colar de Equilíbrio

\begin{tabular}{|c|c|c|c|c|c|c|c|}
\hline \multicolumn{2}{|c|}{ Diâmetro de Bolas } & \multicolumn{6}{|c|}{ Diâmetro Máximo de Bola - \% Massa } \\
\hline $\mathrm{mm}$ & Polegadas & $101.6 \mathrm{~mm}$ & $88.9 \mathrm{~mm}$ & $76,2 \mathrm{~mm}$ & $63,5 \mathrm{~mm}$ & $50,8 \mathrm{~mm}$ & $38,1 \mathrm{~mm}$ \\
\hline 101,6 & 4 & 12 & & & & & \\
\hline 88,9 & $31 / 2$ & 38 & 12 & & & & \\
\hline 76,2 & 3 & 31 & 42 & 16 & & & \\
\hline 63,5 & $21 / 2$ & 15 & 29 & 20 & 17 & & \\
\hline 50,8 & 2 & 7 & 14 & 38 & 37 & 20 & 0 \\
\hline 38,1 & $11 / 2$ & 3 & 6 & 16 & 28 & 47 & 26 \\
\hline 25,4 & 1 & 1 & 3 & 7 & 12 & 22 & 52 \\
\hline 19,1 & $3 / 4$ & 1 & 1 & 3 & 4 & 7 & 14 \\
\hline 12,7 & $1 / 2$ & 0 & 1 & 1 & 2 & 3 & 6 \\
\hline 9,5 & $3 / 8$ & 0 & 0 & 1 & 1 & 1 & 3 \\
\hline
\end{tabular}

Fonte: Bond (1964) Adaptado pelo autor

Para determinação do diâmetro máximo de bolas, foram utilizadas as fórmulas de Bond (BOND 1964) e Azzaroni (AZZARONI 1980), sendo estas apresentadas abaixo:

Fórmula de Bond:

$$
D b=\left(\frac{F}{K}\right)^{0,5}\left(\frac{W i \times S g}{C s \times(D)^{0,5}}\right)^{\frac{1}{3}}
$$

Fórmula de Azzaroni:

$$
D b=5,8 \times(F)^{\frac{1}{3,5}} \times W i^{\frac{1}{2,5}} \times\left(1+\frac{C l}{100}\right)^{\frac{1}{10}} \times(N \times D)^{\frac{-1}{4}}
$$

Onde: 
$\mathrm{D}_{\mathrm{b}}=$ diâmetro máximo de bolas $(\mathrm{mm})$

$\mathrm{F}=\mathrm{D}_{80}$ da alimentação $(\mu \mathrm{m})$

$\mathrm{Wi}=$ Work-index (kWh/ton curta)

$\mathrm{S}_{\mathrm{g}}=$ massa específica do material $\left(\mathrm{g} / \mathrm{cm}^{3}\right)$

$\mathrm{C}_{\mathrm{s}}=$ percentual da velocidade crítica do moinho

$\mathrm{D}=$ diâmetro do moinho $(\mathrm{m})$

$\mathrm{K}$ = fator variável com o tipo de moagem, no caso de moinho com descarga por overflow é igual a 350.

$\mathrm{Cl}=$ carga circulante $(\%)$

$\mathrm{N}$ = velocidade de rotação do moinho (RPM)

Considerando um valor de $\mathrm{WI}$ de $10,9 \mathrm{kWh} / \mathrm{t}$, um $\mathrm{d}_{80}$ na alimentação do moinho de bolas de $10,2 \mathrm{~mm}$ e densidade do minério de $3,9 \mathrm{t} / \mathrm{m}^{3}$, foi obtido um diâmetro máximo de bolas de 4 polegadas, conforme mostrado na tabela 12 .

Tabela 12 - Tamanho Máximo de Bolas

\begin{tabular}{ccc}
\hline Diâmetro de Bolas & $\mathbf{m m}$ & Polegadas \\
\hline Segundo Bond & 106,9 & $41 / 5$ \\
Segundo Azzaroni & 94,3 & $35 / 7$ \\
\hline Média & $\mathbf{1 0 0 , 6}$ & $\mathbf{4}$ \\
\hline
\end{tabular}

Para a determinação do consumo energético no processo de moagem durante os ensaios piloto, foi adotado o seguinte procedimento:

1. Medição do consumo energético do moinho vazio $\left(k W h_{c}\right)$, energia necessária para colocar a carcaça em operação;

2. Medição do consumo energético do moinho com carga de bolas e minério $\left(k W h_{t}\right)$, energia necessária para colocar a carcaça, bolas e minério em operação;

3. Determinação do consumo efetivo de energia $\left(k W h_{\mathrm{ef}}\right)$, conforme mostrado na equação 4.3. Essa equação considera perdas de $5 \%$ de energia no sistema de acionamento do moinho.

$$
k W h_{e f}=\left(k W h_{t}-k W h_{c}\right) \times 0,95
$$


Os resultados do ensaio piloto de moagem em moinho de bolas foram reconciliados pelo Centro de Pesquisas Tecnológicas e foram disponibilizados já ajustados, ou seja, com o balanço de massa fechado ${ }^{2}$.

${ }^{2}$ As informações foram disponibilizadas através do Relatório Técnico GADMF número 234, Teste Piloto Jangada, documento interno Vale 


\subsection{Ensaio Piloto de Moagem Semi-Autógena}

Os ensaios piloto de moagem semi-autógena (SAG) foram realizados no Centro de Investigações Mínero Metalúrgicas (CIMM), localizado em Santiago no Chile. Nos ensaios de moagem SAG, foi utilizada a mesma amostra empregada, tanto para realização do ensaio industrial de britagem, como nos ensaios piloto de moagem em moinho de bolas. A preparação da amostra para alimentação do moinho SAG consistiu na quebra, com rompedor, dos blocos mais grosseiros que 8 polegadas, de forma a permitir o manuseio do material e evitar entupimentos na alimentação do moinho. A figura 44 mostra a distribuição granulométrica de alimentação dos ensaios piloto de moagem SAG.

Figura 44- Granulometria da Alimentação do Ensaio Piloto de Moagem SAG

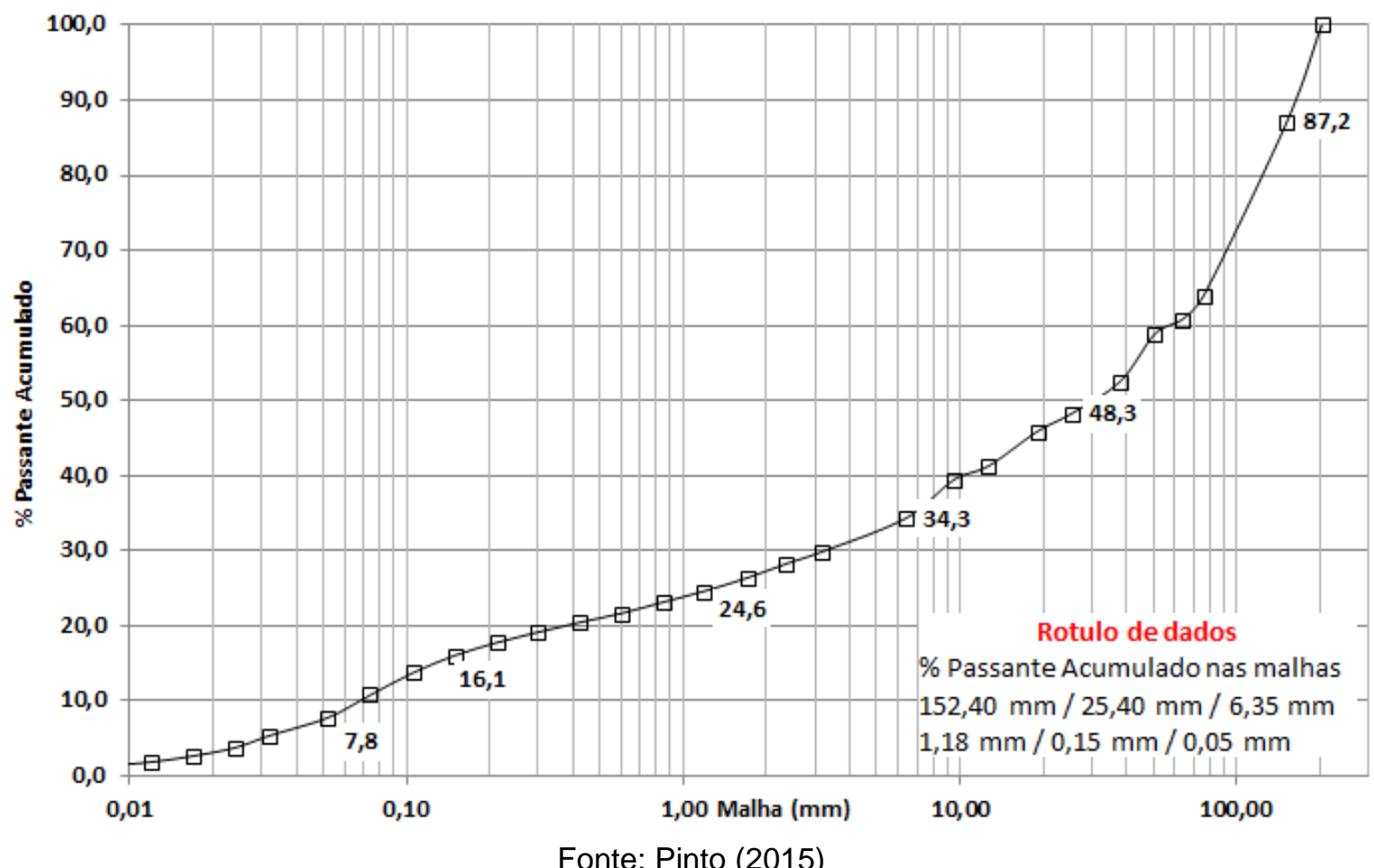

No total, foram realizados cinco ensaios de moagem SAG, sendo três em circuito aberto com recirculação de pebbles, e dois em circuito fechado com classificador espiral. Nos ensaios em circuito aberto, a fração passante no trommel do SAG também foi enviada para o classificador espiral, com o underflow sendo 
estocado para posterior alimentação dos ensaios de moagem em moinho de bolas, enquanto o overflow do mesmo classificador espiral foi considerado como produto final do circuito de moagem.

Nos ensaios de moagem SAG, foi também avaliada a influência da rebritagem dos pebbles recirculados e da redução do top size da alimentação, esta última realizada através da retirada dos blocos mais grosseiros do que 4 polegadas da alimentação do moinho, de forma a simular uma etapa de britagem secundária. $A$ tabela 13 mostra a relação os ensaios de moagem SAG realizados.

Tabela 13 - Ensaios de Moagem SAG

\begin{tabular}{cccccc}
\hline Teste & SAG 1 & SAG 2 & SAG 3 & SAG 4 & SAG 5 \\
\hline Circuito & Aberto & Aberto & Aberto & Fechado & Fechado \\
Britagem Pebbles & Sim & Não & Não & Não & Não \\
$\begin{array}{c}\%>4 \text { pol } \\
\text { Alimentaç̃o Nova }\end{array}$ & 27,8 & 27,8 & 0,0 & 27,8 & 0,0 \\
\hline
\end{tabular}

Os fluxogramas dos ensaios descritos na tabela 13 estão mostrados nas figuras 45 e 46 . Não foi realizado ensaio de moagem em moinho de bolas com o underflow do classificador espiral do ensaio SAG 3, em função do baixo desempenho desta opção de rota, que será mostrada posteriormente. 
Figura 45- Fluxograma Integrado dos Ensaios Piloto de Moagem SAG e e Moagem em Moinho de Bolas
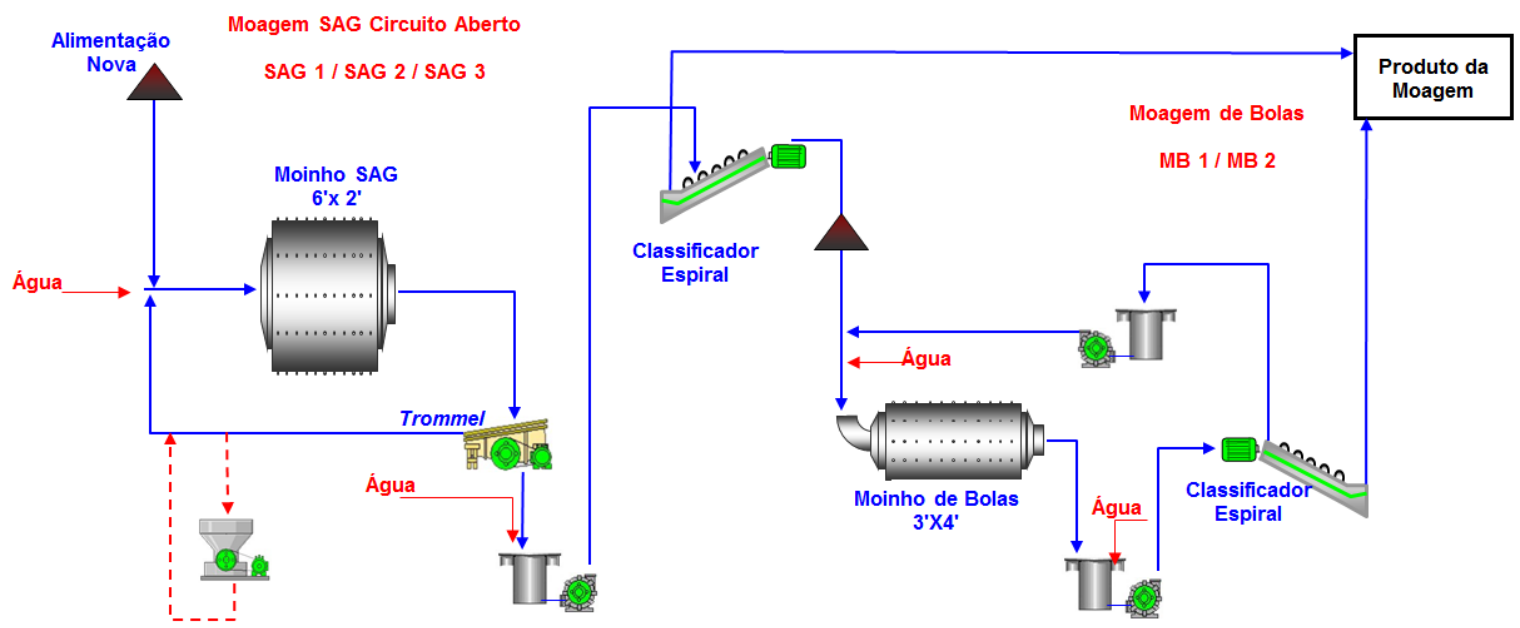

Fonte: Pinto (2015)

Figura 46- Fluxograma dos Ensaios Piloto de Moagem SAG em Circuito Fechado

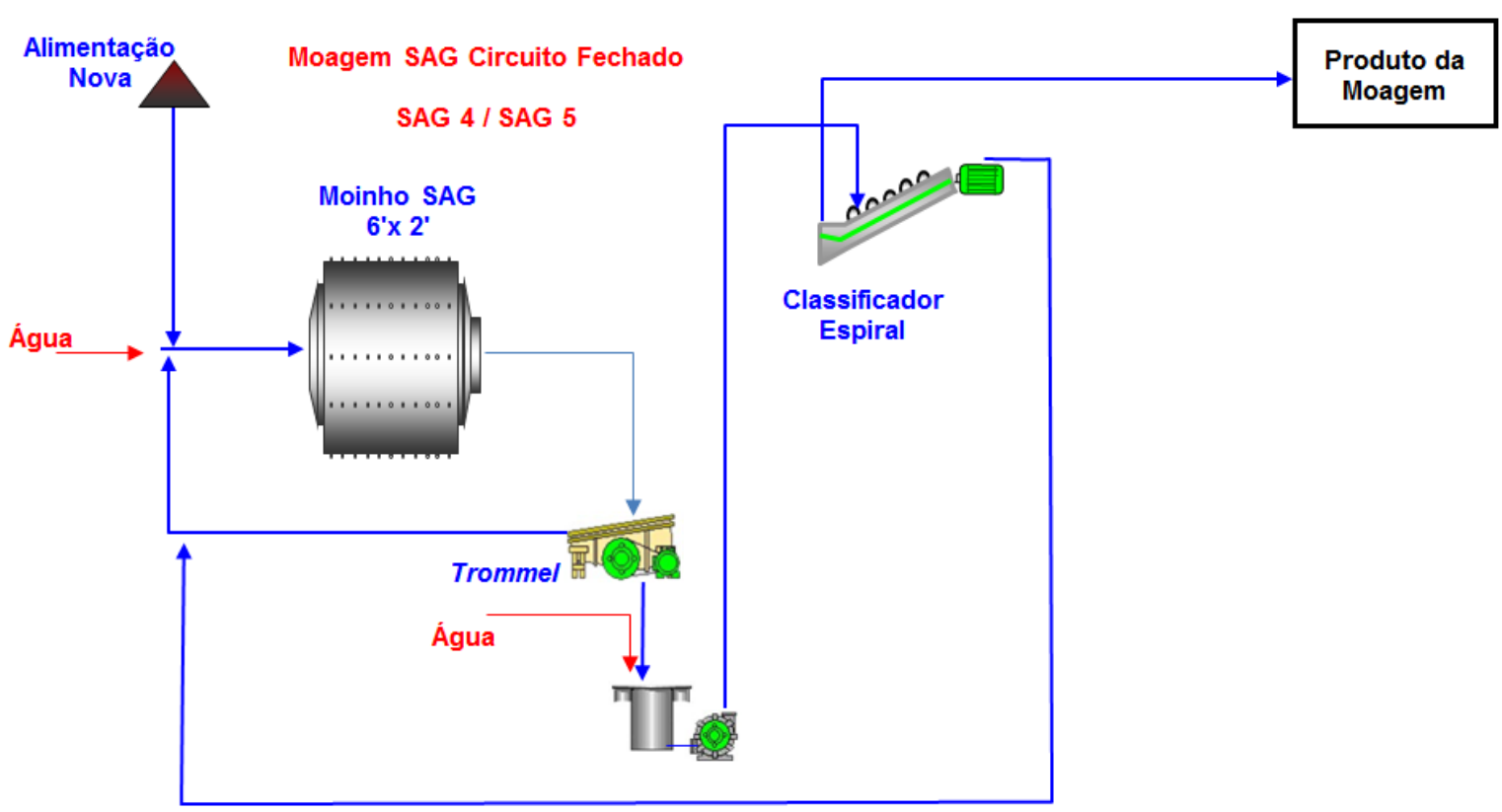

Fonte: Pinto (2015)

Os equipamentos utilizados nos ensaios piloto foram um moinho SAG/AG de 6 pés de diâmetro por 2 pés de comprimento, um moinho de bolas de 3 pés de diâmetro e 4 pés de comprimento, e um classificador espiral com diâmetro de rosca de 12 polegadas. A figura 47 mostra fotografias dos equipamentos da planta piloto do CIMM. 

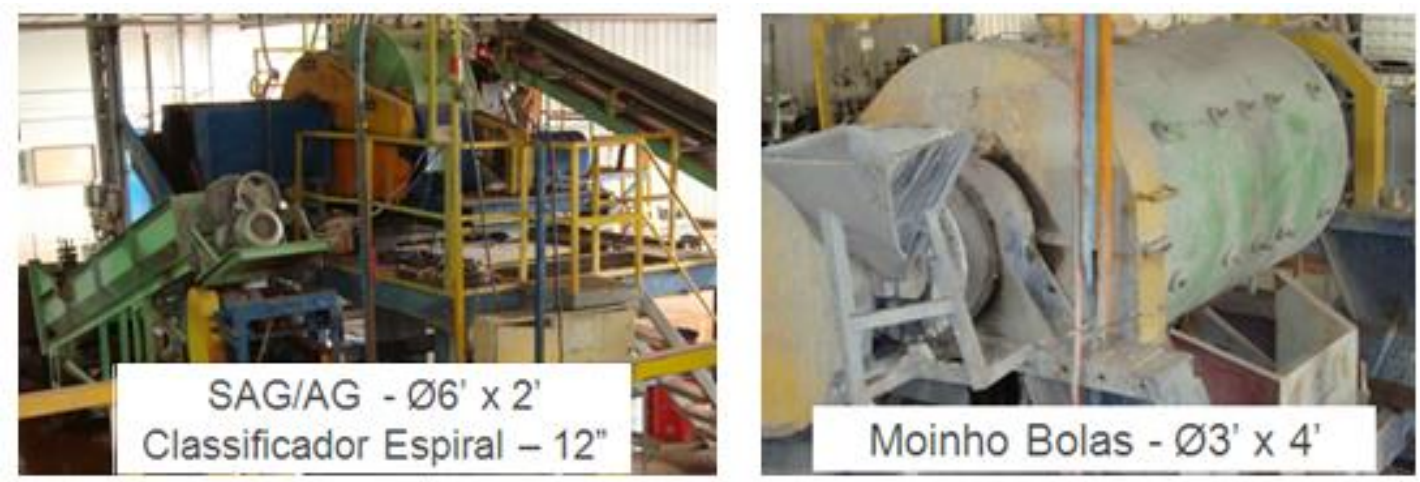

Fonte: Pinto (2015)

As tabelas 14 e 15 mostram os parâmetros operacionais dos equipamentos utilizados para ensaios piloto no CIMM, enquanto que a tabela 16 mostra o colar de bolas considerado para cada ensaio.

Tabela 14 - Parâmetros de Operação do Moinho SAG

Parâmetros de Operação do Moinho SAG

\begin{tabular}{cc}
\hline Diâmetro interno do moinho $(\mathrm{mm})$ & 1740 \\
zomprimento da parte cilíndrica $(\mathrm{mm})$ & 480 \\
Ângulo do cone de alimentação $\left({ }^{\circ}\right)$ & 3,95 \\
Ângulo do cone de descarga $\left({ }^{\circ}\right)$ & 3,95 \\
\% Área aberta da grelha & 30,0 \\
\% Velocidade crítica & 75,0 \\
Densidade do corpo moedor $\left(\mathrm{t} / \mathrm{m}^{3}\right)$ & 7,8 \\
\% Vazios da Carga & 40,0 \\
Densidade da carga $\left(\mathrm{t} / \mathrm{m}^{3}\right)$ & 3,5 \\
\% Bolas & 4,0 \\
\% Enchimento total & 24,4 \\
\hline
\end{tabular}


Tabela 15 - Parâmetros de Operação do Moinho de Bolas com Produto da Moagem SAG

\begin{tabular}{cc}
\hline \multicolumn{2}{c}{ Parâmetros de Operação do Moinho de Bolas com } \\
Produto da Moagem SAG \\
\hline Diâmetro interno do moinho $(\mathrm{mm})$ & 910 \\
Comprimento da parte cilíndrica $(\mathrm{mm})$ & 1220 \\
\% Velocidade crítica & 69,0 \\
Densidade do corpo moedor $\left(\mathrm{t} / \mathrm{m}^{3}\right)$ & 7,8 \\
Densidade da carga $\left(\mathrm{t} / \mathrm{m}^{3}\right)$ & 5,4 \\
\% Bolas & 35,0 \\
\hline
\end{tabular}

Tabela 16 - Colar de Bolas dos Ensaios Piloto de Moagem SAG

\begin{tabular}{ccc}
\hline Testes & $\begin{array}{c}\text { Tamanho de Bolas } \\
(\mathbf{m m})\end{array}$ & \% Massa \\
\hline Moagem SAG & 101,6 & 50 \\
Testes: 1, 2, 3 e 5 & 88,9 & 32 \\
& 76,2 & 18 \\
\hline & 101,6 & 12 \\
Moagem SAG & 88,9 & 17 \\
Teste 4 & 76,2 & 18 \\
& 63,5 & 24 \\
& 50,8 & 29 \\
\hline & 76,2 & 31 \\
Moagem de & 63,5 & 39 \\
Bolas & 50,8 & 19 \\
Testes 1 e 2 & 38,1 & 8 \\
& 25,4 & 3 \\
\hline
\end{tabular}

Após cada um dos ensaios de moagem SAG, o moinho foi descarregado para medição do seu percentual de enchimento, assim como a massa, densidade e granulometria da carga interna do moinho. Para o ensaio SAG 3, não foi feita a caracterização da carga interna, em função do baixo desempenho desta opção de rota, que será mostrada posteriormente.

Todos os fluxos de cada ensaio realizado foram amostrados para posterior determinação da granulometria, percentual de sólidos, densidade da polpa e vazão mássica e volumétrica. A granulometria foi analisada via peneiramento a úmido até a malha de 0,052 mm, e por cyclosizer para as malhas inferiores. Os resultados dos 
ensaios foram reconciliados pela equipe técnica do CIMM e foram disponibilizados já ajustados, ou seja, com o balanço de massa fechado. ${ }^{3}$ Para efeito do presente trabalho, os balanços de massas foram considerados consistentes e, portanto, adotados para a sequência das análises de processo.

${ }^{3}$ As informações foram disponibilizadas através do Informativo de Resultados Número 2, referente ao projeto número 13400202, Programa de Pruebas Piloto de Molienda AG Y SAG para Vale, Brasil. 


\subsection{Drop Weight Test}

O ensaio DWT (Drop Weight Test) avalia, através de impacto, a resistência de partículas individuais do minério em função de seu tamanho (granulometria).

O método de caracterização tecnológica, empregando-se a $\mathrm{Cl}$ (célula de impacto do ensaio DWT), contrasta, conceitualmente, com os métodos baseados em índices de consumo energético específico (kWh/t), ou mesmo com as equações empíricas dele derivadas. O principal fator de diferenciação reside na capacidade da $\mathrm{Cl}$ de reproduzir, separadamente, mecanismos de fragmentação que ocorrem no interior de moinhos autógenos e semi-autógenos, tanto em termos de intensidade, como em termos de tamanho do fragmento. Em particular, a avaliação do efeito do tamanho do fragmento na resistência ao impacto é determinante da viabilidade da moagem autógena e semi autógena. (BERGERMAN, 2009)

Conceitualmente, o ensaio consiste na aplicação de uma energia conhecida (através da queda de uma massa conhecida de uma determinada altura), em uma única partícula, com posterior avaliação da granulometria gerada em função da energia aplicada.

Os parâmetros utilizados para os ensaios de DWT foram desenvolvidos pelo Julius Kruttschnitt Mineral Research Centre (JKMRC), da University of Queensland, na caracterização da quebra de partículas por impacto (KOJOVIC et al., 1999). A única diferença em relação a esse, foi o uso da Célula de Carga de Impacto COPPE ao invés do Drop Weight Tester (DWT), usado no JKMRC. A equivalência entre os resultados obtidos nos dois equipamentos foi demonstrada por Tavares (2003).

A preparação das amostras para os ensaios consistiu, inicialmente, na britagem em britador de mandíbulas DENVER 5" x 6", até a malha de $63 \mathrm{~mm}$, seguida de peneiramento a seco do produto britado no peneirador PRODUTEST nas faixas $63-53 \mathrm{~mm}, 45-37,5 \mathrm{~mm}, 31,5-26,5 \mathrm{~mm}, 22,4-19,0 \mathrm{~mm}, 16,0-13,2 \mathrm{~mm}$. Foi determinado o peso médio das partículas para cada uma das faixas granulométricas acima.

A tabela 17 mostra as energias específicas (kWh/t) aplicadas para cada fração granulométrica, assim como o número de partículas ensaiadas. 
Tabela 17 - Condições experimentais utilizadas nos ensaios DWT

\begin{tabular}{ccc}
\hline $\begin{array}{c}\text { Intervalo de } \\
\text { Tamanhos (mm) }\end{array}$ & $\begin{array}{c}\text { Energia Específica } \\
\text { de Impacto (kWh/t) }\end{array}$ & $\begin{array}{c}\text { Número de } \\
\text { partículas / lote }\end{array}$ \\
\hline \multirow{2}{*}{$\mathbf{6 3 , 0}-\mathbf{5 3 , 0}$} & 0,10 & 10 \\
& 0,25 & 10 \\
& 0,40 & 10 \\
\hline \multirow{3}{*}{$\mathbf{4 5 , 0}-\mathbf{3 7 , 5}$} & 0,10 & 15 \\
& 0,25 & 15 \\
& 1,00 & 15 \\
\hline \multirow{3}{*}{$\mathbf{3 1 , 5}-\mathbf{2 6 , 5}$} & 0,25 & 30 \\
& 1,00 & 30 \\
& 2,50 & 30 \\
\hline \multirow{2}{*}{$2 \mathbf{4}-\mathbf{1 9 , 0}$} & 0,25 & 30 \\
& 1,00 & 30 \\
& 2,50 & 30 \\
\hline \multirow{2}{*}{$\mathbf{1 6 , 0}-\mathbf{1 3 , 2}$} & 0,25 & 30 \\
& 1,00 & 30 \\
\hline
\end{tabular}

As partículas foram quebradas, uma a uma, e os fragmentos, peneirados a seco, usando peneiras que seguem uma série com razão igual à raiz quadrada de dois. As distribuições granulométricas dos fragmentos gerados foram normalizadas e correlacionadas com a energia específica aplicada conforme a equação 4.4 .

$$
t_{10}=A\left(1-e^{-b \times E c s}\right)
$$

Onde:

$t_{10}$ - Percentual passante na malha equivalente a $10 \%$ do tamanho original do fragmento

$E_{c s}-$ Energia específica aplicada na partícula $(\mathrm{kWh} / \mathrm{t})$

$A$ e $b$ - Parâmetros característicos do minério

Os parâmetros $\mathrm{A} \mathrm{e} \mathrm{b}$ indicam o comportamento da amostra quando submetida a impactos, conforme ocorre dentro dos moinhos AG e SAG. Assim, a fragmentação por impacto do material é convenientemente descrita por uma curva que apresenta rápido crescimento inicial (parâmetro b), e tende a um comportamento assintótico, 
descrito pelo parâmetro A. A figura 48 (BERGERMAN 2009) ilustra a curva descrita acima.

Figura 48- Representação da relação energia/fragmentação obtida a partir de ensaios DWT

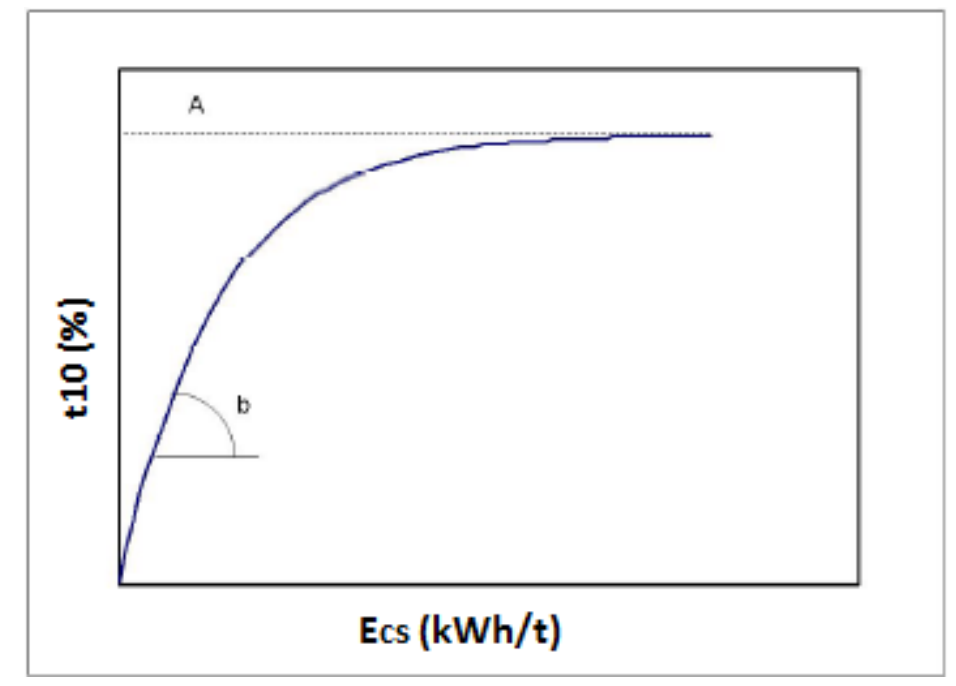

Fonte: Bergerman (2009) Adaptado pelo autor

Dessa forma, quanto menores os parâmetros $A$ e $b$, maior a resistência da amostra à fragmentação por impacto. Assim, o produto dos parâmetros $A$ e b, denominado Índice de Quebra (IQ), é utilizado como parâmetro indicador de resistência à fragmentação por impacto. A tabela 18 (DELBONI, 2003) mostra a classificação dos minérios quanto ao valor de IQ.

Tabela 18 - Classificação de resistência ao impacto de amostras conforme IQ

\begin{tabular}{ccll}
\hline $\begin{array}{c}\text { Intervalo de Valores do Parâmetro IQ } \\
\text { Menor }\end{array}$ & \multicolumn{1}{c}{$\begin{array}{c}\text { Resistência ao } \\
\text { Impacto }\end{array}$} & Sigla \\
\hline 0 & 9,9 & Excepcionalmente Alta & ETA \\
10 & 19,9 & Extremamente Alta & EXA \\
20 & 29,9 & Muito Alta & MTA \\
30 & 39,9 & Alta & ALT \\
40 & 49,9 & Moderadamente Alta & MDA \\
50 & 59,9 & Média & MED \\
60 & 69,9 & Moderadamente Baixa & MDB \\
70 & 89,9 & Baixa & BAI \\
90 & 109,9 & Muito Baixa & MTB \\
& & Extremamente Baixa & ETB \\
\hline
\end{tabular}

Fonte: Delboni (2003) 


\subsection{Ensaio de Resistência à Abrasão}

O ensaio de resistência à abrasão consiste em avaliar a resistência do minério à fragmentação por abrasão, através de tamboramento de uma amostra bitolada do minério. Segundo Bergerman (2009) "Em processos industriais, a abrasão é o principal mecanismo atribuído à fragmentação do minério, com tamanho próximo ao extremo superior da carga do moinho".

O ensaio foi realizado conforme padrão JKMRC, e consistiu no tamboramento de $3 \mathrm{~kg}$ de amostra entre $53 \mathrm{~mm}$ e $37,5 \mathrm{~mm}$ em um moinho de $300 \mathrm{~mm}$ de diâmetro por $300 \mathrm{~mm}$ de comprimento, com 4 barras de elevação interna de $6,6 \mathrm{~mm}$ de largura e 6,6 mm de altura cada. $O$ tempo de duração do tamboramento é dez minutos a $70 \%$ da velocidade crítica, que equivale a $53 \mathrm{rpm}$.

Após o ensaio, a amostra é peneirada a seco entre $37,5 \mathrm{~mm}$ e $0,075 \mathrm{~mm}$, seguindo uma série com razão igual à raiz quadrada de dois. A partir dos dados de análise granulométrica, é calculado $o$ valor de $t_{10}$.

O parâmetro de resistência à abrasão $\left(\mathrm{t}_{\mathrm{a}}\right)$ é definido como um décimo do valor de $t_{10}$ obtido no ensaio de tamboramento acima descrito. Dessa forma, quanto maior o valor de $t_{a}$, menor a resistência à fragmentação por abrasão para o minério em estudo. A tabela 19 (DELBONI, 2003) mostra a classificação dos minérios quanto ao valor de $t_{a}$.

Tabela 19 - Classificação de resistência à abrasão de amostras conforme $t_{a}$

\begin{tabular}{|c|c|c|c|}
\hline \multicolumn{2}{|c|}{ Intervalo de Valores do Parâmetro $t_{a}$} & \multirow{2}{*}{$\begin{array}{l}\text { Resistência à } \\
\text { Abrasão }\end{array}$} & \multirow{2}{*}{ Sigla } \\
\hline Menor & Maior & & \\
\hline 0,00 & 0,19 & Extremamente Alta & EAAb \\
\hline 0,20 & 0,39 & Muito Alta & MTAb \\
\hline 0,40 & 0,59 & Alta & ALAb \\
\hline 0,60 & 0,79 & Moderadamente Alta & MAAb \\
\hline 0,80 & 0,99 & Média & MDAb \\
\hline 1,00 & 1,19 & Moderadamente Baixa & MOAb \\
\hline 1,20 & 1,39 & Baixa & BAAb \\
\hline 1,40 & 1,59 & Muito Baixa & MBAb \\
\hline \multicolumn{2}{|c|}{$>1,60$} & Extremamente Baixa & EBAb \\
\hline
\end{tabular}

Fonte: Delboni (2003) 


\subsection{Ensaios de WI e Abrasividade de Bond}

Para a determinação do Wi de bolas, foi executado o ensaio desenvolvido por Bond (BOND, 1964). Este ensaio considera a utilização de um moinho de bolas de 12 polegadas de comprimento e diâmetro, de revestimento liso e cantos curvos, com uma carga de bolas com massa total de $20,125 \mathrm{~kg}$, distribuída conforme tabela 20 .

Tabela 20 - Distribuição da carga de bolas do ensaio de Bond

\begin{tabular}{ccc}
\hline \multicolumn{2}{l}{ Diâmetro de Bolas } & \multirow{2}{*}{ Número de Bolas } \\
\cline { 1 - 2 } $\mathbf{m m}$ & Polegadas & \\
\hline 36,5 & $13 / 7$ & 36 \\
30,2 & $11 / 5$ & 62 \\
25,4 & 1 & 12 \\
19,1 & $3 / 4$ & 61 \\
15,9 & $5 / 8$ & 114 \\
\hline
\end{tabular}

O ensaio de moagem é realizado a seco, com amostra britada em $3,36 \mathrm{~mm}$. $\mathrm{O}$ ensaio é realizado de forma a simular o circuito fechado com uma carga circulante de $250 \%$. Assim, após cada ciclo, a carga é retirada do moinho, classificada e recomposta a alimentação nova. O número de rotações do moinho em cada ensaio é calculado de forma a manter a massa de undersize igual a 1/3,5 da alimentação nova. A malha de moagem escolhida foi $0,106 \mathrm{~mm}$, de forma a melhor representar 0 circuito industrial que será desenvolvido.

Os ciclos são repetidos até a que a razão entre a massa de undersize produzida e o número de revoluções (Gbp) se repita por pelo menos três vezes, e então saia do equilíbrio. O Wi é, então, calculado pela seguinte equação.

$$
W i=\frac{44,5}{P_{i}^{0,23} \times G b p^{0.82} \times\left(\frac{10}{\sqrt{P_{80}}}-\frac{10}{\sqrt{F_{80}}}\right)}
$$

Onde:

$P_{i}=$ Abertura da malha do ensaio $(\mu \mathrm{m})$, para este trabalho $106 \mu \mathrm{m}$

$\mathrm{G}_{\mathrm{pb}}=$ Quociente entre a massa de undersize produzida e o número de revoluções $(\mathrm{g} / \mathrm{rpm})$ 
$\mathrm{F}_{80}$ e $\mathrm{P}_{80}=$ Tamanho em que passa $80 \%$ da alimentação e do produto, respectivamente $(\mu \mathrm{m})$.

É importante ressaltar que, na equação acima, o Wi é obtido em kWh/st, sendo necessária a multiplicação por 1,102 para a conversão para kWh/t.

O ensaio de abrasividade de Bond, diferentemente do ensaio de resistência à abrasão, mede a abrasividade do minério, sendo utilizado para avaliação do consumo de bolas e desgaste de revestimento de britadores e moinhos. Como neste trabalho não foi feita a quantificação do consumo de bolas e revestimentos, o valor da abrasividade do minério foi utilizado apenas para análise qualitativa.

O ensaio de abrasividade de Bond consiste na avaliação do desgaste de uma palheta de aço com dureza de $500 \mathrm{HB}$, quando submetida a uma hora de trabalho com 400 gramas de minério entre 19,1 mm e 12,5 mm, dentro de um tambor rotativo de $305 \mathrm{~mm}$ de diâmetro e $114 \mathrm{~mm}$ de comprimento. $\mathrm{O}$ tambor gira à frequência de 70 rotações por minuto e a peça de desgaste a 632 rotações por minuto em sentido contrário. $O$ desgaste da palheta em gramas é o valor de abrasividade de Bond para o minério. A tabela 21, classifica os minérios quanto à abrasão:

Tabela 21 - Classificação da abrasividade dos minérios

\begin{tabular}{ccc}
\hline \multicolumn{2}{c}{ Intervalo de valores do parâmetro $A i$} & Abrasividade \\
\cline { 1 - 2 } Menor & Maior & Baixa \\
0,11 & 0,10 & Moderadamente baixa \\
0,21 & 0,20 & Média \\
0,36 & 0,35 & Moderadamente alta \\
0,61 & 0,55 & Alta \\
\hline
\end{tabular}




\subsection{Ensaio de Moabilidade de Donda}

O ensaio de moabilidade foi desenvolvido por Donda (2003), para a remoagem de concentrados de minério de ferro, e teve sua aplicação para moagem primária de minérios de ferro do Quadrilátero Ferrífero comprovada por Donda e Rosa em 2014.

O ensaio de Donda considera a moagem como um fenômeno de remanescência, e, assim, avalia o percentual retido na malha de interesse com a aplicação de diferentes níveis de energia. Com os resultados obtidos, é montado um gráfico do percentual retido na malha de interesse em função da energia de moagem aplicada. A regressão exponencial dessa função fornece $o$ valor de $k$ da equação 3.28.

A figura 49 (DONDA 2003) mostra uma curva do percentual retido em 0,044 $\mathrm{mm}$ em função da energia de moagem aplicada para um concentrado de minério de ferro, com determinação do valor de k por regressão exponencial.

Figura 49- Exemplo de Aplicação do Ensaio de Moabilidade de Donda

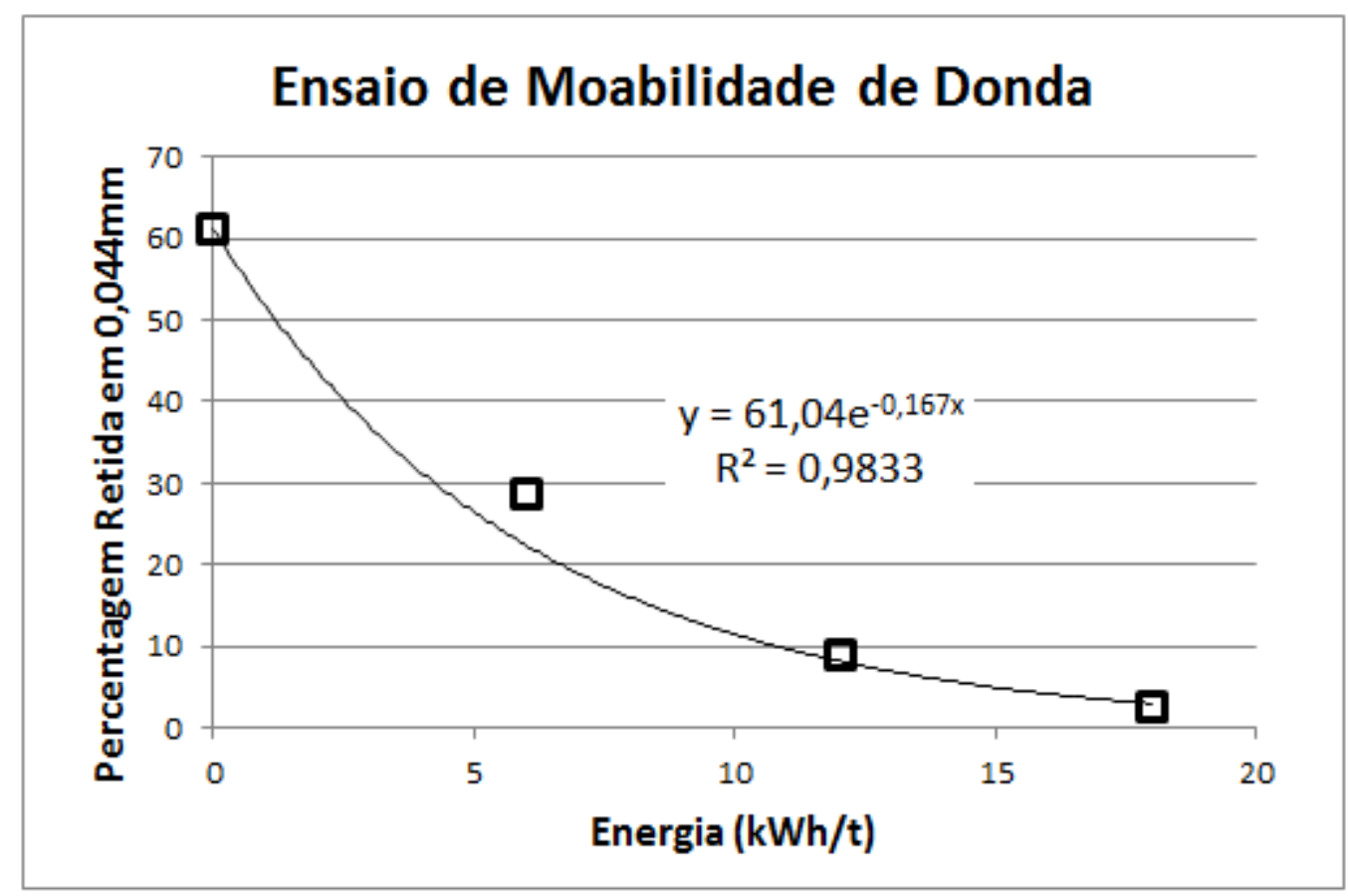

Fonte: Donda (2003) Adaptado pelo autor

Para a aplicação de diferentes energias de moagem, são realizados ensaios em diferentes tempos de moagem. 
Os tempos de moagem devem ser ajustados para minérios caso não atinjam ou excedam muito $o d_{90}$. Recomenda-se fazer a primeira moagem aplicando $8 \mathrm{kWh} / \mathrm{t}$. A partir desta informação inicial, faz-se as outras moagens nos tempos mais adequados. Recomenda-se fazer o ensaio em no mínimo quatro tempos diferentes. (DONDA; ROSA, 2014

O cálculo da energia aplicada em cada ensaio é feito a partir da equação de Rowland (ROWLAND, 1986) para cálculo de potência de moinhos de diâmetros até $0,76 \mathrm{~m}$, mostrada abaixo.

$$
k W_{b}=6,3 D^{0,3} \operatorname{sen}\left(51-22\left(\frac{2,44-D}{2,44}\right)\right)\left(3,2-3 V_{p}\right) C_{s}\left(1-\frac{0,1}{2^{9-10 C_{s}}}\right)
$$

Onde:

$\mathrm{kW}_{\mathrm{b}}=$ Potência em kW por tonelada de bolas, no eixo pinhão

$\mathrm{D}=$ Diâmetro do moinho $(\mathrm{m})$ interno ao revestimento

$V_{p}=$ Fração do volume do moinho ocupada pelas bolas

$\mathrm{C}_{\mathrm{s}}=$ Fração da velocidade crítica

Os parâmetros para a realização dos ensaios de moagem de Donda para a moagem primária estão mostrados na tabela 22 (DONDA; ROSA, 2014). 
Tabela 22 - Parâmetros para Realização do Ensaio de Moabilidade de Donda para a Moagem Primária

\begin{tabular}{|c|c|c|c|}
\hline Parâmetro & \multicolumn{3}{|c|}{ Condição } \\
\hline Diâmetro interno do moinho (m) & \multicolumn{3}{|c|}{0,305} \\
\hline Comprimento interno do moinho $(\mathrm{m})$ & \multicolumn{3}{|c|}{0,305} \\
\hline$\%$ Enchimento & \multicolumn{3}{|c|}{29,6} \\
\hline Relação volume de polpa por volume de vazios & \multicolumn{3}{|c|}{1,07} \\
\hline \% Sólidos em volume & \multicolumn{3}{|c|}{49,75} \\
\hline \% Sólidos em peso & \multicolumn{3}{|c|}{79} \\
\hline$\%$ Velocidade critica & \multicolumn{3}{|c|}{70} \\
\hline Peso do minério (kg) & \multicolumn{3}{|c|}{5,0} \\
\hline Peso da carga $(\mathrm{kg})$ & \multicolumn{3}{|c|}{30,578} \\
\hline Tipo de corpo moedor & \multicolumn{3}{|c|}{ Bolas } \\
\hline \multirow{5}{*}{ Distribuição da carga } & Diâmetro & $\%$ & Peso (kg) \\
\hline & 63,5 & 35 & 10,70 \\
\hline & 50,8 & 41 & 12,54 \\
\hline & 38,1 & 18 & 5,50 \\
\hline & 25,4 & 6 & 1,84 \\
\hline Área especifica da carga $\left(\mathrm{m}^{2} / \mathrm{t}\right)$ & \multicolumn{3}{|c|}{15,5} \\
\hline Volume interno do moinho (litros) & \multicolumn{3}{|c|}{22,24} \\
\hline Volume aparente da carga (litros) & \multicolumn{3}{|c|}{6,576} \\
\hline Volume de vazios da carga (litros) & \multicolumn{3}{|c|}{2,630} \\
\hline Volume da polpa (litros) & \multicolumn{3}{|c|}{2,645} \\
\hline Volume real de minério (litros) & \multicolumn{3}{|c|}{0,696} \\
\hline Volume de água (litros) & \multicolumn{3}{|c|}{1,329} \\
\hline Potência no eixo pinhão (kW) & \multicolumn{3}{|c|}{0,111} \\
\hline $\begin{array}{l}\text { Fator de conversão do tempo de moagem } \\
\text { (minutos) em energia (kWh/t) }\end{array}$ & \multicolumn{3}{|c|}{0,371} \\
\hline Revestimento / lifters do moinho & \multicolumn{3}{|c|}{ Sem revestimento e sem lifter } \\
\hline Limite para cálculo da constante $\mathrm{K}$ & \multirow{2}{*}{\multicolumn{3}{|c|}{$\begin{array}{c}\text { Malha com no mínimo } 3 \% \text { retido } \\
\text { Amostra britada e peneirada, } \\
\text { abaixo de } 9,53 \mathrm{~mm}\end{array}$}} \\
\hline Condição da amostra para realização do ensaio & & & \\
\hline
\end{tabular}

Fonte: Donda e Rosa (2014) 
). 


\section{RESULTADOS}

De forma a facilitar a compreensão dos resultados obtidos, estes são apresentados da seguinte forma:

1- Resultados dos ensaios de caracterização de bancada;

2- Resultados do ensaio industrial de britagem;

3- Resultados dos ensaios piloto de moagem de bolas e SAG.

No item 6 são apresentados os dimensionamentos dos circuitos e a análise comparativa entre as rotas. 


\subsection{Resultados dos Ensaios de Caracterização de Bancada}

Neste item, são apresentados os resultados dos seguintes ensaios de caracterização de cominuição em escala de bancada: Drop Weight Test (DWT), Resistência a Abrasão, Wi e Abrasividade de Bond e Moabilidade de Donda.

Conforme descrito anteriormente, o ensaio DWT corresponde à avaliação do percentual passante na malha equivalente a $10 \%$ do tamanho original do fragmento $\left(t_{10}\right)$, em função da energia específica de impacto aplicada em cada uma das partículas ensaiadas. Os parâmetros $A$ e $b$ da equação 4.5, que correlaciona o $t_{10}$ com a energia aplicada, são obtidos através de regressão. A figura 50 mostra o gráfico de $t_{10}$ em função da energia específica para cada tamanho de partícula testada, a curva de regressão e os parâmetros $\mathrm{A}$ e b.

Figura 50- Resultados dos ensaios de DWT

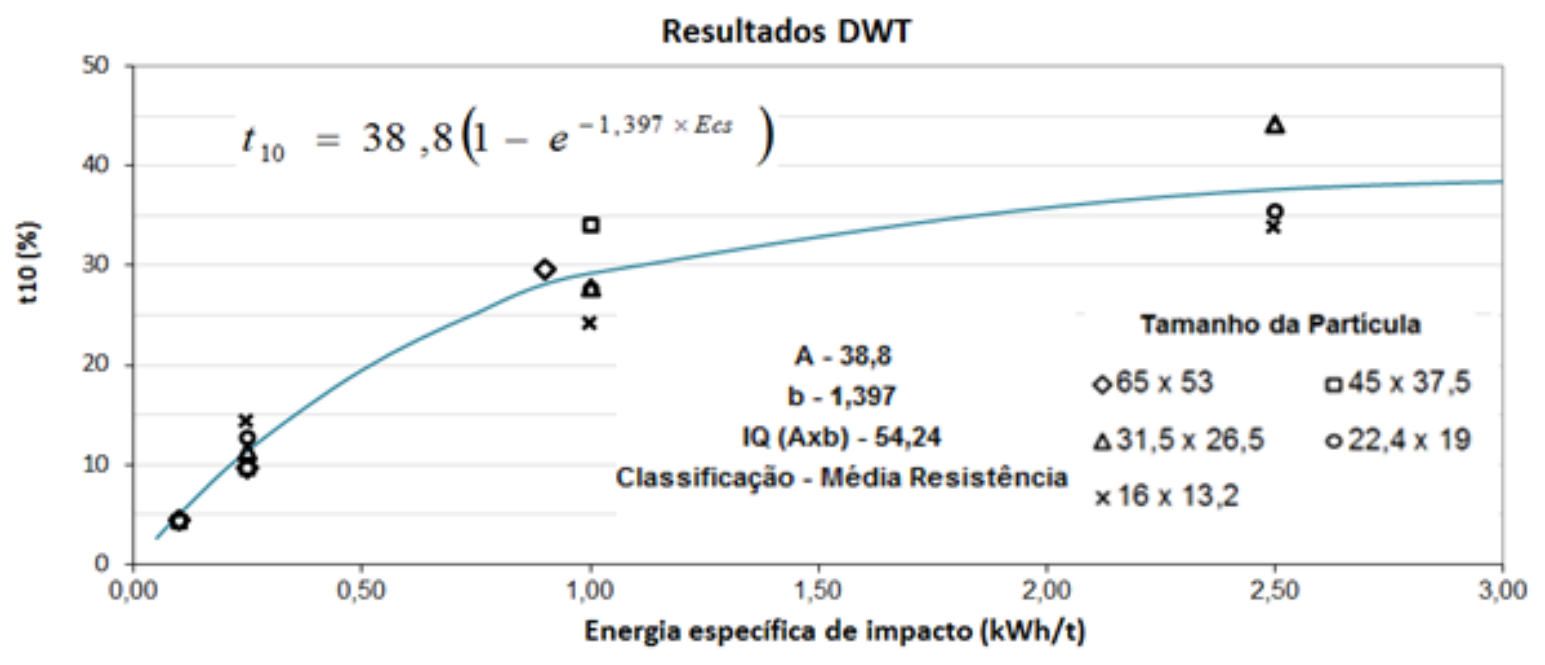

Fonte: Pinto (2015)

No ensaio de resistência a abrasão, foi obtido um valor de $t_{a}$ de 0,550 , o que indica um minério de alta resistência a abrasão, conforme mostrado na tabela 23.

Tabela 23 - Resultados de resistência à abrasão

\begin{tabular}{|c|c|}
\hline \multicolumn{2}{|c|}{ Resistência à Abrasão } \\
\hline ta & Classificação \\
\hline 0,550 & Alta Resistência \\
\hline
\end{tabular}


A tabela 24 mostra os resultados obtidos para o ensaio de Wi de bolas conforme o método de Bond.

Tabela 24 - Resultados de WI de Bond

\begin{tabular}{|c|c|c|}
\hline \multirow{2}{*}{$\begin{array}{c}\text { Abertura } \\
(\mu \mathrm{m})\end{array}$} & \multicolumn{2}{|c|}{$\%$ Passante Acumulado } \\
\hline & Alimentação & Produto \\
\hline 3350 & 100,0 & 100,0 \\
\hline 2360 & 83,6 & 100,0 \\
\hline 1700 & 68,5 & 100,0 \\
\hline 1180 & 55,8 & 100,0 \\
\hline 850 & 47,5 & 100,0 \\
\hline 601 & 41,5 & 100,0 \\
\hline 425 & 36,7 & 100,0 \\
\hline 300 & 33,1 & 100,0 \\
\hline 212 & 29,9 & 100,0 \\
\hline 150 & 26,7 & 100,0 \\
\hline 106 & 23,7 & 81,5 \\
\hline 75 & 18,7 & 62,8 \\
\hline 53 & 14,1 & 48,5 \\
\hline 38 & 10,4 & 37,2 \\
\hline $\mathrm{D} 80(\mu \mathrm{m})$ & 2195 & 103 \\
\hline Gbp (g/rpm) & & 2,12 \\
\hline Work Index & $\mathrm{h} / \mathrm{st}$ ) & 9,9 \\
\hline Work Index & & 10,9 \\
\hline
\end{tabular}

O resultado do ensaio de abrasividade de Bond é apresentado na tabela 25.

Tabela 25 - Resultado do ensaio de abrasividade

\begin{tabular}{|c|c|}
\hline \multicolumn{2}{|c|}{ Abrasividade } \\
\hline ai (g) & Classificação \\
\hline 0,493 & Moderadamente A \\
\hline
\end{tabular}

Os resultados do ensaio de moabilidade de Donda estão apresentados na tabela 26. 
Tabela 26 - Resultados do ensaio de moabilidade de Donda

\begin{tabular}{ccccc}
\hline Ensaio & Tempo (min) & Energia (kWh/t) & $\%>0,150 ~ \mathbf{~ m m}$ & Valor de K \\
\hline $\mathbf{1}$ & 0 & 0,00 & 70,8 & \\
$\mathbf{2}$ & 10 & 3,71 & 33,0 & \\
$\mathbf{3}$ & 20 & 7,43 & 19,6 & 0,161 \\
$\mathbf{4}$ & 30 & 11,14 & 10,2 & \\
$\mathbf{5}$ & 40 & 14,85 & 5,9 & \\
$\mathbf{6}$ & 50 & 18,57 & 4,6 & \\
\hline
\end{tabular}

A figura 51 mostra a curva do percentual retido em $0,15 \mathrm{~mm}$ em função da energia de moagem aplicada, com determinação do valor de k por regressão exponencial.

Figura 51- Resultados dos ensaios de moabilidade de Donda

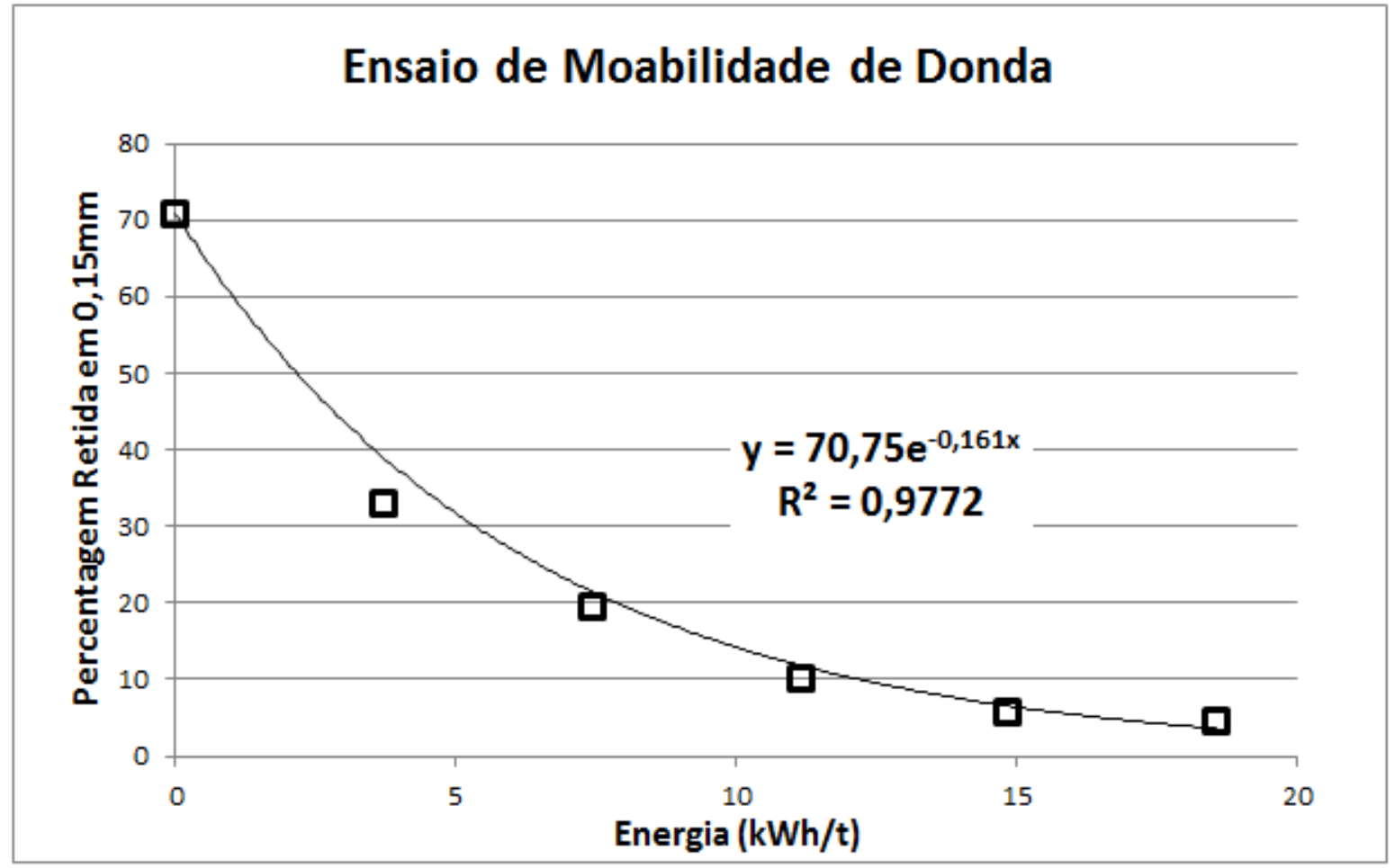

Fonte: Pinto (2015) 


\subsection{Resultados do Ensaio Industrial de Britagem}

Para avaliação da eficiência de britagem, foram realizadas três amostragens da alimentação e descarga do britador terciário, todas para uma abertura na posição fechada (APF) de $25 \mathrm{~mm}$. Para cada amostragem, foi determinada a curva de eficiência de britagem por faixa granulométrica. A partir das eficiências de britagem obtidas em cada amostragem, foi calculada uma eficiência média de britagem. A eficiência na malha de $38 \mathrm{~mm}$ da amostra 02 foi desconsiderada em função de inconsistência na granulometria de descarga do britador. Os resultados completos da granulometria do teste industrial de britagem estão contidos no apêndice $A$.

O gráfico da figura 52 mostra as curvas de eficiência de cada amostra, e a curva média considerada, com destaque para a eficiência de britagem das nas malhas de $50 \mathrm{~mm}, 31,5 \mathrm{~mm}, 25 \mathrm{~mm}, 19 \mathrm{~mm}, 12,5 \mathrm{~mm}, 8,0 \mathrm{~mm}, 6,3 \mathrm{~mm}$, e $0,15 \mathrm{~mm}$.

Figura 52- Curva de Eficiência de Britagem

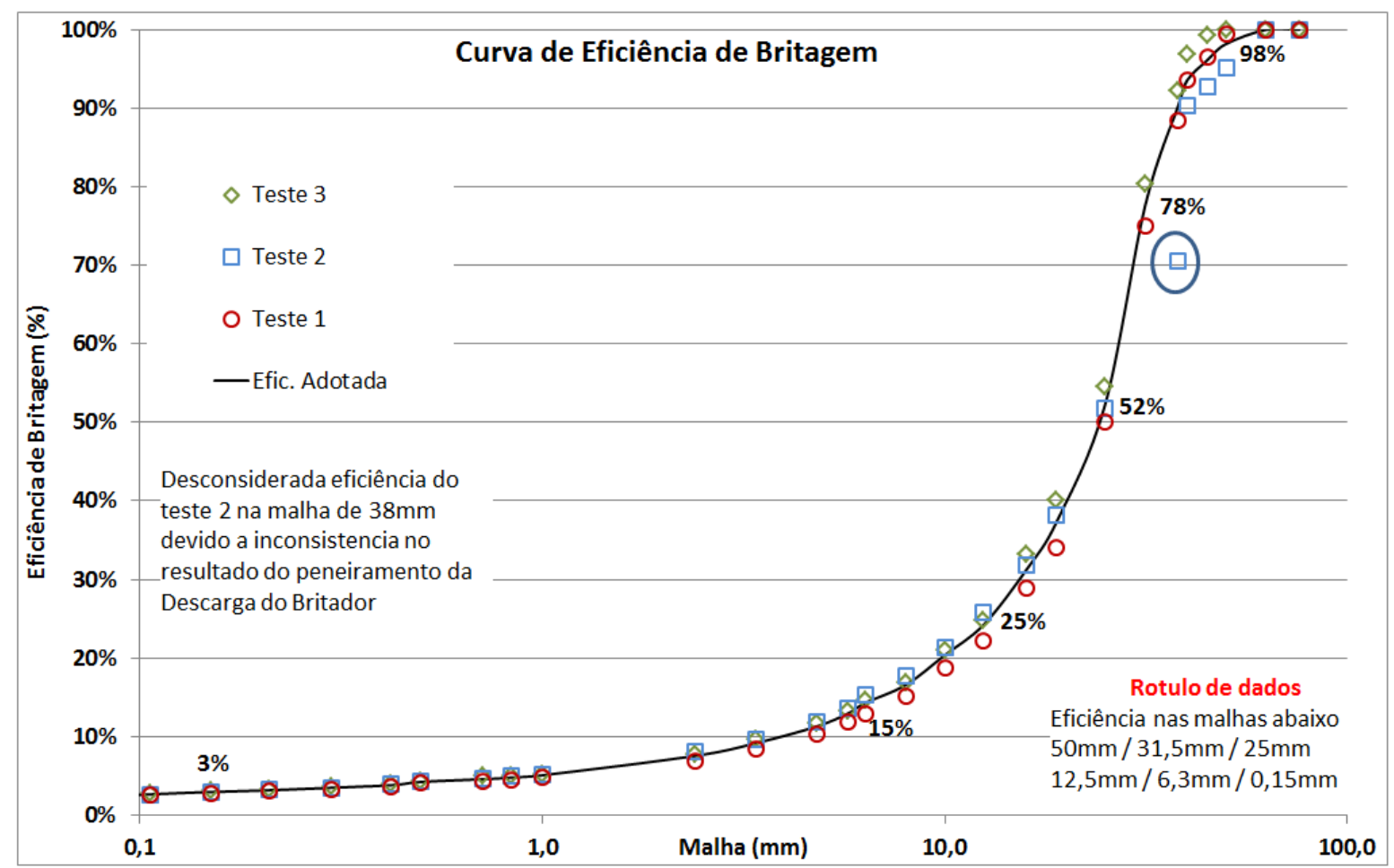

Fonte: Pinto (2015)

Além da eficiência de britagem, foi avaliada também a vazão mássica no britador HP 300, no qual foi realizado o ensaio. A tabela 27 mostra as vazões 
mássicas calculadas durante as três amostragens realizadas, e a tabela 28 , o valor de capacidade para o britador modelo HP 300 descritos no manual de britagem (Metso Minerals 2005) fornecido pelo fabricante do equipamento.

Tabela 27 - Resultados de Vazão Mássica do Ensaio Industrial de Britagem

\begin{tabular}{cccc}
\hline Parâmetro & Teste 01 & Teste 02 & Teste 03 \\
\hline Massa (Kg) & 46,11 & 45,23 & 48,15 \\
Velocidade do TC (m/s) & 2,23 & 2,23 & 2,23 \\
Vazão (t/h) & $\mathbf{3 7 0}$ & $\mathbf{3 6 2}$ & $\mathbf{3 8 6}$ \\
\hline
\end{tabular}

Tabela 28 - Capacidade de Catálogo do Britador do Ensaio Industrial de Britagem

\begin{tabular}{|c|c|c|c|c|c|c|c|}
\hline \multirow[t]{2}{*}{ Equipamento } & \multirow{2}{*}{$\begin{array}{l}\text { Abertura na Posição } \\
\text { Fechada (mm) }\end{array}$} & \multicolumn{3}{|c|}{$\begin{array}{c}\text { Capacidade }(\mathrm{t} / \mathrm{h}) \\
\text { Cálcario Densidade } 1,6 \mathrm{t} / \mathrm{m}^{3}\end{array}$} & \multicolumn{3}{|c|}{$\begin{array}{c}\text { Capacidade (t/h) } \\
\text { Minério de Ferro Densidade } 2,2 \mathrm{t} / \mathrm{m}^{2}\end{array}$} \\
\hline & & Mínimo & Médio & Máximo & Mínimo & Médio & Máximo \\
\hline HP 300 & 25 & 230 & 255 & 280 & 316 & 351 & 385 \\
\hline
\end{tabular}

Fonte: Metso (2005) Adaptado pelo autor

De acordo com os resultados mostrados nas tabelas 28 e 29, a capacidade do britador fornecida pelo fabricante foi coerente com os valores obtidos no ensaio industrial com itabiritos compactos. Dessa forma, adotou-se como válida, neste trabalho, a utilização de dados de catálogo para dimensionamento de britadores cônicos em uma usina para beneficiamento de itabiritos compactos. 


\subsection{Resultados dos Ensaios Piloto de Moagem de Bolas e SAG}

Os resultados dos ensaios piloto de moagem em moinho de bolas e moagem em moinhos SAG são apresentados, já ajustados e reconciliados, ou seja, com o balanço de massa já fechado.

O balanço de massa do ensaio piloto de moagem em moinho de bolas, realizados com material britado em $12,5 \mathrm{~mm}$, para a rota convencional, está representado na tabela 29.

Tabela 29 - Balanço de Massa do Ensaio Piloto de Moagem de Bolas

\begin{tabular}{ccccccc}
\hline Fluxo & $\begin{array}{c}\text { Alimentaçäo } \\
\text { do Moinho }\end{array}$ & $\begin{array}{c}\text { Descarga do } \\
\text { Moinho }\end{array}$ & $\begin{array}{c}\text { Oversize do } \\
\text { Tromell }\end{array}$ & $\begin{array}{c}\text { Undersize do } \\
\text { Tromell }\end{array}$ & $\begin{array}{c}\text { Underflow } \\
\text { do Ciclone }\end{array}$ & $\begin{array}{c}\text { Overflowdo } \\
\text { Ciclone }\end{array}$ \\
\hline Vazão (t/h) & 13,6 & 13,6 & 0,5 & 13,1 & 10,1 & 3,0 \\
Vazão (\%) & 394,2 & 394,2 & 14,2 & 379,7 & 293,9 & 85,8 \\
\% Solidos & 78,3 & 78,3 & 97,0 & 77,7 & 77,7 & 33,1 \\
Densidade de Polpa $\left(\mathrm{t} / \mathrm{m}^{3}\right)$ & 2,39 & 2,39 & 3,57 & 2,36 & 2,36 & 1,33 \\
Volume de Polpa $\left(\mathrm{m}^{3} / \mathrm{h}\right)$ & 7,3 & 7,3 & 0,1 & 7,1 & 5,5 & 6,8 \\
\% & $23,15 \mathrm{~mm}$ & 34,9 & 1,7 & 36,1 & 21,6 & 85,8 \\
P 80 (mm) & 3,14 & 1,23 & 9,84 & 0,92 & 1,50 & 0,12 \\
\hline
\end{tabular}

O gráfico da figura 53 mostra a granulometria da alimentação nova, alimentação do moinho, descarga do moinho, e overflow do ciclone, obtidos no teste piloto. A granulometria completa de todos os fluxos do teste piloto de moagem de bolas se encontra no apêndice $B$. 
Figura 53- Granulometria - Ensaio Piloto Moagem de Bolas

Granulometria - Ensaio Piloto Moagem de Bolas

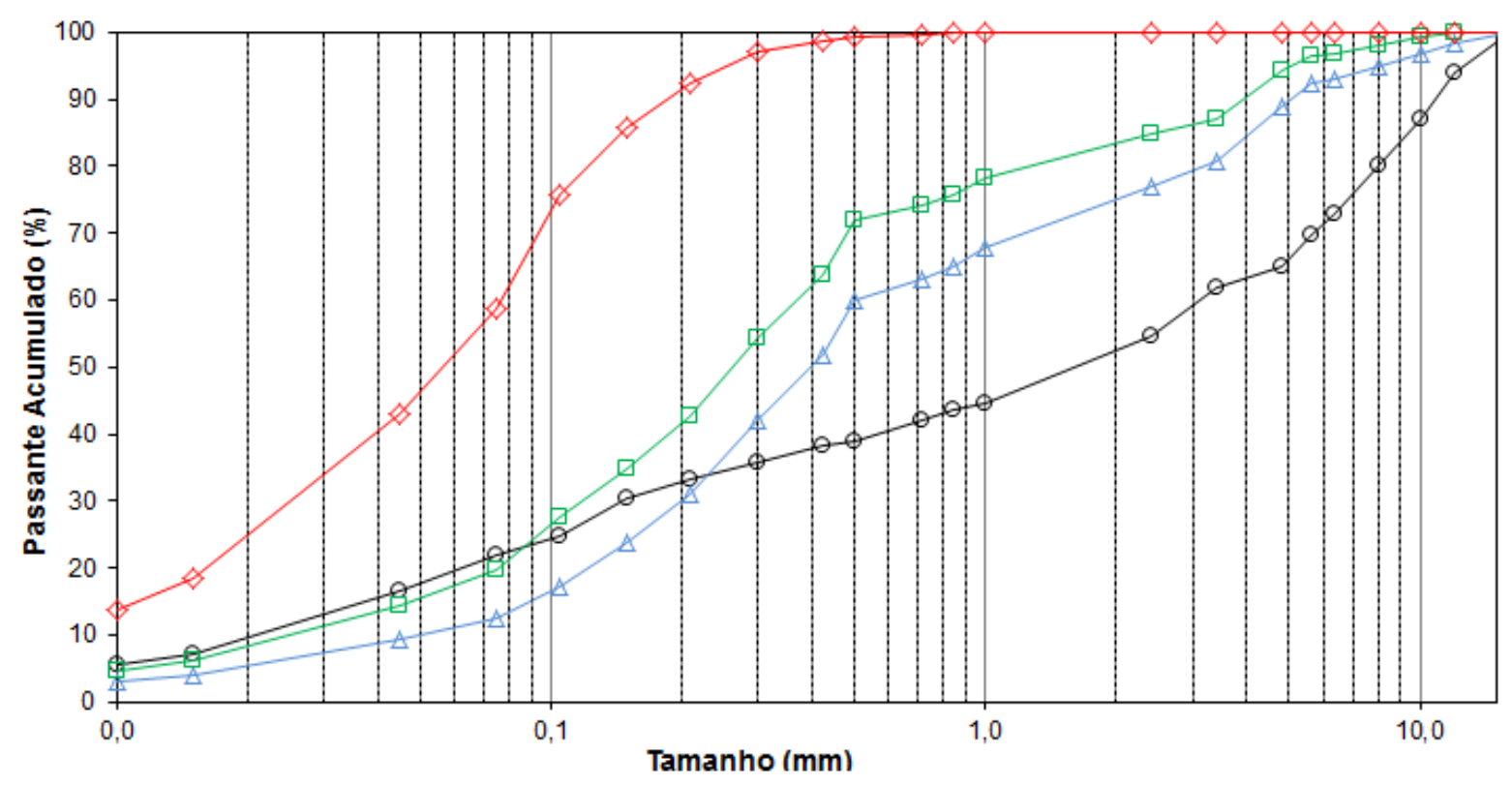

$\bullet$ Alimentação Nova $\triangle$ Alimentação do Moinho $\square$ Descarga do Moinho $\bullet$ Produto da Moagem

Fonte: Pinto (2015)

O consumo de energia calculado a partir de medidas realizadas durante a condução do ensaio piloto de moagem em moinho de bolas, bem como o consumo calculado com base na pela equação de Rowland, estão representados na tabela 30 .

Tabela 30 - Consumo de Energia do Ensaio Piloto de Moagem de Bolas

\begin{tabular}{ccc}
\hline Parâmetro & $\begin{array}{c}\text { Consumo } \\
\text { Total (kWh) }\end{array}$ & $\begin{array}{c}\text { Consumo } \\
\text { Específico (kWh/t) }\end{array}$ \\
\hline Consumo Medido Total de Energia & 27,3 & 7,9 \\
Consumo Medido Efetivo de Energia & 23,5 & 6,8 \\
Consumo de Energia - Equação de Rowland & 24,8 & 7,2 \\
\hline
\end{tabular}

A diferença entre o consumo medido de energia e o consumo calculado a partir da equação de Rowland decorre de que, esta última deve ser utilizada apenas para moinhos com diâmetro maiores que 2,4 m, enquanto que o diâmetro do moinho do ensaio piloto de moagem de bolas é de 1,5 metros. Dessa forma, na análise dos 
resultados e no dimensionamento dos equipamentos, adotou-se utilizar somente o consumo medido de energia.

Os balanços de massa dos ensaios piloto de moagem SAG estão nas tabelas 31 a 36 , que se seguem.

Tabela 31 - Balanço de Massas do Ensaio Piloto de Moagem SAG 1

\begin{tabular}{|c|c|c|c|c|c|c|c|c|}
\hline Fluxo & $\begin{array}{c}\text { Alimentação } \\
\text { Nova }\end{array}$ & $\begin{array}{c}\text { Alimentação } \\
\text { do Moinho }\end{array}$ & $\begin{array}{c}\text { Descarga do } \\
\text { Moinho }\end{array}$ & $\begin{array}{c}\text { Oversize do } \\
\text { Tromell }\end{array}$ & $\begin{array}{c}\text { Undersize do } \\
\text { Tromell }\end{array}$ & $\begin{array}{c}\text { Descarga do } \\
\text { Britador }\end{array}$ & $\begin{array}{l}\text { Underflow do } \\
\text { Classificador }\end{array}$ & $\begin{array}{l}\text { Overflow do } \\
\text { Classificador }\end{array}$ \\
\hline Vazão e Alimentação (t/h) & 1,7 & 1,9 & 1,9 & 0,2 & 1,7 & 0,2 & 1,1 & 0,7 \\
\hline Vazão (\%) & 100,0 & 110,8 & 110,8 & 10,8 & 100,0 & 10,8 & 62,0 & 38,0 \\
\hline$\%$ Solidos & 98,9 & 79,0 & 79,0 & 99,5 & 77,3 & 99,5 & 86,1 & 56,1 \\
\hline Densidade de Polpa $\left(t / m^{3}\right)$ & 3,8 & 2,4 & 2,4 & 3,8 & 2,3 & 3,8 & 2,8 & 1,7 \\
\hline Volume de Polpa $\left(\mathrm{m}^{3} / \mathrm{h}\right)$ & 0,5 & 1,0 & 1,0 & 0,0 & 1,0 & 0,0 & 0,4 & 0,7 \\
\hline
\end{tabular}

Tabela 32 - Balanço de Massas do Ensaio Piloto de Moagem SAG 2

\begin{tabular}{|c|c|c|c|c|c|c|c|}
\hline Fluxo & $\begin{array}{c}\text { Alimentação } \\
\text { Nova }\end{array}$ & $\begin{array}{c}\text { Alimentação do } \\
\text { Moinho }\end{array}$ & $\begin{array}{c}\text { Descarga do } \\
\text { Moinho }\end{array}$ & $\begin{array}{l}\text { Oversize do } \\
\text { Tromell }\end{array}$ & $\begin{array}{c}\text { Undersize do } \\
\text { Tromell }\end{array}$ & $\begin{array}{l}\text { Underflow do } \\
\text { Classificador }\end{array}$ & $\begin{array}{l}\text { Overflow do } \\
\text { Classificador }\end{array}$ \\
\hline Vazão (t/h) & 1,5 & 1,5 & 1,5 & 0,1 & 1,5 & 0,9 & 0,6 \\
\hline \% Solidos & 98,9 & 78,0 & 78,0 & 99,7 & 77,0 & 85,0 & 55,8 \\
\hline Densidade de Polpa $\left(t / \mathrm{m}^{3}\right)$ & 3,8 & 2,4 & 2,4 & 3,8 & 2,3 & 2,7 & 1,7 \\
\hline Volume de Polpa $\left(m^{3} / \mathrm{h}\right)$ & 0,4 & 0,8 & 0,8 & 0,0 & 0,8 & 0,4 & 0,6 \\
\hline
\end{tabular}

Tabela 33 - Balanço de Massas do Ensaio Piloto de Moagem SAG 3

\begin{tabular}{|c|c|c|c|c|c|c|c|}
\hline Fluxo & $\begin{array}{c}\text { Alimentação } \\
\text { Nova }\end{array}$ & $\begin{array}{c}\text { Alimentação do } \\
\text { Moinho }\end{array}$ & $\begin{array}{c}\text { Descarga do } \\
\text { Moinho }\end{array}$ & $\begin{array}{c}\text { Oversize do } \\
\text { Tromell }\end{array}$ & $\begin{array}{l}\text { Undersize do } \\
\text { Tromell }\end{array}$ & $\begin{array}{l}\text { Underflow do } \\
\text { Classificador }\end{array}$ & $\begin{array}{l}\text { Overflow do } \\
\text { Classificador }\end{array}$ \\
\hline Vazão (t/h) & 1,2 & 1,5 & 1,5 & 0,3 & 1,2 & 0,4 & 0,7 \\
\hline$\%$ Solidos & 98,7 & 78,1 & 78,1 & 99,0 & 74,5 & 89,9 & 62,0 \\
\hline Densidade de Polpa $\left(t / \mathrm{m}^{3}\right)$ & 3,7 & 2,4 & 2,4 & 3,8 & 2,2 & 3,0 & 1,9 \\
\hline P $80(\mathrm{~mm})$ & 51,5 & 46,9 & 12,6 & 18,6 & 1,6 & 9,4 & 0,09 \\
\hline
\end{tabular}

Tabela 34 - Balanço de Massas do Ensaio Piloto de Moagem SAG 4

\begin{tabular}{|c|c|c|c|c|c|c|c|}
\hline Fluxo & $\begin{array}{c}\text { Alimentação } \\
\text { Nova }\end{array}$ & $\begin{array}{c}\text { Alimentação do } \\
\text { Moinho }\end{array}$ & $\begin{array}{c}\text { Descarga do } \\
\text { Moinho }\end{array}$ & $\begin{array}{l}\text { Oversize do } \\
\text { Tromell }\end{array}$ & $\begin{array}{c}\text { Undersize do } \\
\text { Tromell }\end{array}$ & $\begin{array}{l}\text { Underflow do } \\
\text { Classificador }\end{array}$ & $\begin{array}{l}\text { Overflow do } \\
\text { Classificador }\end{array}$ \\
\hline Vazão (\%) & 100,0 & 585,0 & 585,0 & 9,4 & 575,7 & 475,7 & 100,0 \\
\hline Densidade de Polpa $\left(t / \mathrm{m}^{3}\right)$ & 3,69 & 2,35 & 2,35 & 3,77 & 2,33 & 2,79 & 1,61 \\
\hline Volume de Polpa $\left(\mathrm{m}^{3} / \mathrm{h}\right)$ & 0,3 & 3,0 & 3,0 & 0,0 & 3,0 & 1,8 & 1,1 \\
\hline$\%<0.15 \mathrm{~mm}$ & 16,1 & 25,6 & 38,8 & 0,0 & 39,4 & 28,1 & 93,0 \\
\hline
\end{tabular}


Tabela 35 - Balanço de Massas do Ensaio Piloto de Moagem SAG 5

\begin{tabular}{|c|c|c|c|c|c|c|c|}
\hline Fluxo & $\begin{array}{c}\text { Alimentação } \\
\text { Nova }\end{array}$ & $\begin{array}{c}\text { Alimentação do } \\
\text { Moinho }\end{array}$ & $\begin{array}{c}\text { Descarga do } \\
\text { Moinho }\end{array}$ & $\begin{array}{c}\text { Oversize do } \\
\text { Tromell }\end{array}$ & $\begin{array}{c}\text { Undersize do } \\
\text { Tromell } \\
\end{array}$ & $\begin{array}{l}\text { Underflow do } \\
\text { Classificador }\end{array}$ & $\begin{array}{l}\text { Overflow do } \\
\text { Classificador }\end{array}$ \\
\hline Vazão (t/h) & 0,9 & 1,9 & 1,9 & 0,3 & 1,7 & 0,8 & 0,9 \\
\hline Vazão (\%) & 100,0 & 216,0 & 216,0 & 31,2 & 184,8 & 84,8 & 100,0 \\
\hline$\%$ Solidos & 98,7 & 79,0 & 79,0 & 99,1 & 76,4 & 90,4 & 67,5 \\
\hline Densidade de Polpa $\left(\mathrm{t} / \mathrm{m}^{3}\right)$ & 3,75 & 2,42 & 2,42 & 3,78 & 2,31 & 3,04 & 2,00 \\
\hline Volume de Polpa $\left(\mathrm{m}^{3} / \mathrm{h}\right)$ & 0,2 & 1,0 & 1,0 & 0,1 & 0,9 & 0,3 & 0,7 \\
\hline
\end{tabular}

Os gráficos das figuras 54 a 56 mostram a granulometria da alimentação nova, descarga do moinho, underflow do trommel e overflow do classificador obtidos nos ensaios piloto de moagem SAG para a rota SAB (SAG 1, SAG 2 e SAG 3). As granulometrias completas de todos os fluxos dos ensaios piloto de moagem SAG se encontram no apêndice C.

Figura 54- Granulometria - Ensaio Piloto de Moagem SAG 1

Granulometria - Ensaio Piloto de Moagem SAG 1

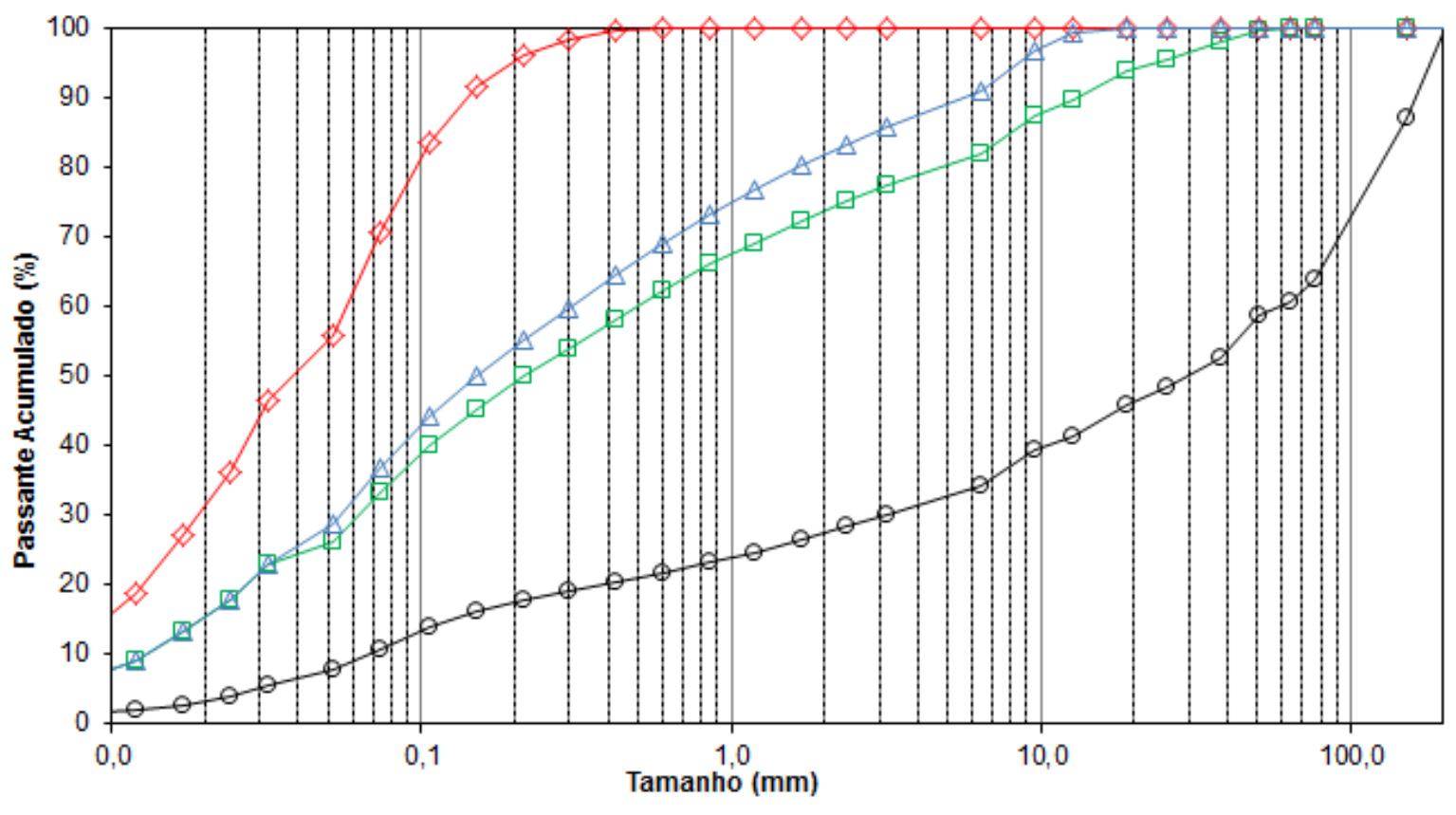

$\smile$ Alimentação Nova $\square$ Descarga do Moinho $\smile$ Overflow do Classificador $\triangle \triangle$ Undersize do Tromell

Fonte: Pinto (2015) 
Figura 55- Granulometria - Ensaio Piloto de Moagem SAG 2

Granulometria - Ensaio Piloto de Moagem SAG 2

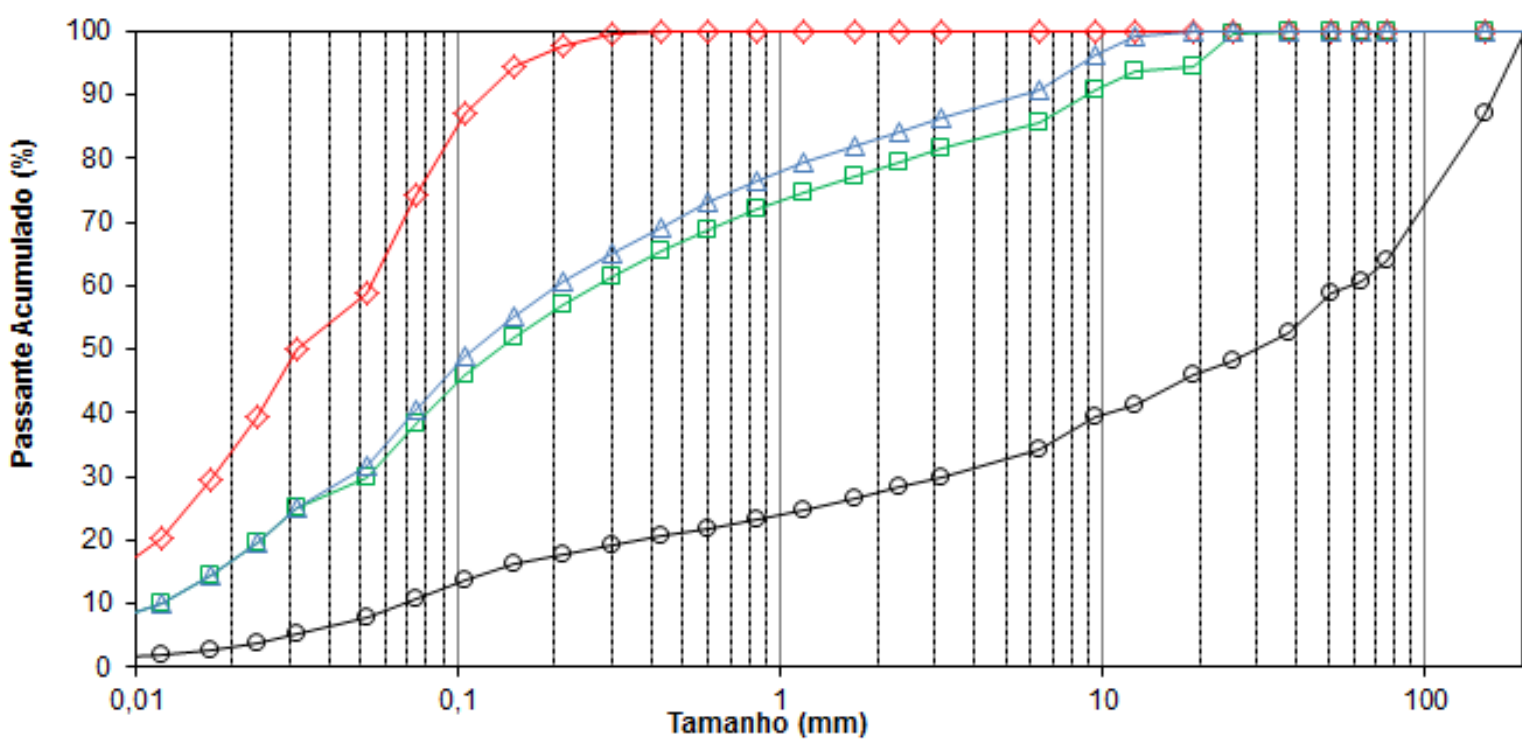

๑Alimentação Nova $\square$-Descarga do Moinho $\smile$ Overflow do Classificador $\triangle$ Undersize do Tromell

Fonte: Pinto (2015)

Figura 56- Granulometria - Ensaio Piloto de Moagem SAG 3

Granulometria - Ensaio Piloto de Moagem SAG 3

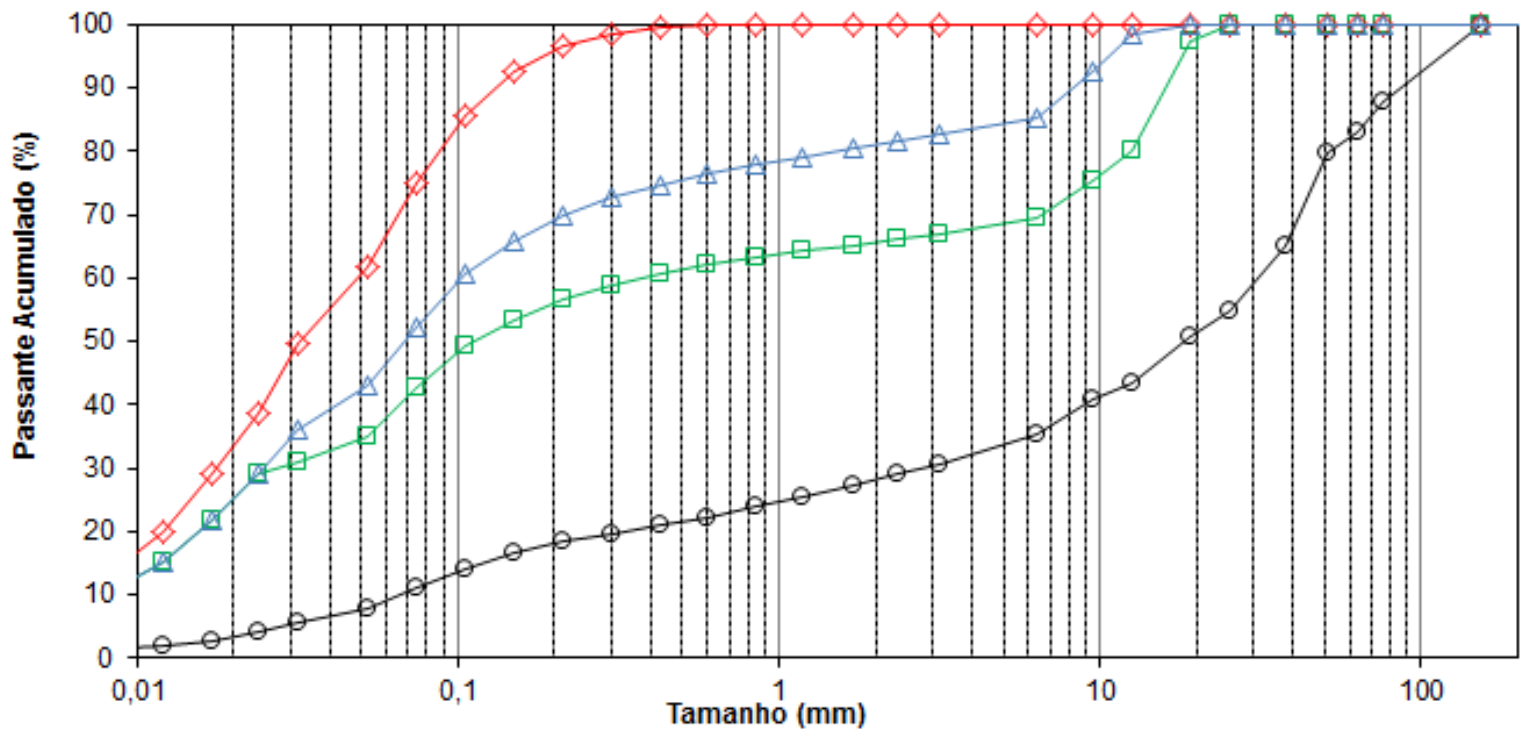

$\multimap$ Alimentação Nova $\square$ Descarga do Moinho $\rightarrow$ Overflow do Classificador $\triangle$ Undersize do Tromell

Fonte: Pinto (2015)

Os gráficos das figuras 57 e 58 mostram as granulometrias da alimentação nova, alimentação total do moinho, undersize do trommel e overflow do classificador obtidos nos ensaios piloto de moagem SAG para a rota SSSAG (SAG 4 e SAG 5). 
Figura 57- Granulometria - Ensaio Piloto de Moagem SAG 4

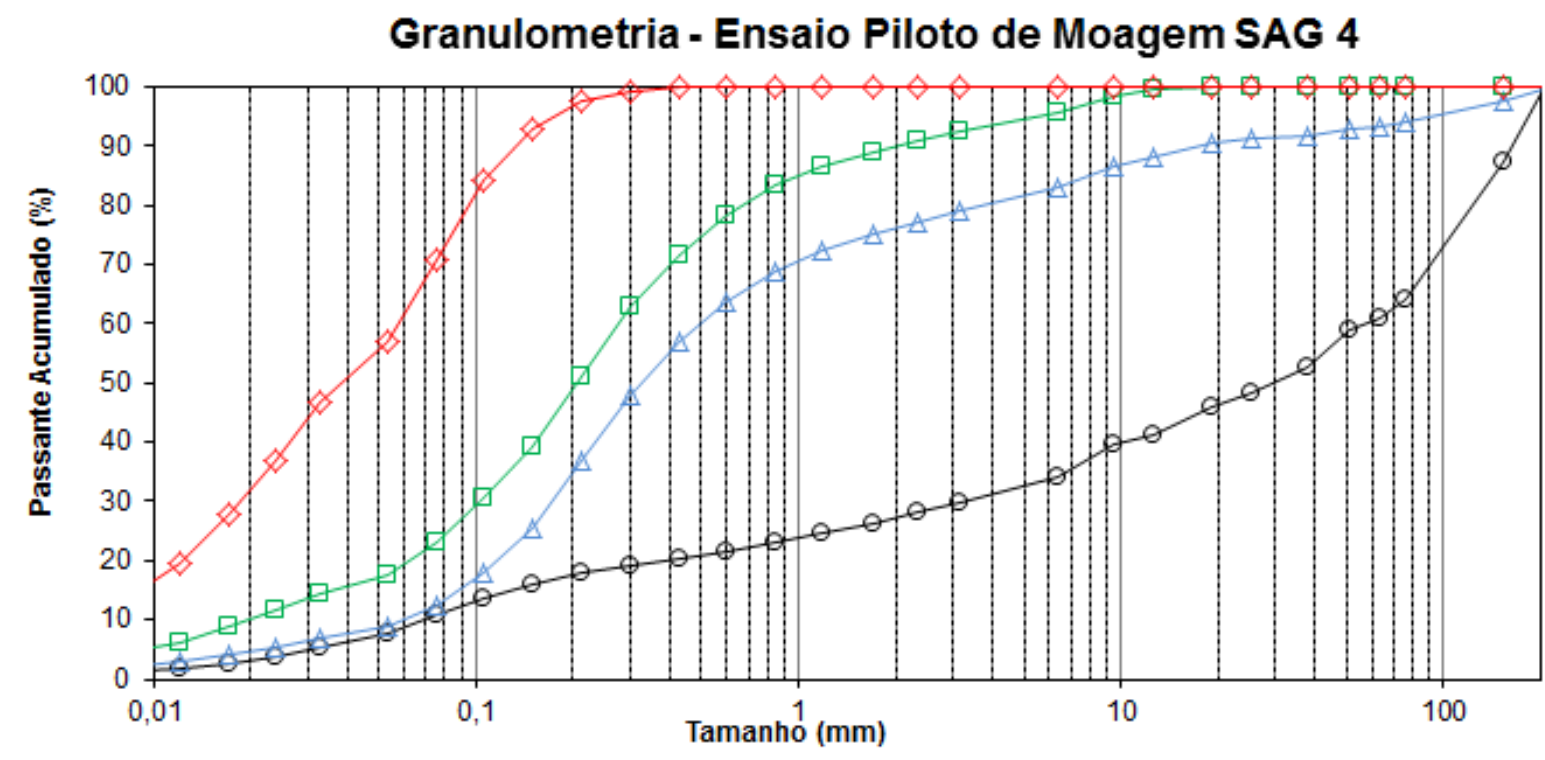

$\smile$ Alimentação Nova $\triangle$ Alimentação do Moinho $\square$ Undersize do Tromell $\smile$ Overflow do Classificador

Fonte: Pinto (2015)

Figura 58- Granulometria - Ensaio Piloto de Moagem SAG 5

\section{Granulometria - Ensaio Piloto de Moagem SAG 5}

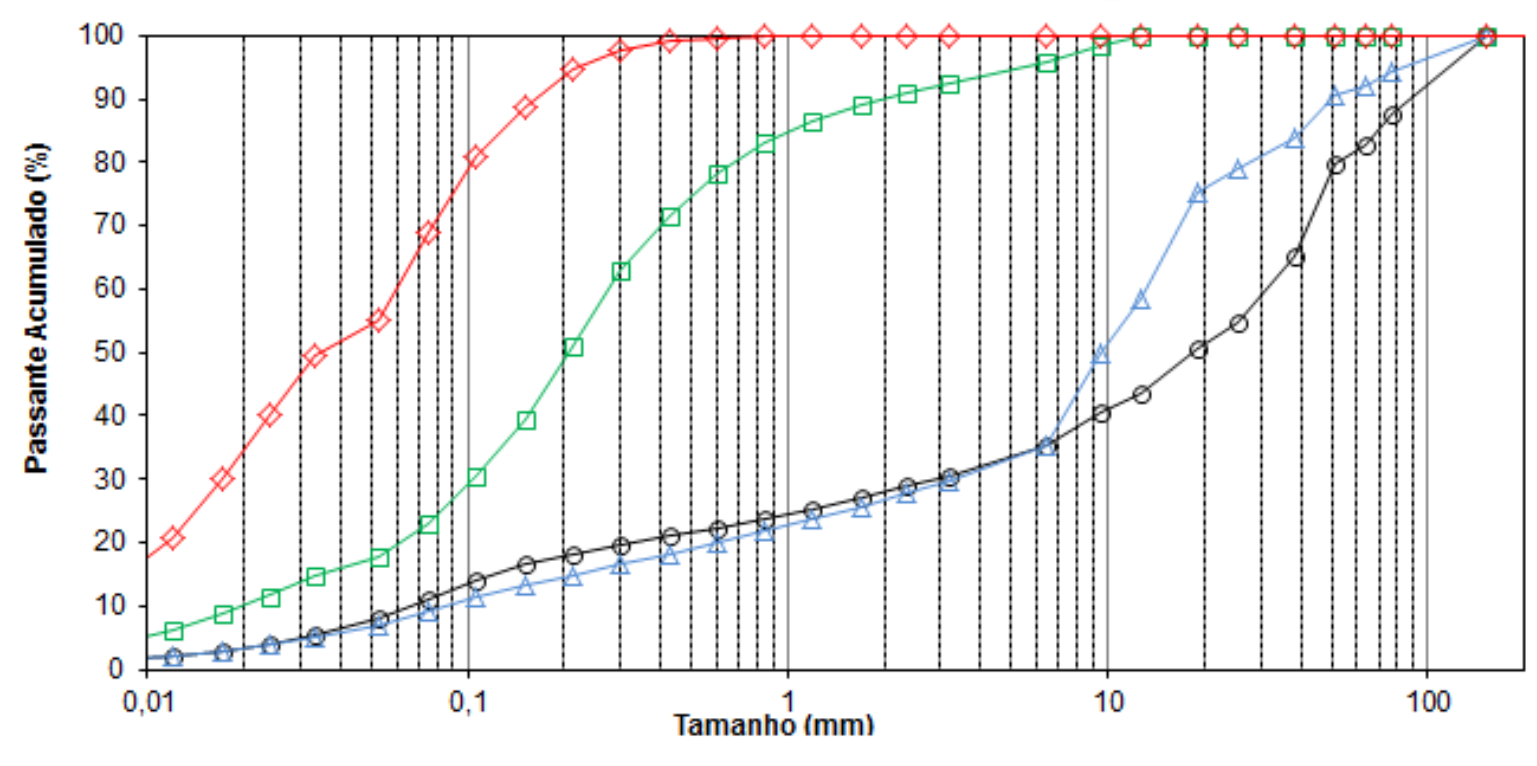

$\smile$ Alimentação Nova $\triangle$ Alimentação do Moinho $\square$ Undersize do Tromell $\prec$ Overflow do Classificador

Fonte: Pinto (2015)

O consumo de energia calculado a partir de medidas obtidas durante a realização dos ensaios piloto de moagem SAG, bem como o consumo calculado a 
partir da equação de Austin, estão representados na tabela 36. Para o ensaio SAG 3 , como não foi realizada a medição da carga interna do moinho SAG, não foi possível calcular o consumo de energia pela equação de Austin. Conforme prática operacional do CIMM, são acrescentados quatro pontos percentuais na carga de bola para cálculo do consumo de energia pela equação de Austin.

Tabela 36 - Consumo de Energia dos Ensaios Piloto de Moagem SAG

\begin{tabular}{cccc}
\hline \multirow{2}{*}{ Ensaio } & Parâmetro & $\begin{array}{c}\text { Consumo Total } \\
\text { (kWh) }\end{array}$ & $\begin{array}{c}\text { Consumo } \\
\text { Especifico (kWh/t) }\end{array}$ \\
\hline \multirow{2}{*}{ SAG 1 } & Consumo Medido Total de Energia & 13,7 & 7,9 \\
& Consumo Medido Efetivo de Energia & 11,2 & 6,5 \\
& Consumo de Energia - Equação de Austin & 12,0 & 6,9 \\
\hline \multirow{2}{*}{ SAG 2 } & Consumo Medido Total de Energia & 14,1 & 9,7 \\
& Consumo Medido Efetivo de Energia & 11,7 & 8,0 \\
\multirow{2}{*}{ SAG 3 } & Consumo de Energia - Equação de Austin & 11,8 & 8,1 \\
& Consumo Medido Total de Energia & 15,6 & 13,2 \\
& Consumo Medido Efetivo de Energia & 13,2 & 11,1 \\
& Consumo de Energia - Equação de Austin & $\mathrm{ND}$ & $\mathrm{ND}$ \\
\hline \multirow{2}{*}{ SAG 4 } & Consumo Medido Total de Energia & 14,1 & 15,2 \\
& Consumo Medido Efetivo de Energia & 11,7 & 12,6 \\
& Consumo de Energia - Equação de Austin & 11,9 & 12,9 \\
\hline \multirow{2}{*}{ SAG 5 } & Consumo Medido Total de Energia & 15,7 & 17,5 \\
& Consumo Medido Efetivo de Energia & 13,2 & 14,7 \\
& Consumo de Energia - Equação de Austin & 12,9 & 14,3 \\
\hline
\end{tabular}

Os resultados das medições da carga interna do moinho SAG para os ensaios SAG 1, 2, 4 e 5, estão listados na tabela 37. Para o ensaio SAG 3, não foi medida a carga interna do moinho. A figura 59 mostra a carga interna do moinho SAG para os ensaios realizados. 
Tabela 37 - Análise da Carga Interna dos Testes de Moagem SAG

\begin{tabular}{|c|c|c|c|c|}
\hline Ensaio & SAG 1 & SAG 2 & SAG 4 & SAG 5 \\
\hline \% Enchimento do Moinho & 21,1 & 20,2 & 20,4 & 18,5 \\
\hline Peso seco da carga $(\mathrm{kg})$ & 749 & 746 & 787 & 759 \\
\hline Volume da carga $\left(\mathrm{m}^{3}\right)$ & 0,3 & 0,3 & 0,3 & 0,2 \\
\hline Densidade Aparente $\left(t / \mathrm{m}^{3}\right)$ & 2,6 & 2,7 & 2,9 & 3,1 \\
\hline$\%<0.15 \mathrm{~mm}$ & 3,0 & 3,4 & 3,6 & 4,3 \\
\hline P $80(\mathrm{~mm})$ & 131,4 & 123,5 & 121,3 & 66,1 \\
\hline \multicolumn{5}{|c|}{ Granulometria (Passante Acumulado) } \\
\hline Malha $(\mathrm{mm})$ & SAG 1 & SAG 2 & SAG 4 & SAG 5 \\
\hline 203,2 & 100,0 & 100,0 & 100,0 & 100,0 \\
\hline 152,4 & 91,6 & 90,4 & 95,4 & 100,0 \\
\hline 127,0 & 77,6 & 83,3 & 83,8 & 100,0 \\
\hline 101,6 & 61,2 & 59,3 & 66,9 & 100,0 \\
\hline 76,2 & 46,4 & 47,9 & 50,5 & 100,0 \\
\hline 50,80 & 28,9 & 32,2 & 35,6 & 82,8 \\
\hline 25,40 & 11,4 & 11,8 & 15,7 & 40,2 \\
\hline 12,70 & 7,2 & 6,2 & 12,1 & 16,8 \\
\hline 9,53 & 6,6 & 5,6 & 11,8 & 13,7 \\
\hline 6,35 & 5,9 & 5,1 & 11,0 & 9,2 \\
\hline 1,180 & 4,6 & 4,4 & 9,3 & 5,6 \\
\hline 0,850 & 4,4 & 4,3 & 8,8 & 5,4 \\
\hline 0,150 & 3,0 & 3,4 & 3,6 & 4,3 \\
\hline
\end{tabular}


Figura 59- Carga Interna dos Ensaios de Moagem SAG
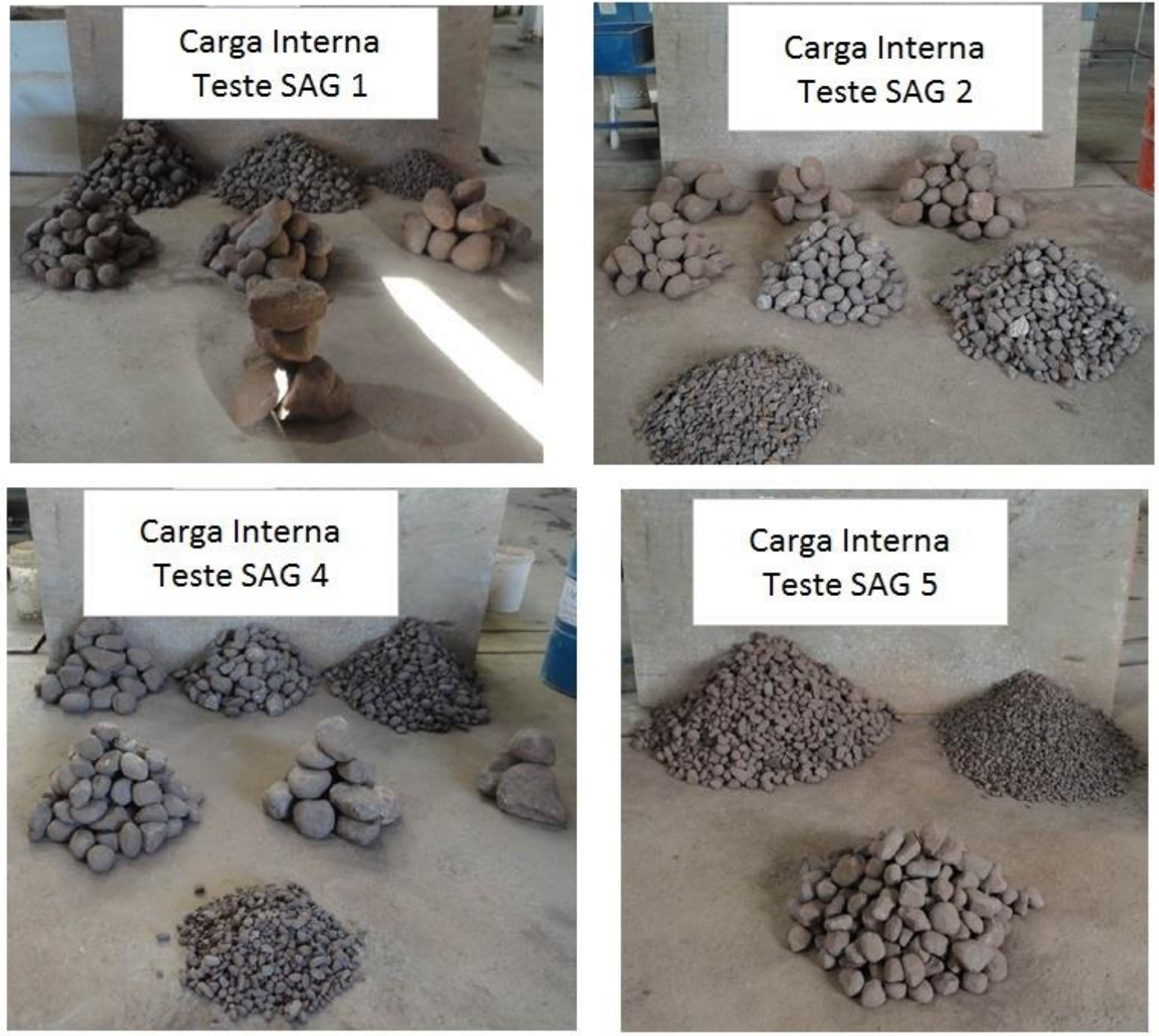

Fonte: Pinto (2015)

Os balanços de massa dos ensaios piloto de moagem em moinho de bolas, realizados com o underflow do classificador espiral dos ensaios SAG 1 e 2, estão apresentados nas tabelas 38 e 39. Estes ensaios serão denominados, respectivamente, MB1 e MB2 para diferenciá-los do ensaio piloto de moagem em moinho de bolas para a rota convencional. 
Tabela 38 - Resultados do Ensaio Piloto de Moagem de Bolas para a Rota SAG (MB1)

\begin{tabular}{cccccc}
\hline Fluxo & $\begin{array}{c}\text { Alimentação } \\
\text { Nova }\end{array}$ & $\begin{array}{c}\text { Alimentação do } \\
\text { Moinho }\end{array}$ & $\begin{array}{c}\text { Descarga do } \\
\text { Moinho }\end{array}$ & $\begin{array}{c}\text { Underflow do } \\
\text { Classificador }\end{array}$ & $\begin{array}{c}\text { Overflow do } \\
\text { Classificador }\end{array}$ \\
\hline Vazão (t/h) & 0,6 & 1,9 & 1,9 & 1,3 & 0,6 \\
Vazão (\%) & 100,0 & 321,2 & 321,2 & 221,2 & 100,0 \\
\% Solidos & 98,1 & 74,0 & 74,0 & 81,1 & 37,5 \\
Densidade de Polpa $\left(\mathrm{t} / \mathrm{m}^{3}\right)$ & 3,85 & 2,26 & 2,26 & 2,57 & 1,39 \\
Volume de Polpa $\left(\mathrm{m}^{3} / \mathrm{h}\right)$ & 0,2 & 1,1 & 1,1 & 0,6 & 1,1 \\
$\%<0.15 \mathrm{~mm}$ & 24,5 & 41,5 & 62,2 & 49,2 & 91,0 \\
P 80 (mm) & 5,12 & 0,54 & 0,24 & 0,29 & 0,10 \\
\hline
\end{tabular}

Tabela 39 - Resultados do Ensaio Piloto de Moagem de Bolas para a Rota SAG (MB 2)

\begin{tabular}{cccccc}
\hline Fluxo & $\begin{array}{c}\text { Alimentação } \\
\text { Nova }\end{array}$ & $\begin{array}{c}\text { Alimentação do } \\
\text { Moinho }\end{array}$ & $\begin{array}{c}\text { Descarga do } \\
\text { Moinho }\end{array}$ & $\begin{array}{c}\text { Underflow do } \\
\text { Classificador }\end{array}$ & $\begin{array}{c}\text { Overflow do } \\
\text { Classificador }\end{array}$ \\
\hline Vazão $(\mathrm{t} / \mathrm{h})$ & 0,6 & 1,9 & 1,9 & 1,3 & 0,6 \\
Vazão $(\%)$ & 100,0 & 321,8 & 321,8 & 221,8 & 100,0 \\
\% Solidos & 98,0 & 74,5 & 74,5 & 81,0 & 37,0 \\
Densidade de Polpa $\left(\mathrm{t} / \mathrm{m}^{3}\right)$ & 3,81 & 2,28 & 2,28 & 2,56 & 1,39 \\
Volume de Polpa $\left(\mathrm{m}^{3} / \mathrm{h}\right)$ & 0,2 & 1,1 & 1,1 & 0,6 & 1,1 \\
\% < $0.15 \mathrm{~mm}$ & 24,2 & 42,0 & 62,7 & 50,0 & 90,7 \\
P 80 $(\mathrm{mm})$ & 5,07 & 0,55 & 0,23 & 0,29 & 0,10 \\
\hline
\end{tabular}

Os gráficos das figuras 60 e 61 mostram as granulometrias da alimentação nova, alimentação do moinho, descarga do moinho e overflow do ciclone para os ensaios MB1 e MB2. 
Figura 60- Granulometria - Ensaio Piloto MB1

Granulometria - Ensaio Piloto MB1

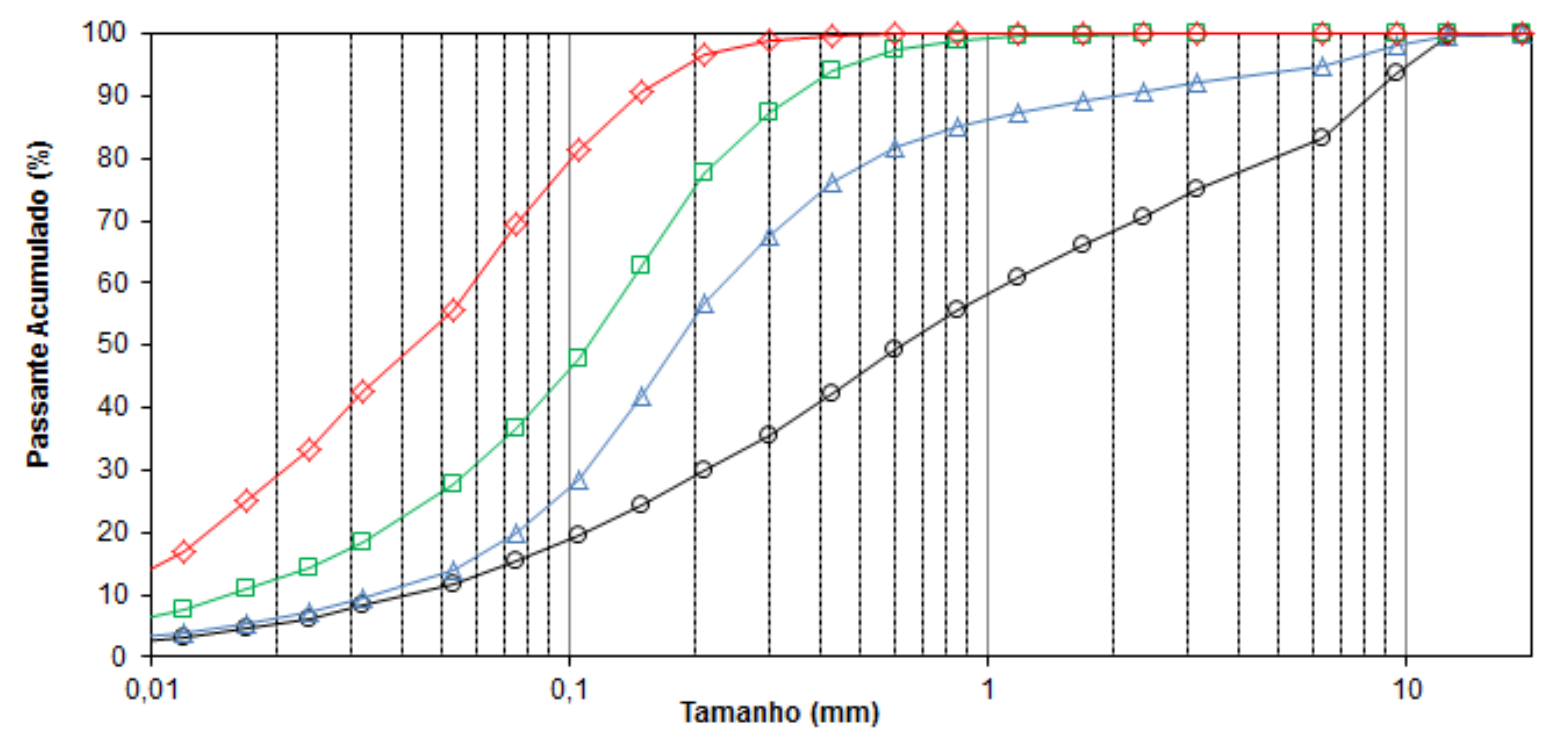

$\neg$ Alimentação Nova $\triangle$ Alimentação do Moin ho $\square$ Descarga do Moinho $\multimap$ Overflow do Ciclone

Fonte: Pinto (2015)

Figura 61- Granulometria - Ensaio Piloto MB2

Granulometria - Ensaio Piloto MB2

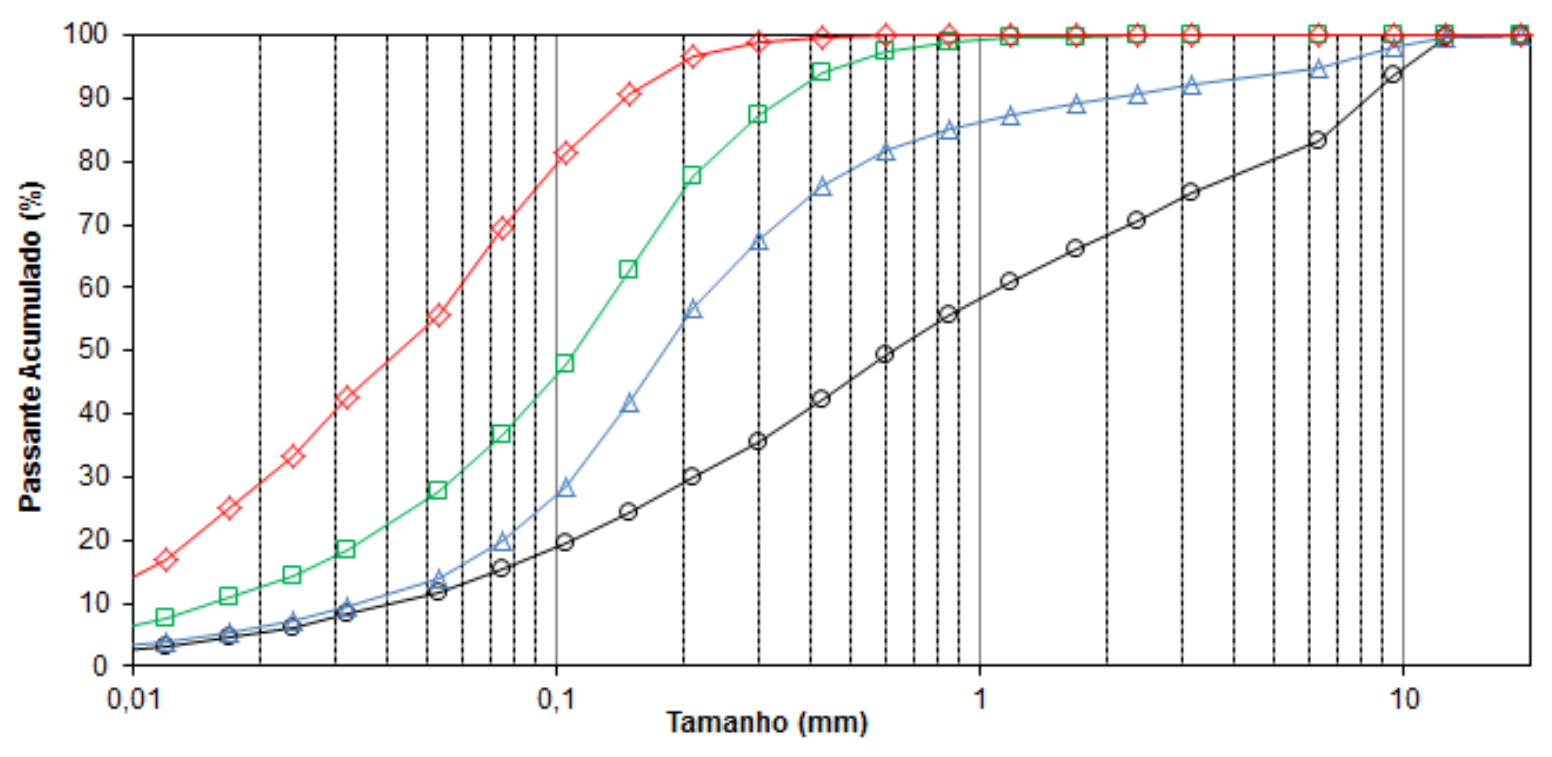

$\rightarrow$ Alimentação Nova $\triangle$ Alimentação do Moinho $\square$ Descarga do Moinho $\rightarrow$ Overflow do Ciclone

Fonte: Pinto (2015)

O consumo de energia calculado a partir de medidas realizadas durante a condução dos ensaios piloto MB1 e MB2, bem como o consumo calculado a partir da equação de Rowland, estão representados na tabela 40. 
Tabela 40 - Consumo de Energia dos Ensaios Piloto MB1 e MB2

\begin{tabular}{cccc}
\hline Ensaio & Parâmetro & $\begin{array}{c}\text { Consumo Total } \\
\mathbf{( k W h )}\end{array}$ & $\begin{array}{c}\text { Consumo } \\
\text { Especifico (kWh/t) }\end{array}$ \\
\hline \multirow{2}{*}{ MB1 } & Consumo Medido Total de Energia & 9,5 & 16,1 \\
& Consumo Medido Efetivo de Energia & 7,5 & 12,7 \\
& Consumo de Energia - Equação de Rowland & 10,8 & 18,3 \\
\hline \multirow{2}{*}{ MB2 } & Consumo Medido Total de Energia & 9,6 & 16,2 \\
& Consumo Medido Efetivo de Energia & 7,5 & 12,8 \\
& Consumo de Energia - Equação de Rowland & 10,8 & 18,4 \\
\hline
\end{tabular}

A diferença entre o consumo medido e o consumo previsto pela equação de Rowland decorre de que esta última deve ser utilizada apenas para moinhos com diâmetro maior que 2,4 metros, enquanto que o diâmetro do moinho do ensaio piloto de moagem de bolas é de 0,91 metros. Dessa forma, adotou-se empregar na análise dos resultados e no dimensionamento dos equipamentos somente o consumo medido de energia. 


\section{DISCUSSÃO DOS RESULTADOS}

A discussão e análise dos resultados obtidos foram conduzidas, inicialmente, de forma individual para cada rota estudada, com a elaboração dos respectivos balanços de massa e o dimensionamento dos equipamentos de processo para 0 circuito de escala industrial correspondente. Posteriormente, foi realizada a comparação dos resultados dos ensaios e dos circuitos dimensionados para as rotas estudadas.

O consumo energético das etapas de moagem foi calculado a partir dos resultados dos ensaios em escala piloto e, posteriormente, comparados aos resultados obtidos pelos métodos de Donda e Bond, a partir dos ensaios em escala de bancada. Para a rota SAB/C foi utilizado diretamente o consumo energético dos ensaios piloto, pois foi considerado como premissa que os resultados dos ensaios são próximos às do circuito industrial correspondente. Para as rotas SSSAG e convencional, foi necessária a realização de simulações, via simulador JKSimMet, de forma a ajustar os valores obtidos nos ensaios piloto às premissas definidas para o circuito industrial. 


\subsection{Rota Convencional}

Para a rota convencional, foram considerados rendimentos operacionais distintos entre os circuitos de britagem e moagem, sendo $6000 \mathrm{~h} / \mathrm{ano}$ para $\mathrm{o}$ primeiro, e $7800 \mathrm{~h} /$ ano para o segundo. Sob tais condições, as vazões de alimentação nova dos circuitos de britagem e moagem foram calculadas, respectivamente, em $4167 \mathrm{t} / \mathrm{h}$ e $3205 \mathrm{t} / \mathrm{h}$.

Para alimentação do circuito de moagem, foi considerada a granulometria de alimentação do ensaio piloto de moagem, e não a granulometria do produto obtida a partir das simulações do circuito industrial de britagem. Essa premissa foi assumida em função do dimensionamento dos equipamentos ter sido realizado a partir dos resultados do ensaio piloto.

\subsubsection{Circuito de Britagem}

Para o cálculo do balanço de massas do circuito de britagem, foi realizado um balanço granulométrico, considerando que a granulometria do produto do britador primário seria a mesma da alimentação dos ensaios piloto de moagem SAG. A eficiência de peneiramento foi considerada de $90 \%$, conforme dados da literatura citados anteriormente. Para o cálculo da eficiência de britagem, foi calibrado um modelo de britador no simulador JKSimMet, tendo por base os resultados do teste industrial de britagem. A partir do modelo calibrado, foram realizadas simulações para diferentes aberturas na posição fechada (APF). A figura 62 mostra a eficiência de britagem do ensaio industrial, assim como os produtos do britador obtidos a partir das simulações para diferentes valores de APF. 
Figura 62- Eficiência de Britagem - Teste Industrial, Calibração e Simulação

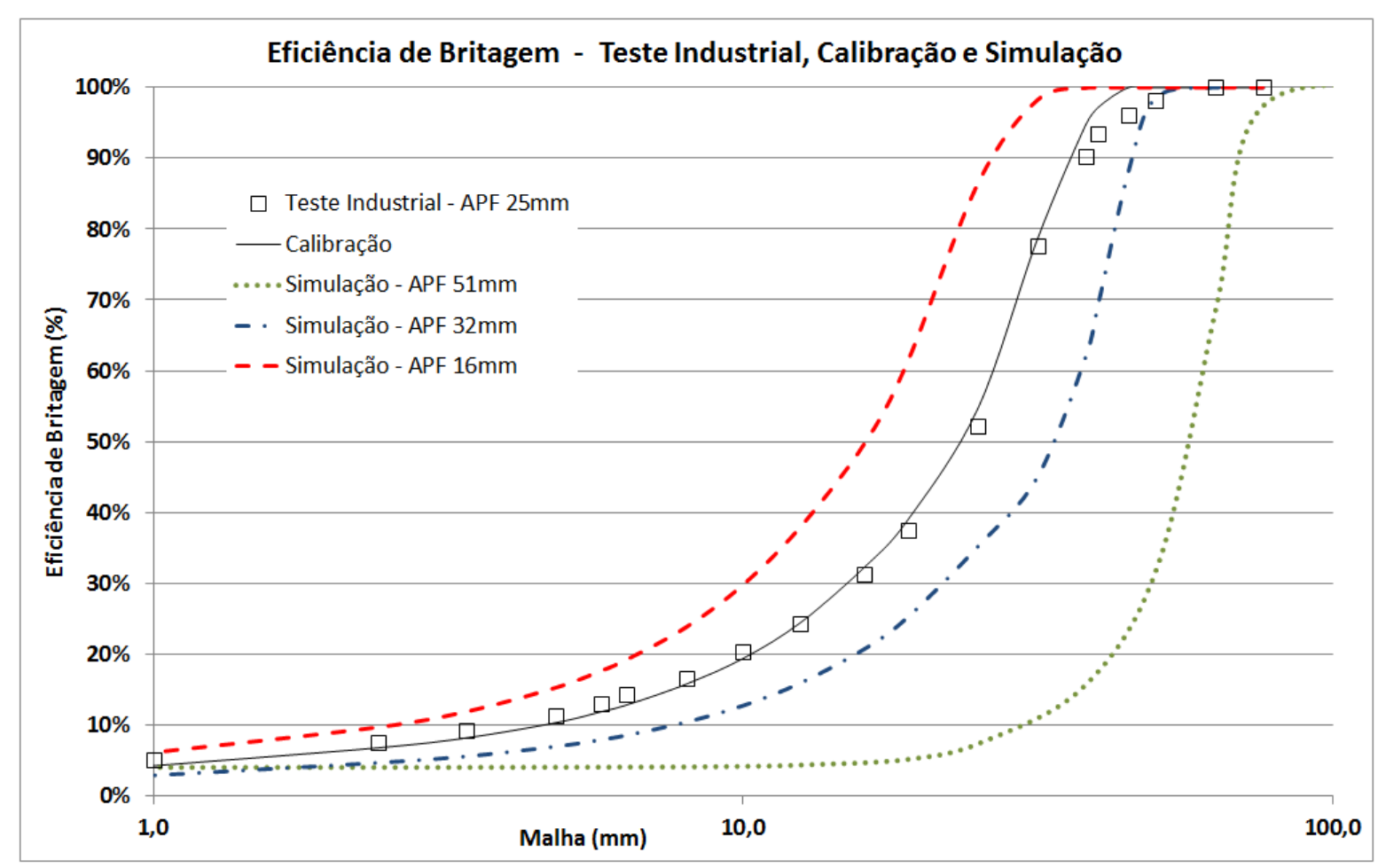

Fonte: Pinto (2015)

Em função dos resultados do ensaio piloto de moagem em moinho de bolas, que mostrou uma geração significativa $(14,2 \%)$ de oversize do trommel, foi considerada a aplicação de quatro estágios de britagem e peneiramento. Neste caso, foi buscado um $D_{95}$ máximo no produto da britagem de $12,7 \mathrm{~mm}$ para alimentação da moagem, de forma a evitar a geração de oversize no trommel do moinho de bolas. A figura 63 mostra o fluxograma de processo para o circuito de britagem da rota convencional, enquanto que a tabela 41 mostra o balanço de massas, incluindo as principais referências granulométricas. 
Figura 63 - Rota Convencional - Fluxograma de Processo da Britagem

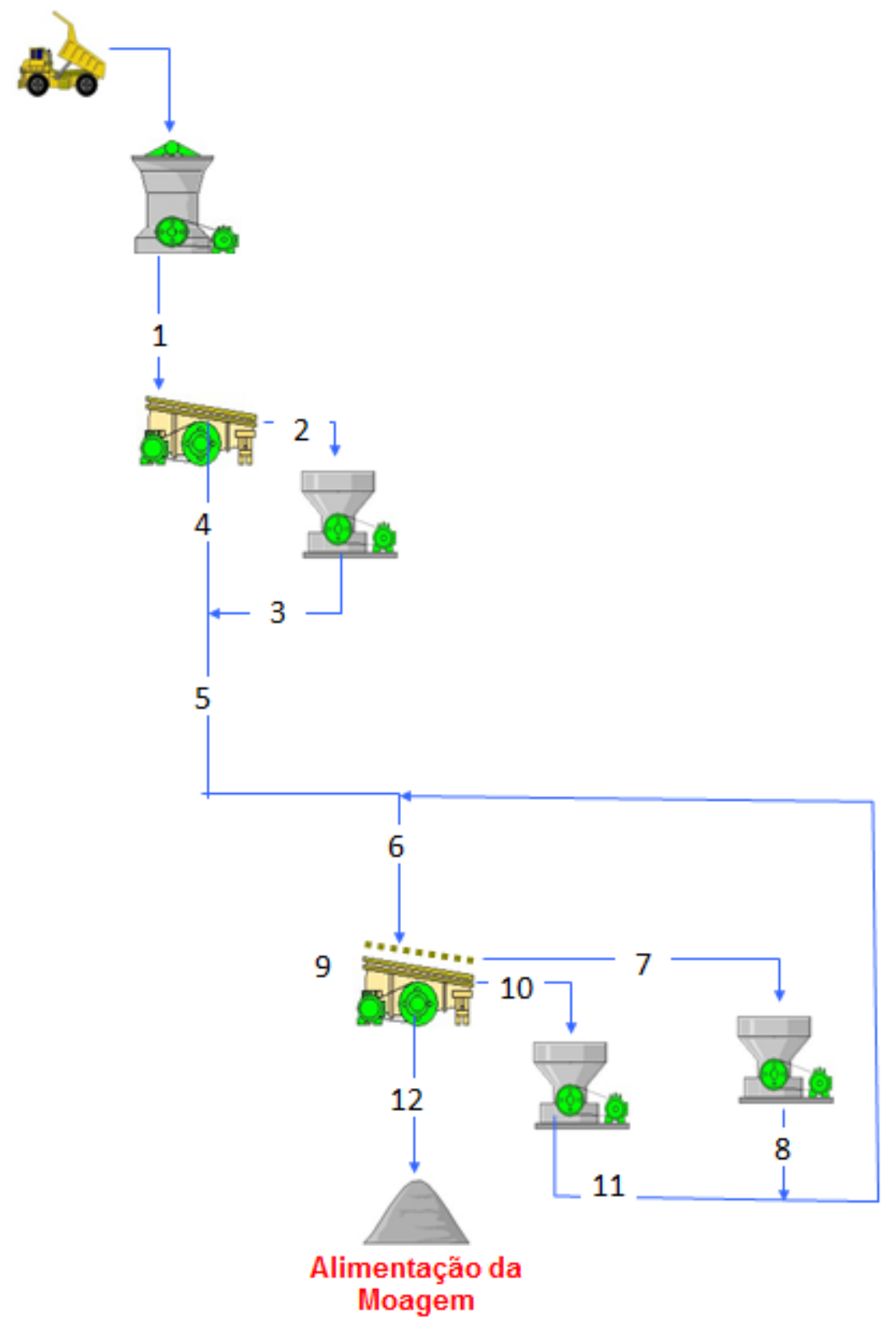

Fonte: Pinto (2015) 
Tabela 41 - Rota Convencional - Balanço de Massa da Britagem

\begin{tabular}{|c|c|c|c|c|c|c|c|}
\hline & \multirow{2}{*}{ Fluxo } & \multicolumn{2}{|c|}{ Vazão } & \multicolumn{4}{|c|}{ Granulometria $(\mathrm{mm})$ - Passante Acumulado } \\
\hline & & th & $\%$ & 76,2 & 38,1 & 25,4 & 12,7 \\
\hline 1 & Descarga Britador Primário & 4167 & 100,0 & 64,0 & 52,6 & 48,3 & 41,3 \\
\hline 2 & Alimentação Britador Secundário & 1731 & 41,5 & 14,8 & 5,6 & 4,8 & 4,0 \\
\hline 3 & Descarga Britador Secundário & 1731 & 41,5 & 97,7 & 47,5 & 31,5 & 18,0 \\
\hline 4 & Undersize Peneira Secundária & 2436 & 58,5 & 99,0 & 86,0 & 79,2 & 67,8 \\
\hline 5 & $\begin{array}{l}\text { Alimentação Nova Peneira } \\
\text { Terciária/Quaternária }\end{array}$ & 4167 & 100,0 & 98,4 & 70,0 & 59,4 & 47,1 \\
\hline 6 & $\begin{array}{l}\text { Alimentação Total Peneira } \\
\text { Terciária/Quaternária }\end{array}$ & 11466 & 275,2 & 99,4 & 84,2 & 74,5 & 41,4 \\
\hline 7 & Alimentação Britador Terciário & 1980 & 47,5 & 96,7 & 26,2 & 17,3 & 9,6 \\
\hline 8 & Descarga Britador Terciário & 1980 & 47,5 & 100,0 & 71,8 & 46,4 & 24,0 \\
\hline 9 & $\begin{array}{l}\text { Alimentação do Segundo Deck } \\
\text { da Peneira }\end{array}$ & 9486 & 227,7 & 100,0 & 96,4 & 86,4 & 48,0 \\
\hline 10 & Alimentação Britador Quaternário & 5319 & 127,7 & 100,0 & 93,5 & 75,8 & 8,8 \\
\hline 11 & Descarga Britador Quaternário & 5319 & 127,7 & 100,0 & 100,0 & 96,7 & 43,4 \\
\hline 12 & Alimentação da Moagem & 4167 & 100,0 & 100,0 & 100,0 & 100,0 & 98,2 \\
\hline
\end{tabular}

As tabelas 42 e 43 mostram, respectivamente, os resultados dos dimensionamentos das peneiras e britadores. Tanto a peneira terciária como a quaternária foram dimensionadas para o deck inferior, ou seja, peneiramento quaternário, considerando $80 \%$ de área efetiva de peneiramento neste deck.

Tabela 42 - Rota Convencional - Dimensionamento de Peneiras

\begin{tabular}{ccc}
\hline Etapa de Peneiramento & $\begin{array}{c}\text { Peneira } \\
\text { Secundária }\end{array}$ & $\begin{array}{c}\text { Peneira Terciária I } \\
\text { Quaternária }\end{array}$ \\
\hline Vazão $(\mathrm{t} / \mathrm{h})$ & 4167 & 9486 \\
Capacidade Especifica $\left(\mathrm{t} / \mathrm{h} / \mathrm{m}^{2}\right)$ & 85 & 35 \\
Dimensões da Peneira $(\mathrm{m})$ Largura X Comprimento & $3,66 \times 7,32$ & $3,66 \times 7,32$ \\
Área de Peneiramento $\left(\mathrm{m}^{2}\right)$ & 26,76 & 21,40 \\
Equipamentos Calculados & 1,8 & 12,7 \\
Equipamentos Adotados & 2 & 13 \\
\hline
\end{tabular}


Tabela 43 - Rota Convencional - Dimensionamento de Britadores

\begin{tabular}{cccc}
\hline Etapa de Britagem & $\begin{array}{c}\text { Britador } \\
\text { Secundário }\end{array}$ & $\begin{array}{c}\text { Britador } \\
\text { Terciário }\end{array}$ & $\begin{array}{c}\text { Britador } \\
\text { Quaternário }\end{array}$ \\
\hline Vazão $(\mathrm{t} / \mathrm{h})$ & 1731 & 1980 & 5319 \\
Potência $(\mathrm{kW})$ & 600 & 600 & 600 \\
Abertura na Posição Fechada (mm) & 51 & 32 & 16 \\
Capacidade do Equipamento (t/h) & 1704 & 1277 & 732 \\
Equipamentos Calculados & 1,0 & 1,6 & 7,3 \\
Equipamentos Adotados & 2 & 2 & 8 \\
\hline
\end{tabular}

Para a britagem secundária, foram adotados dois equipamentos para aumentar a confiabilidade do circuito de britagem, bem como permitir a alimentação direta do britador pela peneira, o que melhora significativamente o arranjo da instalação de britagem.

Além dos equipamentos de processo dimensionados acima, é importante mencionar a necessidade de instalação de uma série de equipamentos de manuseio de minério, como silos, alimentadores e transportadores de correia para a operação do circuito de britagem.

\subsubsection{Circuito de Moagem}

Em função dos resultados do ensaio piloto, que mostraram um alto percentual de expurgo no trommel, bem como $14,2 \%$ retidos em $0,15 \mathrm{~mm}$ no produto da moagem, o circuito foi calibrado no simulador JKSimMet de forma a permitir o ajuste da abertura do trommel, assim como da redução para $10 \%$ passantes em 0,15 mm no produto da moagem. As figuras 64 e 65 comparam os resultados da calibração do ciclone e do moinho de bolas, respectivamente. As granulometrias completas da calibração e simulações realizadas para a moagem de bolas da rota convencional se encontram no apêndice B. 
Figura 64 - Ensaio Piloto de Moagem de Bolas - Calibração do Ciclone

\section{Ensaio Piloto de Moagem de Bolas - Calibração do Ciclone}

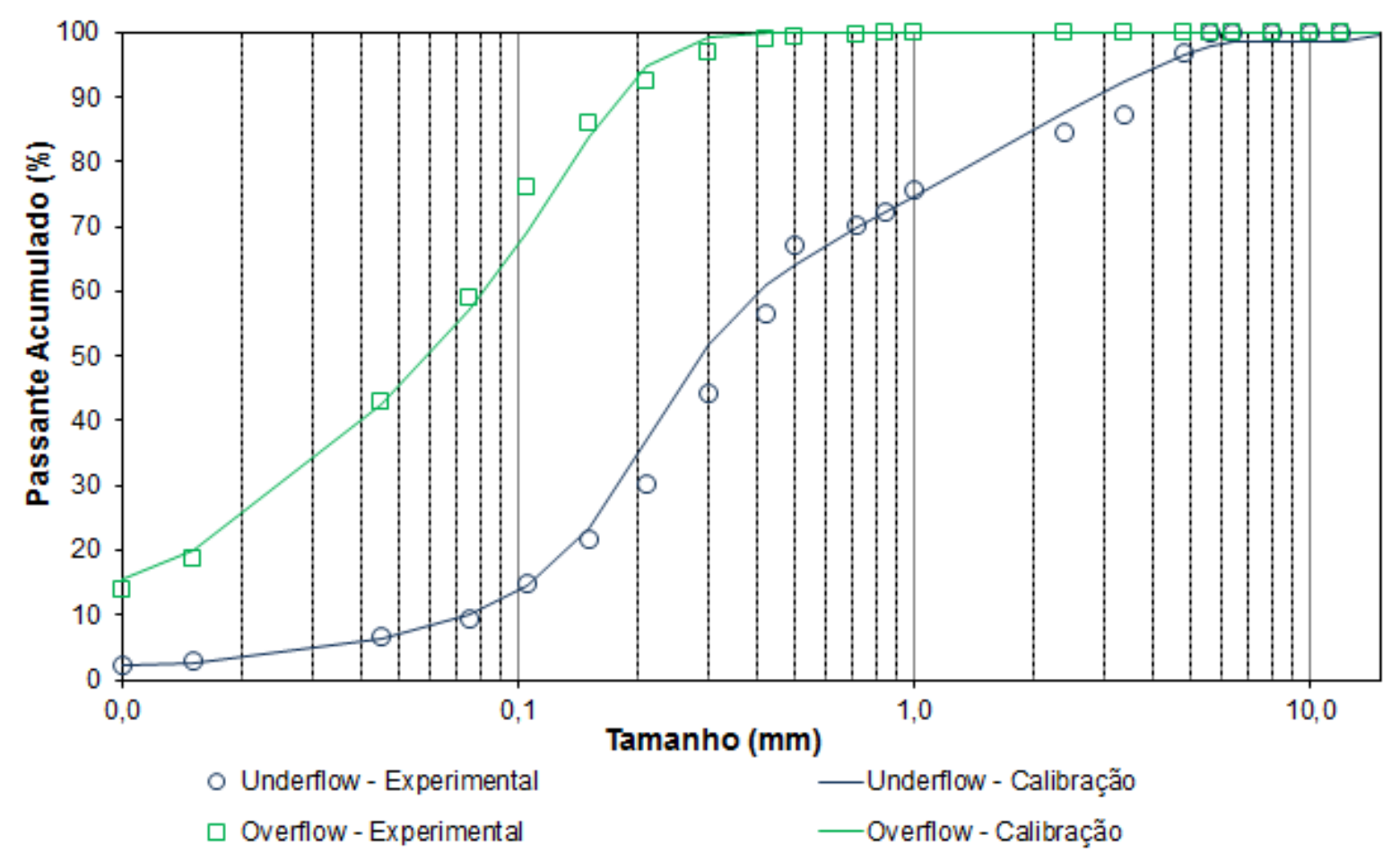

Fonte: Pinto (2015) 
Figura 65 - Ensaio Piloto de Moagem de Bolas - Calibração do Moinho

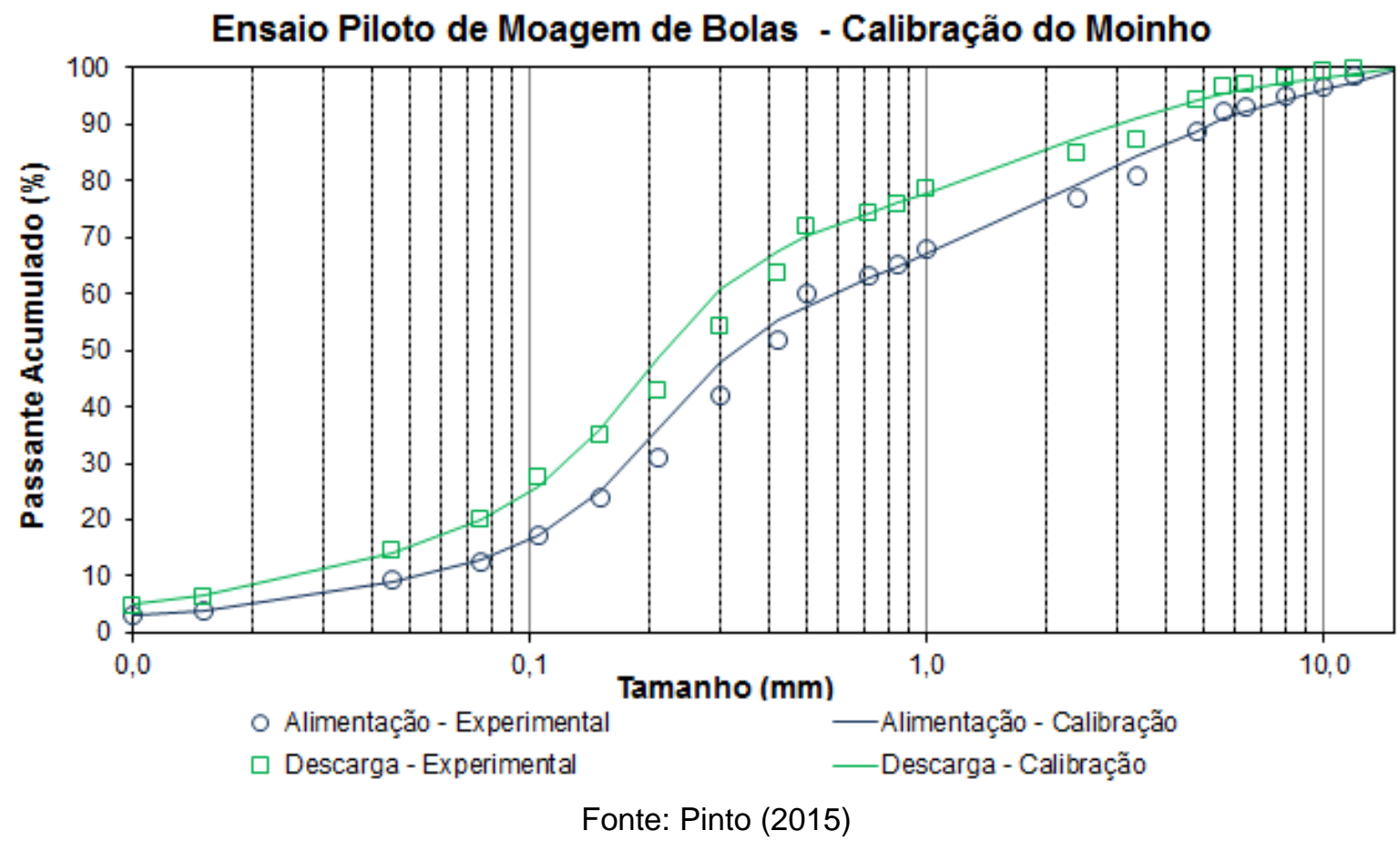

A figura 66 mostra a distribuição do parâmetro $\mathrm{r} / \mathrm{d}^{*}$, conforme ajustado em função da granulometria obtida a partir do ensaio de moagem em moinho de bolas.

Figura 66 - Ensaio Piloto de Moagem de Bolas - Parâmetro r/d *

Ensaio Piloto de Moagem de Bolas - Parâmetro r/d ${ }^{\star}$

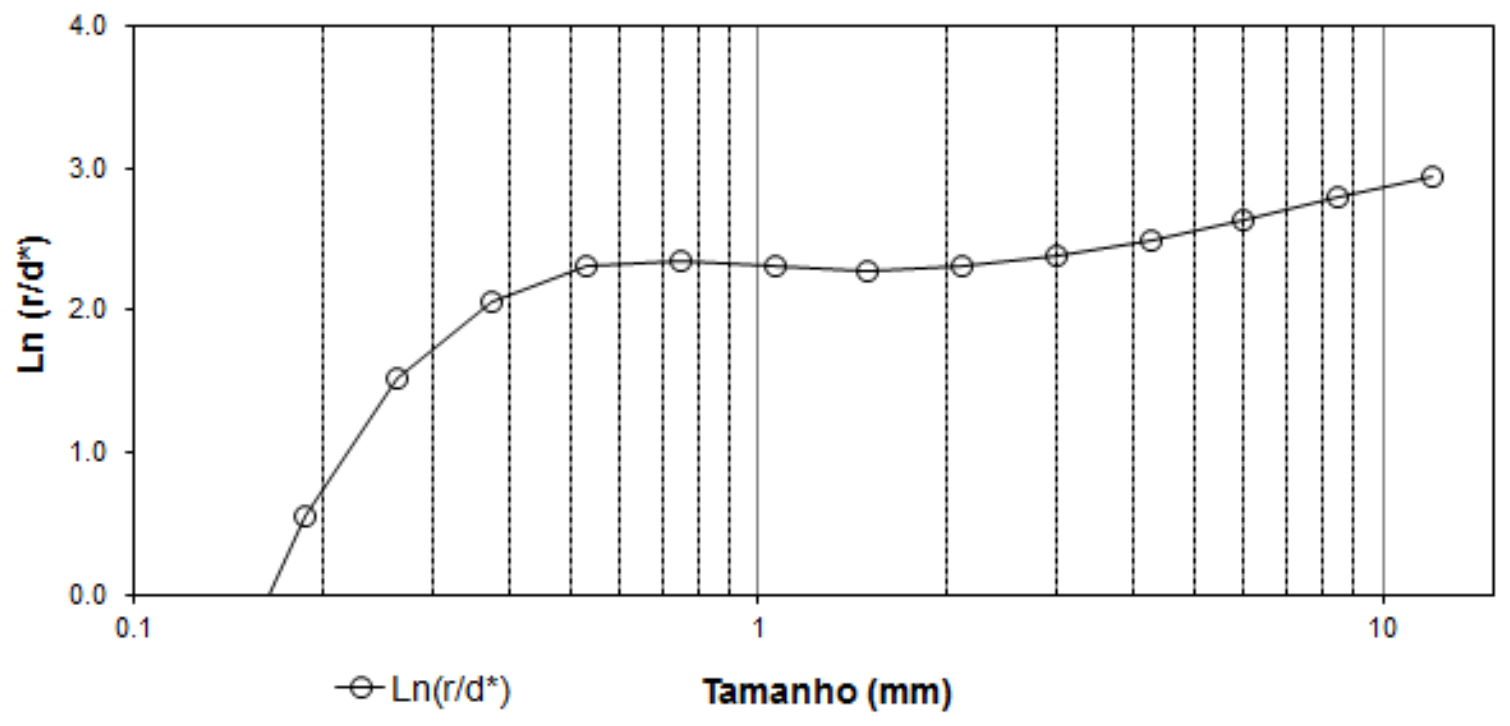

Fonte: Pinto (2015)

A partir da calibração do circuito, foram realizadas duas simulações no simulador JKSimMet. Na primeira, foi simulada a retirada do tromme/ na descarga do 
moinho e a alteração da vazão de alimentação, de forma a se manter a granulometria no produto da moagem obtida no ensaio piloto. $\mathrm{Na}$ segunda simulação, foi alterada a vazão de alimentação, de forma a se obter $10 \%$ de material retido em $0,15 \mathrm{~mm}$ no produto da moagem. As figuras 67 e 68 comparam as granulometrias de descarga do moinho e overflow do ciclone obtidas na primeira e segunda simulações, com a granulometria do circuito calibrado.

Figura 67 - Ensaio Piloto de Moagem de Bolas - Granulometria Simulação 1

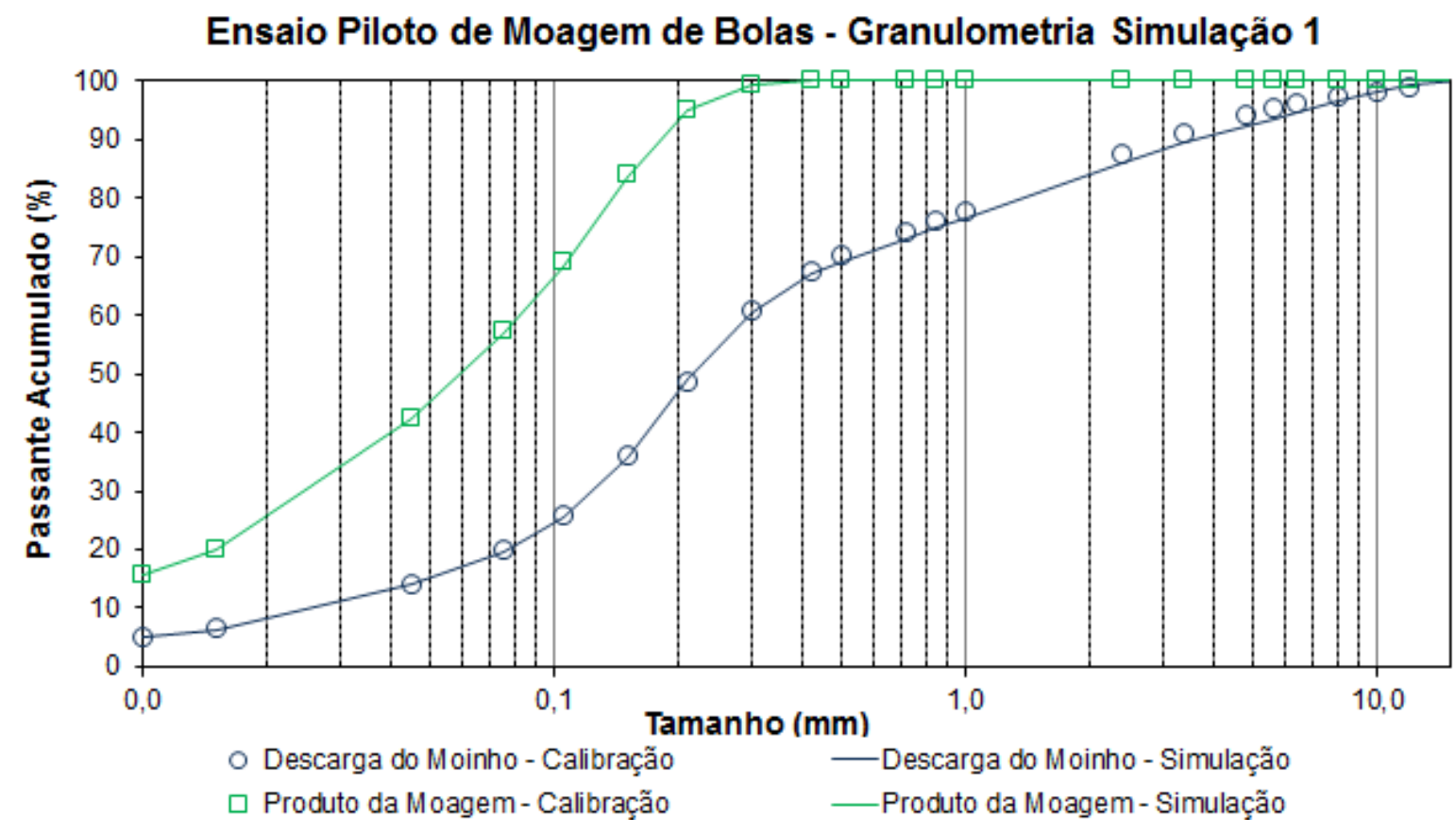

Fonte: Pinto (2015) 
Figura 68 - Ensaio Piloto de Moagem de Bolas - Granulometria Simulação 2

Ensaio Piloto de Moagem de Bolas - Granulometria Simulação 2

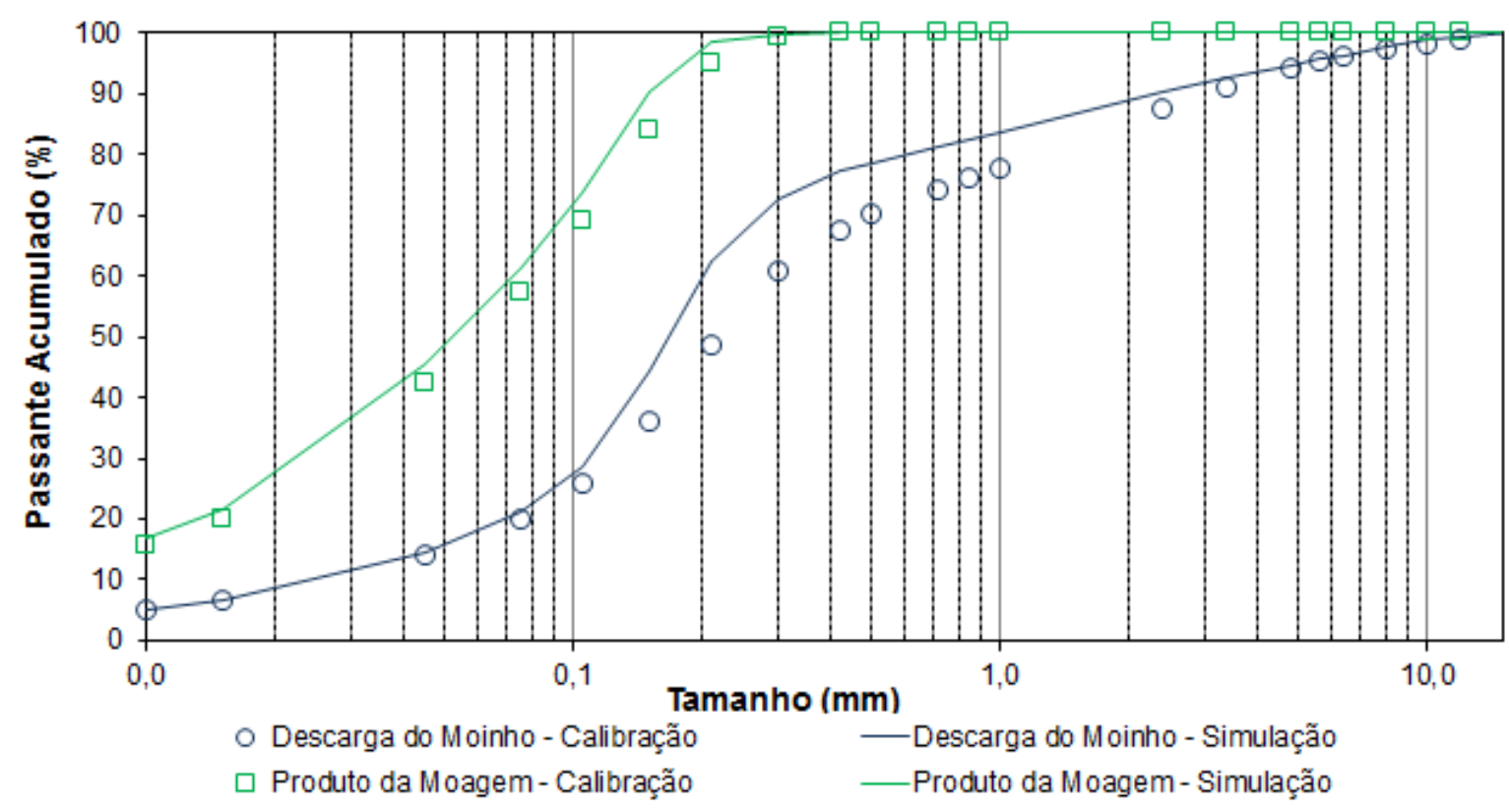

Fonte: Pinto (2015)

A tabela 44 compara os resultados obtidos nas duas simulações com os valores de bancada obtidos para o Wi de Bond e o parâmetro K de Donda. Para as duas simulações realizadas, esses valores foram calculados de forma reversa, com base no consumo energético. 
Tabela 44 - Ensaio Piloto de Moagem de Bolas - Resultados da Simulação

\begin{tabular}{cc}
\hline Ensaio Piloto & \\
\hline Percentagem > 0,15mm Produto & 14,20 \\
Potência Medida do Moinho (kW) & 23,5 \\
Vazão de Alimentação ( $\mathrm{t} / \mathrm{h}$ ) & 3,45 \\
Percentagem Oversize Tromell & 14,20 \\
\hline Simulação 1 & 2,75 \\
\hline Vazão de Alimentação (t/h) & 16,20 \\
Percentagem >0,15mm Produto & 8,5 \\
Consumo Energia (kWh/t) & 0,170 \\
K - Donda (Calculado) & 11,5 \\
WI Operacional (kWh/t) & \\
\hline Simulação 2 & 1,90 \\
\hline Vazão de Alimentação (t/h) & 9,91 \\
Percentagem >0,15mm Produto & 12,4 \\
Consumo Energia (kWh/t) & 0,157 \\
K - Donda (Calculado) & 15,3 \\
WI Operacional (kWh/t) & \\
\hline Valores de Referência & 0,161 \\
\hline K - Donda & 10,9 \\
\hline WI Bond &
\end{tabular}

A partir do consumo específico de energia obtido na simulação 2, foi realizado o dimensionamento do moinho para o circuito industrial. Esse dimensionamento foi comparado com o dimensionamento conduzido com base nos métodos de Donda e de Bond. A tabela 45 compara os dimensionamentos realizados. 
Tabela 45 - Rota Convencional - Dimensionamento do Moinho de Bolas

\begin{tabular}{cccc}
\hline Método & Bond & Donda & $\begin{array}{c}\text { Teste } \\
\text { Piloto/Simulação }\end{array}$ \\
\hline Vazão de sólidos (t/h) & 3205 & 3205 & 3205 \\
Percentagem >0,15mm - Alimentação & 69,5 & 69,5 & 69,5 \\
Percentagem >0,15mm - Produto & 10,0 & 10,0 & 10,0 \\
F80 $(\mu \mathrm{m})$ & 7936 & 7936 & 7936 \\
P80 ( $\mu$ m) & 118 & 118 & 118 \\
Consumo de Energia (kWh/t) & $\mathbf{8 , 8}$ & $\mathbf{1 2 , 0}$ & $\mathbf{1 2 , 4}$ \\
Potência Necessária (kW) & $\mathbf{2 8 1 8 5}$ & $\mathbf{3 8 6 0 0}$ & 3 \\
Número de Moinhos & 3 & 3 & $\mathbf{2 6}$ \\
Diâmetro do Moinho (pés) & $\mathbf{2 4}$ & $\mathbf{2 6}$ & $\mathbf{4 0}$ \\
Comprimento do Moinho (pés) & $\mathbf{3 6}$ & $\mathbf{4 0}$ & 7,8 \\
Diâmetro Interno do Moinho (metros) & 7,2 & 7,8 & 12,0 \\
Comprimento interno do Moinho (metros) & 10,8 & 12,0 & 35,0 \\
Percentagem de Enchimento do Moinho & 35,0 & 35,0 & 76,0 \\
Percentagem Velocidade Crítica & 76,0 & 76,0 & $\mathbf{3 9 7 4 7}$ \\
Potência Instalada (kW) & $\mathbf{2 9 9 5 9}$ & $\mathbf{3 9 7 4 7}$ & \\
\hline
\end{tabular}

De acordo com os resultados mostrados nas tabelas 44 e 45 , o método de Donda para previsão do consumo energético mostrou diferenças pequenas em relação aos resultados obtidos em escala piloto e com as simulações realizadas. $O$ cálculo do consumo de energia pelo método de Bond mostrou um valor menor do que o previsto pelas simulações realizadas. Essa diferença ficou mais acentuada para o cenário de simulação com $10 \%$ retido em $0,15 \mathrm{~mm}$ no produto da moagem.

Para elaboração do balanço de massas do circuito de moagem da rota convencional, foi considerada a carga circulante e os percentuais de sólidos de alimentação e underflow do ciclone obtidos na simulação 2. A figura 69 mostra o fluxograma de processo para o circuito de moagem da rota convencional, enquanto a tabela 46 mostra o respectivo balanço de massas. 
Figura 69 - Rota Convencional - Fluxograma de Processo da Moagem

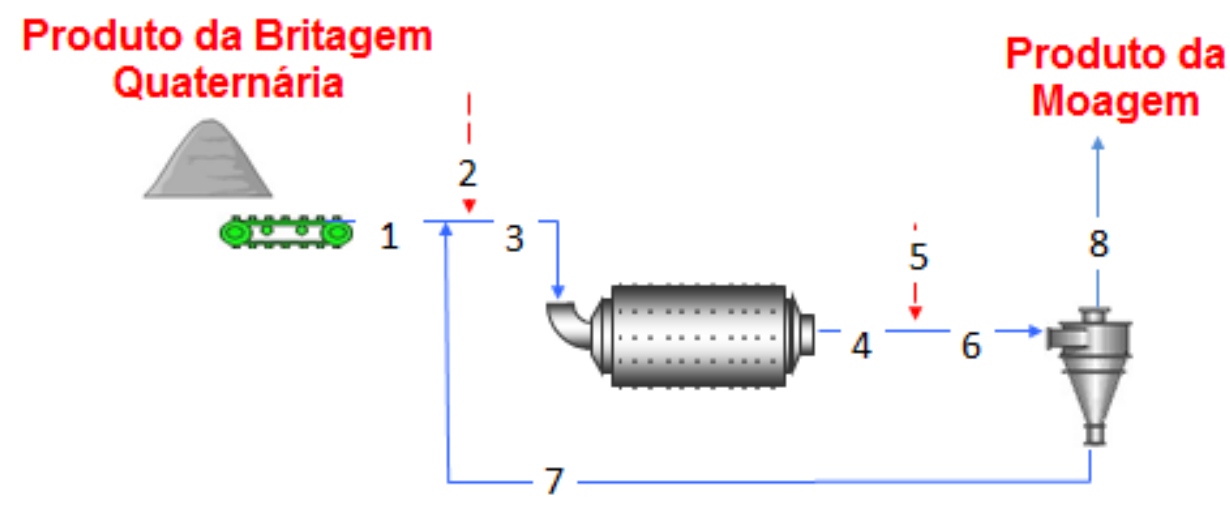

Fonte: Pinto (2015)

Tabela 46 - Rota Convencional - Balanço de Massas da Moagem

\begin{tabular}{|c|c|c|c|c|c|c|}
\hline & \multirow{2}{*}{ Fluxo } & \multicolumn{2}{|c|}{ Vazão de Sólidos } & \multirow{2}{*}{$\%$ Sólidos } & \multirow{2}{*}{$\begin{array}{l}\text { Vazão de Polpa } \\
\qquad\left(\mathrm{m}^{3} / \mathrm{h}\right)\end{array}$} & \multirow{2}{*}{$\begin{array}{l}\text { Vazão de Água } \\
\left(\mathrm{m}^{3} / \mathrm{h}\right)\end{array}$} \\
\hline & & t/h & $\%$ & & & \\
\hline 1 & Alimentação Nova & 3205 & 100 & 95,0 & 996 & 170 \\
\hline 2 & Água Diluição da Moagem & - & - & - & 864 & 864 \\
\hline 3 & Alimentação do Moinho & 15755 & 492 & 78,3 & 8430 & 4369 \\
\hline 4 & Descarga do Moinho & 15755 & 492 & 78,3 & 8430 & 4369 \\
\hline 5 & Água Diluição da Classificação & - & - & - & 6355 & 6355 \\
\hline 6 & Alimentação do Ciclone & 15755 & 492 & 59,5 & 14785 & 10724 \\
\hline 7 & Underflow do Ciclone & 12550 & 392 & 79,0 & 6570 & 3335 \\
\hline 8 & Overflow do Ciclone & 3205 & 100 & 30,3 & 8215 & 7389 \\
\hline
\end{tabular}

A tabela 47 mostra os resultados dos dimensionamentos de ciclones para fechamento do circuito de moagem. A tabela 48 mostra a lista dos equipamentos de processo dimensionados para a rota convencional, a partir do produto da britagem primária. 
Tabela 47 - Rota Convencional - Dimensionamento dos Ciclones

\begin{tabular}{cc}
\hline Parâmetro & $\begin{array}{c}\text { Ciclone de } \\
\text { Classsificação }\end{array}$ \\
\hline Vazão de polpa $\left(\mathrm{m}^{3} / \mathrm{h}\right)$ & 14785 \\
Fator de Projeto & 1,2 \\
Capacidade por Ciclone $\left(\mathrm{m}^{3} / \mathrm{h}\right)$ & 450 \\
Número de Baterias & 3 \\
Ciclones por Bateria Calculado & 13,1 \\
Ciclones por Bateria Adotado & 14 \\
Total de Ciclones Adotado & 42 \\
\hline
\end{tabular}

Tabela 48 - Rota Convencional - Lista de Equipamentos

\begin{tabular}{|c|c|c|}
\hline Etapa de Processo & $\begin{array}{c}\text { Tipo de } \\
\text { Equipamento }\end{array}$ & $\begin{array}{l}\text { Número de } \\
\text { Equipamentos }\end{array}$ \\
\hline Britagem Secundária & $\begin{array}{l}\text { Britador } 600 \mathrm{~kW} \\
\text { APF } 51 \mathrm{~mm}\end{array}$ & 2 \\
\hline Peneiramento Secundário & $\begin{array}{l}\text { Peneira } 12 \text { ' X 24' } \\
\text { Deck Simples }\end{array}$ & 2 \\
\hline Britagem Terciária & $\begin{array}{l}\text { Britador } 600 \mathrm{~kW} \\
\text { APF } 32 \mathrm{~mm}\end{array}$ & 2 \\
\hline Britagem Quaternária & $\begin{array}{l}\text { Britador } 600 \mathrm{~kW} \\
\text { APF } 16 \mathrm{~mm}\end{array}$ & 8 \\
\hline $\begin{array}{c}\text { Peneiramento } \\
\text { Terciário/Quaternário }\end{array}$ & $\begin{array}{c}\text { Peneira } 12^{\prime} \text { X 24' } \\
\text { Duplo Deck }\end{array}$ & 13 \\
\hline Moagem de Bolas & $\begin{array}{c}\text { Moinho } 26^{\prime} \text { X } 40^{\prime} \\
\text { 13,2 MW }\end{array}$ & 3 \\
\hline Ciclones & Ciclone de $26 "$ & 42 \\
\hline
\end{tabular}

Para alimentação dos três moinhos de bolas, é recomendada a utilização de silo com alimentadores. Esse sistema permite a utilização de um único transportador 
de correia para a retomada do minério da pilha pulmão e alimentação da instalação de moagem. Como o minério se encontra britado a $12,7 \mathrm{~mm}$, o risco de entupimento e obstrução no silo é aqui considerado muito baixo. 


\subsection{Rota SAB/C}

Os ensaios em escala piloto realizados com o moinho SAG sem recirculação do underflow do classificador espiral (SAG 1 e SAG 2 e SAG 3), mostraram que a redução do top size da alimentação, simulando a operação de uma britagem secundária (SAG 3), levou a um aumento significativo no consumo energético, que foi de $11,1 \mathrm{kWh} / \mathrm{t}$ para este ensaio contra $8,0 \mathrm{kWh} / \mathrm{t}$ para o ensaio $S A G$ e $6,5 \mathrm{kWh} / \mathrm{t}$ para o ensaio SAG 1. Dessa forma, foi desconsiderada a utilização de britagem secundária para desenvolvimento do circuito $S A B / C$ e não foi realizado ensaio de moagem de bolas com o underflow do classificador para o ensaio SAG 3.

A tabela 49 compara os resultados dos ensaios de moagem SAG e moagem de bolas para os circuitos SABC (SAG 1 e MB1) e SAB (SAG 2 e MB2). Os parâmetros Wi de Bond e o $\mathrm{K}$ de Donda foram calculados de forma reversa, com base no consumo energético do teste piloto, e comparados com os valores obtidos em escala de bancada. 
Tabela 49 - Comparativo dos Ensaios Piloto para as Rotas SABC e SAB

\begin{tabular}{|c|c|c|}
\hline Circuito - Ensaios & SABC - SAG 1/MB1 & SAB - SAG 2/MB2 \\
\hline Energia Especifica - Ensaio SAG (kWh/t) & 6,5 & 8,0 \\
\hline $\begin{array}{c}\text { Percentagem }<0.15 \mathrm{~mm} \text { - Undersize do Tromell - } \\
\text { Ensaio SAG }\end{array}$ & 50,2 & 55,1 \\
\hline $\begin{array}{l}\text { Percentagem Underflow no Classificador Espiral - } \\
\text { Ensaio SAG }\end{array}$ & $62,0 \%$ & $60,2 \%$ \\
\hline $\begin{array}{l}\text { Percentagem }<0.15 \mathrm{~mm} \text { no Overflow no } \\
\text { Classificador Espiral - Ensaio SAG }\end{array}$ & 91,6 & 94,4 \\
\hline Energia do Ensaio de Moagem de Bolas (kWh/t) & 12,7 & 12,8 \\
\hline Energia Corrigida da Moagem de Bolas (kWh/t) & 7,8 & 7,7 \\
\hline $\begin{array}{l}\text { Percentagem }<0.15 \mathrm{~mm} \text { no Overflow no } \\
\text { Classificador Espiral - Ensaio de Moagem de Bolas }\end{array}$ & 91,0 & 90,7 \\
\hline Energia Especifica - Total (kWh/t) & 14,3 & 15,7 \\
\hline Percentagem $<0.15 \mathrm{~mm}$ no Produto da Moagem & 91,2 & 92,2 \\
\hline K - Donda (Calculado) & 0,157 & 0,151 \\
\hline WI Operacional (kWh/t) & 14,6 & 15,9 \\
\hline \multicolumn{3}{|c|}{ Valores de Referência } \\
\hline K - Donda & \multicolumn{2}{|c|}{0,161} \\
\hline WI Bond & \multicolumn{2}{|c|}{10,9} \\
\hline
\end{tabular}

De acordo com os resultados mostrados na tabela 49, a rebritagem dos pebbles levou a uma redução do consumo específico de energia da etapa de moagem SAG de $8,0 \mathrm{kWh} / \mathrm{t}$ para 6,5 kWh/t. Para a moagem de bolas, o consumo específico de energia foi o praticamente o mesmo para as duas rotas, quais sejam, $7,8 \mathrm{kWh} / \mathrm{t}$ para a rota $\mathrm{SABC}$ e $7,7 \mathrm{kWh} / \mathrm{t}$ para a rota $\mathrm{SAB}$, mesmo com o undersize do trommel do circuito $S A B C$ tendo apresentado 5 pontos percentuais a menos de material abaixo de $0,15 \mathrm{~mm}$. A figura 70 compara as curvas granulométricas do undersize do trommel obtidas nos ensaios piloto SAG 1 e SAG 2. 
Figura 70 - Ensaio SAG 1 e SAG 2 - Granulometria do Undersize do Tromell

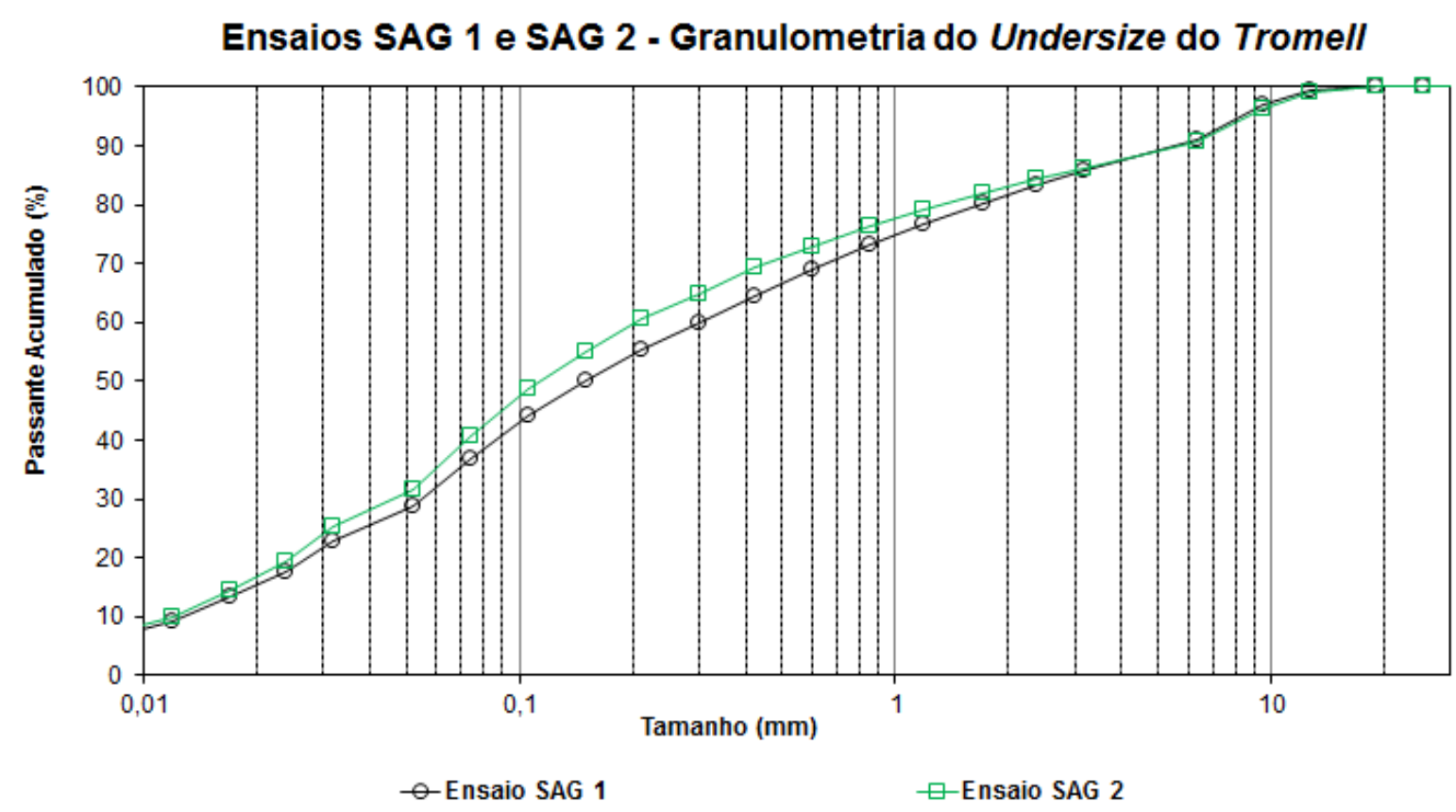

Fonte: Pinto (2015)

O consumo de energia previsto pelo método de Donda ficou próximo do consumo total obtido nos ensaios em escala piloto, tanto para a rota $S A B$, quanto para a rota $S A B C$. Por outro lado, o consumo previsto pelo método de Bond mostrou diferenças consideradas elevadas em relação aos resultados obtidos em escala piloto.

A tabela 50 mostra o dimensionamento do moinho SAG considerando as rotas $S A B C$ e SAB. Neste caso, duas alternativas de circuito foram consideradas, pois devido à alta quantidade relativa de minerais magnéticos, a rota $S A B C$ pode ser tecnicamente inviável em função da dificuldade de separação entre de bolas de aço e pebbles na alimentação da rebritagem. 
Tabela 50 - Rota SAB/C - Dimensionamento do Moinho SAG

\begin{tabular}{ccc}
\hline Parâmetro & Rota SABC & Rota SAB \\
\hline Vazão de sólidos (t/h) & 3205 & 3205 \\
Percentagem >0,15mm - Alimentação & 83,9 & 83,9 \\
Percentagem >0,15mm - Produto & 50,2 & 55,1 \\
F80 $(\mu \mathrm{m})$ & 128752 & 124783 \\
P80 $(\mu \mathrm{m})$ & 1652 & 1326 \\
Consumo de Energia (kWh/t) & $\mathbf{6 , 5}$ & $\mathbf{8 , 0}$ \\
Potência Necessária (kW) & $\mathbf{2 0 7 9 7}$ & $\mathbf{2 5 7 1 9}$ \\
Número de Moinhos & 1 & 1 \\
Diâmetro do Moinho (pés) & $\mathbf{3 8}$ & $\mathbf{4 0}$ \\
Comprimento do Moinho (pés) & $\mathbf{3 2}$ & $\mathbf{3 4}$ \\
Diâmetro Interno do Moinho (metros) & 11,4 & 12,0 \\
Comprimento interno do Moinho (metros) & 9,6 & 10,2 \\
Percentagem de Enchimento Total do Moinho & 25,0 & 25,0 \\
Percentagem de Bolas do Moinho & 8,0 & 8,0 \\
Porosidade da Carga & 0,4 & 0,4 \\
Percentagem Velocidade Crítica & 76,0 & 76,0 \\
Potência Instalada (kW) & $\mathbf{2 1 5 8 4}$ & $\mathbf{2 6 1 3 8}$ \\
\hline
\end{tabular}

Em função dos resultados dos ensaios pilotos, que mostraram o mesmo consumo energético para a moagem de bolas para as rotas $S A B$ e $S A B C$, foi realizado um único dimensionamento para a etapa de moagem em moinhos de bolas. Neste caso, foi considerando um consumo específico de energia de 7,77 $\mathrm{kWh} / \mathrm{t}$, equivalente à média dos valores obtido para cada uma das rotas. A tabela 51 mostra os resultados do dimensionamento do moinho de bolas para as rotas SAB e SABC. 
Tabela 51 - Rota SAB/C - Dimensionamento do Moinho de Bolas

\begin{tabular}{cc}
\hline Parâmetro & Rota SAB/C \\
\hline Vazão (t/h) & 3205 \\
Consumo de Específico de Energia (kWh/t) & $\mathbf{7 , 7 7}$ \\
Potência Necessária (kW) & $\mathbf{2 4 9 0 3}$ \\
Número de Moinhos & 2 \\
Diâmetro do Moinho (pés) & $\mathbf{2 6}$ \\
Comprimento do Moinho (pés) & $\mathbf{3 8}$ \\
Diâmetro Interno do Moinho (metros) & 7,8 \\
Comprimento interno do Moinho (metros) & 11,4 \\
\% de Enchimento do Moinho & 35,0 \\
\% Velocidade Crítica & 76,0 \\
Potência Instalada (kW) & $\mathbf{2 5 1 5 6}$ \\
\hline
\end{tabular}

A partir dos percentuais de oversize do trommel e de carga circulante obtidos nos ensaios piloto, foi calculado o balanço de massa do circuito em escala industrial para as rotas SAB e SABC. Como os ensaios piloto para essa rota foram realizados com classificador espiral, foram adotados os mesmos percentuais de sólidos na alimentação e no underflow do ciclone obtidos no ensaio de moagem de bolas para a rota convencional. A figura 71 mostra o fluxograma de processo e as tabelas 52 e 53 , o balanço de massas para as rotas SAB e SABC respectivamente. 
Figura 71 - Rota SAB/C - Fluxograma de Processo da Moagem

\section{Produto da Britagem \\ Primária}
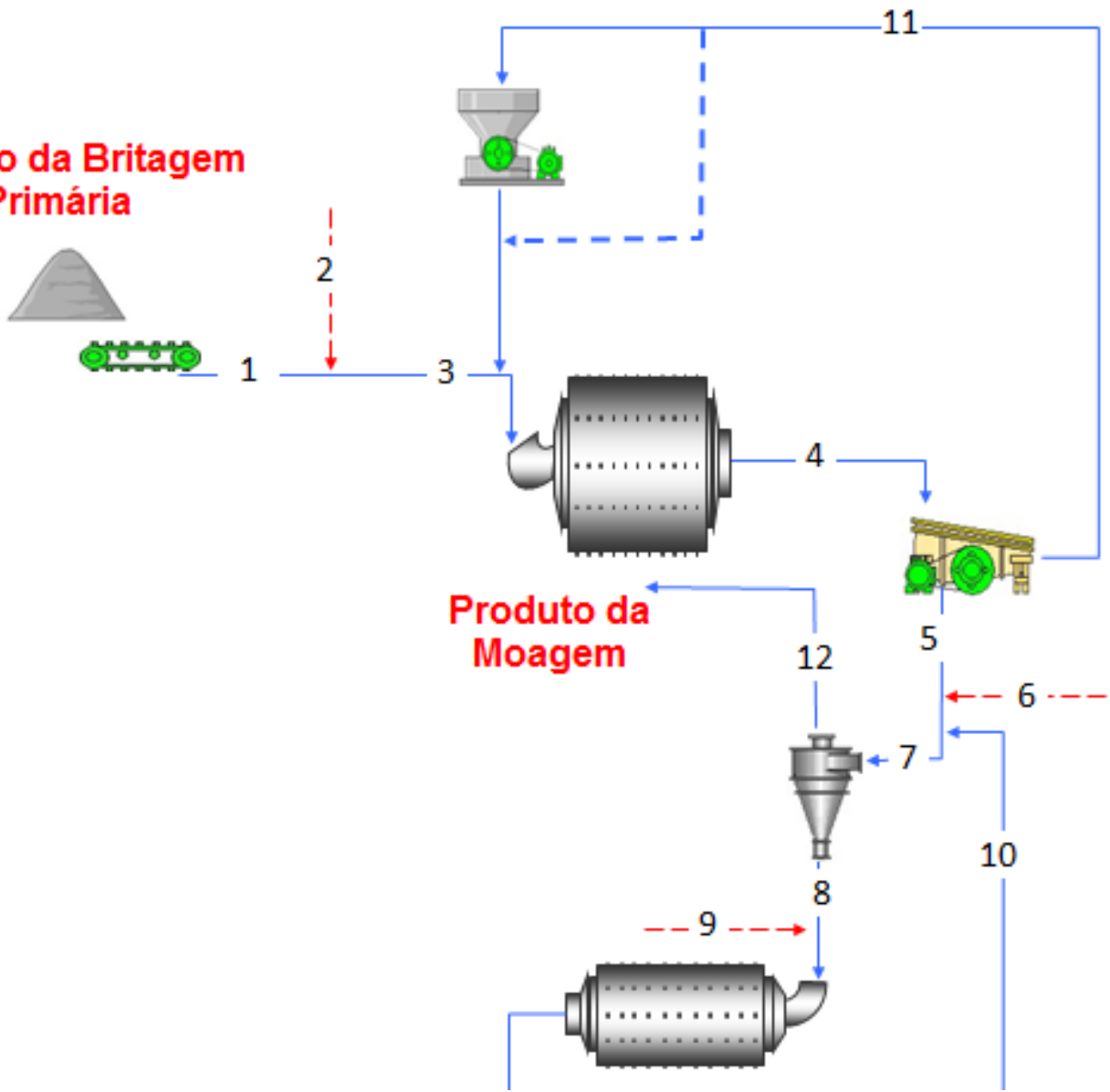

Fonte: Pinto (2015) 
Tabela 52 - Rota SAB - Balanço de Massa da Moagem

\begin{tabular}{|c|c|c|c|c|c|c|}
\hline & \multirow{2}{*}{ Fluxo } & \multicolumn{2}{|c|}{ Vazão de Sólidos } & \multirow{2}{*}{ \% Sólidos } & \multirow{2}{*}{$\begin{array}{l}\text { Vazão de Polpa } \\
\qquad\left(\mathrm{m}^{3} / \mathrm{h}\right)\end{array}$} & \multirow{2}{*}{$\begin{array}{c}\text { Vazão de Água } \\
\qquad\left(\mathrm{m}^{3} / \mathrm{h}\right)\end{array}$} \\
\hline & & t/h & $\%$ & & & \\
\hline 1 & Alimentação Nova & 3205 & 100 & 95,0 & 996 & 170 \\
\hline 2 & Água Diluição da Moagem SAG & - & - & - & 767 & 767 \\
\hline 3 & Alimentação do Moinho SAG & 3398 & 106 & 78,0 & 1834 & 958 \\
\hline 4 & Descarga do Moinho SAG & 3398 & 106 & 78,0 & 1834 & 958 \\
\hline 5 & Undersize da Peneira & 3205 & 100 & 77,4 & 1763 & 937 \\
\hline 6 & Água Diluição do Ciclone & - & - & - & 4303 & 4303 \\
\hline 7 & Alimentação do Ciclone & 12243 & 382 & 59,5 & 11489 & 8333 \\
\hline 8 & Underflow do Ciclone & 9038 & 282 & 79,1 & 4710 & 2381 \\
\hline 9 & $\begin{array}{l}\text { Água Diluição do Moinho de } \\
\text { Bolas }\end{array}$ & - & - & - & 712 & 712 \\
\hline 10 & Descarga do Moinho de Bolas & 9038 & 282 & 74,5 & 5423 & 3093 \\
\hline 11 & Oversize da Peneira & 193 & 6 & 90,0 & 71 & 21 \\
\hline 12 & Overflow do Ciclone & 3205 & 100 & 35,0 & 6778 & 5952 \\
\hline
\end{tabular}

Tabela 53 - Rota SABC - Balanço de Massa da Moagem

\begin{tabular}{|c|c|c|c|c|c|c|}
\hline \multirow{2}{*}{\multicolumn{2}{|c|}{ Fluxo }} & \multicolumn{2}{|c|}{ Vazão de Sólidos } & \multirow[t]{2}{*}{ \% Sólidos } & \multirow{2}{*}{$\begin{array}{l}\text { Vazão de Polpa } \\
\qquad\left(\mathrm{m}^{3} / \mathrm{h}\right)\end{array}$} & \multirow{2}{*}{$\begin{array}{l}\text { Vazão de Água } \\
\qquad\left(m^{3} / h\right)\end{array}$} \\
\hline & & th & $\%$ & & & \\
\hline 1 & Alimentação Nova & 3205 & 100 & 95,0 & 996 & 170 \\
\hline 2 & Água Diluição da Moagem SAG & - & - & - & 793 & 793 \\
\hline 3 & Alimentação do Moinho SAG & 3552 & 111 & 78,0 & 1917 & 1002 \\
\hline 4 & Descarga do Moinho SAG & 3552 & 111 & 78,0 & 1917 & 1002 \\
\hline 5 & Undersize da Peneira & 3205 & 100 & 76,9 & 1789 & 963 \\
\hline 6 & Água Diluição do Ciclone & - & - & - & 4290 & 4290 \\
\hline 7 & Alimentação do Ciclone & 12281 & 383 & 59,5 & 11525 & 8360 \\
\hline 8 & Underflow do Ciclone & 9076 & 283 & 79,0 & 4747 & 2407 \\
\hline 9 & Água Diluição do Moinho de Bolas & - & - & - & 699 & 699 \\
\hline 10 & Descarga do Moinho de Bolas & 9076 & 283 & 74,5 & 5446 & 3107 \\
\hline 11 & $\begin{array}{l}\text { Oversize da Peneira - Alimentação do } \\
\text { Britador de Pebbles }\end{array}$ & 347 & 11 & 90,0 & 128 & 39 \\
\hline 12 & Overflow do Ciclone & 3205 & 100 & 35,0 & 6778 & 5952 \\
\hline
\end{tabular}


A tabela 54 mostra os resultados do dimensionamento dos ciclones para fechamento do circuito de moagem, enquanto as tabelas 55 e 56 indicam a lista de equipamentos de processo para as rotas $S A B$ e $S A B C$, respectivamente. Para a britagem de pebbles foi adotado um britador de $600 \mathrm{~kW}$ de potência, com APF de 16 $\mathrm{mm}$.

\begin{tabular}{|c|c|c|}
\hline Parâmetro & $\begin{array}{c}\text { Ciclones - Rota } \\
\text { SAB }\end{array}$ & $\begin{array}{c}\text { Ciclones - Rota } \\
\text { SABC }\end{array}$ \\
\hline Vazão de polpa $\left(\mathrm{m}^{3} / \mathrm{h}\right)$ & 11489 & 11525 \\
\hline Fator de Projeto & 1,2 & 1,2 \\
\hline Capacidade por Ciclone $\left(\mathrm{m}^{3} / \mathrm{h}\right)$ & 450 & 450 \\
\hline Número de Baterias & 2 & 2 \\
\hline Ciclones por Bateria Calculado & 15,3 & 15,4 \\
\hline Ciclones por Bateria Adotado & 16 & 16 \\
\hline Total de Ciclones Adotado & 32 & 32 \\
\hline \multicolumn{3}{|c|}{ Tabela 55 - Rota SAB - Dimensionamento dos Equipamentos } \\
\hline Etapa de Processo & $\begin{array}{c}\text { Tipo de } \\
\text { Equipamento }\end{array}$ & $\begin{array}{c}\text { Número de } \\
\text { Equipamentos }\end{array}$ \\
\hline Moagem SAG & $\begin{array}{c}\text { Moinho } 40^{\prime} \text { X } 34^{\prime} \\
26,1 \mathrm{MW}\end{array}$ & 1 \\
\hline Peneiramento do SAG & $\begin{array}{c}\text { Peneira 12' X 24' } \\
\text { Duplo Deck }\end{array}$ & 1 \\
\hline Moinho de Bolas & $\begin{array}{c}\text { Moinho } 26^{\prime} \text { X } 38 \\
12,6 \mathrm{MW}\end{array}$ & 2 \\
\hline Ciclones & Ciclone de 26" & 32 \\
\hline
\end{tabular}


Tabela 56 - Rota SABC - Dimensionamento dos Equipamentos

\begin{tabular}{ccc}
\hline Etapa de Processo & $\begin{array}{c}\text { Tipo de } \\
\text { Equipamento }\end{array}$ & $\begin{array}{c}\text { Número de } \\
\text { Equipamentos }\end{array}$ \\
\hline Moagem SAG & $\begin{array}{c}\text { Moinho 38' X 32' } \\
21,6 \mathrm{MW}\end{array}$ & 1 \\
Peneiramento do SAG & $\begin{array}{c}\text { Peneira 12' X 24' } \\
\text { Duplo Deck } \\
\text { Britador 660 kW } \\
\text { APF } 16 \mathrm{~mm}\end{array}$ & 1 \\
Moinho de Bolas & $\begin{array}{c}\text { Moinho 26' X 38' } \\
12,6 \mathrm{MW}\end{array}$ & 2 \\
Ciclones & Ciclone de 26" & 32 \\
\hline
\end{tabular}

Um aspecto positivo no dimensionamento da rota $S A B / C$ é a utilização de um único moinho SAG, o que elimina a necessidade de silos na alimentação do moinho, e permite a instalação de um único transportador de correia para a retomada do material da pilha pulmão e alimentação do moinho SAG. 


\subsection{Rota SSSAG}

Os ensaios em escala piloto, realizados com o moinho SAG em circuito fechado com o classificador espiral (SAG 4 e SAG 5), mostraram dois aspectos a serem destacados. O primeiro foi que a redução do top size da alimentação, simulando a operação de um britagem secundária, levou a um aumento no consumo energético de 12,6 kWh/t para 14,7 kWh/t, enquanto o segundo foi a geração de um produto mais grosseiro no overflow do classificador espiral, $7 \%$ retido em $0,15 \mathrm{~mm}$ para o ensaio SAG 4 e $12 \%$ retido em $0,15 \mathrm{~mm}$ para o ensaio SAG 5 . Com base em tais resultados, decidiu-se adotar a configuração SSSAG sem a britagem secundária, tendo, portanto, por base os resultados do ensaio SAG 4.

Em função da granulometria do produto da moagem no ensaio piloto SAG 4, $7 \%$ retido em $0,15 \mathrm{~mm}$, o circuito foi calibrado no simulador JKSimMet para a simulação de aumento de vazão de alimentação, de forma a se obter $10 \%$ de retidos em $0,15 \mathrm{~mm}$ no produto da moagem. As figuras 72 e 73 comparam os resultados da calibração do classificador espiral e do moinho SAG, respectivamente. As granulometrias completas da calibração e simulações realizadas para a moagem SAG encontram-se no apêndice $C$. 
Figura 72 - Ensaio Piloto SAG 4 - Calibração do Classificador Espiral

Ensaio Piloto SAG 4 - Calibração do Classificador Espiral

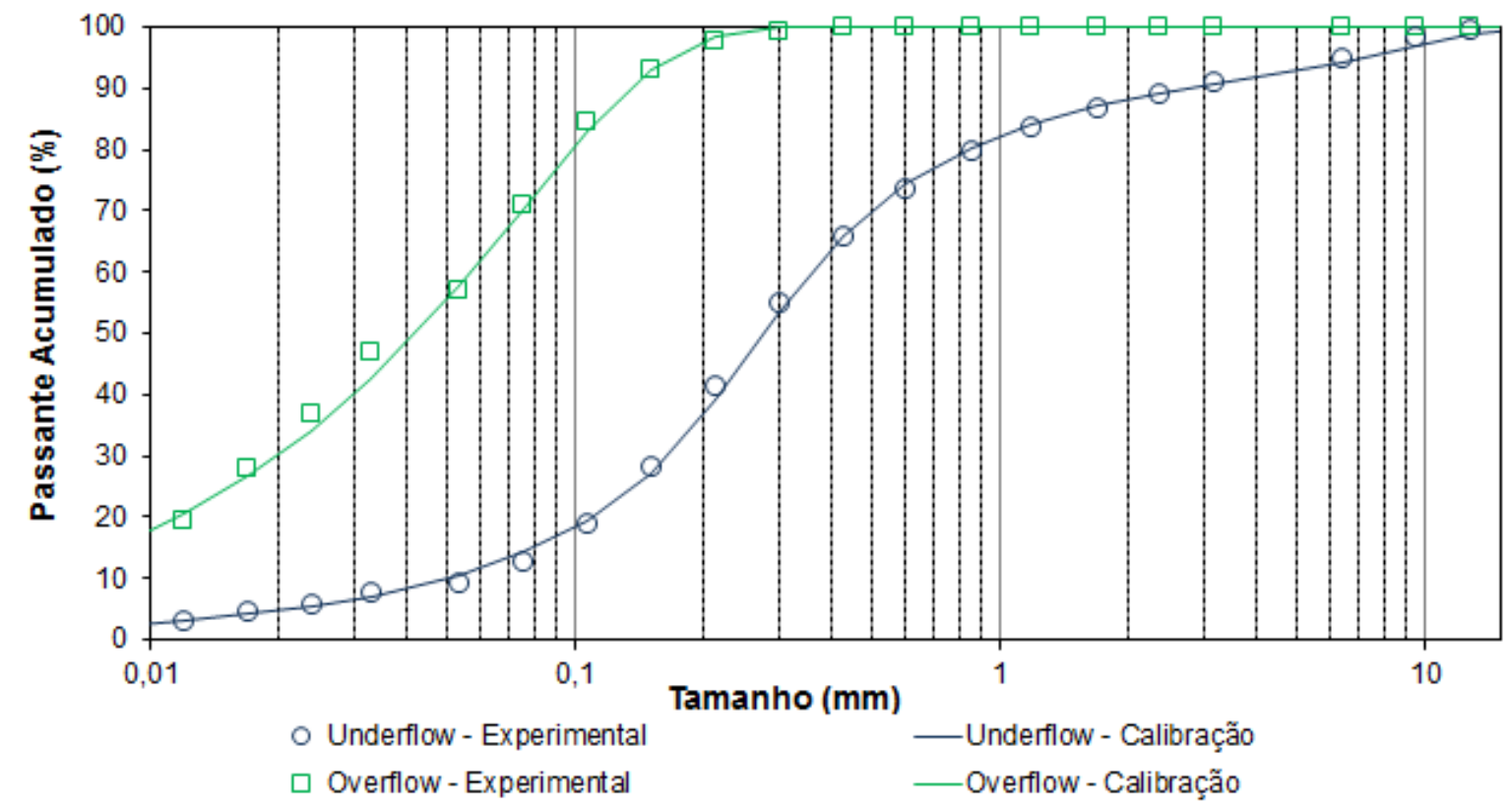

Fonte: Pinto (2015)

Figura 73 - Ensaio Piloto SAG 4 - Calibração do Moinho

Ensaio Piloto SAG 4 - Calibração do Moinho

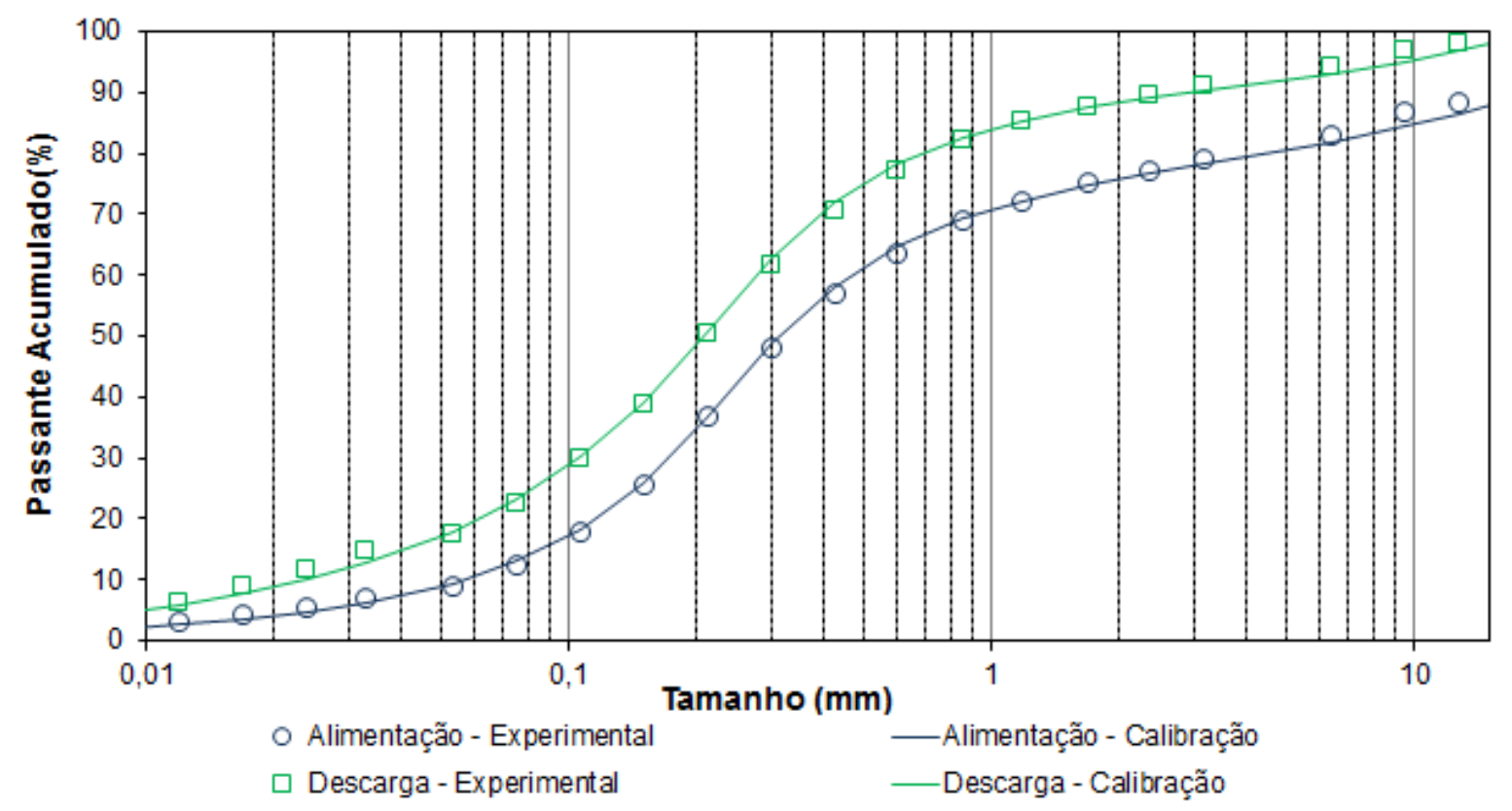

Fonte: Pinto (2015) 
As figuras 74 e 75 mostram, respectivamente, a distribuição do parâmetro $\mathrm{r} / \mathrm{d}^{*}$ e a distribuição da taxa de descarga do moinho SAG conforme obtidas a partir da calibração do moinho SAG.

Figura 74 - Ensaio Piloto SAG 4 - Parâmetro r/d*

Ensaio Piloto SAG 4- Parâmetro $r / d^{*}$

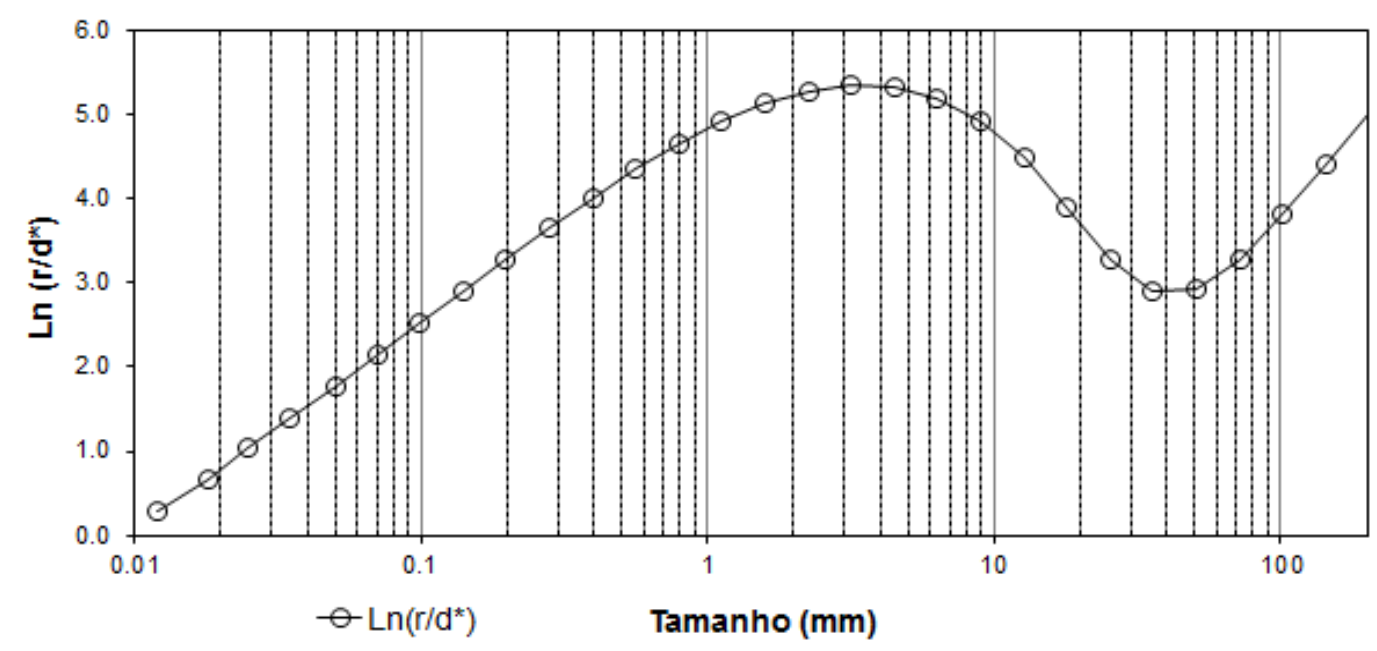

Fonte: Pinto (2015)

Figura 75 - Ensaio Piloto SAG 4 - Taxa de Descarga do Moinho

Ensaio Piloto SAG 4 - Taxa de Descarga

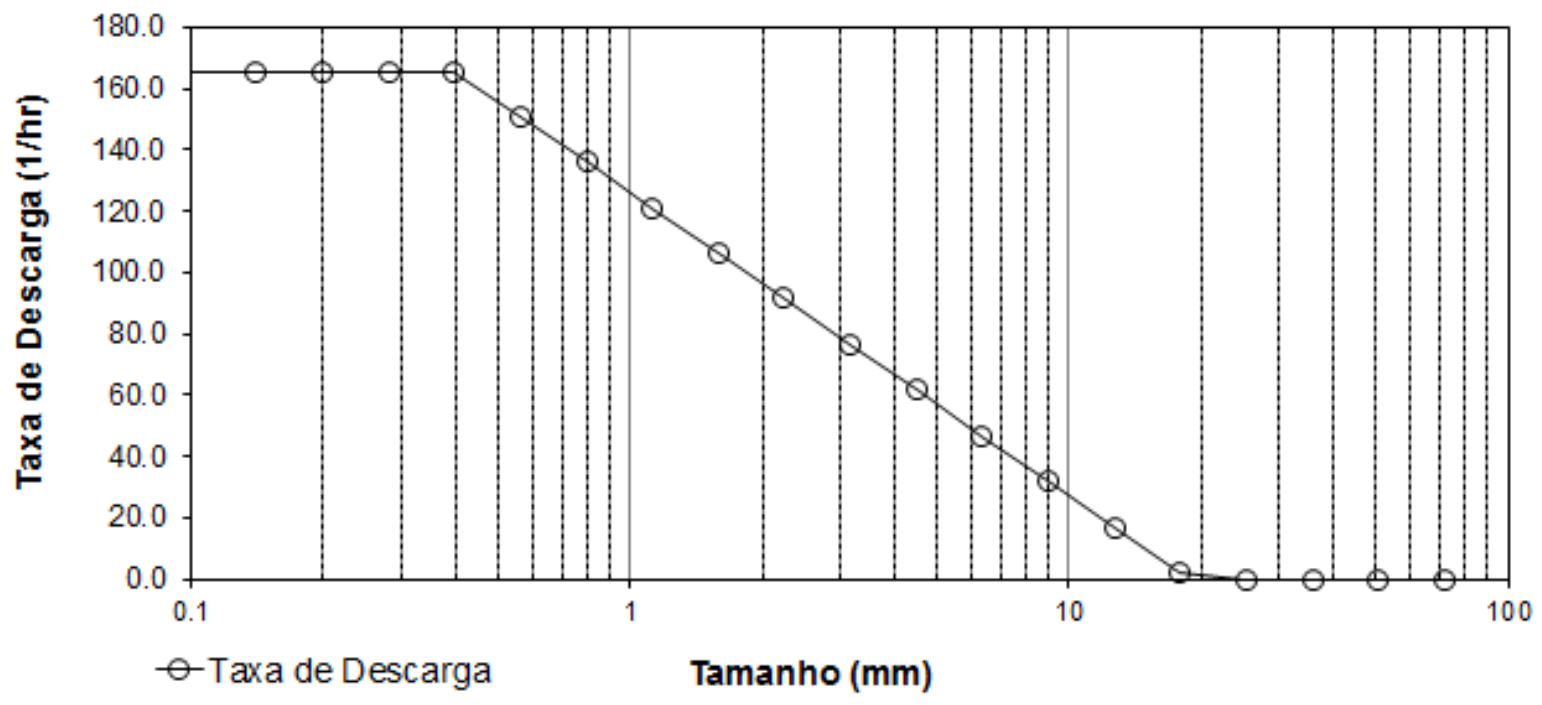

Fonte: Pinto (2015)

A partir da calibração do circuito, foi realizada uma simulação no simulador JKSimMet, com aumento na vazão de alimentação, buscando 10\% retidos em 0,15 
$\mathrm{mm}$ no produto da moagem. A figura 76 compara as granulometrias de descarga do moinho SAG e overflow do ciclone obtidas na simulação com as respectivas granulometrias do circuito calibrado.

Figura 76 - Ensaio Piloto SAG 4 - Granulometria Simulação

Ensaio Piloto SAG 4 - Granulometria Simulação

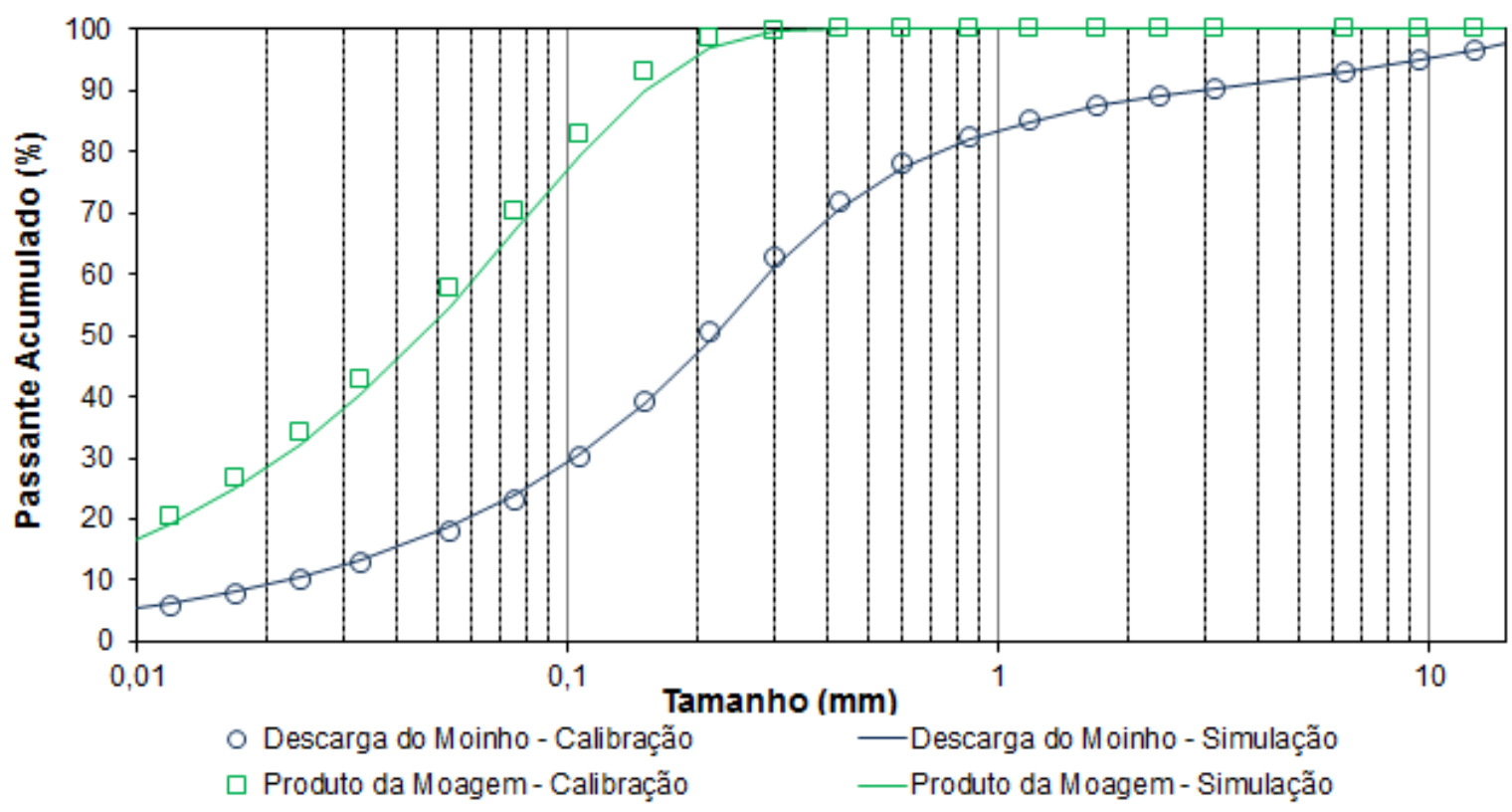

Fonte: Pinto (2015)

A tabela 57 compara os resultados obtidos no ensaio piloto e na simulação com os valores de bancada obtidos para o Wi de Bond e o parâmetro K de Donda. Para o ensaio piloto e a simulação, os valores de Wi de Bond e $\mathrm{K}$ de Donda foram calculados de forma reversa, com base no consumo energético do ensaio piloto e da simulação realizada. 
Tabela 57 - Ensaio Piloto SAG 4 - Resultados da Simulação

\begin{tabular}{cc}
\hline Ensaio Piloto & SAG 4 \\
\hline Percentagem > 0,15mm Produto & 7,00 \\
Potência Medida do Moinho (kW) & 11,67 \\
Vazão de Alimentação (t/h) & 0,93 \\
Percentagem Carga Circulante & 475,67 \\
Percentagem Oversize Tromell & 9,36 \\
Consumo Energia (kWh/t) & 12,6 \\
K - Donda (Calculado) & 0,198 \\
Wl Operacional (kWh/t) & 12,5 \\
\hline Simulação - 10\% >0,15mm & \\
\hline Percentagem > 0,15mm Produto & 9,98 \\
Potência Medida do Moinho (kW) & 11,67 \\
Vazão de Alimentação (t/h) & 0,99 \\
Percentagem Carga Circulante & 405,82 \\
Percentagem Oversize Tromell & 13,03 \\
Consumo Energia (kWh/t) & 11,8 \\
K - Donda (Calculado) & 0,180 \\
Wl Operacional (kWh/t) & 12,7 \\
\hline Valores de Referência & 0,161 \\
\hline K - Donda & 10,9 \\
\hline Wl Bond &
\end{tabular}

A partir do consumo específico de energia obtido na simulação, foi realizado o dimensionamento do moinho SAG para o circuito industrial. Esse dimensionamento foi comparado aos dimensionamentos obtidos através dos métodos de Donda e de Bond. A tabela 58 compara os dimensionamentos realizados para a rota SSSAG. 
Tabela 58 - Rota SSSAG - Dimensionamento do Moinho SAG

\begin{tabular}{cccc}
\hline Método & Bond & Donda & $\begin{array}{c}\text { Teste } \\
\text { Piloto/Simulação }\end{array}$ \\
\hline Vazão de sólidos (t/h) & 3205 & 3205 & 3205 \\
Percentagem >0,15mm - Alimentação & 84 & 84 & 84 \\
Percentagem >0,15mm - Produto & 10 & 10 & 10 \\
F80 $(\mu \mathrm{m})$ & 119568 & 119568 & 119568 \\
P80 $(\mu \mathrm{m})$ & 108 & 108 & 108 \\
Consumo de Energia (kWh/t) & $\mathbf{1 0 , 1 8}$ & $\mathbf{1 3 , 2 1}$ & $\mathbf{1 1 , 8 5}$ \\
Potência Necessária (kW) & $\mathbf{3 2 6 2 6}$ & $\mathbf{4 2 3 4 3}$ & 2 \\
Número de Moinhos & 2 & 2 & $\mathbf{3 6}$ \\
Diâmetro do Moinho (pés) & $\mathbf{3 6}$ & $\mathbf{3 6}$ & $\mathbf{3 3}$ \\
Comprimento do Moinho (pés) & $\mathbf{2 8}$ & $\mathbf{3 6}$ & 10,8 \\
Diâmetro Interno do Moinho (metros) & 10,8 & 10,8 & 9,9 \\
Comprimento interno do Moinho (metros) & 8,4 & 10,8 & 25,0 \\
Percentagem de Enchimento Total do Moinho & 25,0 & 25,0 & 8,0 \\
Percentagem de Bolas do Moinho & 8,0 & 8,0 & 0,4 \\
Porosidade da Carga & 0,4 & 0,4 & 76,0 \\
Percentagem Velocidade Crítica & 76,0 & 76,0 & $\mathbf{3 8 8 3 5}$ \\
Potência Instalada (kW) & $\mathbf{3 2 8 6 0}$ & $\mathbf{4 2 4 2 0}$ &
\end{tabular}

De acordo com os resultados mostrados nas tabelas 57 e 58, tanto o método de Donda, quanto o método de Bond mostraram diferenças significativas em relação ao consumo energético obtido a partir dos resultados de ensaios piloto. Estes mesmos dois métodos também indicaram diferenças significativas em relação ao consumo energético obtido a partir da simulação realizada. .

A partir dos percentuais de oversize do trommel e de carga circulante obtidos no ensaio piloto, foi calculado o balanço de massas do circuito em escala industrial. Como os ensaios piloto para essa rota foram realizados com classificador espiral, foram adotados os mesmos percentuais de sólidos na alimentação e no underflow do ciclone, conforme verificados no ensaio de moagem de bolas para a rota convencional. A figura 77 representa o fluxograma de processo, enquanto a tabela 59 mostra o balanço de massas obtido. 
Figura 77 - Rota SSSAG - Fluxograma de Processo da Moagem

\section{Produto da Britagem} Primária
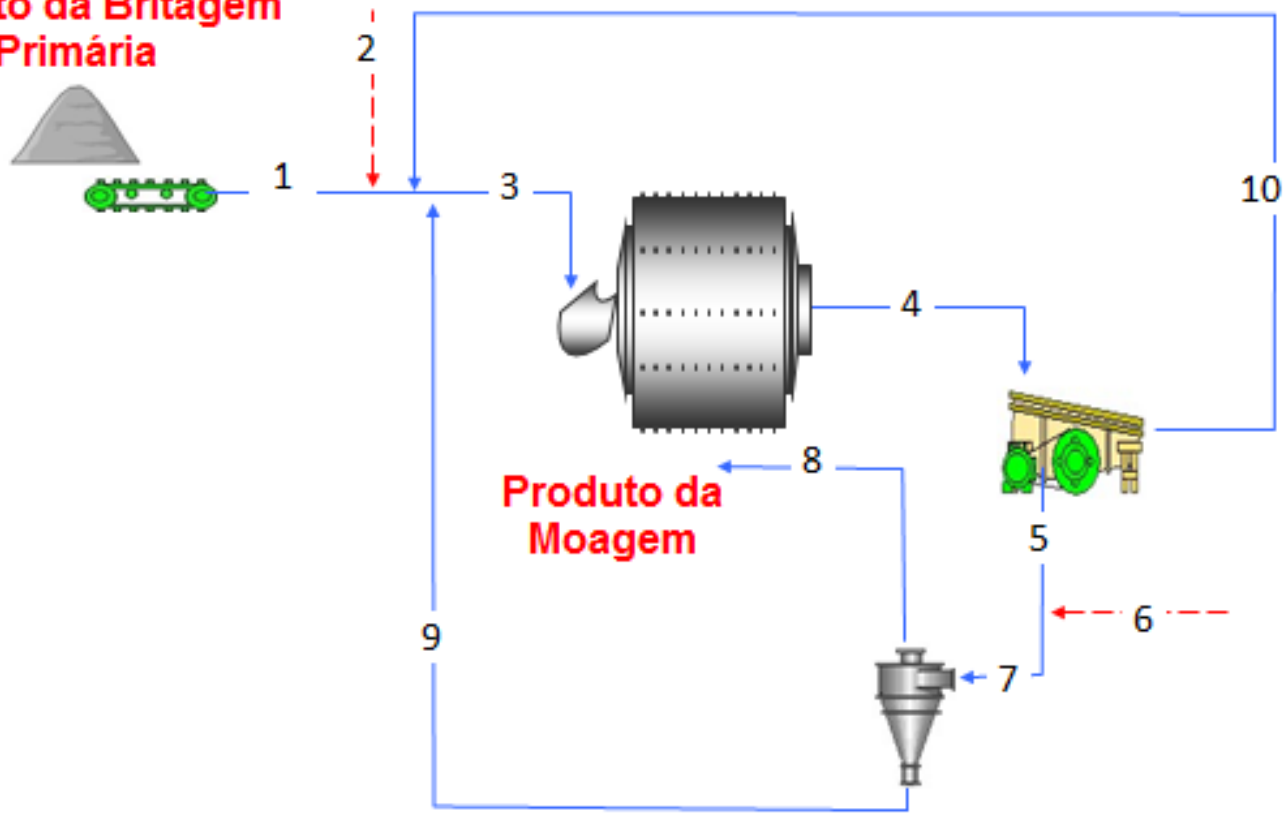

Fonte: Pinto (2015)

Tabela 59 - Rota SSSAG - Balanço de Massa da Moagem

\begin{tabular}{|c|c|c|c|c|c|c|}
\hline & \multirow[t]{2}{*}{ Fluxo } & \multicolumn{2}{|c|}{ Vazão de Sólidos } & \multirow[t]{2}{*}{ \% Sólidos } & \multirow{2}{*}{$\begin{array}{l}\text { Vazão de Polpa } \\
\qquad\left(\mathrm{m}^{3} / \mathrm{h}\right)\end{array}$} & \multirow{2}{*}{$\begin{array}{l}\text { Vazão de Água } \\
\left(\mathrm{m}^{3} / \mathrm{h}\right)\end{array}$} \\
\hline & & th & $\%$ & & & \\
\hline 1 & Alimentação Nova & 3205 & 100 & 95,0 & 995 & 169 \\
\hline 2 & Água Diluição da Moagem & - & - & - & 936 & 936 \\
\hline 3 & Alimentação do Moinho & 16629 & 519 & 78,3 & 8895 & 4609 \\
\hline 4 & Descarga do Moinho & 16629 & 519 & 78,3 & 8895 & 4609 \\
\hline 5 & Undersize da Peneira & 16212 & 506 & 78,0 & 8740 & 4562 \\
\hline 6 & Água Diluição do Ciclone & - & - & - & 6473 & 6473 \\
\hline 7 & Alimentação do Ciclone & 16212 & 506 & 59,5 & 15213 & 11035 \\
\hline 8 & Overflow do Ciclone & 3205 & 100 & 29,7 & 8403 & 7577 \\
\hline 9 & Underflow do Ciclone & 13007 & 406 & 79,0 & 6810 & 3457 \\
\hline & Oversize da Peneira & 418 & 13 & 90,0 & 154 & 46 \\
\hline
\end{tabular}

A tabela 60 mostra os resultados dos dimensionamentos dos ciclones para fechamento do circuito de moagem, enquanto que a tabela 61 mostra a lista de equipamentos de processo dimensionados para a rota SSSAG. 
Tabela 60 - Rota SSSAG - Dimensionamento dos Ciclones

\begin{tabular}{cc}
\hline Parâmetro & $\begin{array}{c}\text { Ciclone de } \\
\text { Classsificação }\end{array}$ \\
\hline Vazão de polpa $\left(\mathrm{m}^{3} / \mathrm{h}\right)$ & 15213 \\
Fator de Projeto & 1,2 \\
Capacidade por Ciclone $\left(\mathrm{m}^{3} / \mathrm{h}\right)$ & 450 \\
Número de Baterias & 4 \\
Ciclones por Bateria Calculado & 10,1 \\
Ciclones por Bateria Adotado & 10 \\
Total de Ciclones Adotado & 40 \\
\hline
\end{tabular}

Tabela 61 - Rota SSSAG - Lista de Equipamentos

\begin{tabular}{ccc}
\hline $\begin{array}{c}\text { Etapa de } \\
\text { Processo }\end{array}$ & $\begin{array}{c}\text { Tipo de } \\
\text { Equipamento }\end{array}$ & $\begin{array}{c}\text { Número de } \\
\text { Equipamentos }\end{array}$ \\
\hline Moagem SAG & $\begin{array}{c}\text { Moinho } 36^{\prime} \times 33^{\prime} \\
19,4 \mathrm{MW}\end{array}$ & 2 \\
$\begin{array}{c}\text { Peneiramento do } \\
\text { SAG }\end{array}$ & $\begin{array}{c}\text { Peneira 12' X 24' } \\
\text { Duplo Deck }\end{array}$ & 2 \\
Ciclones & Ciclone de 26" & 40 \\
\hline
\end{tabular}

As alternativas para alimentação dos dois moinhos SAG a partir da pilha pulmão são: a implantação de dois transportadores de correia para retomada do minério da pilha pulmão, e alimentação direta dos moinhos, ou um único transportador de correia alimentando um silo, além de dois alimentadores para alimentação do moinho.

A primeira alternativa, com a construção de dois transportadores, pode ter um impacto significativo no CAPEX do projeto, posto que estes transportadores são longos, acima de 500 metros, e é necessária a construção de um túnel sob a pilha pulmão para instalação do transportador de correia. 
A segunda alternativa, com alimentação dos moinhos através de um silo com dois alimentadores, pode levar a sérios problemas operacionais, como entupimentos e obstruções dos alimentadores dos moinhos, posto que o moinho SAG seria alimentado com produto de britador primário, portanto, com a presença de blocos acima de $200 \mathrm{~mm}$.

Enquanto os ensaios piloto para a rota SSSAG foram realizados em um moinho com relação comprimento versus diâmetro de 0,3, o moinho do circuito industrial foi dimensionado com uma relação comprimento versus diâmetro de 0,9. Essa alteração nas dimensões do moinho pode levar a alterações significativas na carga circulante, e até mesmo no consumo energético da moagem. Para uma estimativa da operação do circuito com um moinho de maior relação comprimento versus diâmetro, foi realizada uma simulação do circuito do ensaio piloto com um moinho de 6 pés de diâmetro por 6 pés de comprimento. $O$ consumo de energia da simulação realizada foi calculado pela equação de Austin, equação 3.3. O resultado indicou um consumo específico de 11,7 kWh/t, bem próximo, portanto, ao valor de $11,8 \mathrm{kWh} / \mathrm{t}$ obtido para a simulação sem alteração nas dimensões do moinho. A tabela 62 mostra o balanço de massas obtido a partir da simulação descrita.

Tabela 62 - Rota SSSAG - Balanço de Massa da Simulação Moinho 6' X 6'

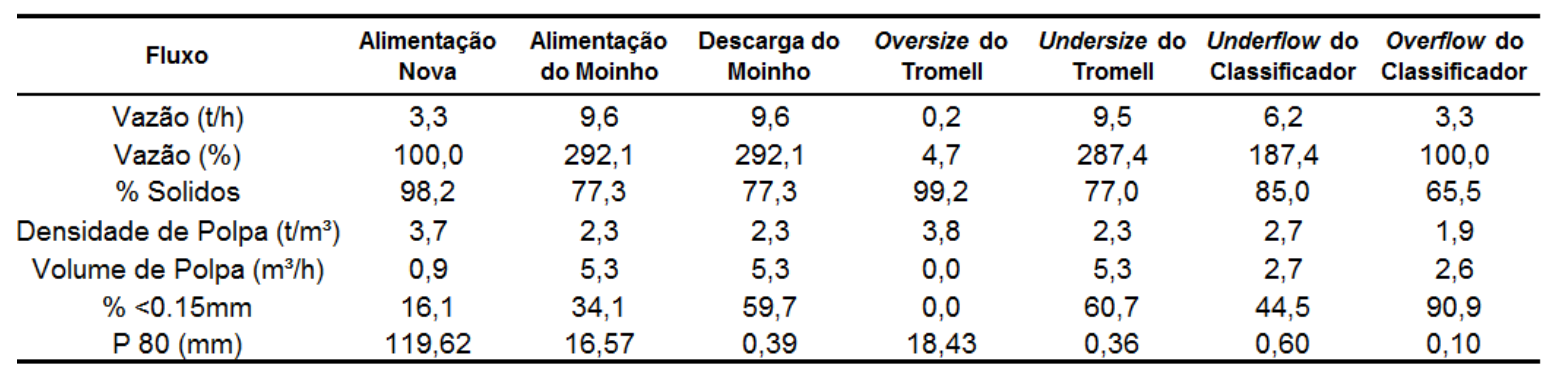

Conforme mostrado na tabela 62, a alteração nas dimensões do moinho levou a uma redução significativa na carga circulante, que ficou em 187\%, contra $406 \%$ obtida na simulação sem alteração das dimensões do moinho SAG. Essa redução na carga circulante diminui consideravelmente o fluxo de polpa no moinho SAG, cujos resultados são a redução das dimensões das bombas e da quantidade de ciclones utilizados para fechamento do circuito de moagem. 
De toda forma, é recomendável a realização de ensaio piloto com um moinho, com uma relação comprimento versus diâmetro entre 0,8 e 1, para confirmação da redução da carga circulante e da manutenção do consumo específico de energia. 


\subsection{Comparação das Rotas de Cominuição}

As rotas para cominuição de itabiritos compactos desenvolvidas neste trabalho foram comparadas com base nos seguintes aspectos:

1- Geração de lamas no produto da moagem,

2- Consumo energético, e

3- Quantitativo de equipamentos de processo (cominuição, peneiramento e classificação).

\subsubsection{Geração de Lamas}

A tabela 63 mostra o percentual de lamas, material abaixo de $0,010 \mathrm{~mm}$, no produto da moagem para as quatro rotas estudadas, considerando os resultados obtidos diretamente nos ensaios piloto e através das simulações realizadas. Como para as rotas SAB e SABC não foram realizadas simulações, adotou-se o percentual de lamas obtidos nos respectivos ensaios piloto.

Tabela 63 - Comparação do Percentual de Lamas no Produto da Moagem

\begin{tabular}{ccc}
\hline $\begin{array}{c}\text { Percentual de Lamas }(<0,010 \mathrm{~mm}) \text { no } \\
\text { Produto da Moagem }\end{array}$ & Teste Piloto & Simulação \\
\hline Rota Convencional & 13,7 & 17,0 \\
Rota SAB & 14,4 & - \\
Rota SABC & 13,6 & - \\
Rota SSSAG & 14,7 & 15,4 \\
\hline
\end{tabular}

De acordo com os resultados mostrados na tabela 63 , as quantidades de lamas contidas no produto da moagem dos ensaios piloto foram similares para as quatro rotas estudadas. Neste caso, não é possível verificar uma tendência de maior geração de lamas para qualquer das rotas a partir dos resultados obtidos.

Os percentuais de lama no produto da moagem previstos pelas simulações realizadas não está coerente com os valores esperados. Para a rota SSSAG, a simulação teve por objetivo aumentar o percentual retido em $0,15 \mathrm{~mm}$ de $7 \%$ para 
$10 \%$, reduzindo a ação da moagem sobre o material. Dessa forma, considerou-se inconsistente a previsão de um aumento no percentual de lamas de $14,7 \%$ para $15,4 \%$, respectivamente. Da mesma forma, para a rota convencional, o simulador previu um aumento no percentual de lamas de $13,7 \%$ obtido no ensaio piloto para $17,0 \%$ na simulação. Esse aumento é muito expressivo, mesmo considerando que a simulação reduziu de $14,2 \%$ para $9,9 \%$ o percentual retido em $0,15 \mathrm{~mm}$ no produto da moagem.

\subsubsection{Consumo de Energia}

A tabela 64 mostra os valores de consumo de energia, por operação de cominuição, para cada uma das rotas estudadas.

Tabela 64 - Comparação do Consumo de Energia para as Rotas de Cominuição

\begin{tabular}{ccccc}
\hline $\begin{array}{c}\text { Consumo de Energia (kWh/t) } \\
\text { por Etapa de Cominuiçäo }\end{array}$ & $\begin{array}{c}\text { Rota } \\
\text { Convencional }\end{array}$ & Rota SAB & Rota SABC & $\begin{array}{c}\text { Rota } \\
\text { SSSAG }\end{array}$ \\
\hline Britagem & 2,0 & - & 0,2 & \\
Moagem SAG & - & 8,0 & 6,5 & 11,8 \\
Moagem de Bolas & 12,4 & 7,8 & 7,8 & \\
Consumo Total & $\mathbf{1 4 , 4}$ & $\mathbf{1 5 , 8}$ & $\mathbf{1 4 , 5}$ & $\mathbf{1 1 , 8}$ \\
\hline
\end{tabular}

A rota SSSAG mostrou o menor consumo de energia, 11,8 kWh/t. A rota convencional e a rota SABC apresentaram consumos energéticos próximos, 14,4 $\mathrm{kWh} / \mathrm{t}$ e $14,5 \mathrm{kWh} / \mathrm{t}$, respectivamente, enquanto a rota SAB indicou o maior consumo de energia, 15,8 kWh/t.

Esses resultados mostram que a moagem SAG tem um menor consumo de energia para a cominuição de itabiritos compactos, se comparada à moagem em moinhos de bolas. Essa maior eficiência energética fica mais acentuada quando é comparado o consumo da rota SSSAG com o moinho de bolas da rota convencional, $11,8 \mathrm{kWh} / \mathrm{t}$ contra $12,4 \mathrm{kWh} / \mathrm{t}$, respectivamente. Ou seja, o moinho SAG em circuito fechado teve um consumo inferior ao moinho de bolas, mesmo com uma alimentação significativamente mais grosseira, conforme mostrado na figura 78 . 
Figura 78 - Granulometria - Alimentação do Moinho de Bolas e do Moinho SAG

Granulometria - Alimentação do Moinho de Bolas e do Moinho SAG

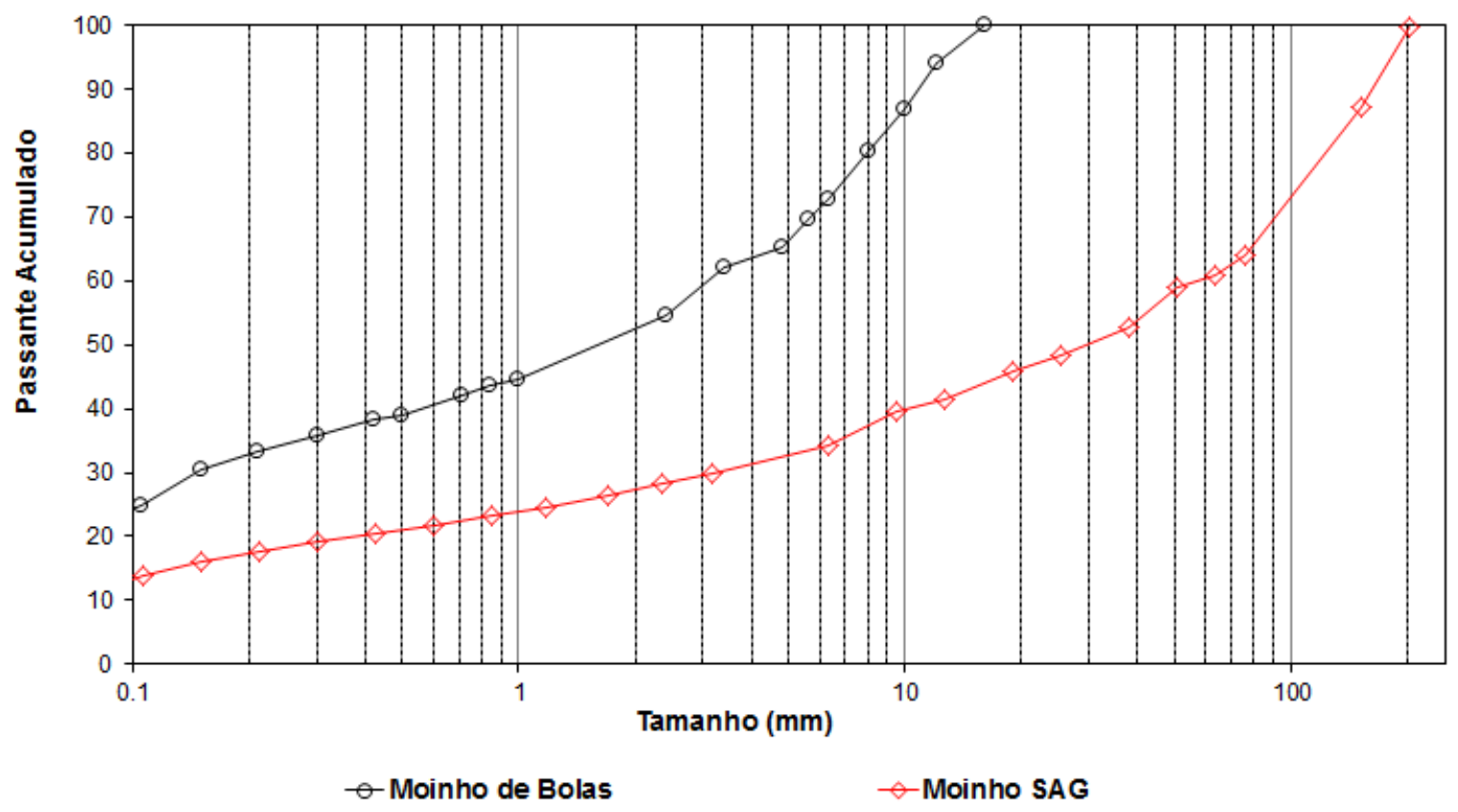

Fonte: Pinto (2015)

Além do menor consumo de energia, a moagem SAG pode levar a uma redução significativa do consumo de corpos moedores, principalmente se for considerado que o minério apresentou uma abrasividade moderadamente alta, conforme estimada pelo índice de abrasão de Bond, cujo resultado foi de 0,493.

\subsubsection{Quantitativo de Equipamentos}

A tabela 65 mostra o quantitativo de equipamentos de processo para cada rota estudada.

Tabela 65 - Comparação do Quantitativo de Equipamentos para as Rotas de Cominuição

\begin{tabular}{|c|c|c|c|c|c|c|c|}
\hline \multirow{2}{*}{$\begin{array}{c}\text { Rotas de } \\
\text { Cominuição }\end{array}$} & \multirow{2}{*}{$\begin{array}{c}\text { Britadores - } \\
600 \mathrm{~kW}\end{array}$} & \multirow{2}{*}{$\begin{array}{l}\text { Peneiras - } \\
\text { 12'X24' }\end{array}$} & \multirow{2}{*}{$\begin{array}{c}\text { Ciclone - } \\
26 "\end{array}$} & \multicolumn{2}{|c|}{ Moinhos SAG } & \multicolumn{2}{|c|}{ Moinhos de Bolas } \\
\hline & & & & $\begin{array}{c}\text { Potência } \\
\text { (MW) }\end{array}$ & Quantidade & $\begin{array}{l}\text { Potência } \\
\text { (MW) }\end{array}$ & Quantidade \\
\hline Rota Convencional & 12 & 15 & 42 & 0,0 & 0 & 13,2 & 3 \\
\hline Rota SSSAG & 0 & 2 & 40 & 19,4 & 2 & 0,0 & 0 \\
\hline Rota SAB & 0 & 1 & 32 & 26,1 & 1 & 12,6 & 2 \\
\hline Rota SABC & 1 & 1 & 32 & 21,6 & 1 & 12,6 & 2 \\
\hline
\end{tabular}


A rota convencional apresenta o maior número de equipamentos, principalmente em função do elevado número de peneiras e britadores. Esses equipamentos demandam grandes estruturas civis e equipamentos de manuseio, como silos, alimentadores e transportadores de correia, que aumentam, de forma significativa, o CAPEX do projeto, além de aumentar a área impactada pelo projeto.

As rotas de moagem SAG, SAB/C e SSSAG indicaram um número significativamente menor de equipamentos, o que permite a utilização de apenas um prédio para os equipamentos de cominuição, com correspondente redução na área impactada pelo projeto.

A rota SSSAG possui a menor quantidade de moinhos, apenas dois moinhos SAG. Todavia, é necessária atenção para o manuseio da alimentação dos moinhos SAG, posto que é necessária a divisão da alimentação nova, com material passante em $200 \mathrm{~mm}$, para dois moinhos. Desta forma, seriam necessárias as implantações de dois transportadores de correia para retomada do material da pilha pulmão ou, alternativamente, a instalação de um silo com dois alimentadores para alimentarem os moinhos SAG. 


\section{CONCLUSÕES}

Nos estudos realizados para desenvolvimentos de rotas de cominuição para itabiritos compactos a rota SSSAG indicou o menor consumo de energia, 11,8 kWh/t, enquanto a rota $S A B$ indicou o maior consumo, $15,8 \mathrm{kWh} / \mathrm{t}$. As rotas convencional e SABC - apresentaram um consumo semelhante de energia, quais sejam, 14,4 kWh/t e $14,5 \mathrm{kWh} / \mathrm{t}$, respectivamente. Além do menor consumo de energia, a rota SSSAG possui também o menor quantitativo de equipamentos de cominuição com apenas dois moinhos SAG, o que permite uma instalação mais compacta.

De toda forma, para uma maior assertividade na previsão da carga circulante e do fluxo de polpa dentro do moinho SAG para a rota SSSAG, recomenda-se a realização de ensaios piloto em um moinho com relação comprimento versus diâmetro (L/D) entre 0,8 e 1. O moinho utilizado no ensaio piloto descrito neste estudo apresentava uma relação $L / D$ de 0,3 , resultando em uma carga circulante de $475 \%$. A simulação realizada com um moinho de relação L/D de 1 mostrou redução na carga circulante para $187 \%$, sem impacto no consumo específico de energia. Todavia, é importante a confirmação desses resultados através de ensaios em escala piloto.

Além dos pontos citados acima, foi possível obter as seguintes conclusões durante o desenvolvimento do trabalho:

- Na rota convencional de cominuição, é necessário o emprego de quatro estágios de britagem para geração de produto menor que 12,7 mm para alimentação da moagem, de forma a minimizar a geração de oversize (expurgo) no trommel.

- Os dados de capacidade dos britadores cônicos, fornecidos pelo catálogo do fabricante selecionado, se mostraram coerentes com a vazão de alimentação do britador obtida em ensaio industrial. Desta forma, considerou-se válida a utilização das informações de catálogo para dimensionamento dos britadores cônicos, sem a necessidade de aplicação de fatores de restrição de capacidade.

- A utilização de britagem secundária, com a redução do top size de alimentação do moinho SAG, levou a um aumento no consumo energético da 
moagem SAG, tanto para a rota SAB/C quanto SSSAG. Dessa forma, é recomendada a alimentação da moagem SAG com produto da britagem primária, salvo a necessidade de redução do top size da alimentação, em função de restrições ao manuseio de fragmentos relativamente grosseiros

- A utilização de britagem de pebbles levou a uma redução de $18,8 \%$ no consumo de energia da moagem SAG para a rota $S A B / C$, sem aumento no consumo de energia da moagem de bolas.

- O consumo energético previsto pelo método de Donda ficou próximo ao obtido nos ensaios em escala piloro para a rota convencional e SAB/C. Já o consumo energético previsto pelo método de Bond mostrou consumos de energia significativamente inferiores aos obtidos nos ensaios, em escala piloto, para todas as rotas estudadas.

- O percentual de lamas, material passante em 0,010 mm, no produto da moagem dos ensaios piloto, apresentou valores semelhantes para todas as rotas estudadas, variando de $13,6 \%$ para a rota $S A B C$ a $14,7 \%$ para a rota SSSAG. As simulações realizadas para as rotas convencional e SSSAG mostraram valores inconsistentes de percentual de lamas no produto da moagem. 


\section{REFERÊNCIAS}

ALMEIDA, S.L.M.; FIGUEIRA, H.V.O.; LUZ, A.B. Cominuição. In: SAMPAIO, J.A.; ALMEIDA, S.L.M.; LUZ, A.B. Tratamento de minérios. 4. ed. Rio de Janeiro: CETEM/MCT, 2004. p. 113-193.

ALVES, V.K. Otimização de carga moedora utilizando ferramentas de modelamento matemático e simulação de moagem. 2006. 155 p. Dissertação (Mestrado) - Escola de Engenharia, Universidade Federal de Minas Gerais, Belo Horizonte, 2006.

ASBJÖRNSSON, G.; HULTÉN, E.; EVERTSSON, M. Modelling and simulation of dynamic crushing plant behaviour with MATLAB/Simulink. Minerals Engineering, Oxford, v. 43-44, p. 112-120, Apr. 2013. / Apresentado ao INTERNATIONAL COMMINUTION SYMPOSIUM, $8^{\text {th }}$, 2012, Cape Town, South Africa $/$.

AUSTIN, L.G. Mill power equations for SAG mills. Minerals and Metallurgical Processing, Littleton, v. 7, n. 1, p. 57-63, Feb. 1990.

AZZARONI, E. Tamaño de lós medios de molienda y práctica de recarga múltiple. In: SIMPOSIUM SOBRE MOLIENDA, 3., 1980, Santiago. Anales. Santiago: ARMCO Chile , 1980.

BERALDO, J.L. Moagem de minérios em moinhos tubulares. São Paulo: Edgard Blucher, 1987. $143 \mathrm{p}$.

BERGERMAN, M.G. Modelagem e simulação do circuito de moagem do Sossego. 2009. 208 p. Dissertação (Mestrado) - Escola Politécnica, Universidade de São Paulo, São Paulo, 2009.

BURGER, B.; VARGAS, L.; AREVALO, H.; VICUNA, S.; SEIDEL, J.; VALERY, W.; JANKOVIC, A.; VALLE, R.; NOZAWA, E. Yanacocha gold single stage SAG mill design, operation and optimization. In: INTERNATIONAL CONFERENCE ON AUTOGENOUS AND SEMIAUTOGENOUS GRINDING TECHNOLOGY, 2011, Vancouver, Canada. Proceedings. [Westmount]: Canadian Institute of Mining and Metallurgy, 2011. 1 CD-ROM

BOND, F.C. Lab equipment and tests help predict metal consumption in crushing and grinding units. Engineering Mining Journal, New York, v.165, n.6, p.169-176, Jun. 1964.

BOND, F. C. Testing and calculations. In: WEISS ,N.L. SME mineral processing handbook. New York: American Institute of Mining, Metallurgical, and Petroleum Engineers, 1985. v.1, pt.2, Section 3, Chap. 5, p. 3A-16/3A-27.

CARRISSO, R.C.C.; CORREIA, J.C.G. Classificação e peneiramento. In: LUZ, A.B.; SAMPAIO, J.A., ALMEIDA, S.L.M. Tratamento de minérios. 4. ed. Rio de Janeiro: CETEM/MCT, 2004. p. 195-238. 
CHAVES, A.P.; PERES, A.E.C. Teoria e prática do tratamento de minérios. 2. ed. São Paulo: Signus Editora, 2003. v. 3: Britagem, peneiramento e moagem.

DANCE, A.; VALERY, W.; ROFE, A.; RADFORD, A. Conversion of the Barrick Granny Smith grinding circuit to single stage SAG milling. In: INTERNATIONAL CONFERENCE ON AUTOGENOUS AND SEMIAUTOGENOUS GRINDING TECHNOLOGY, 2011, Vancouver, Canada. Proceedings. [Westmount]: Canadian Institute of Mining and Metallurgy, 2011. 1 CD-ROM

DELBONI JUNIOR, H. Modelagem e simulação dos circuitos de moagem e classificação. São Paulo: Universidade de São Paulo, 2003. Apostila para disciplina de pós graduação do Departamento de Engenharia de Minas e de Petróleo, PMI-5004 - Modelagem e Simulação dos Circuitos de Moagem e Classificação.

DELBONI JUNIOR, H.; ROSA, M.A.N.; BERGERMAN, M.G.; NARDI, R.P. Optimisation of the Sossego SAG mill. In: INTERNATIONAL CONFERENCE ON AUTOGENOUS AND SEMIAUTOGENOUS GRINDING TECHNOLOGY, 2006, Vancouver, Canada. Proceedings. Vancouver: University of British Columbia. Department of Mining Engineering, 2006. v.1, p.1/39-1/50.

DELBONI JUNIOR, H. Cominuição. In: FERNANDES, F. et al. (Ed.). Tendências tecnológicas Brasil 2015: Geociências e tecnologia mineral. Rio de Janeiro: CETEM/MCT, 2007. p.103-131.

DONDA, J.D. Um método para prever o consumo específico de energia na (re)moagem de concentrados de minérios de ferro em moinhos de bolas. 2003. 136 p. Tese (Doutorado) - Escola de Engenharia, Universidade Federal de Minas Gerais, Belo Horizonte, 2003.

DONDA, J.D.; ROSA, A.C. A lei de moagem: comprovação para minério de ferro. Ouro Preto: L\&E Graphar, 2014. 219 p.

ENERGY EFFICIENCY EXCHANGE. Canberra Austrália. Crushing Energy Costs in the Mining Sector. Disponível em: http://eex.gov.au/2013/11/crushingenergy-costs-in-the-mining-sector/ Acesso em 24 mai. 2015.

FOGGIATO, B. Previsão de desempenho do circuito de moagem de Carajás. 2009. 232 p. Dissertação (Mestrado) - Escola Politécnica, Universidade de São Paulo, São Paulo, 2009.

HERBST, J.A.; LO, Y.C.; FLINTOFF, B. Size reduction and liberation. In: FUERSTENAU, M.C.; HAN, K.N. Principles of mineral processing. Littleton: Society for Mining, Metallurgy, and Exploration, 2003. p. 119-173.

HULTÉN, E.; ASBJÖRNSSON, G.; EVERTSSON, M. Tuning of real-time algorithm for crushing plants using a dynamic crushing plant simulator. In: INTERNATIONAL COMMINUTION SYMPOSIUM, $8^{\text {th }}$, 2012, Cape Town, South Africa. Comminution '12: proceedings. Cornwall, UK: MEI Conferences, 2012. 1 CD ROM. 
KELSALL, D.F. A further study of the hydraulic cyclone. Chemical Engineering Science, v.2, p. 254-272, Dec. 1953.

KOJOVIC, T., MORREL, S., MORRISON, R.D., NAPIER-MUNN, T.J., Mineral Comminuition Circuits; Their Operation and Optimisation, 2nd Edition. Australia: Julius Kruttschnitt Mineral Research Centre, 1999. 413p.

LATCHIREDDI, S.R. Moddeling the performance of grates and pulp lifters in autogenous and semi autogenous mills. 2002. 282 p. Thesis (PhD) - Julius Kruttschnitt Mineral Research Centre, University of Queensland, Brisbane, 2002.

LYNCH, A.J., Mineral Crushing and Grinding Circuits: Their Simulation, Optimisation, Design and Control. New York: Elsevier Scientific Publishing Company, 1977. 340 p.LIMA, N.P.; SILVA, K.C.; PENA, I.J. Metodologia empregada para escalonamento de circuitos de peneiramento e britagem. In: SIMPÓSIO BRASILEIRO DE MINÉRIO DE FERRO, 10., 2009, Ouro Preto. Anais. São Paulo: ABM, 2009. 1 CD-ROM.

LIMA, N.P.; PINTO, P.H.F.; RODRIGUES, A.F.V.; DELBONI JUNIOR, H. Rotas de cominuição para itabiritos do Quadrilátero Ferrífero. In: SIMPÓSIO BRASILEIRO DE MINÉRIO DE FERRO, 14., 2013, Belo Horizonte. Anais. São Paulo: ABM, 2013. 1 CD-ROM.

NAPIER-MUNN, T.J.; KOJOVIC, T.; MORREL, S.; MORRISON, R.D. (Ed.). Mineral comminution circuits: their operation and optimization. $2^{\text {nd }}$. ed. Indooroopilly, Qld: Julius Kruttschnitt Mineral Research Centre, 1999. 413 p.

MARQUES, M.L.S. Comportamento de minérios de ferro na concentração por flotação na presença de lamas. 2013. 88 p. Dissertação (Mestrado) - Escola de Engenharia, Universidade Federal de Minas Gerais, Belo Horizonte, 2013.

METSO MINERALS. Manual de britagem. 6 ed. São Paulo, 2005.

MONTENEGRO, L.C.M. Aplicação de métodos numéricos na simulação da moagem em moinhos de bolas utilizando o modelo do balanço populacional. 1997. 255 p. Dissertação (Mestrado) - Escola de Engenharia, Universidade Federal de Minas Gerais, Belo Horizonte,1997.

RABELO, P.J.B. DONDA, J.D. PERES, A.E.C. CHAVES, A.P. Rittinger, 1,4 séculos depois uma demonstração de sua aplicação a uma instalação industrial. Metalurgia e Materiais Caderno Técnico, São Paulo, v.6, p.463-467, 2007.

ROWLAND,C.A. Ball mill scale up - diameter factors. In: SYMPOSIUM HONORING NATHANIEL ARBITER ON HIS $75^{\text {TH }}$ BIRTHDAY, 1986, New Orleans. Advances in mineral processing: a half-century of progress in application of theory to practice: proceedings... Littleton: Society of Mining Engineers of AIME, 1986. p. 605-617.

SANDVIK. Manual de britadores cônicos. São Paulo, 2011. 1v. 
SOUZA, E.S. Rota de processo para aproveitamento de rochas itabiríticas estéreis da Mina de Conceição. 2005. 104 p. Dissertação (Mestrado) Escola de Engenharia, Universidade Federal de Minas Gerais, Belo Horizonte, 2005.

TAVARES, L.M. Caracterização tecnológica de amostras de minério de cobre de Salobo usando a Célula de Carga de Impacto COPPE, Rio de Janeiro, Fundação COOPETEC, 2003, 22p. (Relatório de Projeto PEMM4535).

WHITEN, W.J. A matrix theory of comminution machines. Chemical Engineering Science, v. 29, n.2, p. 589-599, 1974.

WILLS, B.A.; NAPIER-MUNN, T. Will's mineral processing technology: an introduction to the practical aspects of ore treatment and mineral recovery. $7^{\text {th }}$ ed. Amsterdam: Elsevier Science, 2006. 444 p. 


\section{APÊNDICE A}

\section{Resultados do Ensaio Industrial de Britagem}

Amostra 1

\begin{tabular}{|c|c|c|c|c|c|c|c|}
\hline \multirow[b]{2}{*}{$\begin{array}{l}\text { Malha } \\
(\mathrm{mm})\end{array}$} & \multicolumn{3}{|c|}{ Alimentação } & \multicolumn{3}{|c|}{ Descarga } & \multirow[b]{2}{*}{$\begin{array}{c}\text { Eficiencia } \\
(\%)\end{array}$} \\
\hline & $\begin{array}{l}\text { Ret. } \\
\text { Simples } \\
(\%)\end{array}$ & $\begin{array}{c}\text { Ret. } \\
\text { Acumulado } \\
(\%)\end{array}$ & $\begin{array}{c}\text { Pass. } \\
\text { Acumulado } \\
(\%)\end{array}$ & $\begin{array}{l}\text { Ret. } \\
\text { Simples } \\
(\%)\end{array}$ & \begin{tabular}{|c|} 
Ret. \\
Acumulado \\
$(\%)$
\end{tabular} & $\begin{array}{c}\text { Pass. } \\
\text { Acumulado } \\
\text { (\%) }\end{array}$ & \\
\hline 100,0 & 0,00 & 0,00 & 100,00 & 0,00 & 0,00 & 100,00 & \\
\hline 76,0 & 2,98 & 2,98 & 97,02 & 0,00 & 0,00 & 100,00 & $100 \%$ \\
\hline 63,0 & 23,47 & 26,45 & 73,55 & 0,00 & 0,00 & 100,00 & $100 \%$ \\
\hline 50,0 & 39,14 & 65,59 & 34,41 & 0,38 & 0,38 & 99,62 & $99 \%$ \\
\hline 45,0 & 8,88 & 74,47 & 25,53 & 2,27 & 2,65 & 97,35 & $96 \%$ \\
\hline 40,0 & 14,15 & 88,62 & 11,38 & 3,10 & 5,75 & 94,25 & $94 \%$ \\
\hline 38,0 & 2,88 & 91,50 & 8,50 & 4,89 & 10,64 & 89,36 & $88 \%$ \\
\hline 31,5 & 5,65 & 97,15 & 2,85 & 13,72 & 24,36 & 75,64 & $75 \%$ \\
\hline 25,0 & 2,40 & 99,54 & 0,46 & 25,30 & 49,66 & 50,34 & $50 \%$ \\
\hline 19,0 & 0,08 & 99,62 & 0,38 & 16,12 & 65,78 & 34,22 & $34 \%$ \\
\hline 16,0 & 0,00 & 99,62 & 0,38 & 5,02 & 70,80 & 29,20 & $29 \%$ \\
\hline 12,5 & 0,08 & 99,70 & 0,30 & 6,74 & 77,53 & 22,47 & $22 \%$ \\
\hline 10,0 & 0,01 & 99,71 & 0,29 & 3,44 & 80,97 & 19,03 & $19 \%$ \\
\hline 8,0 & 0,04 & 99,74 & 0,26 & 3,64 & 84,62 & 15,38 & $15 \%$ \\
\hline 6,4 & 0,01 & 99,75 & 0,25 & 2,25 & 86,87 & 13,13 & $13 \%$ \\
\hline 5,8 & 0,00 & 99,76 & 0,24 & 1,03 & 87,90 & 12,10 & $12 \%$ \\
\hline 4,8 & 0,02 & 99,78 & 0,22 & 1,56 & 89,46 & 10,54 & $10 \%$ \\
\hline 3,4 & 0,02 & 99,79 & 0,21 & 1,95 & 91,41 & 8,59 & $8 \%$ \\
\hline 2,4 & 0,01 & 99,80 & 0,20 & 1,55 & 92,95 & 7,05 & $7 \%$ \\
\hline 1,0 & 0,01 & 99,81 & 0,19 & 2,06 & 95,02 & 4,98 & $5 \%$ \\
\hline 0,84 & 0,00 & 99,81 & 0,19 & 0,28 & 95,30 & 4,70 & $5 \%$ \\
\hline 0,71 & 0,00 & 99,81 & 0,19 & 0,30 & 95,60 & 4,40 & $4 \%$ \\
\hline 0,50 & 0,00 & 99,82 & 0,18 & 0,20 & 95,80 & 4,20 & $4 \%$ \\
\hline 0,42 & 0,00 & 99,82 & 0,18 & 0,41 & 96,21 & 3,79 & $4 \%$ \\
\hline 0,30 & 0,01 & 99,83 & 0,17 & 0,31 & 96,52 & 3,48 & $3 \%$ \\
\hline 0,21 & 0,01 & 99,83 & 0,17 & 0,31 & 96,83 & 3,17 & $3 \%$ \\
\hline 0,15 & 0,01 & 99,84 & 0,16 & 0,23 & 97,06 & 2,94 & $3 \%$ \\
\hline 0,106 & 0,01 & 99,85 & 0,15 & 0,29 & 97,35 & 2,65 & $3 \%$ \\
\hline 0,075 & 0,02 & 99,87 & 0,13 & 0,46 & 97,81 & 2,19 & $2 \%$ \\
\hline 0,045 & 0,03 & 99,90 & 0,10 & 0,63 & 98,44 & 1,56 & $1 \%$ \\
\hline$-0,045$ & 0,10 & 100,00 & 0,00 & 1,56 & 100,00 & 0,00 & $0 \%$ \\
\hline
\end{tabular}


Amostra 2

\begin{tabular}{|c|c|c|c|c|c|c|c|}
\hline \multirow[b]{2}{*}{$\begin{array}{l}\text { Malha } \\
(\mathrm{mm})\end{array}$} & \multicolumn{3}{|c|}{ Alimentação } & \multicolumn{3}{|c|}{ Descarga } & \multirow[b]{2}{*}{$\begin{array}{c}\text { Eficiencia } \\
(\%)\end{array}$} \\
\hline & $\begin{array}{c}\text { Ret. } \\
\text { Simples } \\
\text { (\%) }\end{array}$ & $\begin{array}{c}\text { Ret. } \\
\text { Acumulado } \\
\text { (\%) }\end{array}$ & \begin{tabular}{|c} 
Pass. \\
Acumulado \\
(\%)
\end{tabular} & $\begin{array}{c}\text { Ret. } \\
\text { Simples } \\
(\%)\end{array}$ & $\begin{array}{c}\text { Ret. } \\
\text { Acumulado } \\
\text { (\%) }\end{array}$ & $\begin{array}{c}\text { Pass. } \\
\text { Acumulado } \\
\text { (\%) }\end{array}$ & \\
\hline 100,0 & 0,00 & 0,00 & 100,00 & 0,00 & 0,00 & 100,00 & \\
\hline 76,0 & 9,05 & 9,05 & 90,95 & 0,00 & 0,00 & 100,00 & $100 \%$ \\
\hline 63,0 & 12,21 & 21,26 & 78,74 & 0,00 & 0,00 & 100,00 & $100 \%$ \\
\hline 50,0 & 31,47 & 52,73 & 47,27 & 2,60 & 2,60 & 97,40 & $95 \%$ \\
\hline 45,0 & 10,96 & 63,69 & 36,31 & 2,06 & 4,66 & 95,34 & $93 \%$ \\
\hline 40,0 & 14,05 & 77,74 & 22,26 & 2,93 & 7,59 & 92,41 & $90 \%$ \\
\hline 38,0 & 5,29 & 83,02 & 16,98 & 16,87 & 24,46 & 75,54 & $71 \%$ \\
\hline 25,0 & 6,37 & 97,81 & 2,19 & 22,68 & 47,14 & 52,86 & $52 \%$ \\
\hline 19,0 & 1,51 & 99,32 & 0,68 & 14,19 & 61,33 & 38,67 & $38 \%$ \\
\hline 16,0 & 0,20 & 99,52 & 0,48 & 6,51 & 67,84 & 32,16 & $32 \%$ \\
\hline 12,5 & 0,06 & 99,58 & 0,42 & 6,09 & 73,93 & 26,07 & $26 \%$ \\
\hline 10,0 & 0,07 & 99,66 & 0,34 & 4,41 & 78,33 & 21,67 & $21 \%$ \\
\hline 8,0 & 0,05 & 99,70 & 0,30 & 3,76 & 82,10 & 17,90 & $18 \%$ \\
\hline 6,4 & 0,02 & 99,73 & 0,27 & 2,38 & 84,48 & 15,52 & $15 \%$ \\
\hline 5,8 & 0,02 & 99,74 & 0,26 & 1,66 & 86,14 & 13,86 & $14 \%$ \\
\hline 4,8 & 0,01 & 99,76 & 0,24 & 1,85 & 87,98 & 12,02 & $12 \%$ \\
\hline 3,4 & 0,01 & 99,77 & 0,23 & 2,27 & 90,26 & 9,74 & $10 \%$ \\
\hline 2,4 & 0,01 & 99,78 & 0,22 & 1,45 & 91,71 & 8,29 & $8 \%$ \\
\hline 1,0 & 0,02 & 99,80 & 0,20 & 2,88 & 94,59 & 5,41 & $5 \%$ \\
\hline 0,84 & 0,00 & 99,80 & 0,20 & 0,34 & 94,92 & 5,08 & $5 \%$ \\
\hline 0,71 & 0,00 & 99,81 & 0,19 & 0,33 & 95,25 & 4,75 & $5 \%$ \\
\hline 0,50 & 0,00 & 99,81 & 0,19 & 0,23 & 95,48 & 4,52 & $4 \%$ \\
\hline 0,42 & 0,01 & 99,82 & 0,18 & 0,49 & 95,97 & 4,03 & $4 \%$ \\
\hline 0,30 & 0,01 & 99,82 & 0,18 & 0,36 & 96,33 & 3,67 & $4 \%$ \\
\hline 0,21 & 0,01 & 99,83 & 0,17 & 0,34 & 96,66 & 3,34 & $3 \%$ \\
\hline 0,15 & 0,01 & 99,84 & 0,16 & 0,25 & 96,91 & 3,09 & $3 \%$ \\
\hline 0,106 & 0,01 & 99,85 & 0,15 & 0,32 & 97,23 & 2,77 & $3 \%$ \\
\hline 0,075 & 0,02 & 99,87 & 0,13 & 0,49 & 97,71 & 2,29 & $2 \%$ \\
\hline 0,045 & 0,03 & 99,89 & 0,11 & 0,70 & 98,41 & 1,59 & $1 \%$ \\
\hline$-0,045$ & 0,11 & 100,00 & 0,00 & 1,59 & 100,00 & 0,00 & $0 \%$ \\
\hline
\end{tabular}


Amostra 3

\begin{tabular}{|c|c|c|c|c|c|c|c|}
\hline \multirow[b]{2}{*}{$\begin{array}{l}\text { Malha } \\
(\mathrm{mm})\end{array}$} & \multicolumn{3}{|c|}{ Alimentação } & \multicolumn{3}{|c|}{ Descarga } & \multirow[b]{2}{*}{$\begin{array}{c}\text { Eficiencia } \\
(\%)\end{array}$} \\
\hline & $\begin{array}{c}\text { Ret. } \\
\text { Simples } \\
(\%)\end{array}$ & $\begin{array}{c}\text { Ret. } \\
\text { Acumulado } \\
(\%)\end{array}$ & $\begin{array}{c}\text { Pass. } \\
\text { Acumulado } \\
\text { (\%) }\end{array}$ & $\begin{array}{c}\text { Ret. } \\
\text { Simples } \\
\text { (\%) }\end{array}$ & $\begin{array}{c}\text { Ret. } \\
\text { Acumulado } \\
\text { (\%) }\end{array}$ & $\begin{array}{c}\text { Pass. } \\
\text { Acumulado } \\
(\%)\end{array}$ & \\
\hline 100,0 & 0,00 & 0,00 & 100,00 & 0,00 & 0,00 & 100,00 & \\
\hline 76,0 & 18,10 & 18,10 & 81,90 & 0,00 & 0,00 & 100,00 & $100 \%$ \\
\hline 63,0 & 13,98 & 32,07 & 67,93 & 0,00 & 0,00 & 100,00 & $100 \%$ \\
\hline 50,0 & 26,73 & 58,80 & 41,20 & 0,00 & 0,00 & 100,00 & $100 \%$ \\
\hline 45,0 & 9,27 & 68,08 & 31,92 & 0,48 & 0,48 & 99,52 & $99 \%$ \\
\hline 40,0 & 11,59 & 79,66 & 20,34 & 2,05 & 2,53 & 97,47 & $97 \%$ \\
\hline 38,0 & 4,22 & 83,88 & 16,12 & 4,06 & 6,59 & 93,41 & $92 \%$ \\
\hline 31,5 & 6,70 & 90,59 & 9,41 & 11,20 & 17,79 & 82,21 & $80 \%$ \\
\hline 25,0 & 6,54 & 97,13 & 2,87 & 26,40 & 44,18 & 55,82 & $55 \%$ \\
\hline 19,0 & 2,19 & 99,32 & 0,68 & 15,40 & 59,58 & 40,42 & $40 \%$ \\
\hline 16,0 & 0,24 & 99,56 & 0,44 & 6,97 & 66,55 & 33,45 & $33 \%$ \\
\hline 12,5 & 0,12 & 99,68 & 0,32 & 8,47 & 75,02 & 24,98 & $25 \%$ \\
\hline 10,0 & 0,02 & 99,70 & 0,30 & 3,85 & 78,87 & 21,13 & $21 \%$ \\
\hline 8,0 & 0,03 & 99,73 & 0,27 & 4,04 & 82,91 & 17,09 & $17 \%$ \\
\hline 6,4 & 0,02 & 99,75 & 0,25 & 2,21 & 85,12 & 14,88 & $15 \%$ \\
\hline 5,8 & 0,01 & 99,76 & 0,24 & 1,37 & 86,49 & 13,51 & $13 \%$ \\
\hline 4,8 & 0,01 & 99,77 & 0,23 & 1,62 & 88,11 & 11,89 & $12 \%$ \\
\hline 3,4 & 0,01 & 99,78 & 0,22 & 2,15 & 90,26 & 9,74 & $10 \%$ \\
\hline 2,4 & 0,01 & 99,79 & 0,21 & 1,89 & 92,15 & 7,85 & $8 \%$ \\
\hline 1,0 & 0,01 & 99,81 & 0,19 & 2,49 & 94,63 & 5,37 & $5 \%$ \\
\hline 0,84 & 0,00 & 99,81 & 0,19 & 0,27 & 94,91 & 5,09 & $5 \%$ \\
\hline 0,71 & 0,00 & 99,81 & 0,19 & 0,03 & 94,93 & 5,07 & $5 \%$ \\
\hline 0,50 & 0,01 & 99,82 & 0,18 & 0,61 & 95,54 & 4,46 & $4 \%$ \\
\hline 0,42 & 0,00 & 99,82 & 0,18 & 0,36 & 95,90 & 4,10 & $4 \%$ \\
\hline 0,30 & 0,01 & 99,83 & 0,17 & 0,32 & 96,22 & 3,78 & $4 \%$ \\
\hline 0,21 & 0,01 & 99,83 & 0,17 & 0,31 & 96,53 & 3,47 & $3 \%$ \\
\hline 0,15 & 0,01 & 99,85 & 0,15 & 0,22 & 96,75 & 3,25 & $3 \%$ \\
\hline 0,106 & 0,01 & 99,86 & 0,14 & 0,34 & 97,08 & 2,92 & $3 \%$ \\
\hline 0,075 & 0,02 & 99,88 & 0,12 & 0,45 & 97,53 & 2,47 & $2 \%$ \\
\hline 0,045 & 0,04 & 99,92 & 0,08 & 0,63 & 98,16 & 1,84 & $2 \%$ \\
\hline$-0,045$ & 0,08 & 100,00 & 0,00 & 1,84 & 100,00 & 0,00 & $0 \%$ \\
\hline
\end{tabular}




\section{APÊNDICE B}

\section{Ensaio Piloto de Moagem de Bolas}

Ensaio de Moagem de Bolas

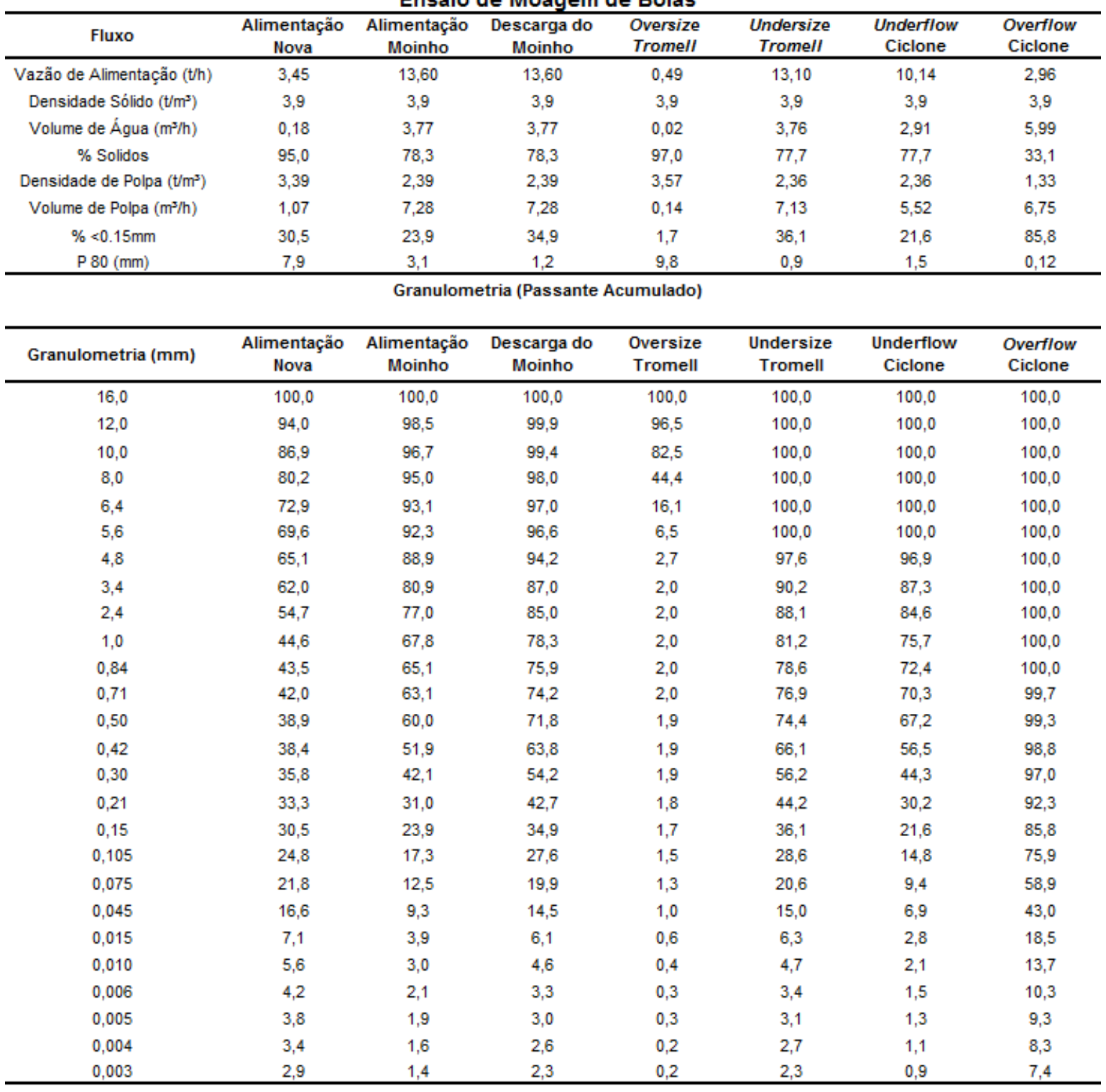


Calibração Moagem de Bolas

\begin{tabular}{|c|c|c|c|c|c|c|c|}
\hline Fluxo & $\begin{array}{c}\text { Alimentação } \\
\text { Nova }\end{array}$ & $\begin{array}{c}\text { Alimentação } \\
\text { Moinho }\end{array}$ & $\begin{array}{c}\text { Descarga do } \\
\text { Moinho }\end{array}$ & $\begin{array}{l}\text { Oversize } \\
\text { Tromell } \\
\end{array}$ & $\begin{array}{c}\text { Undersize } \\
\text { Tromell }\end{array}$ & $\begin{array}{c}\text { Underflow } \\
\text { Ciclone }\end{array}$ & $\begin{array}{c}\text { Overflow } \\
\text { Ciclone }\end{array}$ \\
\hline Vazão de Alimentação (t/h) & 3,45 & 13,73 & 13,73 & 0,43 & 13,31 & 10,28 & 3,02 \\
\hline Densidade Sólido $\left(t / m^{3}\right)$ & 3,9 & 3,9 & 3,9 & 3,9 & 3,9 & 3,9 & 3,9 \\
\hline Volume de Água $\left(\mathrm{m}^{3} / \mathrm{h}\right)$ & 0,18 & 3,81 & 3,81 & 0,02 & 3,79 & 2,82 & 6,23 \\
\hline$\%$ Solidos & 95,0 & 78,3 & 78,3 & 95,7 & 77,8 & 78,5 & 32,7 \\
\hline Densidade de Polpa $\left(t / \mathrm{m}^{3}\right)$ & 3,39 & 2,39 & 2,39 & 3,45 & 2,37 & 2,40 & 1,32 \\
\hline $\mathrm{P} 80(\mathrm{~mm})$ & 7,9 & 2,5 & 1,2 & 10,1 & 1,0 & 1,4 & 0,14 \\
\hline \multicolumn{8}{|c|}{ Granulometria (Passante Acumulado) } \\
\hline Granulometria (mm) & $\begin{array}{c}\text { Alimentação } \\
\text { Nova }\end{array}$ & $\begin{array}{c}\text { Alimentação } \\
\text { Moinho }\end{array}$ & $\begin{array}{c}\text { Descarga do } \\
\text { Moinho }\end{array}$ & $\begin{array}{c}\text { Oversize } \\
\text { Tromell }\end{array}$ & $\begin{array}{c}\text { Undersize } \\
\text { Tromell }\end{array}$ & $\begin{array}{c}\text { Underflow } \\
\text { Ciclone }\end{array}$ & $\begin{array}{c}\text { Overflow } \\
\text { Ciclone }\end{array}$ \\
\hline 8,0 & 80,4 & 94,0 & 97,2 & 43,0 & 98,9 & 98,6 & 100,0 \\
\hline 6,4 & 73,3 & 92,2 & 96,1 & 8,5 & 98,9 & 98,6 & 100,0 \\
\hline 5,6 & 70,0 & 90,9 & 95,3 & 0,0 & 98,5 & 98,1 & 100,0 \\
\hline 4,8 & 66,7 & 88,8 & 94,0 & 0,0 & 97,3 & 96,4 & 100,0 \\
\hline 3,4 & 61,0 & 84,4 & 91,1 & 0,0 & 94,0 & 92,3 & 100,0 \\
\hline 2,4 & 55,4 & 79,4 & 87,5 & 0,0 & 90,3 & 87,5 & 100,0 \\
\hline 1,0 & 44,8 & 67,1 & 77,8 & 0,0 & 80,3 & 74,5 & 100,0 \\
\hline 0,84 & 43,4 & 64,9 & 76,1 & 0,0 & 78,5 & 72,2 & 100,0 \\
\hline 0,71 & 42,0 & 62,8 & 74,3 & 0,0 & 76,6 & 69,8 & 100,0 \\
\hline 0,50 & 39,1 & 57,9 & 70,1 & 0,0 & 72,3 & 64,2 & 100,0 \\
\hline 0,045 & 16,5 & 9,0 & 14,2 & 0,0 & 14,6 & 6,4 & 42,5 \\
\hline 0,015 & 7,2 & 3,9 & 6,5 & 0,0 & 6,7 & 2,7 & 20,1 \\
\hline 0,010 & 5,6 & 3,0 & 5,0 & 0,0 & 5,2 & 2,1 & 15,7 \\
\hline 0,006 & 4,2 & 2,2 & 3,7 & 0,0 & 3,9 & 1,6 & 11,6 \\
\hline 0,005 & 3,8 & 2,0 & 3,4 & 0,0 & 3,5 & 1,4 & 10,5 \\
\hline 0,004 & 3,3 & 1,8 & 2,9 & 0,0 & 3,0 & 1,2 & 9,2 \\
\hline 0,003 & 2,9 & 1,5 & 2,6 & 0,0 & 2,7 & 1,1 & 8,1 \\
\hline
\end{tabular}


Simulação Moagem de Bolas - Tromell Aberto

\begin{tabular}{|c|c|c|c|c|c|}
\hline Fluxo & $\begin{array}{c}\text { Alimentação } \\
\text { Nova }\end{array}$ & $\begin{array}{c}\text { Alimentação } \\
\text { Moinho }\end{array}$ & $\begin{array}{c}\text { Descarga do } \\
\text { Moinho }\end{array}$ & $\begin{array}{l}\text { Underflow } \\
\text { Ciclone }\end{array}$ & $\begin{array}{c}\text { Overflow } \\
\text { Ciclone }\end{array}$ \\
\hline Vazão de Alimentação (t/h) & 2,75 & 12,62 & 12,62 & 9,87 & 2,75 \\
\hline Densidade Sólido $\left(\mathrm{t} / \mathrm{m}^{3}\right)$ & 3,9 & 3,9 & 3,9 & 3,9 & 3,9 \\
\hline Volume de Água $\left(\mathrm{m}^{3} / \mathrm{h}\right)$ & 0,15 & 3,50 & 3,50 & 2,67 & 5,90 \\
\hline \% Solidos & 95,0 & 78,3 & 78,3 & 78,7 & 31,8 \\
\hline Densidade de Polpa $\left(t / m^{3}\right)$ & 3,39 & 2,39 & 2,39 & 2,40 & 1,31 \\
\hline Volume de Polpa $\left(\mathrm{m}^{3} / \mathrm{h}\right)$ & 0,86 & 6,75 & 6,75 & 5,21 & 6,61 \\
\hline$\%<0.15 \mathrm{~mm}$ & 30,3 & 24,2 & 35,9 & 22,5 & 83,8 \\
\hline $\mathrm{P} 80(\mathrm{~mm})$ & 8,0 & 3,1 & 1,4 & 2,1 & 0,14 \\
\hline \multicolumn{6}{|c|}{ Granulometria (Passante Acumulado) } \\
\hline Granulometria (mm) & $\begin{array}{c}\text { Alimentação } \\
\text { Nova }\end{array}$ & $\begin{array}{c}\text { Alimentação } \\
\text { Moinho }\end{array}$ & $\begin{array}{c}\text { Descarga do } \\
\text { Moinho }\end{array}$ & $\begin{array}{l}\text { Underflow } \\
\text { Ciclone }\end{array}$ & $\begin{array}{l}\text { Overflow } \\
\text { Ciclone }\end{array}$ \\
\hline 16,0 & 100,0 & 100,0 & 100,0 & 100,0 & 100,0 \\
\hline 12,0 & 94,0 & 97,8 & 99,1 & 98,9 & 100,0 \\
\hline 10,0 & 88,1 & 95,6 & 98,2 & 97,6 & 100,0 \\
\hline 8,0 & 79,8 & 92,0 & 96,5 & 95,5 & 100,0 \\
\hline 6,4 & 73,0 & 88,8 & 94,7 & 93,2 & 100,0 \\
\hline 5,6 & 69,5 & 87,0 & 93,6 & 91,8 & 100,0 \\
\hline 4,8 & 65,7 & 84,7 & 92,2 & 90,1 & 100,0 \\
\hline 3,4 & 61,3 & 81,1 & 89,6 & 86,7 & 100,0 \\
\hline 2,4 & 55,0 & 76,1 & 85,9 & 82,0 & 100,0 \\
\hline 1,0 & 44,6 & 64,4 & 76,5 & 69,9 & 100,0 \\
\hline 0,84 & 43,5 & 62,5 & 74,8 & 67,8 & 100,0 \\
\hline 0,71 & 42,0 & 60,4 & 73,1 & 65,6 & 100,0 \\
\hline 0,50 & 38,9 & 55,8 & 69,1 & 60,5 & 100,0 \\
\hline 0,42 & 38,2 & 53,5 & 66,9 & 57,7 & 99,9 \\
\hline 0,30 & 35,8 & 46,7 & 60,5 & 49,7 & 99,3 \\
\hline 0,21 & 33,4 & 35,5 & 48,9 & 36,1 & 95,0 \\
\hline 0,15 & 30,3 & 24,2 & 35,9 & 22,5 & 83,8 \\
\hline 0,105 & 25,0 & 15,9 & 25,4 & 13,4 & 68,3 \\
\hline 0,075 & 21,7 & 12,1 & 19,7 & 9,4 & 56,9 \\
\hline 0,045 & 16,6 & 8,4 & 14,0 & 6,1 & 42,3 \\
\hline 0,015 & 7,1 & 3,6 & 6,4 & 2,6 & 20,0 \\
\hline 0,010 & 5,6 & 2,8 & 5,0 & 2,0 & 15,7 \\
\hline 0,006 & 4,2 & 2,1 & 3,7 & 1,5 & 11,6 \\
\hline 0,005 & 3,8 & 1,9 & 3,3 & 1,3 & 10,5 \\
\hline 0,004 & 3,3 & 1,6 & 2,9 & 1,2 & 9,2 \\
\hline 0,003 & 2,9 & 1,4 & 2,6 & 1,0 & 8,1 \\
\hline
\end{tabular}


Simulação Moagem de Bolas - Tromell Aberto e $10 \%>0,15 \mathrm{~mm}$

\begin{tabular}{cccccc}
\hline Fluxo & $\begin{array}{c}\text { Alimentação } \\
\text { Nova }\end{array}$ & $\begin{array}{c}\text { Alimentação } \\
\text { Moinho }\end{array}$ & $\begin{array}{c}\text { Descarga do } \\
\text { Moinho }\end{array}$ & $\begin{array}{c}\text { Underflow } \\
\text { Ciclone }\end{array}$ & $\begin{array}{c}\text { Overflow } \\
\text { Ciclone }\end{array}$ \\
\hline Vazão de Alimentação $(\mathrm{t} / \mathrm{h})$ & 1,90 & 9,34 & 9,34 & 7,44 & 1,90 \\
Densidade Sólido $\left(\mathrm{t} / \mathrm{m}^{3}\right)$ & 3,9 & 3,9 & 3,9 & 3,9 & 3,9 \\
Volume de Água $\left(\mathrm{m}^{3} / \mathrm{h}\right)$ & 0,10 & 2,59 & 2,59 & 1,98 & 4,37 \\
\% Solidos & 95,0 & 78,3 & 78,3 & 79,0 & 30,3 \\
Densidade de Polpa $\left(\mathrm{t} / \mathrm{m}^{3}\right)$ & 3,39 & 2,39 & 2,39 & 2,42 & 1,29 \\
Volume de Polpa $\left(\mathrm{m}^{3} / \mathrm{h}\right)$ & 0,59 & 5,00 & 5,00 & 3,89 & 4,86 \\
$\%$ \% $0.15 \mathrm{~mm}$ & 30,3 & 32,1 & 44,2 & 32,5 & 90,1 \\
$\mathrm{P} 80(\mathrm{~mm})$ & 8,0 & 2,1 & 0,6 & 1,0 & 0,12 \\
\hline
\end{tabular}

Granulometria (Passante Acumulado)

\begin{tabular}{|c|c|c|c|c|c|}
\hline Granulometria (mm) & $\begin{array}{c}\text { Alimentação } \\
\text { Nova }\end{array}$ & $\begin{array}{c}\text { Alimentação } \\
\text { Moinho }\end{array}$ & $\begin{array}{c}\text { Descarga do } \\
\text { Moinho }\end{array}$ & $\begin{array}{l}\text { Underflow } \\
\text { Ciclone }\end{array}$ & $\begin{array}{l}\text { Overflow } \\
\text { Ciclone }\end{array}$ \\
\hline 16,0 & 100,0 & 100,0 & 100,0 & 100,0 & 100,0 \\
\hline 12,0 & 94,0 & 98,2 & 99,4 & 99,3 & 100,0 \\
\hline 10,0 & 88,1 & 96,3 & 98,7 & 98,4 & 100,0 \\
\hline 8,0 & 79,8 & 93,4 & 97,5 & 96,9 & 100,0 \\
\hline 6,4 & 73,0 & 90,8 & 96,3 & 95,4 & 100,0 \\
\hline 5,6 & 69,5 & 89,4 & 95,6 & 94,5 & 100,0 \\
\hline 4,8 & 65,7 & 87,7 & 94,6 & 93,3 & 100,0 \\
\hline 3,4 & 61,3 & 84,9 & 92,8 & 90,9 & 100,0 \\
\hline 2,4 & 55,0 & 81,1 & 90,3 & 87,8 & 100,0 \\
\hline 1,0 & 44,6 & 72,5 & 83,7 & 79,6 & 100,0 \\
\hline 0,84 & 43,5 & 71,1 & 82,6 & 78,1 & 100,0 \\
\hline 0,71 & 42,0 & 69,6 & 81,4 & 76,6 & 100,0 \\
\hline 0,50 & 38,9 & 66,2 & 78,6 & 73,2 & 100,0 \\
\hline 0,42 & 38,2 & 64,6 & 77,1 & 71,3 & 100,0 \\
\hline 0,30 & 35,8 & 59,5 & 72,6 & 65,6 & 99,9 \\
\hline 0,21 & 33,4 & 49,1 & 62,3 & 53,1 & 98,5 \\
\hline 0,15 & 30,3 & 32,1 & 44,2 & 32,5 & 90,1 \\
\hline 0,105 & 25,0 & 18,5 & 28,5 & 16,9 & 73,8 \\
\hline 0,075 & 21,7 & 13,0 & 21,1 & 10,8 & 61,4 \\
\hline 0,045 & 16,6 & 8,5 & 14,4 & 6,4 & 45,5 \\
\hline 0,015 & 7,1 & 3,5 & 6,5 & 2,6 & 21,7 \\
\hline 0,010 & 5,6 & 2,7 & 5,0 & 2,0 & 17,0 \\
\hline 0,006 & 4,2 & 2,0 & 3,7 & 1,5 & 12,6 \\
\hline 0,005 & 3,8 & 1,8 & 3,4 & 1,3 & 11,3 \\
\hline 0,004 & 3,3 & 1,6 & 2,9 & 1,2 & 9,9 \\
\hline 0,003 & 2,9 & 1,4 & 2,6 & 1,0 & 8,7 \\
\hline
\end{tabular}




\section{APÊNDICE C}

\section{Ensaio Piloto de Moagem SAG}

Ensaio Piloto SAG 1

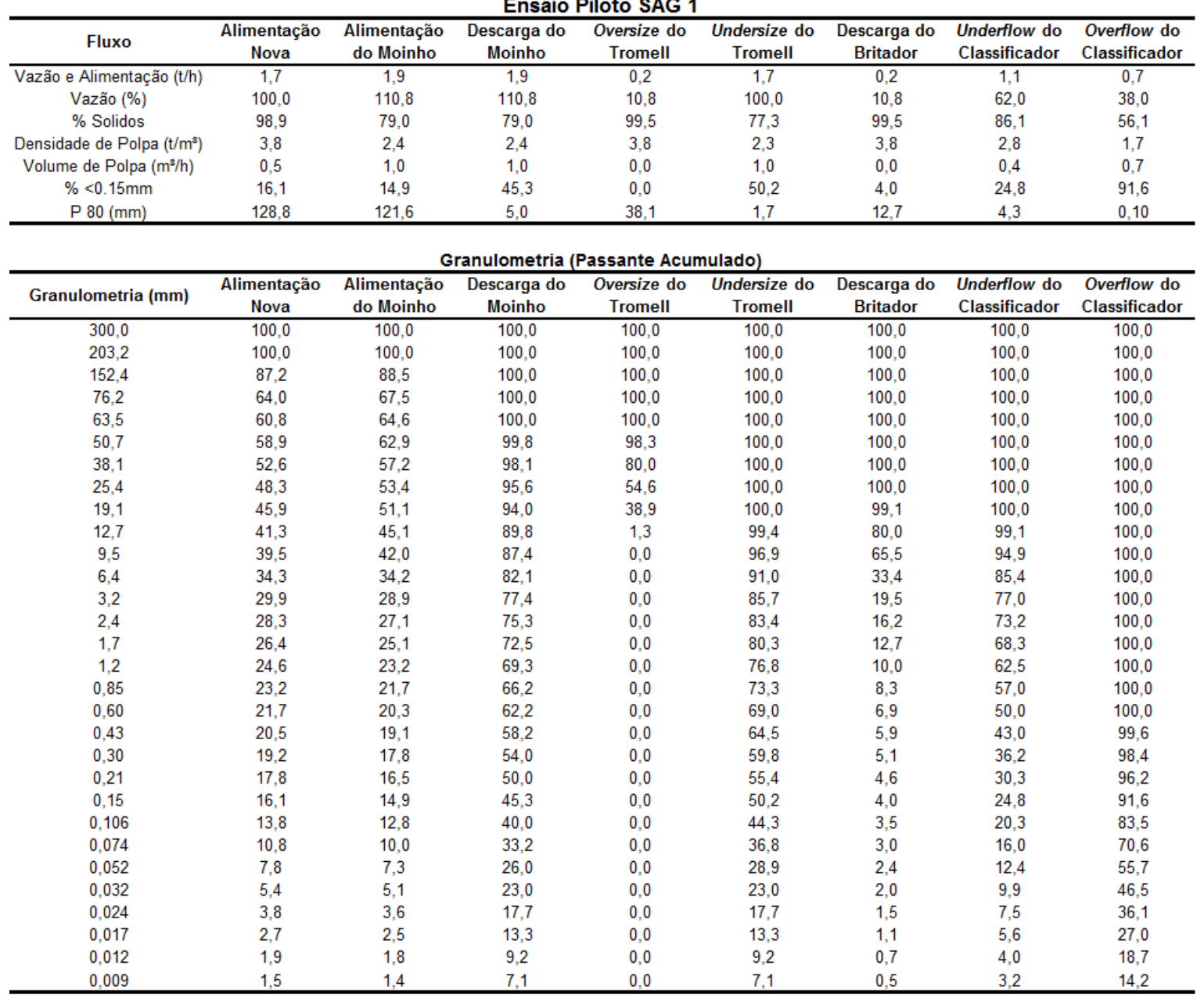


Ensaio Piloto SAG 2

\begin{tabular}{|c|c|c|c|c|c|c|c|}
\hline Fluxo & $\begin{array}{c}\text { Alimentação } \\
\text { Nova }\end{array}$ & $\begin{array}{c}\text { Alimentação } \\
\text { do Moinho }\end{array}$ & $\begin{array}{c}\text { Descarga do } \\
\text { Moinho }\end{array}$ & $\begin{array}{l}\text { Oversize do } \\
\text { Tromell }\end{array}$ & $\begin{array}{c}\text { Undersize do } \\
\text { Tromell }\end{array}$ & $\begin{array}{l}\text { Underflow do } \\
\text { Classificador }\end{array}$ & $\begin{array}{l}\text { Overflow do } \\
\text { Classificador }\end{array}$ \\
\hline Vazão e Alimentação (t/h) & 1,5 & 1,5 & 1,5 & 0,1 & 1,5 & 0,9 & 0,6 \\
\hline Vazão $(\%)$ & 100,0 & 106,0 & 106,0 & 6,0 & 100,0 & 60,2 & 39,8 \\
\hline Densidade de Polpa $\left(\mathrm{t} / \mathrm{m}^{3}\right)$ & 3,8 & 2,4 & 2,4 & 3,8 & 2,3 & 2,7 & 1,7 \\
\hline Volume de Polpa $\left(\mathrm{m}^{3} / \mathrm{h}\right)$ & 0,4 & 0,8 & 0,8 & 0,0 & 0,8 & 0,4 & 0,6 \\
\hline$\%<0.15 \mathrm{~mm}$ & 16,1 & 15,2 & 51,9 & 0,0 & 55,1 & 29,1 & 94,4 \\
\hline \multicolumn{8}{|c|}{ Granulometria (Passante Acumulado) } \\
\hline Granulometria (mm) & $\begin{array}{c}\text { Alimentação } \\
\text { Nova }\end{array}$ & $\begin{array}{c}\text { Alimentação } \\
\text { do Moinho }\end{array}$ & $\begin{array}{c}\text { Descarga do } \\
\text { Moinho }\end{array}$ & $\begin{array}{c}\text { Oversize do } \\
\text { Tromell }\end{array}$ & $\begin{array}{c}\text { Undersize do } \\
\text { Tromell }\end{array}$ & $\begin{array}{l}\text { Underflow do } \\
\text { Classificador }\end{array}$ & $\begin{array}{l}\text { Overflow do } \\
\text { Classificador }\end{array}$ \\
\hline 300,0 & 100,0 & 100,0 & 100,0 & 100,0 & 100,0 & 100,0 & 100,0 \\
\hline 203,2 & 100,0 & 100,0 & 100,0 & 100,0 & 100,0 & 100,0 & 100,0 \\
\hline 38,1 & 52,6 & 55,3 & 100,0 & 99,5 & 100,0 & 100,0 & 100,0 \\
\hline 25,4 & 48,3 & 50,7 & 99,5 & 90,6 & 100,0 & 100,0 & 100,0 \\
\hline 19,1 & 45,9 & 43,4 & 94,4 & 1,8 & 100,0 & 100,0 & 100,0 \\
\hline 12,7 & 41,3 & 39,0 & 93,6 & 0,0 & 99,3 & 98,8 & 100,0 \\
\hline 9,5 & 39,5 & 37,3 & 90,8 & 0,0 & 96,2 & 93,7 & 100,0 \\
\hline 6,4 & 34,3 & 32,4 & 85,6 & 0,0 & 90,8 & 84,7 & 100,0 \\
\hline 3,2 & 29,9 & 28,2 & 81,4 & 0,0 & 86,4 & 77,3 & 100,0 \\
\hline 2,4 & 28,3 & 26,7 & 79,5 & 0,0 & 84,3 & 73,9 & 100,0 \\
\hline 1,7 & 26,4 & 24,9 & 77,3 & 0,0 & 82,0 & 70,0 & 100,0 \\
\hline 1,2 & 24,6 & 23,2 & 74,7 & 0,0 & 79,2 & 65,5 & 100,0 \\
\hline 0,85 & 23,2 & 21,9 & 72,1 & 0,0 & 76,5 & 60,9 & 100,0 \\
\hline 0,052 & 7,8 & 7,4 & 29,9 & 0,0 & 31,7 & 13,9 & 58,7 \\
\hline 0,032 & 5,4 & 5,1 & 25,2 & 0,0 & 25,2 & 11,4 & 50,2 \\
\hline 0,024 & 3,8 & 3,6 & 19,4 & 0,0 & 19,4 & 8,7 & 39,4 \\
\hline 0,017 & 2,7 & 2,5 & 14,6 & 0,0 & 14,6 & 6,5 & 29,6 \\
\hline 0,012 & 1,9 & 1,8 & 10,1 & 0,0 & 10,1 & 4,6 & 20,4 \\
\hline 0,009 & 1,5 & 1,4 & 7,7 & 0,0 & 7,7 & 3,5 & 15,6 \\
\hline
\end{tabular}


Ensaio Piloto SAG 3

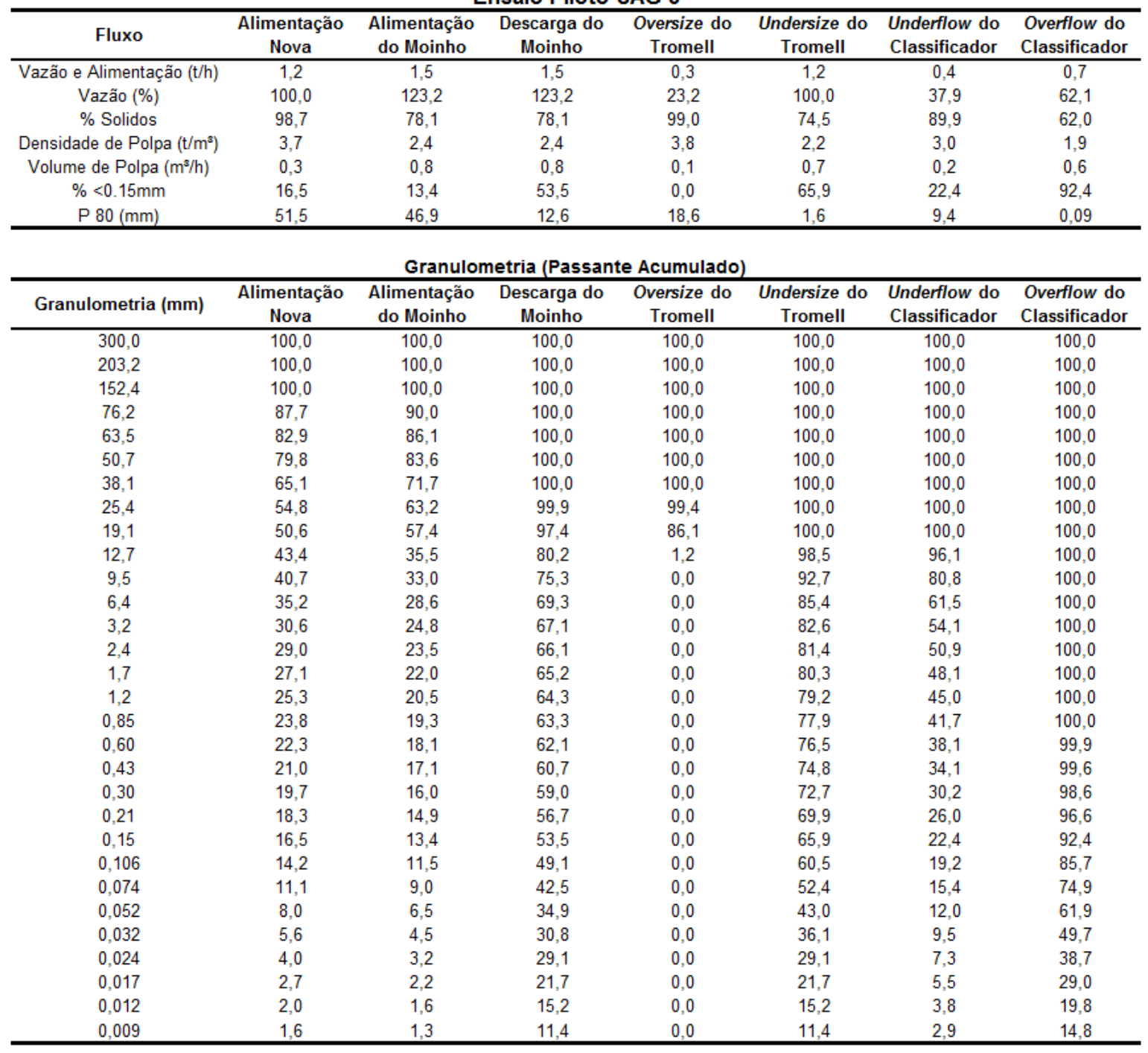


Ensaio Piloto SAG 4

\begin{tabular}{|c|c|c|c|c|c|c|c|}
\hline Fluxo & $\begin{array}{c}\text { Alimentação } \\
\text { Nova }\end{array}$ & $\begin{array}{c}\text { Alimentação } \\
\text { do Moinho }\end{array}$ & $\begin{array}{c}\text { Descarga do } \\
\text { Moinho }\end{array}$ & $\begin{array}{l}\text { Oversize do } \\
\text { Tromell }\end{array}$ & $\begin{array}{c}\text { Undersize do } \\
\text { Tromell }\end{array}$ & $\begin{array}{l}\text { Underflow do } \\
\text { Classificador }\end{array}$ & $\begin{array}{l}\text { Overflow do } \\
\text { Classificador }\end{array}$ \\
\hline Vazão e Alimentação (t/h) & 0,9 & 5,4 & 5,4 & 0,1 & 5,3 & 4,4 & 0,9 \\
\hline Vazão (\%) & 100,0 & 585,0 & 585,0 & 9,4 & 575,7 & 475,7 & 100,0 \\
\hline Densidade de Polpa $\left(\mathrm{t} / \mathrm{m}^{3}\right)$ & 3,7 & 2,3 & 2,3 & 3,8 & 2,3 & 2,8 & 1,6 \\
\hline Volume de Polpa $\left(\mathrm{m}^{3} / \mathrm{h}\right)$ & 0,3 & 3,0 & 3,0 & 0,0 & 3,0 & 1,8 & 1,1 \\
\hline$\%<0.15 \mathrm{~mm}$ & 16,1 & 25,6 & 38,8 & 0,0 & 39,4 & 28,1 & 93,0 \\
\hline \multicolumn{8}{|c|}{ Granulometria (Passante Acumulado) } \\
\hline Granulometria (mm) & $\begin{array}{c}\text { Alimentação } \\
\text { Nova }\end{array}$ & $\begin{array}{c}\text { Alimentação } \\
\text { do Moinho }\end{array}$ & $\begin{array}{c}\text { Descarga do } \\
\text { Moinho }\end{array}$ & $\begin{array}{c}\text { Oversize do } \\
\text { Tromell }\end{array}$ & $\begin{array}{c}\text { Undersize do } \\
\text { Tromell } \\
\end{array}$ & $\begin{array}{l}\text { Underflow do } \\
\text { Classificador }\end{array}$ & $\begin{array}{l}\text { Overflow do } \\
\text { Classificador }\end{array}$ \\
\hline 300,0 & 100,0 & 100,0 & 100,0 & 100,0 & 100,0 & 100,0 & 100,0 \\
\hline 203,2 & 99,8 & 99,8 & 100,0 & 100,0 & 100,0 & 100,0 & 100,0 \\
\hline 38,1 & 52,6 & 91,9 & 100,0 & 100,0 & 100,0 & 100,0 & 100,0 \\
\hline 25,4 & 48,3 & 91,2 & 100,0 & 100,0 & 100,0 & 100,0 & 100,0 \\
\hline 19,1 & 45,9 & 90,6 & 99,9 & 91,1 & 100,0 & 100,0 & 100,0 \\
\hline 12,7 & 41,3 & 88,2 & 98,2 & 1,6 & 99,8 & 99,7 & 100,0 \\
\hline 9,5 & 39,5 & 86,7 & 97,0 & 0,0 & 98,6 & 98,3 & 100,0 \\
\hline 6,4 & 34,3 & 82,9 & 94,1 & 0,0 & 95,7 & 94,8 & 100,0 \\
\hline 3,2 & 29,9 & 79,1 & 91,1 & 0,0 & 92,6 & 91,0 & 100,0 \\
\hline 2,4 & 28,3 & 77,3 & 89,6 & 0,0 & 91,0 & 89,2 & 100,0 \\
\hline 1,7 & 26,4 & 75,0 & 87,6 & 0,0 & 89,1 & 86,7 & 100,0 \\
\hline 1,2 & 24,6 & 72,2 & 85,1 & 0,0 & 86,5 & 83,6 & 100,0 \\
\hline 0,85 & 23,2 & 68,8 & 82,0 & 0,0 & 83,3 & 79,8 & 100,0 \\
\hline 0,60 & 21,7 & 63,7 & 77,1 & 0,0 & 78,3 & 73,8 & 100,0 \\
\hline 0,032 & 5,4 & 7,1 & 14,6 & 0,0 & 14,6 & 7,6 & 46,7 \\
\hline 0,024 & 3,8 & 5,5 & 11,6 & 0,0 & 11,6 & 6,0 & 36,8 \\
\hline 0,017 & 2,7 & 4,1 & 8,8 & 0,0 & 8,8 & 4,5 & 27,8 \\
\hline 0,012 & 1,9 & 2,9 & 6,2 & 0,0 & 6,2 & 3,2 & 19,4 \\
\hline 0,009 & 1,5 & 2,4 & 4,8 & 0,0 & 4,8 & 2,6 & 14,7 \\
\hline
\end{tabular}


Ensaio Piloto SAG 5

\begin{tabular}{|c|c|c|c|c|c|c|c|}
\hline Fluxo & $\begin{array}{c}\text { Alimentação } \\
\text { Nova }\end{array}$ & $\begin{array}{c}\text { Alimentação } \\
\text { do Moinho }\end{array}$ & $\begin{array}{c}\text { Descarga do } \\
\text { Moinho }\end{array}$ & $\begin{array}{l}\text { Oversize do } \\
\text { Tromell }\end{array}$ & $\begin{array}{c}\text { Undersize do } \\
\text { Tromell }\end{array}$ & $\begin{array}{l}\text { Underflow do } \\
\text { Classificador }\end{array}$ & $\begin{array}{l}\text { Overflow do } \\
\text { Classificador }\end{array}$ \\
\hline Vazão (\%) & 100,0 & 216,0 & 216,0 & 31,2 & 184,8 & 84,8 & 100,0 \\
\hline Densidade de Polpa $\left(t / \mathrm{m}^{3}\right)$ & 3,7 & 2,4 & 2,4 & 3,8 & 2,3 & 3,0 & 2,0 \\
\hline Volume de Polpa $\left(\mathrm{m}^{3} / \mathrm{h}\right)$ & 0,2 & 1,0 & 1,0 & 0,1 & 0,9 & 0,3 & 0,7 \\
\hline$\%<0.15 \mathrm{~mm}$ & 16,5 & 13,1 & 46,7 & 0,0 & 54,5 & 14,0 & 88,9 \\
\hline \multicolumn{8}{|c|}{ Granulometria (Passante Acumulado) } \\
\hline Granulometria (mm) & $\begin{array}{c}\text { Alimentação } \\
\text { Nova }\end{array}$ & $\begin{array}{c}\text { Alimentação } \\
\text { do Moinho }\end{array}$ & $\begin{array}{c}\text { Descarga do } \\
\text { Moinho }\end{array}$ & $\begin{array}{l}\text { Oversize do } \\
\text { Tromell }\end{array}$ & $\begin{array}{c}\text { Undersize do } \\
\text { Tromell }\end{array}$ & $\begin{array}{l}\text { Underflow do } \\
\text { Classificador }\end{array}$ & $\begin{array}{l}\text { Overflow do } \\
\text { Classificador }\end{array}$ \\
\hline 300,0 & 100,0 & 100,0 & 100,0 & 100,0 & 100,0 & 100,0 & 100,0 \\
\hline 203,2 & 100,0 & 100,0 & 100,0 & 100,0 & 100,0 & 100,0 & 100,0 \\
\hline 38,1 & 65,1 & 83,8 & 100,0 & 100,0 & 100,0 & 100,0 & 100,0 \\
\hline 25,4 & 54,8 & 79,0 & 100,0 & 99,8 & 100,0 & 100,0 & 100,0 \\
\hline 19,1 & 50,6 & 75,4 & 98,3 & 88,3 & 100,0 & 100,0 & 100,0 \\
\hline 12,7 & 43,4 & 58,3 & 84,7 & 1,3 & 98,6 & 96,9 & 100,0 \\
\hline 9,5 & 40,7 & 49,8 & 77,4 & 0,0 & 90,3 & 78,9 & 100,0 \\
\hline 6,4 & 35,2 & 35,3 & 65,4 & 0,0 & 76,3 & 48,4 & 100,0 \\
\hline 3,2 & 30,6 & 29,8 & 62,0 & 0,0 & 72,3 & 39,8 & 100,0 \\
\hline 2,4 & 29,0 & 27,8 & 60,7 & 0,0 & 70,8 & 36,5 & 100,0 \\
\hline 1,7 & 27,1 & 25,7 & 59,5 & 0,0 & 69,4 & 33,5 & 100,0 \\
\hline 1,2 & 25,3 & 23,7 & 58,3 & 0,0 & 68,0 & 30,5 & 100,0 \\
\hline 0,85 & 23,8 & 21,9 & 57,2 & 0,0 & 66,8 & 27,7 & 100,0 \\
\hline 0,60 & 22,3 & 20,0 & 55,9 & 0,0 & 65,2 & 24,6 & 99,7 \\
\hline 0,024 & 4,0 & 3,9 & 20,4 & 0,0 & 23,8 & 5,1 & 40,1 \\
\hline 0,017 & 2,7 & 2,7 & 15,1 & 0,0 & 17,7 & 3,8 & 30,2 \\
\hline 0,012 & 2,0 & 2,0 & 10,4 & 0,0 & 12,1 & 2,7 & 20,9 \\
\hline 0,009 & 1,6 & 1,5 & 7,6 & 0,0 & 8,9 & 2,0 & 15,8 \\
\hline
\end{tabular}


Calibração Ensaio SAG 4

\begin{tabular}{|c|c|c|c|c|c|c|c|}
\hline Fluxo & $\begin{array}{c}\text { Alimentação } \\
\text { Nova }\end{array}$ & $\begin{array}{c}\text { Alimentação } \\
\text { do Moinho }\end{array}$ & $\begin{array}{c}\text { Descarga do } \\
\text { Moinho }\end{array}$ & $\begin{array}{c}\text { Oversize do } \\
\text { Tromell }\end{array}$ & $\begin{array}{c}\text { Undersize do } \\
\text { Tromell }\end{array}$ & $\begin{array}{l}\text { Underflow do } \\
\text { Classificador }\end{array}$ & $\begin{array}{l}\text { Overflow do } \\
\text { Classificador }\end{array}$ \\
\hline Vazão e Alimentação (t/h) & 0,9 & 5,4 & 5,4 & 0,1 & 5,2 & 4,3 & 0,9 \\
\hline Vazão $(\%)$ & 100,0 & 579,0 & 579,0 & 14,7 & 564,3 & 464,3 & 100,0 \\
\hline Densidade de Polpa $\left(t / \mathrm{m}^{3}\right)$ & 3,7 & 2,3 & 2,3 & 3,8 & 2,3 & 2,9 & 1,6 \\
\hline Volume de Polpa $\left(\mathrm{m}^{3} / \mathrm{h}\right)$ & 0,3 & 3,0 & 3,0 & 0,0 & 2,9 & 1,7 & 1,2 \\
\hline$\%<0.15 \mathrm{~mm}$ & 16,0 & 25,8 & 39,1 & 0,0 & 40,1 & 28,8 & 92,8 \\
\hline \multicolumn{8}{|c|}{ Granulometria (Passante Acumulado) } \\
\hline Granulometria (mm) & $\begin{array}{c}\text { Alimentação } \\
\text { Nova }\end{array}$ & $\begin{array}{c}\text { Alimentação } \\
\text { do Moinho }\end{array}$ & $\begin{array}{c}\text { Descarga do } \\
\text { Moinho } \\
\end{array}$ & $\begin{array}{c}\text { Oversize do } \\
\text { Tromell } \\
\end{array}$ & $\begin{array}{c}\text { Undersize do } \\
\text { Tromell } \\
\end{array}$ & $\begin{array}{l}\text { Underflow do } \\
\text { Classificador }\end{array}$ & $\begin{array}{l}\text { Overflow do } \\
\text { Classificador }\end{array}$ \\
\hline 300,0 & 100,0 & 100,0 & 100,0 & 100,0 & 100,0 & 100,0 & 100,0 \\
\hline 203,2 & 99,8 & 100,0 & 100,0 & 100,0 & 100,0 & 100,0 & 100,0 \\
\hline 38,1 & 53,1 & 91,9 & 100,0 & 100,0 & 100,0 & 100,0 & 100,0 \\
\hline 25,4 & 48,3 & 91,1 & 100,0 & 100,0 & 100,0 & 100,0 & 100,0 \\
\hline 19,1 & 45,7 & 90,0 & 99,4 & 94,7 & 100,0 & 100,0 & 100,0 \\
\hline 12,7 & 41,3 & 86,5 & 96,7 & 1,1 & 99,2 & 99,0 & 100,0 \\
\hline 9,5 & 39,1 & 84,5 & 95,0 & 0,0 & 97,6 & 97,1 & 100,0 \\
\hline 6,4 & 34,3 & 81,6 & 93,0 & 0,0 & 95,4 & 94,4 & 100,0 \\
\hline 3,2 & 29,9 & 78,2 & 90,3 & 0,0 & 92,7 & 91,1 & 100,0 \\
\hline 2,4 & 28,3 & 76,7 & 89,1 & 0,0 & 91,5 & 89,6 & 100,0 \\
\hline 1,7 & 26,4 & 74,8 & 87,5 & 0,0 & 89,8 & 87,6 & 100,0 \\
\hline 1,2 & 24,6 & 72,2 & 85,3 & 0,0 & 87,5 & 84,8 & 100,0 \\
\hline 0,85 & 23,2 & 69,2 & 82,5 & 0,0 & 84,6 & 81,3 & 100,0 \\
\hline 0,052 & 7,9 & 9,4 & 18,0 & 0,0 & 18,5 & 10,1 & 57,6 \\
\hline 0,032 & 5,3 & 6,3 & 12,8 & 0,0 & 13,1 & 6,7 & 42,7 \\
\hline 0,024 & 3,8 & 4,8 & 10,0 & 0,0 & 10,3 & 5,1 & 34,2 \\
\hline 0,017 & 2,7 & 3,6 & 7,7 & 0,0 & 7,9 & 3,9 & 26,6 \\
\hline 0,012 & 1,9 & 2,7 & 5,9 & 0,0 & 6,0 & 2,9 & 20,5 \\
\hline 0,009 & 1,5 & 2,1 & 4,7 & 0,0 & 4,8 & 2,3 & 16,4 \\
\hline
\end{tabular}


Simulação SAG $4-10 \%>0,15 \mathrm{~mm}$

\begin{tabular}{|c|c|c|c|c|c|c|c|}
\hline Fluxo & $\begin{array}{c}\text { Alimentação } \\
\text { Nova }\end{array}$ & $\begin{array}{c}\text { Alimentação } \\
\text { do Moinho }\end{array}$ & $\begin{array}{c}\text { Descarga do } \\
\text { Moinho }\end{array}$ & $\begin{array}{c}\text { Oversize do } \\
\text { Tromell }\end{array}$ & $\begin{array}{c}\text { Undersize do } \\
\text { Tromell }\end{array}$ & $\begin{array}{l}\text { Underflow do } \\
\text { Classificador }\end{array}$ & $\begin{array}{l}\text { Overflow do } \\
\text { Classificador }\end{array}$ \\
\hline Vazão e Alimentação (t/h) & 1,0 & 5,1 & 5,1 & 0,1 & 5,0 & 4,0 & 1,0 \\
\hline Vazão (\%) & 100,0 & 518,9 & 518,9 & 13,0 & 505,8 & 405,8 & 100,0 \\
\hline Densidade de Polpa $\left(t / \mathrm{m}^{3}\right)$ & 3,7 & 2,3 & 2,3 & 3,8 & 2,3 & 2,8 & 1,6 \\
\hline Volume de Polpa $\left(\mathrm{m}^{3} / \mathrm{h}\right)$ & 0,3 & 2,8 & 2,8 & 0,0 & 2,8 & 1,6 & 1,2 \\
\hline$\%<0.15 \mathrm{~mm}$ & 16,1 & 24,4 & 38,7 & 0,0 & 39,7 & 27,3 & 90,0 \\
\hline \multicolumn{8}{|c|}{ Granulometria (Passante Acumulado) } \\
\hline Granulometria (mm) & $\begin{array}{c}\text { Alimentação } \\
\text { Nova }\end{array}$ & $\begin{array}{c}\text { Alimentação } \\
\text { do Moinho }\end{array}$ & $\begin{array}{c}\text { Descarga do } \\
\text { Moinho }\end{array}$ & $\begin{array}{c}\text { Oversize do } \\
\text { Tromell }\end{array}$ & $\begin{array}{c}\text { Undersize do } \\
\text { Tromell }\end{array}$ & $\begin{array}{l}\text { Underflow do } \\
\text { Classificador }\end{array}$ & $\begin{array}{l}\text { Overflow do } \\
\text { Classificador }\end{array}$ \\
\hline 300,0 & 100,0 & 100,0 & 100,0 & 100,0 & 100,0 & 100,0 & 100,0 \\
\hline 203,2 & 99,8 & 100,0 & 100,0 & 100,0 & 100,0 & 100,0 & 100,0 \\
\hline 38,1 & 52,6 & 90,9 & 100,0 & 100,0 & 100,0 & 100,0 & 100,0 \\
\hline 25,4 & 48,3 & 90,0 & 99,9 & 100,0 & 100,0 & 100,0 & 100,0 \\
\hline 19,1 & 45,9 & 89,0 & 99,4 & 91,8 & 99,9 & 99,9 & 100,0 \\
\hline 12,7 & 41,3 & 85,4 & 96,7 & 1,1 & 99,2 & 99,0 & 100,0 \\
\hline 9,5 & 39,4 & 83,3 & 95,0 & 0,0 & 97,6 & 96,9 & 100,0 \\
\hline 6,4 & 34,3 & 80,3 & 93,0 & 0,0 & 95,4 & 94,3 & 100,0 \\
\hline 3,2 & 29,9 & 76,8 & 90,3 & 0,0 & 92,6 & 90,8 & 100,0 \\
\hline 2,4 & 28,3 & 75,2 & 89,0 & 0,0 & 91,3 & 89,2 & 100,0 \\
\hline 1,7 & 26,4 & 73,2 & 87,3 & 0,0 & 89,6 & 87,0 & 100,0 \\
\hline 1,2 & 24,6 & 70,4 & 84,9 & 0,0 & 87,1 & 83,9 & 100,0 \\
\hline 0,85 & 23,2 & 67,2 & 82,0 & 0,0 & 84,1 & 80,2 & 100,0 \\
\hline 0,60 & 21,7 & 62,4 & 77,5 & 0,0 & 79,5 & 74,4 & 100,0 \\
\hline 0,032 & 5,4 & 6,6 & 13,3 & 0,0 & 13,7 & 7,1 & 40,4 \\
\hline 0,024 & 3,8 & 5,0 & 10,5 & 0,0 & 10,7 & 5,4 & 32,2 \\
\hline 0,017 & 2,7 & 3,7 & 8,0 & 0,0 & 8,3 & 4,1 & 25,0 \\
\hline 0,012 & 1,9 & 2,8 & 6,1 & 0,0 & 6,3 & 3,1 & 19,2 \\
\hline 0,009 & 1,5 & 2,2 & 4,9 & 0,0 & 5,0 & 2,5 & 15,4 \\
\hline
\end{tabular}


Simulação SAG $4-10 \%>0,15 \mathrm{~mm}$ - Moinho $6^{\prime} \times 6^{\prime}$

\begin{tabular}{|c|c|c|c|c|c|c|c|}
\hline Fluxo & $\begin{array}{c}\text { Alimentação } \\
\text { Nova }\end{array}$ & $\begin{array}{c}\text { Alimentação } \\
\text { do Moinho }\end{array}$ & $\begin{array}{c}\text { Descarga do } \\
\text { Moinho }\end{array}$ & $\begin{array}{c}\text { Oversize do } \\
\text { Tromell }\end{array}$ & $\begin{array}{c}\text { Undersize do } \\
\text { Tromell }\end{array}$ & $\begin{array}{l}\text { Underflow do } \\
\text { Classificador }\end{array}$ & $\begin{array}{l}\text { Overflow do } \\
\text { Classificador }\end{array}$ \\
\hline Vazão e Alimentação (t/h) & 3,3 & 9,6 & 9,6 & 0,2 & 9,5 & 6,2 & 3,3 \\
\hline Vazão $(\%)$ & 100,0 & 292,1 & 292,1 & 4,7 & 287,4 & 187,4 & 100,0 \\
\hline Densidade de Polpa $\left(t / \mathrm{m}^{3}\right)$ & 3,7 & 2,3 & 2,3 & 3,8 & 2,3 & 2,7 & 1,9 \\
\hline Volume de Polpa $\left(\mathrm{m}^{3} / \mathrm{h}\right)$ & 0,9 & 5,3 & 5,3 & 0,0 & 5,3 & 2,7 & 2,6 \\
\hline$\%<0.15 \mathrm{~mm}$ & 16,1 & 34,1 & 59,7 & 0,0 & 60,7 & 44,5 & 90,9 \\
\hline
\end{tabular}

Granulometria (Passante Acumulado)

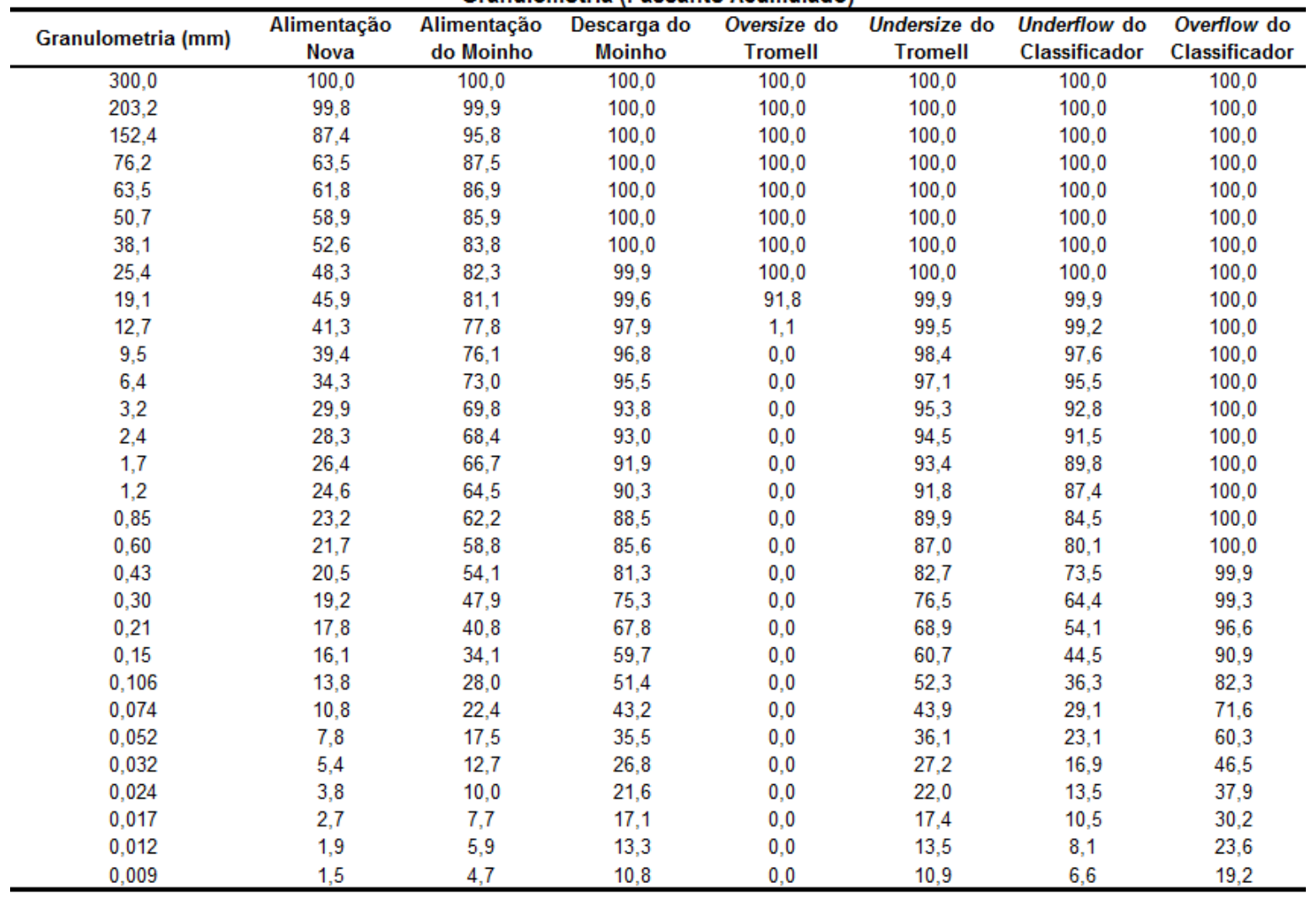


Ensaio de Moagem de Bolas - MB1

\begin{tabular}{|c|c|c|c|c|c|}
\hline Fluxo & $\begin{array}{c}\text { Alimentação } \\
\text { Nova }\end{array}$ & $\begin{array}{c}\text { Alimentação } \\
\text { do Moinho }\end{array}$ & $\begin{array}{c}\text { Descarga do } \\
\text { Moinho } \\
\end{array}$ & $\begin{array}{l}\text { Underflow do } \\
\text { Classificador }\end{array}$ & $\begin{array}{l}\text { Overflow do } \\
\text { Classificador }\end{array}$ \\
\hline Vazão e Alimentação (t/h) & 0,6 & 1,9 & 1,9 & 1,3 & 0,6 \\
\hline Vazão (\%) & 100,0 & 321,2 & 321,2 & 221,2 & 100,0 \\
\hline$\%$ Solidos & 98,1 & 74,0 & 74,0 & 81,1 & 37,5 \\
\hline Densidade de Polpa $\left(\mathrm{t} / \mathrm{m}^{3}\right)$ & 3,9 & 2,3 & 2,3 & 2,6 & 1,4 \\
\hline Volume de Polpa $\left(\mathrm{m}^{3} / \mathrm{h}\right)$ & 0,2 & 1,1 & 1,1 & 0,6 & 1,1 \\
\hline$\%<0.15 \mathrm{~mm}$ & 24,5 & 41,5 & 62,2 & 49,2 & 91,0 \\
\hline $\mathrm{P} 80(\mathrm{~mm})$ & 5,1 & 0,5 & 0,2 & 0,3 & 0,10 \\
\hline \multicolumn{6}{|c|}{ Granulometria (Passante Acumulado) } \\
\hline Granulometria (mm) & $\begin{array}{c}\text { Alimentação } \\
\text { Nova }\end{array}$ & $\begin{array}{c}\text { Alimentação } \\
\text { do Moinho }\end{array}$ & $\begin{array}{c}\text { Descarga do } \\
\text { Moinho }\end{array}$ & $\begin{array}{l}\text { Underflow do } \\
\text { Classificador }\end{array}$ & $\begin{array}{l}\text { Overflow do } \\
\text { Classificador }\end{array}$ \\
\hline 30,0 & 100,0 & 100,0 & 100,0 & 100,0 & 100,0 \\
\hline 25,4 & 100,0 & 100,0 & 100,0 & 100,0 & 100,0 \\
\hline 19,1 & 100,0 & 100,0 & 100,0 & 100,0 & 100,0 \\
\hline 12,7 & 99,5 & 99,8 & 100,0 & 100,0 & 100,0 \\
\hline 9,5 & 93,8 & 98,1 & 100,0 & 100,0 & 100,0 \\
\hline 6,4 & 83,3 & 94,8 & 100,0 & 100,0 & 100,0 \\
\hline 3,2 & 75,1 & 92,2 & 99,9 & 99,9 & 100,0 \\
\hline 2,4 & 70,7 & 90,8 & 99,9 & 99,9 & 100,0 \\
\hline 1,7 & 66,1 & 89,3 & 99,8 & 99,7 & 100,0 \\
\hline 1,2 & 60,7 & 87,3 & 99,5 & 99,3 & 100,0 \\
\hline 0,85 & 55,6 & 85,1 & 98,9 & 98,4 & 100,0 \\
\hline 0,60 & 49,4 & 81,6 & 97,4 & 96,2 & 100,0 \\
\hline 0,43 & 42,3 & 76,0 & 93,9 & 91,2 & 99,7 \\
\hline 0,30 & 35,6 & 67,7 & 87,4 & 82,2 & 98,8 \\
\hline 0,21 & 29,9 & 56,8 & 77,5 & 68,9 & 96,5 \\
\hline 0,15 & 24,2 & 42,0 & 62,7 & 50,0 & 90,7 \\
\hline 0,106 & 19,4 & 28,6 & 47,8 & 32,8 & 81,2 \\
\hline 0,075 & 15,4 & 19,9 & 36,8 & 22,0 & 69,5 \\
\hline 0,053 & 11,7 & 14,1 & 27,8 & 15,2 & 55,7 \\
\hline 0,032 & 8,4 & 9,5 & 18,5 & 10,0 & 42,6 \\
\hline 0,024 & 6,3 & 7,3 & 14,3 & 7,7 & 33,2 \\
\hline 0,017 & 4,6 & 5,5 & 10,9 & 5,9 & 25,0 \\
\hline 0,012 & 3,2 & 3,9 & 7,6 & 4,2 & 17,1 \\
\hline 0,009 & 2,5 & 3,1 & 5,8 & 3,3 & 12,6 \\
\hline
\end{tabular}


Ensaio de Moagem de Bolas - MB2

\begin{tabular}{|c|c|c|c|c|c|}
\hline Fluxo & $\begin{array}{c}\text { Alimentação } \\
\text { Nova }\end{array}$ & $\begin{array}{l}\text { Alimentação } \\
\text { do Moinho }\end{array}$ & $\begin{array}{c}\text { Descarga do } \\
\text { Moinho }\end{array}$ & $\begin{array}{l}\text { Underflow do } \\
\text { Classificador }\end{array}$ & $\begin{array}{l}\text { Overflow do } \\
\text { Classificador }\end{array}$ \\
\hline Vazão e Alimentação (t/h) & 0,6 & 1,9 & 1,9 & 1,3 & 0,6 \\
\hline Vazão (\%) & 100,0 & 321,8 & 321,8 & 221,8 & 100,0 \\
\hline$\%$ Solidos & 98,0 & 74,5 & 74,5 & 81,0 & 37,0 \\
\hline Densidade de Polpa $\left(\mathrm{t} / \mathrm{m}^{3}\right)$ & 3,8 & 2,3 & 2,3 & 2,6 & 1,4 \\
\hline Volume de Polpa $\left(\mathrm{m}^{3} / \mathrm{h}\right)$ & 0,2 & 1,1 & 1,1 & 0,6 & 1,1 \\
\hline$\%<0.15 \mathrm{~mm}$ & 24,2 & 42,0 & 62,7 & 50,0 & 90,7 \\
\hline P $80(\mathrm{~mm})$ & 5,1 & 0,6 & 0,2 & 0,3 & 0,10 \\
\hline \multicolumn{6}{|c|}{ Granulometria (Passante Acumulado) } \\
\hline Granulometria (mm) & $\begin{array}{c}\text { Alimentação } \\
\text { Nova }\end{array}$ & $\begin{array}{c}\text { Alimentação } \\
\text { do Moinho }\end{array}$ & $\begin{array}{c}\text { Descarga do } \\
\text { Moinho }\end{array}$ & $\begin{array}{l}\text { Underflow do } \\
\text { Classificador }\end{array}$ & $\begin{array}{l}\text { Overflow do } \\
\text { Classificador }\end{array}$ \\
\hline 30,0 & 100,0 & 100,0 & 100,0 & 100,0 & 100,0 \\
\hline 25,4 & 100,0 & 100,0 & 100,0 & 100,0 & 100,0 \\
\hline 19,1 & 100,0 & 100,0 & 100,0 & 100,0 & 100,0 \\
\hline 12,7 & 99,5 & 99,8 & 100,0 & 100,0 & 100,0 \\
\hline 9,5 & 93,8 & 98,1 & 100,0 & 100,0 & 100,0 \\
\hline 6,4 & 83,3 & 94,8 & 100,0 & 100,0 & 100,0 \\
\hline 3,2 & 75,1 & 92,2 & 99,9 & 99,9 & 100,0 \\
\hline 2,4 & 70,7 & 90,8 & 99,9 & 99,9 & 100,0 \\
\hline 1,7 & 66,1 & 89,3 & 99,8 & 99,7 & 100,0 \\
\hline 1,2 & 60,7 & 87,3 & 99,5 & 99,3 & 100,0 \\
\hline 0,85 & 55,6 & 85,1 & 98,9 & 98,4 & 100,0 \\
\hline 0,60 & 49,4 & 81,6 & 97,4 & 96,2 & 100,0 \\
\hline 0,43 & 42,3 & 76,0 & 93,9 & 91,2 & 99,7 \\
\hline 0,30 & 35,6 & 67,7 & 87,4 & 82,2 & 98,8 \\
\hline 0,21 & 29,9 & 56,8 & 77,5 & 68,9 & 96,5 \\
\hline 0,15 & 24,2 & 42,0 & 62,7 & 50,0 & 90,7 \\
\hline 0,106 & 19,4 & 28,6 & 47,8 & 32,8 & 81,2 \\
\hline 0,075 & 15,4 & 19,9 & 36,8 & 22,0 & 69,5 \\
\hline 0,053 & 11,7 & 14,1 & 27,8 & 15,2 & 55,7 \\
\hline 0,032 & 8,4 & 9,5 & 18,5 & 10,0 & 42,6 \\
\hline 0,024 & 6,3 & 7,3 & 14,3 & 7,7 & 33,2 \\
\hline 0,017 & 4,6 & 5,5 & 10,9 & 5,9 & 25,0 \\
\hline 0,012 & 3,2 & 3,9 & 7,6 & 4,2 & 17,1 \\
\hline 0,009 & 2,5 & 3,1 & 5,8 & 3,3 & 12,6 \\
\hline
\end{tabular}

